\title{
Nondestructive evaluation of FRP composite bridge componenets using infrared thermography and digital tap tesing
}

Ruben Mangal Joshi

Follow this and additional works at: https://researchrepository.wvu.edu/etd

\section{Recommended Citation}

Joshi, Ruben Mangal, "Nondestructive evaluation of FRP composite bridge componenets using infrared thermography and digital tap tesing" (2018). Graduate Theses, Dissertations, and Problem Reports. 4001. https://researchrepository.wvu.edu/etd/4001

This Problem/Project Report is protected by copyright and/or related rights. It has been brought to you by the The Research Repository @WVU with permission from the rights-holder(s). You are free to use this Problem/Project Report in any way that is permitted by the copyright and related rights legislation that applies to your use. For other uses you must obtain permission from the rights-holder(s) directly, unless additional rights are indicated by a Creative Commons license in the record and/ or on the work itself. This Problem/Project Report has been accepted for inclusion in WVU Graduate Theses, Dissertations, and Problem Reports collection by an authorized administrator of The Research Repository @ WVU. For more information, please contact researchrepository@mail.wvu.edu. 


\title{
Nondestructive Evaluation of FRP Composite Bridge Components Using Infrared Thermography and Digital Tap Testing
}

\author{
Ruben M. Joshi \\ Problem Report submitted to the \\ at West Virginia University \\ in partial fulfillment of the requirements \\ for the degree of \\ Master of Science \\ in \\ Civil Engineering \\ Udaya B. Halabe, Ph.D., P.E., Chair \\ Hota V. S. GangaRao, Ph.D., P.E. \\ Hema J. Siriwardane, Ph.D., P.E.
}

Benjamin M. Statler College of Engineering and Mineral Resources

Department of Civil and Environmental Engineering

Morgantown, West Virginia

2018

Keywords: Infrared Thermography, IRT; Digital Tap Testing; Fiber Reinforced Polymer, FRP; Composites; Debonds; Delaminations 


\section{ABSTRACT}

\section{Nondestructive Evaluation of FRP Composite Bridge Components Using Infrared Thermography and Digital Tap Testing}

\section{Ruben M Joshi}

Aging of civil infrastructures is one of the major problems faced by the engineering industry today, with the concrete structures cracking and the steel reinforcement corroding due to exposure to deicing chemicals, resulting in shorter service life. An alternative to the degrading infrastructures made of concrete and steel is the use of Fiber Reinforced Polymer (FRP) composites, which are noncorrosive. Use of FRP as structural components such as bridge decks and retrofitting jackets can solve the problem of aging with enhanced durability in future constructions. But, proper installation of newer material in structurally important infrastructure requires a reliable method of evaluation or testing. Nondestructive Testing (NDT) or Evaluation (NDE) is a method that can detect the anomalies in the FRP structures keeping the physical properties of the structure intact.

Infrared Thermography (IRT) and Digital Tap Testing (DTT) are two extensively used NDT techniques for inspection of infrastructures, because of their portability and easy-to-handle features. This problem report discusses the advanced and conventional IRT and DTT methods to detect subsurface defects in FRP composite bridge components and FRP rehabilitated concrete bridge. Advanced IRT offers high-end infrared camera and robust digital image processing abilities to locate sub-surface defects in the structures, which, in some cases, conventional IRT fails to do. In addition, this report also includes IRT based tests using a low-cost halogen lamp heater, which is compared to the heating capability of VoyageIR Pro (advanced IRT equipment). Also, Digital Tap Hammer was used for rapid evaluation of the defects in the structural members, which provides a scientific alternative to the traditional coin tap method. The extent of applicability of DTT method compared to IRT was studied using several FRP specimens in the laboratory. DTT was limited to defects at lower depth, such as debonds in thin FRP wraps and could not detect delaminations in thick FRP members. The methods were also used in field testing of concrete box beams rehabilitated with carbon FRP fabrics. The field testing enabled the detection of debonds which helped in their immediate repair. 


\section{ACKNOWLEDGEMENT}

I would like to express my deepest gratitude to my academic and research advisor, Dr. Udaya B. Halabe for his invaluable support, guidance, and motivation throughout my Master of Science in Civil Engineering (MSCE) degree program. His endless encouragement and assistance helped me accomplish this research study. Dr. Halabe, with his understanding and expertise in the field of nondestructive testing, guided me through my Master's degree so I am very thankful to him.

I would like to thank Dr. Hota V.S. GangaRao and Dr. Hema J. Siriwardane for serving as members in the Advisory and Examining Committee (AEC) for my MS Problem Report.

I am very grateful to the Department of Civil and Environmental Engineering at West Virginia University for providing me with the opportunity to gain academic experience through financial support in the form of teaching assistantship. I would also like to thank the U.S. Army Corps of Engineers for loaning their Advanced Infrared Thermography system which was used in this research.

I would like to thank my parents (Mr. Puspa Mangal Joshi and Mrs. Bishnu Devi Joshi Bhansakarya), my friend (Ms. Samjhana Maharjan), and my sisters (Mrs. Bipu Joshi Karmacharya and Mrs. Ruby Joshi Adhikari) for their continuous love, support, and encouragement throughout my Master's degree. 


\section{TABLE OF CONTENTS}

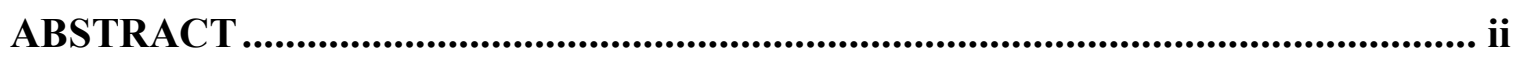

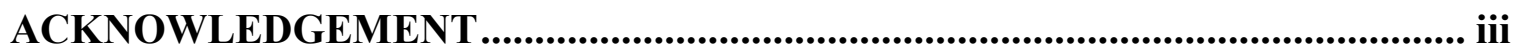

LIST OF FIGURES.............................................................................................ii

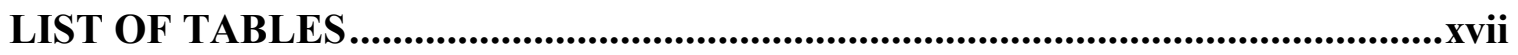

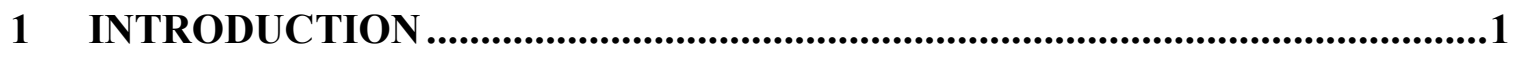

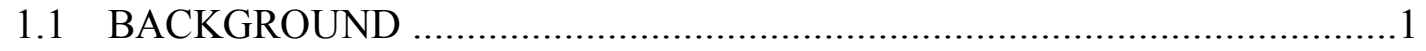

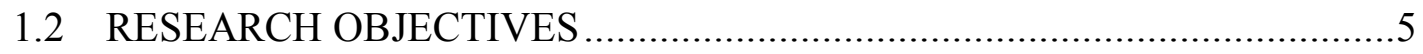

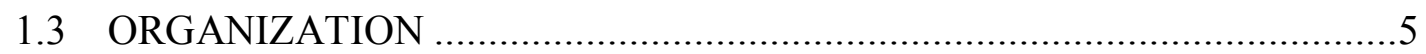

2 INFRARED THERMOGRAPHY (IRT) AND DIGITAL TAP TESTING

EQUIPMENT .....................................................................................................6

2.1 ADVANCED INFRARED THERMOGRAPHY SYSTEM (VoyageIR Pro) ..6

2.2 CONVENTIONAL INFRARED CAMERA (FLIR InfraCAM SD) ................

2.3 DIGITAL TAP HAMMER (Rapid Damage Detection Device - RD3) ...........9

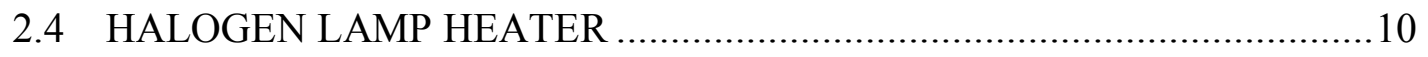

3 LITERATURE REVIEW: CONVENTIONAL AND ADVANCED IRT AND DIGITAL TAP TESTING ......................................................................................11

3.1 CONVENTIONAL INFRARED THERMOGRAPHY ................................11

3.1.1 Applications of Thermography in Nondestructive Testing of Structures

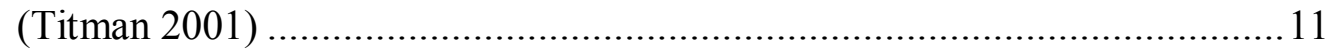

3.1.2 Infrared Thermography and GPR Techniques for Condition Assessment of RC Bridges (Halabe et al. 2012) .......................................... 12

3.1.3 Thermal Infrared Inspection of FRP Bridge Decks for Health Monitoring (Miceli et al. 2003) ...... 
3.1.4 Nondestructive Evaluation of FRP Strengthening Systems Bonded on RC Structures using Pulse Stimulated Infrared Thermography (Taillade et al. 2012) 17

3.2 ADVANCED INFRARED THERMOGRAPHY .20

3.2.1 Thermographic Characterization of Composites (Shepard 2013) .......20

3.2.2 Defect Depth Determination in a CFRP Structure using TSR

Technique (Oswald-Tranta et al. 2014)

3.3 DIGITAL TAP TESTING .24

3.3.1 Electronic Tap Hammer for Composite Damage Assessment (Georgeson et al. 1996)

3.3.2 Applicability of a Tapping Method to Nondestructive Inspection of Carbon Fiber Reinforced Thermoplastics (Lyu et al. 2015).........................26

4 IRT AND DIGITAL TAP TESTING LABORATORY RESULTS ...................29

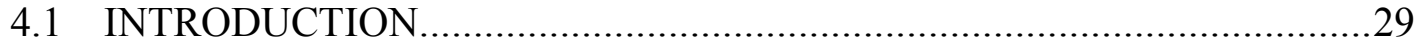

4.2 PREPARATION OF FRP BRIDGE DECKS WITH DEFECTS ....................30

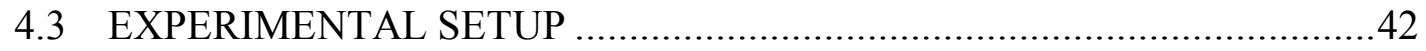

4.4 IRT AND DIGITAL TAP TESTING RESULTS .......................................45

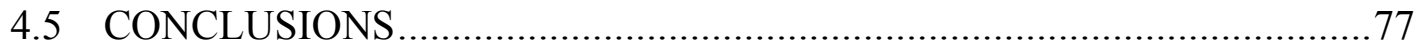

5 FIELD TESTING OF WHITEDAY CREEK BRIDGE ...................................79

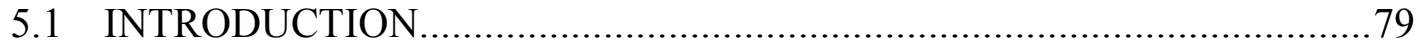

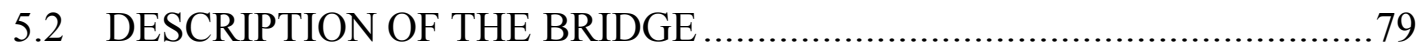

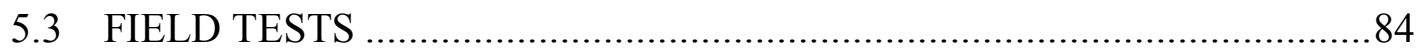

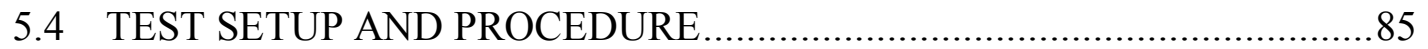

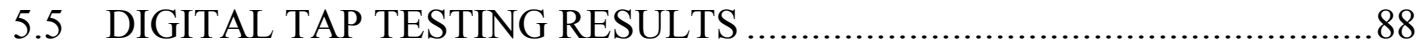


5.6 INFRARED THERMOGRAPHY TESTING RESULTS

5.7 DIGITAL TAP TESTING RESULTS AFTER REPAIR WORKS ...............99

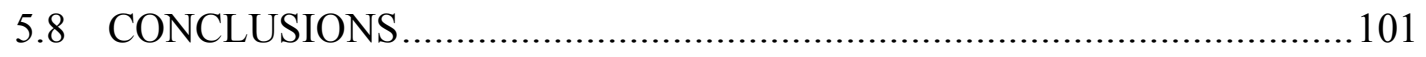

6 CONCLUSIONS AND RECOMMENDATIONS ........................................ 103

6.1 CONCLUSIONS ........................................................................ 103

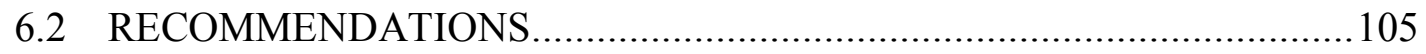

REFERENCES .............................................................................................. 106

APPENDIX A - ADDITIONAL FIGURES FOR LABORATORY

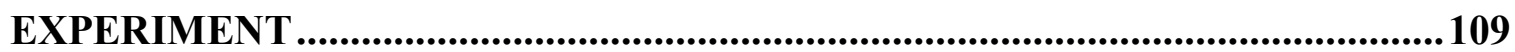




\section{LIST OF FIGURES}

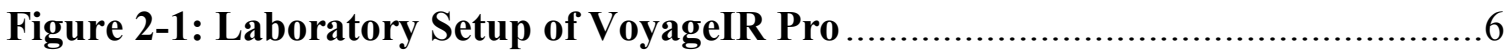

Figure 2-2: Reconstruction of data in the software MOSAIQ ..............................

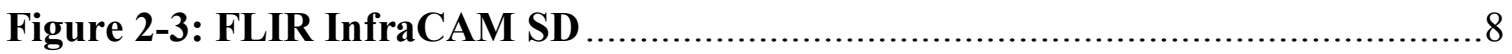

Figure 2-4: Digital Tap Hammer - Rapid Damage Detection Device $\left(\right.$ RD $\left.^{3}\right)$............ 9

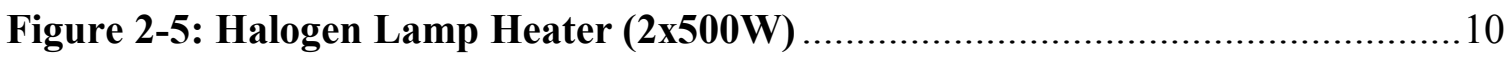

Figure 3-1: Thermal image of poor insulation system in the walls (left) and thermal image of precast RC building showing heat loss at joints (right) (Titman 2001) ......12

Figure 3-2: Another pier cap in the RC bridge (left) and thermal image of the surface showing defect as hot spot (right) (Halabe et al. 2012) ........................................ 13

Figure 3-3: Close-up view of the damaged piers and pier cap on the south side of the bridge (Halabe et al. 2012)

Figure 3-4: Damaged pier cap in the RC bridge (left) and thermal image of the surface captured by infrared camera after heating (right) (Halabe et al. 2012) ..................14

Figure 3-5: Model GFRP Bridge Deck (Miceli et al. 2003) .................................15

Figure 3-6: Schematic diagram of model GFRP bridge deck (left) and Thermal image of the bridge deck taken after 6 minutes of heating (right) (Miceli et al. 2003) .......16

Figure 3-7: Full-size FRP bridge deck embedded in roadway (left) and Thermal image of the bridge deck showing tire heat at the top (right) (Miceli et al. 2003).

Figure 3-8: Concrete Slab Reinforced with Bonded FRP Plates along with Defects (Taillade et al. 2012)

Figure 3-9: Thermal Image at the beginning of thermal relaxation (left) and after 52 seconds after heating (right) (Taillade et al. 2012) .............................................. 18

Figure 3-10: FRP Strengthened Box-Girders of the Bridge (Taillade et al. 2012) ....19

Figure 3-11: Schematic diagram of infrared thermography on the bridge (left) and thermal images showing defects on the wrap (right) (Taillade et al. 2012)

Figure 3-12: Logarithmic Surface Temperature vs Time plot (left), first derivative (center) and second derivative (right) with respect to logarithmic time (Shepard 2013)

Figure 3-13: 12-ply graphite epoxy sample with embedded polymer inserts and flat bottom holes (Shepard 2013). 
Figure 3-14: Contrast images (left to right) for raw, $1^{\text {st }}, 2^{\text {nd }}$ derivative and $2 d t_{\text {peak }}$ (Shepard 2013).

Figure 3-15: CFRP layers with Teflon inserts in the sample before applying vacuum infusion molding process (Oswald-Tranta et al. 2014). .23

Figure 3-16: 3D map of the transmission measurement of the CFRP sample with Teflon inserts (Oswald-Tranta et al. 2014) .23

Figure 3-17: $2^{\text {nd }}$ derivative image of the CFRP specimen calculate after TSR fitting (Oswald-Tranta et al. 2014).

Figure 3-18: Typical $\mathrm{RD}^{3}$ force-time pulse for good area (left) and debond (right) (Georgeson et al. 1996) .25

Figure 3-19: $\mathrm{RD}^{3}$ results on fiberglass/epoxy skin, Nomex honeycomb core test panel (Georgeson et al. 1996) .25

Figure 3-20: Experimental setups for tapping method: Global method (left) and Local method (right) (Lyu et al. 2015) ....

Figure 3-21: Damping and frequency analysis of the specimens for global method: Signal form microphone (left) and accelerometer (right) (Lyu et al. 2015).............27

Figure 3-22: Force-profile of the specimens for local method (Lyu et al. 2015) .......28

Figure 4-1: Fiber Reinforced Polymer (FRP) bridge deck samples - left (www.thomasnet.com) and right (www.materialstoday.com) ...............................29

Figure 4-2: Materials used to prepare air-filled defects to be inserted into the GFRP bridge deck specimen (Vasudevan 2004)

Figure 4-3: Water-filled defects of sizes 3" x 3", 2" x 2" and 1" x 1" to be inserted into the GFRP bridge deck specimen (Roy 2004)

Figure 4-4: Water-filled defects embedded in the flanges of the FRP bridge deck specimens (Roy 2004) 32

Figure 4-5: Side 1 (left) and Side 2 (right) of the GFRP deck specimen BD1 .32

Figure 4-6: Schematic diagram of debonds on Side 1 (left) and Side 2 (right) of the GFRP deck specimen BD1 (Vasudevan 2004).

Figure 4-7: Side 1 (left) and Side 2 (right) of the GFRP deck specimen JD1 .... .33

Figure 4-8: Delamination of size 3" x 3" on Side 1 (left) and of sizes 2" x 2" and 1" $x$ 1" on Side 2 (right) of GFRP deck specimen JD1 (Vasudevan 2004) .

Figure 4-9: Side 1 (left) and Side 2 (right) of the GFRP deck specimen JD2 .34

Figure 4-10: Schematic diagram of 3" $x$ 3" sized debond on Side 1 of the GFRP deck specimen JD2 
Figure 4-11: Side 1 (left) and Side 2 (right) of the GFRP deck specimen WJD2 .....35 Figure 4-12: Schematic diagram of 3" $x$ 3" sized debond on both sides of the GFRP

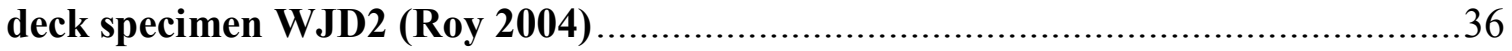

Figure 4-13: Side 1 (left) and Side 2 (right) of the GFRP deck specimen WJD3 ......36

Figure 4-14: Schematic diagram of debonds on Side 2 of the GFRP deck specimen WJD3 (Roy 2004). 37

Figure 4-15: Side 1 (left) and Side 2 (right) of the GFRP deck specimen AS2 .........37

Figure 4-16: Schematic diagram of debonds on Side 1 of the GFRP deck specimen AS2 38

Figure 4-17: Side 1 (left) and Side 2 (right) of the GFRP deck specimen AS3 .........38

Figure 4-18: Schematic diagram of debonds on both sides of the GFRP deck specimen AS3

Figure 4-19: Side 1 (left) and Side 2 (right) of the defect-free GFRP-wrapped concrete cylinder

Figure 4-20: Side 1 containing air-filled defect (left) and defect-free Side 2 (right) of the GFRP-wrapped concrete cylinder

Figure 4-21: Side 1 (left) and Side 2 (right) of the GFRP-wrapped concrete cylinder, both containing 1 " $x 1$ " water-filled defect

Figure 4-22: Side 1 (left) and Side 2 (right) of the GFRP composite square tube .....41

Figure 4-23: Laboratory setup of advanced infrared thermography on FRP specimens using VoyageIR Pro

Figure 4-24: Components of VoyageIR Pro used in the laboratory experiment for advanced infrared thermography

Figure 4-25: FLIR InfraCAM SD showing thermal image of a specimen in laboratory experiment

Figure 4-26: Laboratory setup of conventional infrared thermography using a halogen lamp heater

Figure 4-27: Raw thermal images of Side 1 (left) and Side 2 (right) of the deck specimen BD1 after 20 seconds of heating.

Figure 4-28: 1st derivative images of Side 1 (left) and Side 2 (right) of the deck specimen BD1 after 20 seconds of heating

Figure 4-29: TSR image (left), $1^{\text {st }}$ derivative image (center), and $2^{\text {nd }}$ derivative image (right) of Side 1 of the deck specimen BD1 after 50 seconds of heating 
Figure 4-30: TSR image (left), $1^{\text {st }}$ derivative image (center), and $2^{\text {nd }}$ derivative image (right) of Side 2 of the deck specimen BD1 after 50 seconds of heating

Figure 4-31: TSR image (left), $1^{\text {st }}$ derivative image (center), and $2^{\text {nd }}$ derivative image (right) of Side 1 of the deck specimen BD1 after 100 seconds of heating

Figure 4-32: TSR image (left), $1^{\text {st }}$ derivative image (center), and $2^{\text {nd }}$ derivative image (right) of Side 2 of the deck specimen BD1 after 100 seconds of heating

Figure 4-33: Plot of TSR intensity along line A-A (left) and of $2^{\text {nd }}$ derivative intensity along line B-B (right). 48

Figure 4-34: Thermal images of Side 1 (left) and Side 2 (right) of BD1 taken from FLIR InfraCAM SD after 20 seconds of heating from VoyageIR Pro system

Figure 4-35: Thermal images of Side 1 (left) and Side 2 (right) of BD1 taken from FLIR InfraCAM SD after 50 seconds of heating from VoyageIR Pro system

Figure 4-36: Thermal images of Side 1 (left) and Side 2 (right) of BD1 taken from FLIR InfraCAM SD after 50 seconds of heating from halogen lamp heater

Figure 4-37: Thermal image of Side 2 of BD1 taken from FLIR InfraCAM SD after 100 seconds of heating from halogen lamp heater.

Figure 4-38: $1^{\text {st }}$ derivative images of Side 1 (left) and Side 2 (right) of the deck specimen JD1 after 50 seconds of heating.

Figure 4-39: Raw thermal images of Side 1 (left) and Side 2 (right) of the deck specimen JD1 after 200 seconds of heating.

Figure 4-40: Plot of $1^{\text {st }}$ derivative intensity along the line $\mathrm{C}-\mathrm{C}$ (left) and along the line D-D (right) .52

Figure 4-41: Thermal images of Side 1 (left) and Side 2 (right) of JD1 taken from FLIR InfraCAM SD after 50 seconds of heating from VoyageIR Pro system .52

Figure 4-42: Thermal images of Side 1 (left) and Side 2 (right) of JD1 taken from FLIR InfraCAM SD after 100 seconds of heating from halogen lamp heater .53

Figure 4-43: Raw thermal images of Side 1 of the deck specimen JD2 after 50 seconds of heating (left) and 200 seconds of heating (right) .53

Figure 4-44: $2^{\text {nd }}$ derivative image of Side 1 of the deck specimen JD2 after 100 seconds of heating (left) and plot of $2^{\text {nd }}$ derivative intensity along the line E-E (right) ..........54

Figure 4-45: Thermal image of Side 1 of JD2 taken from FLIR InfraCAM SD after 50 seconds of heating from VoyageIR Pro system. .54

Figure 4-46: Thermal images of Side 1 of JD2 taken from FLIR InfraCAM SD after 200 seconds of heating from halogen lamp heater. .55 
Figure 4-47: Raw thermal images of uncovered Side 1 (left) and covered Side 2 (right) of the deck specimen WJD2 after 50 seconds of heating.

Figure 4-48: $1^{\text {st }}$ derivative images of uncovered Side 1 of the deck specimen WJD2 after 50 seconds (left), 100 seconds (center), and 200 seconds (right) of heating .....56

Figure 4-49: $1^{\text {st }}$ derivative images of covered Side 2 of the deck specimen WJD2 after 50 seconds (left), 100 seconds (center), and 200 seconds (right) of heating. .56

Figure 4-50: Plot of $1^{\text {st }}$ derivative intensity along the line F-F on Side 1 of the deck specimen WJD2

Figure 4-51: Thermal images of Side 1 (left) and Side 2 (right) of WJD2 taken from FLIR InfraCAM SD after 100 seconds of heating from VoyageIR Pro system ........58

Figure 4-52: Thermal images of Side 1 (left) and Side 2 (right) of WJD2 taken from FLIR InfraCAM SD after 100 seconds of heating from halogen lamp heater .........58

Figure 4-53: Raw thermal images of covered Side 1 (left) and uncovered Side 2 (right) of the deck specimen WJD3 after 50 seconds of heating.

Figure 4-54: 1st derivative image of Side 1 of the deck specimen WJD3 after 100 seconds of heating.

Figure 4-55: 1st derivative images of Side 2 of the deck specimen WJD3 after 100 seconds of heating (left) and after 200 seconds of heating (right).

Figure 4-56: Plot of 1st derivative intensity along the line G-G on Side 1 of the deck specimen WJD3

Figure 4-57: Thermal images of Side 1 (left) and Side 2 (right) of WJD3 taken from FLIR InfraCAM SD after 200 seconds of heating from VoyageIR Pro system

Figure 4-58: Thermal images of Side 1 (left) and Side 2 (right) of WJD3 taken from FLIR InfraCAM SD after 100 seconds of heating from halogen lamp heater

Figure 4-59: Raw thermal image of Side 1 of the deck specimen AS2 after 50 seconds of heating.

Figure 4-60: $1^{\text {st }}$ derivative image of Side 1 of the deck specimen AS2 after 100 seconds of heating (left) and plot of $1^{\text {st }}$ derivative intensity along the line H-H (right).... .62

Figure 4-61: : Thermal images of Side 1 of AS2 taken from FLIR InfraCAM SD after 50 seconds (left) and 100 seconds of heating (right) from halogen lamp heater .63

Figure 4-62: Thermal images of Side 1 of AS2 taken from FLIR InfraCAM SD after 50 seconds (left) and 100 seconds of heating (right) from VoyageIR Pro system ......63

Figure 4-63: Raw thermal images of Side 1 (left) and Side 2 (right) of the deck specimen AS3 after 100 seconds of heating .64 
Figure 4-64: $1^{\text {st }}$ derivative images of Side 1 (left) and Side 2 (right) of the deck specimen AS3 after 50 seconds of heating

Figure 4-65: Plot of $1^{\text {st }}$ derivative intensity along the line I-I (left) and along the line J-J (right)

Figure 4-66: Thermal images of Side 1 (left) and Side 2 (right) of AS3 taken from FLIR InfraCAM SD after 50 seconds of heating from VoyageIR Pro system

Figure 4-67: Thermal images of Side 1 (left) and Side 2 (right) of AS3 taken from FLIR InfraCAM SD after 50 seconds of heating from halogen lamp heater .... .66

Figure 4-68: Raw thermal images of Side 1 (left) and Side 2 (right) of the defect-free cylinder specimen after 50 seconds of heating.

Figure 4-69: 2nd derivative images of Side 1 (left) and Side 2 (right) of the defect-free cylinder specimen after 50 seconds of heating.

Figure 4-70: Thermal images of Side 1 (left) and Side 2 (right) of defect-free cylinder taken from FLIR InfraCAM SD after 50 seconds of heating from VoyageIR Pro system.

Figure 4-71: Thermal images of Side 1 (left) and Side 2 (right) of defect-free cylinder taken from FLIR InfraCAM SD after 50 seconds of heating from halogen lamp heater

Figure 4-72: Raw thermal image of Side 1 of the GFRP-wrapped concrete cylinder specimen with 2" $\times 2$ 2" sized air-filled debond after 50 seconds of heating ... .68

Figure 4-73: 1st derivative (left) and 2nd derivative (right) images of Side 1 of the GFRP-wrapped concrete cylinder specimen with 2" 12 " sized air-filled debond after 50 seconds of heating

Figure 4-74: Plot of 1 st derivative intensity along the line K-K

Figure 4-75: Thermal image of Side 1 of the cylinder with air-filled debond taken from FLIR InfraCAM SD after 50 seconds of heating from VoyageIR Pro system .70

Figure 4-76: Thermal image of Side 1 of the cylinder with air-filled debond taken from FLIR InfraCAM SD after 50 seconds of heating from halogen lamp heater...70

Figure 4-77: Raw thermal images of Side 1 (left) and Side 2 (right) of the cylinder specimen with water-filled debonds after 50 seconds of heating .71

Figure 4-78: 1st derivative images of Side 1 (left) and Side 2 (right) of the cylinder specimen with water-filled debonds after 50 seconds of heating ..... .71

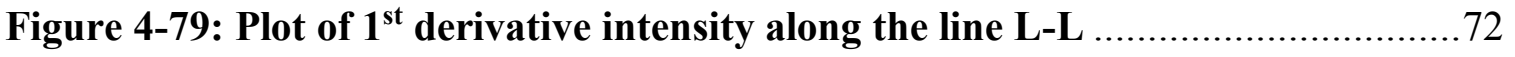


Figure 4-80: Thermal images of Side 1 (left) and Side 2 (right) of the cylinder with water-filled debonds taken from FLIR InfraCAM SD after 50 seconds of heating from VoyageIR Pro system .72

Figure 4-81: Thermal images of Side 1 (left) and Side 2 (right) of the cylinder with water-filled debonds taken from FLIR InfraCAM SD after 50 seconds of heating from

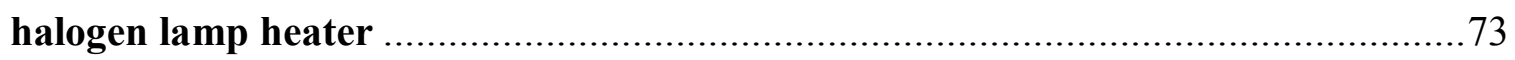

Figure 4-82: Raw thermal image of Side 1 (left) of the GFRP composite square tube

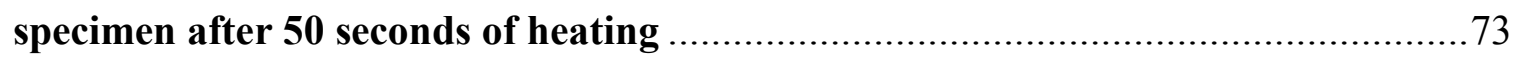

Figure 4-83: $1^{\text {st }}$ derivative thermal image of Side 1 of the GFRP composite square tube specimen after 50 seconds of heating (left) and plot of $1^{\text {st }}$ derivative intensity along the line M-M (right) .74

Figure 4-84: Thermal image of Side 1 of the GFRP composite square tube taken from FLIR InfraCAM SD after 50 seconds of heating from VoyageIR Pro (left) and halogen

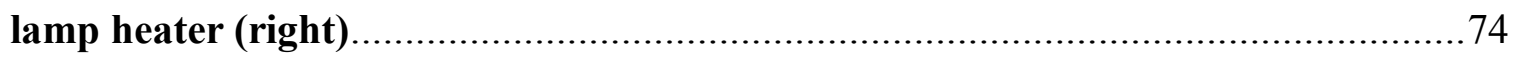

Figure 5-1: Location of Whiteday Bridge, WV ............................................... 80

Figure 5-2: West Elevation of the Whiteday Bridge (Kollias 2015) .......................81

Figure 5-3: Main Span Beam - Exposed Strands (Kollias 2015)..........................81

Figure 5-4: Heaving on the wearing surface at Pier 2 deck joint (left) and Longitudinal

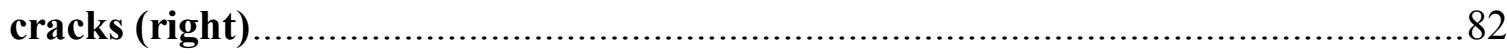

Figure 5-5: Main Span Beam repaired with CFRP fabric ...................................... 82

Figure 5-6: Wearing surface of the Whiteday Bridge under repair work................83

Figure 5-7: Concrete spalling at the surface of contact with water in Pier 1 (Kollias 2015) .83

Figure 5-8: Cross-section at mid-span of the Whiteday Bridge .84

Figure 5-9: Plan of the Main Span of the Whiteday Bridge with numbering of the beams and positioning of the CFRP fabric laminates .84

Figure 5-10: Digital Tap Testing with Rapid Damage Detection Device $\left(\mathrm{RD}^{3}\right)$ on the Whiteday Bridge. .85

Figure 5-11: Marks and Labels on the Debonded Areas of the repaired beams .......86

Figure 5-12: Infrared Test Setup with VoyageIR Pro and FLIR InfraCAM ...........87

Figure 5-13: Defective Spots 1-1 (left) and 1-2 (right) on Beam 1 of the Whiteday Bridge .88

Figure 5-14: Debond 2-1 on Beam 2 (left) and Defect-free Beam 3 (right) of the Whiteday Bridge. .89 
Figure 5-15: Defective Spots 4-1 (left) and 4-2 (right) on Beam 4 of the Whiteday Bridge

Figure 5-16: Debonds 7-1 (left) and 7-2 (right) on Beam 7 of the Whiteday Bridge 90 Figure 5-17: Defective Spots 8-1 (left) and 8-2 (right) on Beam 8 of the Whiteday Bridge. 90

Figure 5-18: Debond 8-3 with two small pockets on Beam 8 of Whiteday Bridge ....91

Figure 5-19: Plan of the Main Span of the Whiteday Bridge with numbering of the beams and positioning of the CFRP fabric laminates

Figure 5-20: Raw Thermal Image from VoyageIR Pro (left) and Infrared Image from FLIR InfraCAM SD (right) of the Debond 1-1 on Beam 1 of the Whiteday Bridge.93

Figure 5-21: Raw Thermal Image from VoyageIR Pro (left) and Infrared Image from FLIR InfraCAM SD (right) of the Debond 1-2 on Beam 1 of the Whiteday Bridge.94

Figure 5-22: Raw Thermal Image from VoyageIR Pro (left) and Infrared Image from FLIR InfraCAM SD (right) of the Debond 2-1 on Beam 2 of the Whiteday Bridge.94

Figure 5-23: Raw Thermal Image from VoyageIR Pro (left) and Infrared Image from FLIR InfraCAM SD (right) of the Defective Spot 4-1 on Beam 4 of the Whiteday Bridge. .95

Figure 5-24: Raw Thermal Image from VoyageIR Pro (left) and Infrared Image from FLIR InfraCAM SD (right) of the Defect-free Beam 3 of the Whiteday Bridge......95

Figure 5-25: Raw Thermal Image from VoyageIR Pro (left) and Infrared Image from FLIR InfraCAM SD (right) of the Defective Spot 4-2 on Beam 4 of the Whiteday Bridge.

Figure 5-26: Raw Thermal Image from VoyageIR Pro (left) and Infrared Image from FLIR InfraCAM SD (right) of the Defective Spot 7-1 on Beam 7 of the Whiteday Bridge.

Figure 5-27: Raw Thermal Image from VoyageIR Pro (left) and Infrared Image from FLIR InfraCAM SD (right) of the Defective Spot 7-2 on Beam 7 of the Whiteday Bridge.

Figure 5-28: Raw Thermal Image from VoyageIR Pro (left) and Infrared Image from FLIR InfraCAM SD (right) of the Defective Spot 8-1 on Beam 8 of the Whiteday Bridge.

Figure 5-29: Raw Thermal Image from VoyageIR Pro (left) and Infrared Image from FLIR InfraCAM SD (right) of the Defective Spot 8-2 on Beam 8 of the Whiteday Bridge. .98 
Figure 5-30: Raw Thermal Image from VoyageIR Pro (left) and Infrared Image from FLIR InfraCAM SD (right) of the Defective Spot 8-3 on Beam 8 of the Whiteday Bridge. 99

Figure A-1: Thermal images of Side 1 (left) and Side 2 (right) of BD1 taken from FLIR InfraCAM SD after 100 seconds of heating from VoyageIR Pro system 109

Figure A-2: Raw thermal images of Side 1 (left) and Side 2 (right) of the deck specimen JD1 after 100 seconds of heating.

Figure A-3: $1^{\text {st }}$ derivative images of Side 1 (left) and Side 2 (right) of the deck specimen JD1 after 100 seconds of heating.

Figure A-4: Thermal images of Side 1 (left) and Side 2 (right) of JD1 taken from FLIR InfraCAM SD after 100 seconds of heating from VoyageIR Pro system 110

Figure A-5: Thermal images of Side 1 (left) and Side 2 (right) of JD1 taken from FLIR InfraCAM SD after 50 seconds of heating from halogen lamp heater 110

Figure A-6: Thermal images of Side 1 of JD2 taken from FLIR InfraCAM SD after 100 seconds of heating from VoyageIR Pro system. 110

Figure A-7: Thermal images of Side 1 of JD2 taken from FLIR InfraCAM SD after 50 seconds (left) and 100 seconds (right) of heating from halogen lamp heater...... 110

Figure A-8: Raw thermal images of uncovered Side 1 (left) and covered Side 2 (right) of the deck specimen WJD2 after 100 seconds of heating.

Figure A-9: Thermal images of Side 1 (left) and Side 2 (right) of WJD2 taken from FLIR InfraCAM SD after 50 seconds of heating from VoyageIR Pro system 110

Figure A-10: Thermal images of Side 1 (left) and Side 2 (right) of WJD2 taken from FLIR InfraCAM SD after 50 seconds of heating from halogen lamp heater 110

Figure A-11: Thermal images of Side 1 (left) and Side 2 (right) of WJD3 taken from FLIR InfraCAM SD after 50 seconds of heating from VoyageIR Pro system ........110

Figure A-12: Thermal images of Side 1 (left) and Side 2 (right) of WJD3 taken from FLIR InfraCAM SD after 100 seconds of heating from VoyageIR Pro system ......110

Figure A-13: Thermal images of Side 1 (left) and Side 2 (right) of WJD3 taken from FLIR InfraCAM SD after 50 seconds of heating from halogen lamp heater 110

Figure A-14: Raw thermal image of Side 1 of the deck specimen AS2 after 100 seconds of heating.

Figure A-15: $1^{\text {st }}$ derivative image of Side 1 of the deck specimen AS2 after 50 seconds (left) and 100 seconds (right) of heating. 110 
Figure A-16: Plot of $1^{\text {st }}$ derivative intensity along the line 1-1 (left) and line 2-2 (right)

Figure A-17: Raw thermal images of Side 1 (left) and Side 2 (right) of the deck specimen AS3 after 50 seconds of heating

Figure A-18: $1^{\text {st }}$ derivative images of Side 1 (left) and Side 2 (right) of the deck specimen AS3 after 100 seconds of heating 110

Figure A-19: : Thermal images of Side 1 (left) and Side 2 (right) of AS3 taken from FLIR InfraCAM SD after 100 seconds of heating from VoyageIR Pro system ......110

Figure A-20: Thermal images of Side 1 (left) and Side 2 (right) of AS3 taken from FLIR InfraCAM SD after 100 seconds of heating from halogen lamp heater 110

Figure A-21: Thermal images of Side 1 (left) and Side 2 (right) of the cylinder with water-filled debonds taken from FLIR InfraCAM SD after 100 seconds of heating from VoyageIR Pro system 110

Figure A-22: Thermal images of Side 1 (left) and Side 2 (right) of the cylinder with water-filled debonds taken from FLIR InfraCAM SD after 100 seconds of heating from halogen lamp heater .110

Figure A-23: $1^{\text {st }}$ derivative thermal image of Side 1 of the GFRP composite square tube specimen after 100 seconds of heating (left) and plot of $1^{\text {st }}$ derivative intensity along the line 3-3 (right)

Figure A-24: Thermal image of Side 1 of the GFRP composite square tube taken from FLIR InfraCAM SD after 100 seconds of heating from VoyageIR Pro system (left) and halogen lamp heater (right). 110 


\section{LIST OF TABLES}

Table 4-1: Digital Tap Testing Results for Laboratory Experiment .....................76

Table 5-1: Digital Tap Testing Results on the Whiteday Bridge .........................92

Table 5-2: Digital Tap Testing Results on the Whiteday Bridge after Repair Works 100 


\section{INTRODUCTION}

\subsection{BACKGROUND}

The aging of infrastructures has been a constant problem for engineers in the field and the major challenge has been to make a decision on whether rehabilitation of a structure is sufficient or a total replacement is required. Therefore, a reliable method of testing or evaluation of the infrastructure is needed. Several conventional destructive testing and nondestructive testing methods have been in use to evaluate structural condition. The conventional testing method involves physical inspection of the structures for determining the condition (Halabe et al. 1995). This method is of time-consuming nature where in-depth assessment requires complicated procedures of destructive physical analysis and subjective evaluation through visual inspection (Halabe et al. 1995). Modern nondestructive testing (NDT), on the other hand, consists of scientific techniques used to evaluate the structural component without damage. NDT is a quick and convenient method, which, as the name suggests, provides an unbiased, unaffected in-situ evaluation of the structure.

Nondestructive Evaluation (NDE) through NDT techniques, unlike destructive testing, does not alter the physical properties of the structure or material, so it is very useful in new constructions as well as rehabilitation works. NDT methods depend on electromagnetic radiation, sound and other signals to examine the integrity and composition of the structures (www.wikipedia.org). The most commonly used NDT methods are Radiography, Magnetic Particle Testing, Infrared Thermography, Ultrasonic Testing, and Remote Field Testing (www.nde-ed.org). Some other NDT methods include Acoustic Emission Testing, Digital Tap Testing, and Electromagnetic Testing. Each of these methods have their advantages and disadvantages and in different cases, appropriate NDT method is selected based on the requirements. Selecting a particular method is governed by the type of material to be examined, geometry of structural component and potential discontinuities, such as cracks, voids, debonds and delaminations. This report concentrates on the usefulness and effectiveness of two NDT techniques - namely Infrared Thermography and Digital Tap Testing - to detect subsurface debonds and delaminations. 
Infrared Thermography (IRT) is a nondestructive testing method that involves detecting thermal energy emitted by an object and displaying the results in the form of surface temperature distribution. The distribution of surface temperature relates to the subsurface condition of the object where any form of discontinuity affects the rate of flow of heat and the effects are exhibited by the surface temperature differentials. Infrared imaging is a technique that generates visual images from the invisible infrared radiation emitted by the object when excited by heat either naturally or artificially. The surface temperature differential is the result of difference in thermal conductivity and thermal diffusivity between defective and defect-free areas. If artificially heated, the infrared images are captured using infrared camera only after removal of the heat source. The airfilled defects are shown as hot spots upon heating; however, using a cooling source instead of heat source alters the results. The alteration occurs even when the defect is water-filled in place of air-filled (Halabe et al. 2007). Infrared Thermography gives consistent results for any defect provided that the surface heating or cooling is uniform. The efficiency of infrared thermography increases with the ability to scan large areas and interpret data in a relatively short time-period (Halabe et al. 2007).

Thermography Techniques can be classified as Passive and Active Thermography. Passive Thermography refers to the thermal inspection of the object where the surface to be tested is naturally at a higher temperature than the surrounding. Passive Thermography requires no external source of heat and thus the infrared image can be taken without any heating. An example of Passive Thermography is infrared testing of a metal pipe carrying hot fluid, where the hot fluid heats the pipe naturally. Active Thermography, on the other hand, requires a controlled heating or cooling of the surface to create temperature differential with the surrounding. The externally heated surface is studied with infrared camera throughout the process of returning to thermal equilibrium (Spring et al. 2011). Mostly, structural components require Active Thermography since the components need thermal excitation to detect any subsurface discontinuity by analyzing the thermal gradient between the surface and the surrounding. The various techniques based on Active Thermography include flash (pulsed) thermography, lock-in thermography and vibrothermography (Spring et al. 2011). 
Flash or Pulsed Thermography is the mostly used active thermography based on its fast uniform heating, variable capture rates and wide software analysis options. Pulsed Thermography systems, in general, consist of a high-resolution infrared camera, high power flash lamps and a processing computer. When the surface of the object is subjected to the pulse of light energy emitted by the flash lamps, the heat transfers to the subsurface and several images are taken that allows for the detection of defects in different materials (Spring et al. 2011). Flash Thermography gives the assessment of the subsurface condition faster than other nondestructive methods. With advancement in analysis techniques, flash or pulsed thermography provides improved ability to determine deeper and more subtle subsurface anomalies (Spring et al. 2011).

Thermographic Signal Reconstruction (TSR) is one of the newer techniques in analyzing the thermographic data where raw temporal data recorded for each pixel in the thermal image is reconstructed into a mathematical function (Shepard et al. 2002). The reconstruction of thermal data comprises of reduction of noise and optimization of thermal contrast within the surface. This helps in more precise measurement of the size as well as depth of the defect in the object. TSR method is based on the single pixel approach where the noise is reduced by converting each logarithmic pixel time history to a mathematical equation (Shepard et al. 2015). This noise-reduced pixel time history is differentiated with respect to time and the $1^{\text {st }}$ and $2^{\text {nd }}$ derivatives of an infinitely thick sample are straight horizontal lines with amplitudes -0.5 and 0 respectively. Any defect in the sample obstructs the heat flow and breaks the symmetry of the derivatives, thus results in reduction of maximum and minimum amplitudes of the signals (Shepard et al. 2015).

Digital Tap Testing is an NDE technique, which offers a scientific alternative to the traditional coin tap (or tap hammer) testing. Digital Tap Testing is a numerical based approach to determine the presence of defects in the structure. Since the conventional coin tap method depends on the inspector's ability of hearing and interpretation, the results are highly subjective and not always accurate. Boeing accounted for the problem of subjectivity along with the interference from the surrounding noise while developing a new low-cost coin tap based testing method. This was done by instrumenting the traditional tap hammer with a force transducer and related electronic system (Georgeson et al. 1996). 
Fiber Reinforced Polymer (FRP) is a composite material made of polymer matrix (resin) and Fibers (usually glass, carbon, aramid or basalt). Recently, FRP has been a very popular material for construction and rehabilitation purposes. FRP is mostly used to increase the strength of the beams, columns and slabs of buildings and bridges. The features of FRP such as light weight, high strength-to-weight ratio, durability, high resistance to corrosion and low maintenance cost make it a very suitable material for use in civil infrastructures (Liang and GangaRao 2004). The fiber in the FRP composite provides strength while the resin is responsible for binding the fibers together and transferring the stress between the fibers. There are several forms of FRP members such as FRP reinforcement bars, FRP bridge decks, FRP I-sections and other sections made out of FRP composite. The FRP bridge decks are increasingly being used these days because of their light-weight, high-strength and sustainability factors; however, the primary strengthening form of FRP composites is the FRP wraps which is applied to the reinforced concrete (RC) or timber structures. The strength of the FRP wrapped structure, however, is adversely affected by the formation of debonds between the FRP fabric and underlying concrete or timber. Debonds can be formed under the FRP fabric as a result of incorrect installation of the wraps, insufficient curing of resin, exposure to extreme temperature gradient or harsh freeze-thaw cycles. Thus, the detection of defects and evaluation of the integrity of the component is very important. The ability of nondestructive testing (NDT) methods to locate defect areas within the FRP members has significantly improved over the years (Maio et al. 2016). The dimensions of the debond can be determined in a short period of time using advanced methods of NDT.

The FRP wraps are extensively used, these days, to repair damaged beams and columns since they are easy to apply and provide considerable strength increment. So, to guarantee that the design strength of the wrap is obtained, the debonds need to be identified and rectified properly. NDT methods are very useful for this purpose since they provide reliable information about the defects in the wraps without causing any alteration to the physical properties of the wrapped structure. Digital Tap Testing and Infrared Thermography are two NDT methods used in this study. While digital tap testing provides quick assessment of the wraps, infrared thermography helps to acquire more detailed information on the debonds between the FRP wraps and the underlying concrete. 


\subsection{RESEARCH OBJECTIVES}

(i) To investigate two different nondestructive testing methods, i.e., Infrared Thermography and Digital Tap Testing, using several FRP composite specimens and compare their results.

(ii) To review the conventional infrared thermography and the advanced infrared thermography techniques and compare and contrast them.

(iii) To evaluate the infrared (raw, TSR, 1D and 2D) images obtained from advanced infrared thermography (VoyageIR Pro) and study the differences from conventional infrared images (FLIR InfraCAM).

(iv) To conduct infrared thermography tests using two heat sources, VoyageIR Pro and Halogen Lamp Heater, and compare the outputs obtained from the two heat sources in order to determine the optimum heating.

(v) To study the effectiveness of Infrared Thermography and Digital Tap Testing in the field for detecting debonds between the Carbon Fiber Reinforced Polymer (CFRP) fabric and underlying concrete box beams of a rehabilitated bridge.

\subsection{ORGANIZATION}

This problem report is organized into six chapters. Chapter 1 presents the introduction to the Nondestructive Testing (NDT) methods including infrared thermography and digital tap testing, and use of Fiber Reinforced Polymer (FRP) composites. Chapter 1 also presents the objectives of this research. Chapter 2 describes the advanced and conventional infrared thermography devices and digital tap hammer. Chapter 3 reviews some of the important literatures related to laboratory and field experiments performed on concrete and composite members using infrared thermography. Chapter 4 discusses the application of digital tap testing and infrared thermography in detecting defects in various laboratory samples using advanced and conventional infrared devices along with different heating devices. Chapter 5 presents the results of field-testing of a Carbon FRP wrapped concrete box beams of a bridge using digital tap testing and infrared thermography. Chapter 6 concludes this problem report by summarizing the key outcomes obtained from this study, along with some recommendations. All the references used in this problem report are listed at the end. 


\section{INFRARED THERMOGRAPHY (IRT) AND DIGITAL TAP TESTING EQUIPMENT}

Two different techniques - namely Infrared Thermography and Digital Tap Testing - are used for detection of defects in the FRP fabric. The infrared thermography testing requires a heating source and an infrared camera that captures the surface radiation. A sophisticated advanced infrared system with built-in heating system is very useful for tests in the field while the conventional low-cost infrared camera is also reliable to detect debonds in the field. In addition, a digital tap testing equipment is also described in this chapter.

\subsection{ADVANCED INFRARED THERMOGRAPHY SYSTEM (VoyageIR Pro)}

The advanced infrared thermography equipment, VoyageIR Pro, was developed by Thermal Wave Imaging (TWI). VoyageIR Pro is a flexible and convenient device designed especially for field applications. It is based on Thermographic Signal Reconstruction (TSR) method, which is used to capture, analyze and process pulse thermography data sequences. TSR method, as explained in the previous chapter, allows detection of subsurface anomalies that are not clear or obvious in the raw image. Figure 2-1 shows the laboratory setup of the VoyageIR Pro.
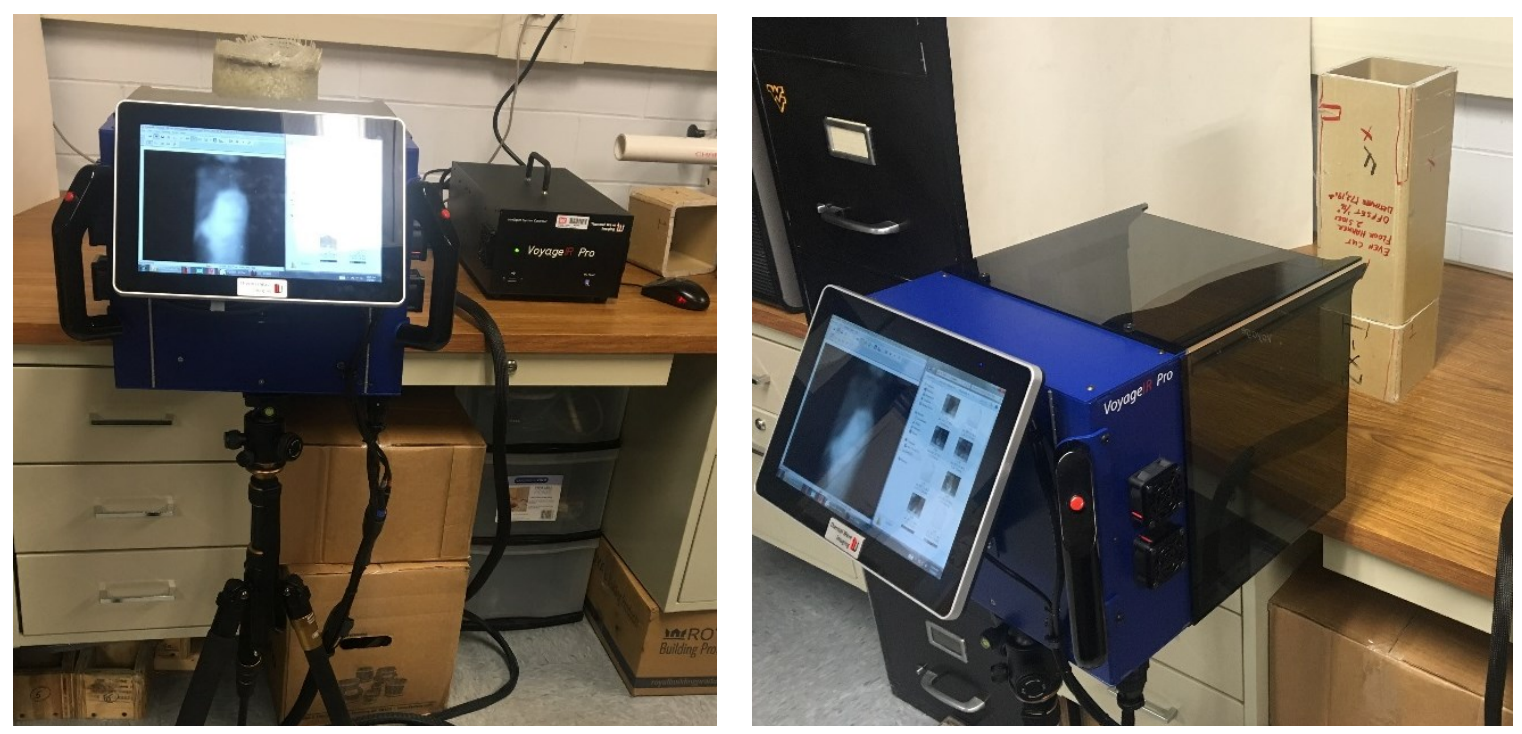

Figure 2-1: Laboratory Setup of VoyageIR Pro 
VoyageIR Pro is a relatively expensive device, which costs around $\$ 60,000$. The computer-controlled heating system and powerful analysis software along with the miniature infrared camera are responsible for the high price of the device. VoyageIR Pro is a system of hardware and software components. The hardware includes the inspection head with infrared camera, heating source, touchscreen monitor mounted on a tripod stand and Input/Output (I/O) Controller connected by cables. The miniature long-wave uncooled microbolometer infrared camera includes a $14.25 \mathrm{~mm}$ lens with a 640x480 pixels Focal Plane Array (FPA) running at a frequency of $30 \mathrm{~Hz}$ and can detect radiation in the spectral range of 8 to 14 microns. The heat source consists of an array of fully synchronized miniature heat lamps with precise control over key parameters like pulse width and amplitude. The heat flux from the heat source was measured to be $800 \mathrm{Watts} / \mathrm{m}^{2}$ at a distance of 24". The integrated 10" touchscreen tablet display features a streamlined software User Interface that provides complete control and remote system operation. However, the backbone of the VoyageIR Pro system is the I/O System Controller, which allows a network of electronics to perform all the major functions, such as heat source synchronization and control, digital data capture and analysis and trigger I/O.

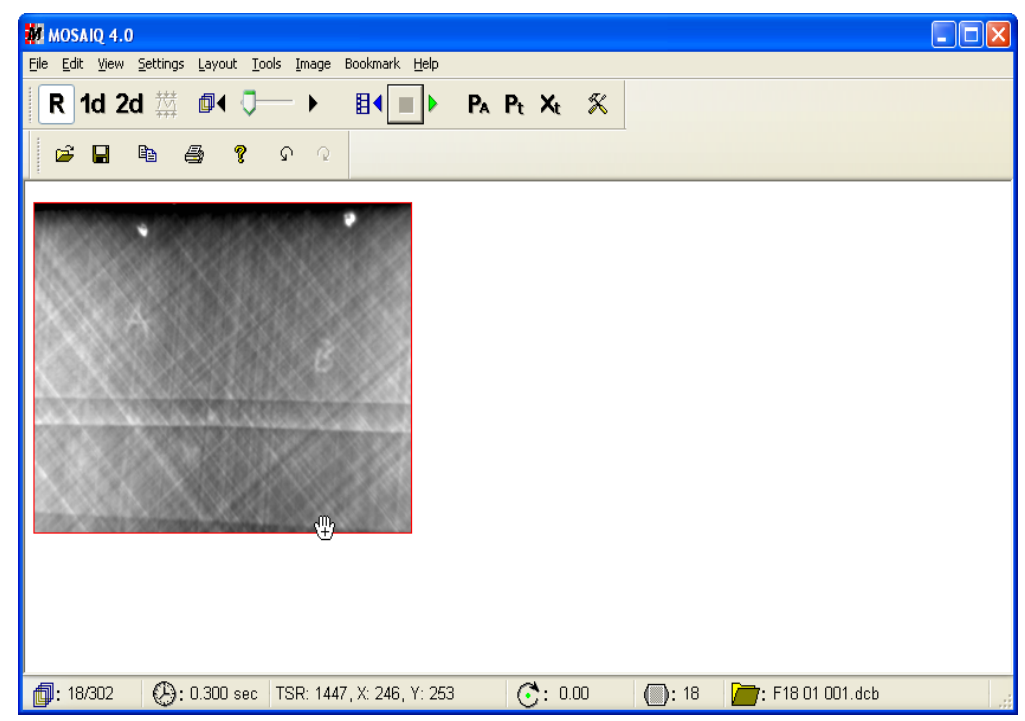

Figure 2-2: Reconstruction of data in the software MOSAIQ

The associated software is an integral part of the VoyageIR Pro system, which is designed to provide a user-friendly interface and easy access to all the program functions. The VoyageIR software allows capturing and processing the data with options to set up all the necessary parameters like trigger mode, capture rate and heating time. The 
reconstruction of the data can be done using another software program called MOSAIQ (Figure 2-2). MOSAIQ allows TSR processing of the captured data, which is converted to reconstructed format. The reconstructed data can be used to obtain raw, $1^{\text {st }}$ and $2^{\text {nd }}$ timederivative images along with TSR results. The reconstruction of the thermographic data helps locate defects that are not visible or clear in the raw image. The software archives the data in a compressed format, which can be saved as Audio Video Interleave 'AVI' movie format to study the reconstructed output.

\subsection{CONVENTIONAL INFRARED CAMERA (FLIR InfraCAM SD)}

The conventional infrared camera used for this study, as shown in Figure 2-3, is FLIR InfraCAM SD. This is a low-cost $(\sim \$ 4,000)$ handheld camera, which is commercially available and is capable of capturing thermal images of the surface with temperature in the range of $-10^{\circ} \mathrm{C}$ to $+350^{\circ} \mathrm{C}$ with an accuracy of $\pm 0.1^{\circ} \mathrm{C}$ at a temperature of $30^{\circ} \mathrm{C}$. This device, weighing 1.21 pounds, offers a quick and convenient method of analyzing any member in the field. The thermal images taken from FLIR InfraCAM SD are stored in the format of standard radiometric JPEG files on a removable SD card. These JPEG files can directly be studied to identify debonds which is represented by the hot spots in the image. The thermal image file can further be analyzed using the associated QuickReport software that provides information on minimum, maximum, and average temperatures of an area in the image.
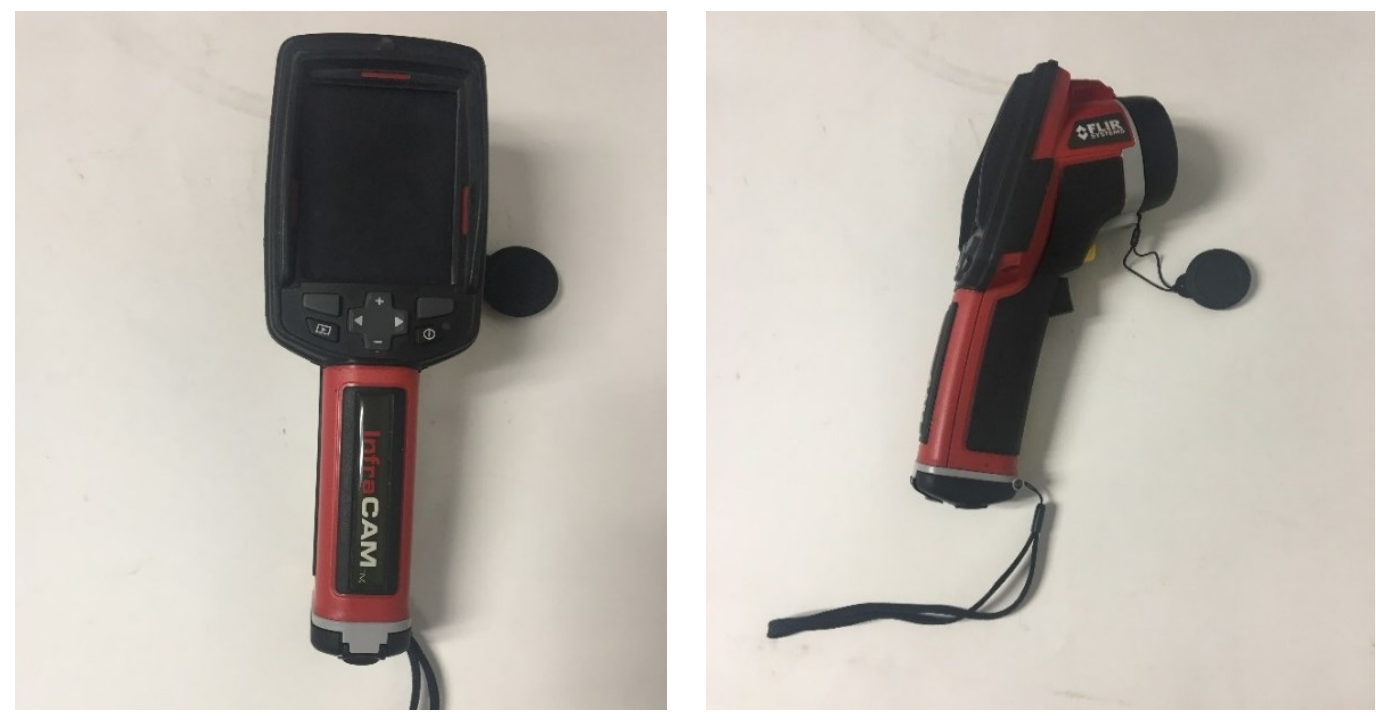

Figure 2-3: FLIR InfraCAM SD 
The 3.5" LCD display on the camera provides a $16 \mathrm{~K}$ color thermal image with a resolution of $120 \times 120$ pixels. This allows for the measurement of smaller temperature differences, hence sharper images can be obtained. Since this conventional infrared camera requires external heating source for testing, a halogen lamp heater is also used for this study, which is described later in this chapter. In the field, an advanced infrared system with built-in heating system, like VoyageIR Pro, is desired to accelerate the testing procedure. However, the cost of the halogen lamp heater $(\sim 30)$ and FLIR InfraCAM SD $(\sim \$ 4,000)$ is much lower than the $\$ 60,000$ price tag for the VoyageIR Pro.

\subsection{DIGITAL TAP HAMMER (Rapid Damage Detection Device - RD ${ }^{3}$ )}

The digital tap hammer, called Rapid Damage Detection Device $\left(\mathrm{RD}^{3}\right)$, is a low cost device ( \$1500) developed by Boeing Defense and Space Group for use on composite structures. The $\mathrm{RD}^{3}$ is marketed by WichiTech Industries, Inc. and consists of a low weight detection hammer containing an accelerometer connected to a handheld module by a cable as shown in Figure 2-4. The module contains digital logic components and a liquid crystal digital display powered by a 9 Volt battery. The accelerometer in the hammer translates the force-time pulse generated from each tap into a voltage pulse and the corresponding pulse width in microseconds is computed and displayed as a number on the digital display.

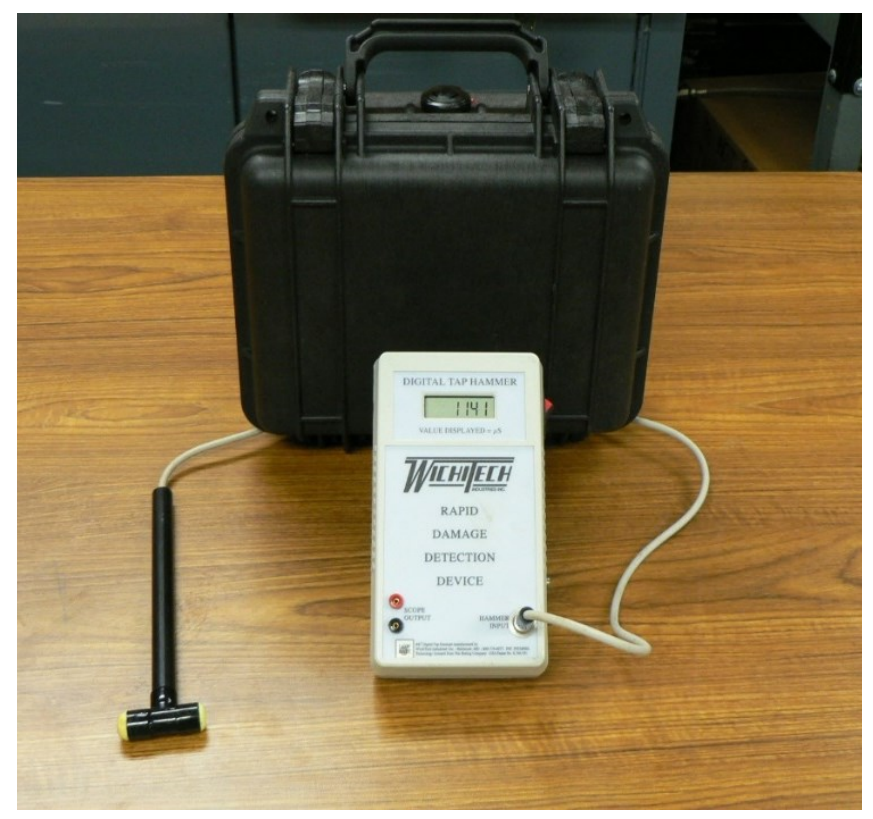

Figure 2-4: Digital Tap Hammer - Rapid Damage Detection Device (RD $\left.{ }^{3}\right)$ 
Since the pulse width is related to the mechanical impedance of the structure being inspected, any debond or delamination in the structure will produce wider force-time pulse (Georgeson et al. 1996). Thus, this is reflected in the digital display as a number higher than that of defect-free region. The threshold for differentiating debonds from defect-free areas is a number that is $10 \%$ greater than that of defect-free area. While this display number is generally independent of the tapping force, it should be noted that if the tap is too light, the $\mathrm{RD}^{3}$ will display an erroneous number.

\subsection{HALOGEN LAMP HEATER}

Along with the heating source from the VoyageIR Pro, a halogen lamp heater (Figure 2-5) was used to heat the composite samples in the laboratory. This was done to compare the heating system of the VoyageIR Pro against conventional heaters. This heater was used for heating the components before capturing the thermal images using the infrared camera. It is a $1000 \mathrm{~W}$ halogen twin-head lamp heater with two $500 \mathrm{~W}$ bulbs on a telescoping tripod stand. With high output reflectors, the desired heat can be obtained to heat the surface of the components for infrared testing. The heat flux from the heater was measured to be 168 Watts $/ \mathrm{m}^{2}$ at a distance of 24" using just one lamp. For inspecting samples in the laboratory, the heater was able to supply uniform heat over the surface at a distance of about 24". For field inspection, a distance of 12 " to 24 " is recommended. For locating debonds in FRP specimens in the laboratory, different heating durations were set to determine the ideal heating time.

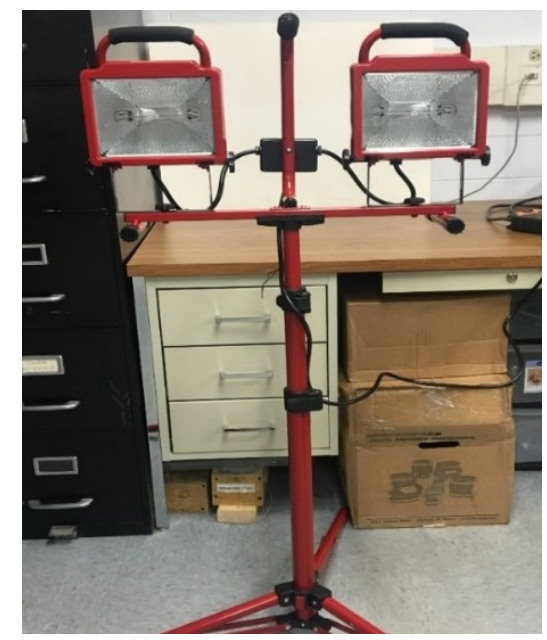

Figure 2-5: Halogen Lamp Heater (2x500W) 


\section{LITERATURE REVIEW: CONVENTIONAL AND ADVANCED IRT AND DIGITAL TAP TESTING}

\subsection{CONVENTIONAL INFRARED THERMOGRAPHY}

Infrared thermography, where the thermal image taken of an excited surface, has been studied and researched for quite some time. Before the advent of advanced infrared thermography, there were many articles and papers published that describe the applications of conventional infrared techniques in evaluating different structural components. This section reviews some of the important studies and works done in the past.

\subsubsection{Applications of Thermography in Nondestructive Testing of Structures (Titman 2001)}

\section{Introduction}

Thermal imaging or Infrared Thermography is a commonly used technique in the field of nondestructive testing of structural components. Thermography allows the structure to fully function even during the testing, which is its advantage over other inspection methods. The 'visual' nature of the results from the infrared thermography helps to interpret and evaluate the structure (Titman 2001).

\section{$\underline{\text { Applications }}$}

The applications of infrared thermography can be seen in many contexts in nondestructive testing. The evaluation of building envelope like heating or cooling system, insulation in the walls, and leaks in the roof can be efficiently done using thermography (Figure 3-1). The structures with concrete spalling exposed to strong solar radiation have been tested successfully using infrared thermography in many countries. Light weight timber framed buildings can be inspected after sunset using thermal imaging. Similarly, thermography can also be used to test the services in the building. Pipework and electrical wiring in buildings can be accurately located within walls using infrared thermography. 

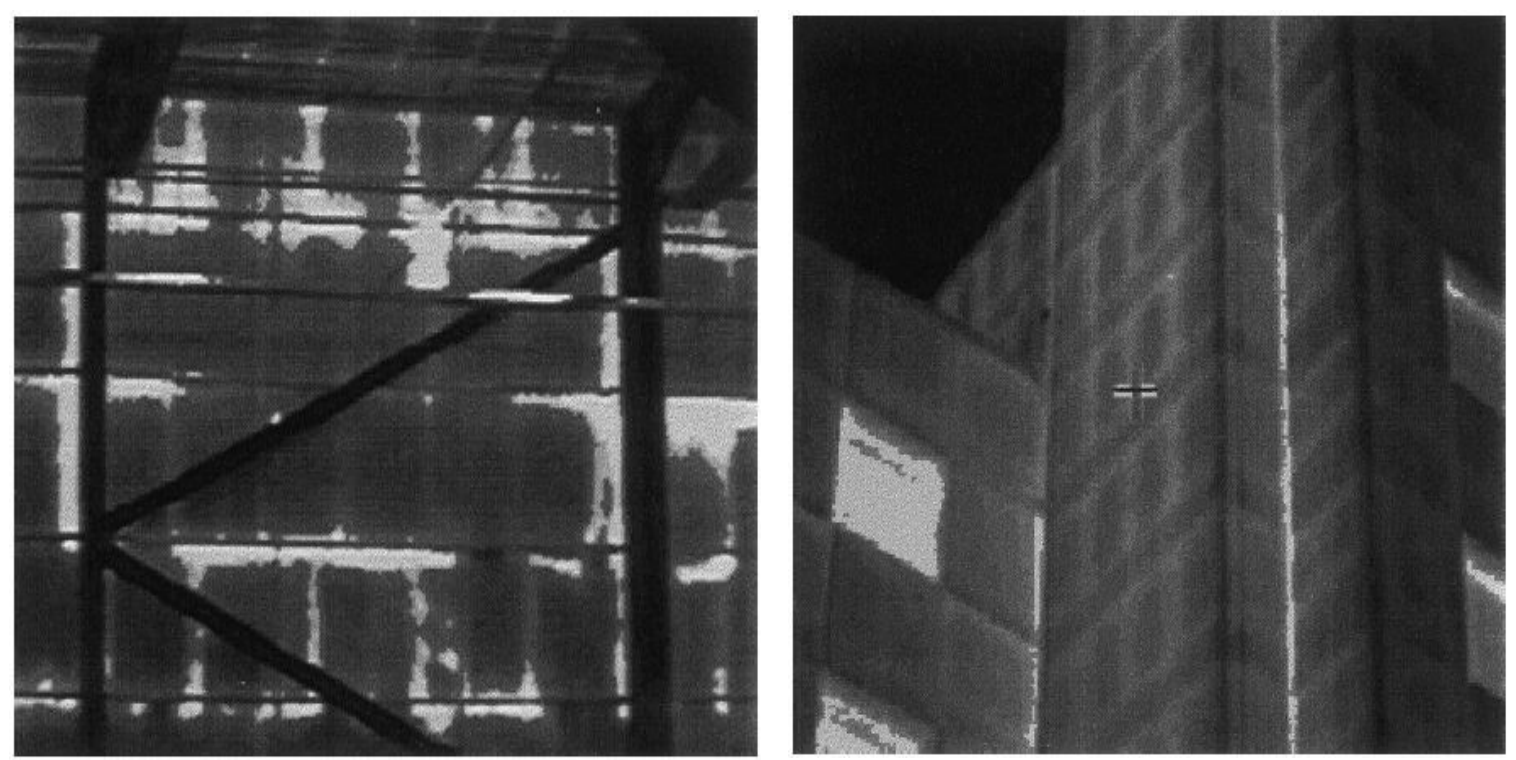

Figure 3-1: Thermal image of poor insulation system in the walls (left) and thermal image of precast RC building showing heat loss at joints (right) (Titman 2001)

\section{Conclusion}

The infrared thermography can be useful in various structural situations. It, not only provides a cost-effective inspection method, but also gives a rapid and reliable evaluation of structure and other associated services. Thermal imaging of structures made of different materials like concrete and timber can be very helpful in any future repair.

\subsubsection{Infrared Thermography and GPR Techniques for Condition Assessment of RC Bridges (Halabe et al. 2012)}

\section{$\underline{\text { Introduction }}$}

The paper talks about two of the nondestructive testing methods - infrared thermography and ground penetrating radar for assessing a reinforced concrete (RC) bridge. Since this problem report is focused mainly on infrared testing, only the methodology involving infrared thermography will be reviewed in this section. The use of infrared thermography allows the detection of subsurface voids and delaminations in the reinforced concrete bridges. This serves in taking necessary steps regarding repair or rehabilitation of the bridge. The paper presents the application of infrared testing in evaluation of an RC bridge in West Virginia. 


\section{$\underline{\text { Experimentation }}$}

The piers and pier cap on the south side of the RC bridge in context had been severely damaged due to rain water seepage (Figure 3-2). The infrared thermography testing was conducted on these RC components using a shop heater and a low-cost portable infrared camera. After heating the surface for about 15 minutes, thermal images of the surface were captured to locate the defects in the damaged region. The infrared images for the piers and pier cap showed the defective areas as hot spots, as shown in Figure 3-3. Similar results were obtained for all other damaged areas (Figure 3-4).

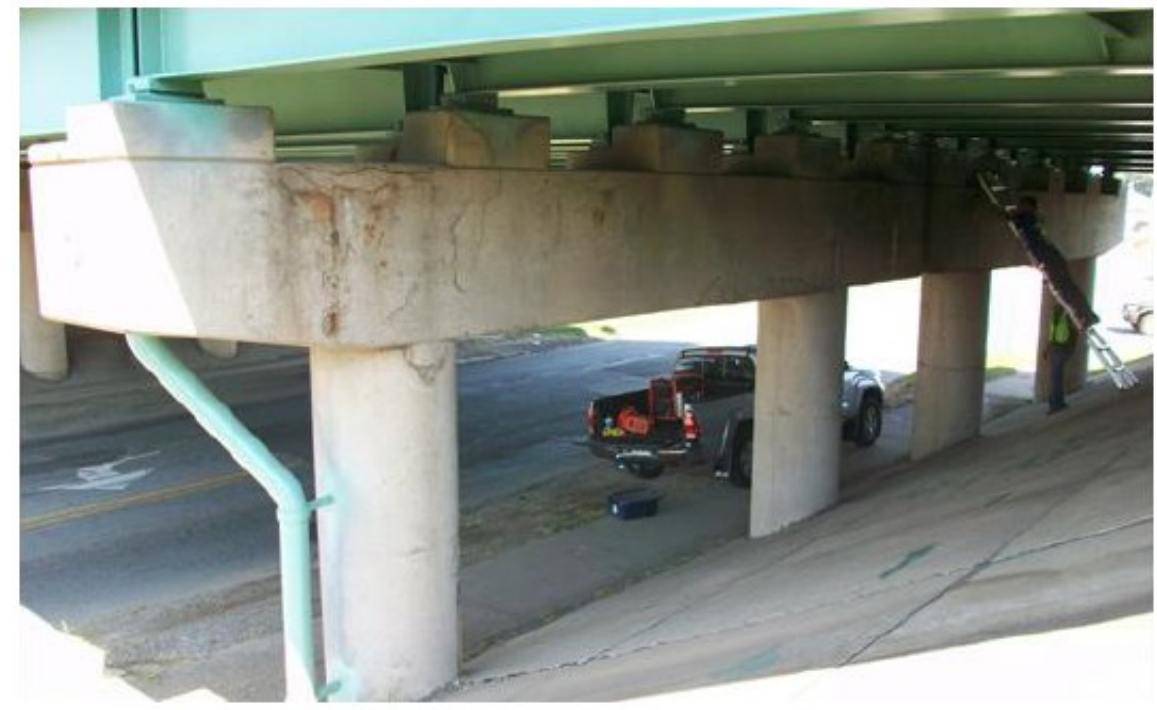

Figure 3-3: Close-up view of the damaged piers and pier cap on the south side of the bridge (Halabe et al. 2012)
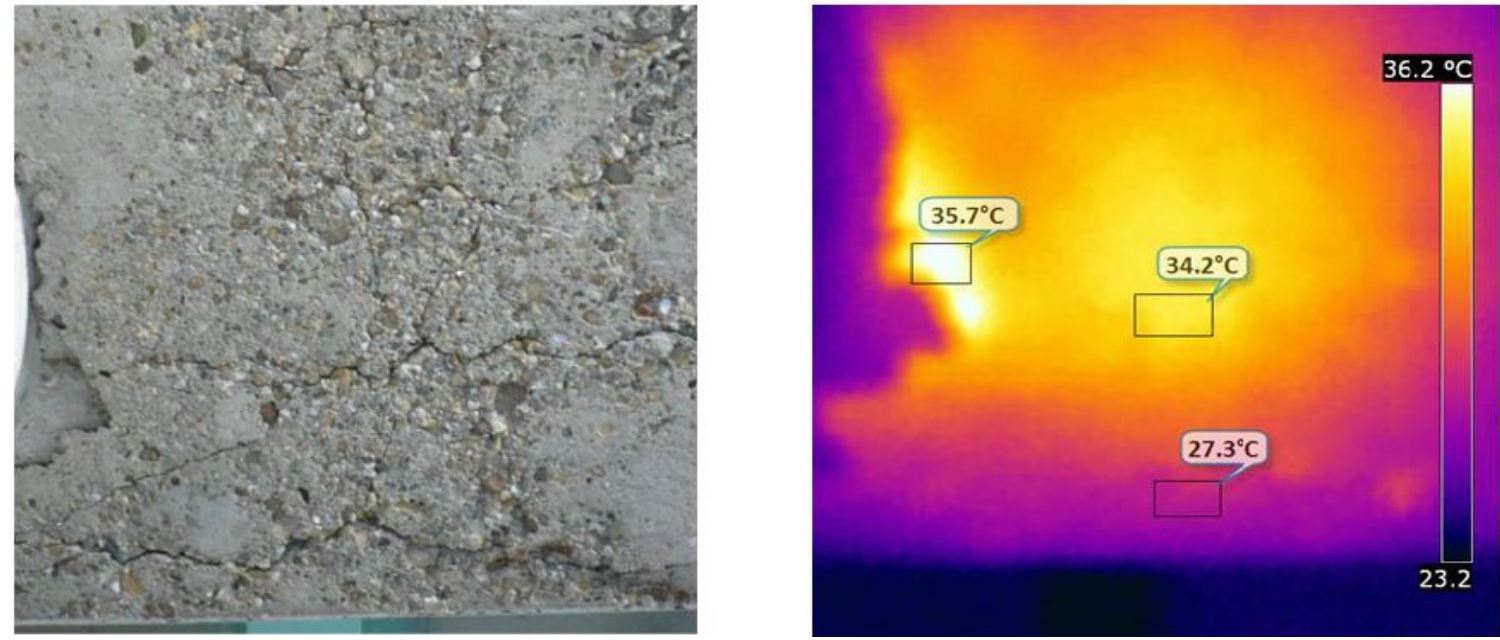

Figure 3-2: Another pier cap in the RC bridge (left) and thermal image of the surface showing defect as hot spot (right) (Halabe et al. 2012) 

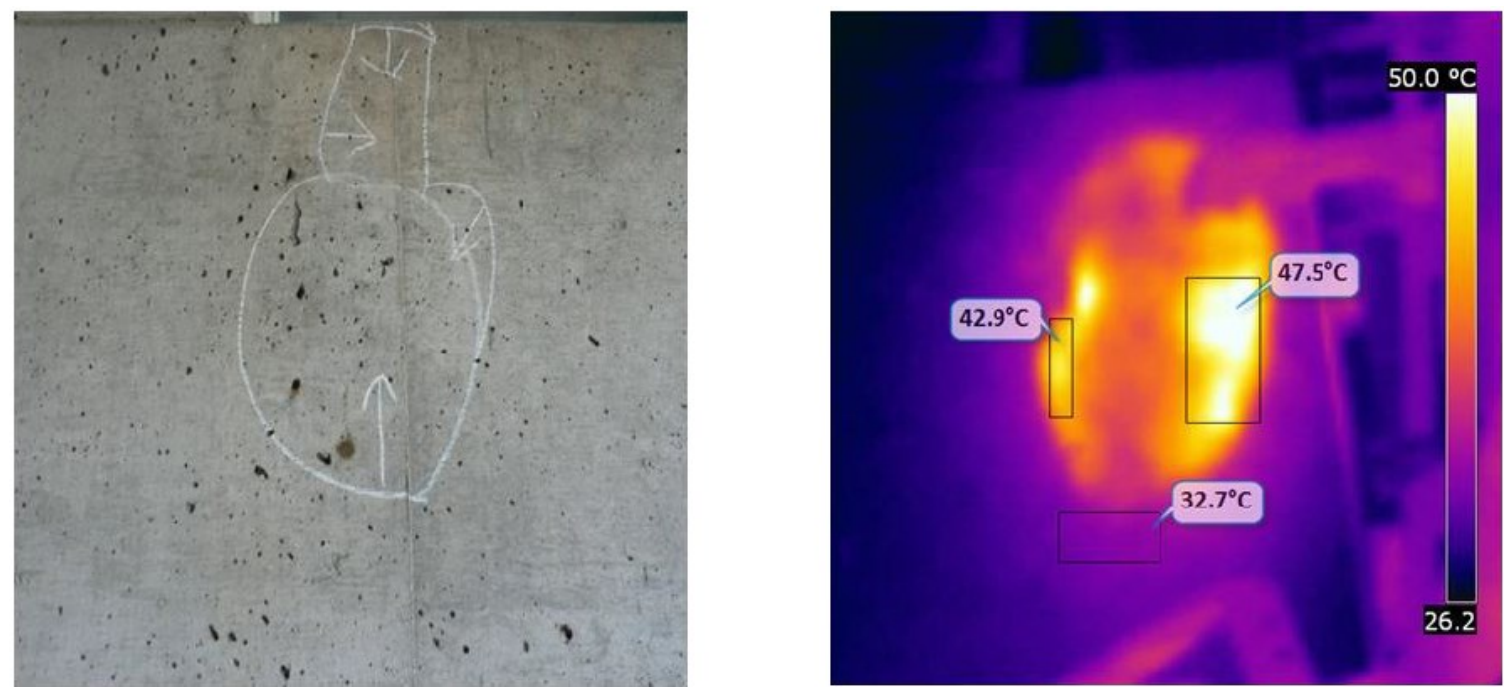

Figure 3-4: Damaged pier cap in the RC bridge (left) and thermal image of the surface captured by infrared camera after heating (right) (Halabe et al. 2012)

\section{$\underline{\text { Conclusion }}$}

This study concludes that the hidden defects within the surface can be located by the infrared testing method. The infrared thermography done on the damaged RC components of the bridge allowed the provisions for rehabilitation by wrapping them with FRP fabrics.

\subsubsection{Thermal Infrared Inspection of FRP Bridge Decks for Health Monitoring} (Miceli et al. 2003)

\section{Introduction}

To overcome the limitations of traditional bridge component materials (i.e., reinforced concrete and steel), Fiber Reinforced Polymer (FRP) composites can be used as a replacement to the superstructure of the bridge. With the advantages of higher strength to weight ratio and lower corrosion rate, FRP helps for the longevity of the bridge structure. However, to make the FRP a commonly used construction material, a quick and convenient method of monitoring the condition over time should be adopted. This paper suggests thermal infrared method as a reliable inspection method to evaluate the health of FRP components in a bridge structure. The most probable failure mode during strength and fatigue testing of a Glass Fiber Reinforced Polymer (GFRP) bridge deck component is 
debonding between the GFRP layers, which leads to large deflections, reduction in stiffness and ultimately, structural failure of the deck (Lopez-Anido et al. 1998).

\section{$\underline{\text { Experimentation }}$}

The paper included laboratory testing and field testing of full-size GFRP bridge decks. The GFRP deck components for both, laboratory testing and field testing, were made from alternating layers of random mat fibers and unidirectional roving in an isophthalic polymer resin. The deck consisted of GFRP square tubes sandwiched between plates of same GFRP material (Figure 3-5).

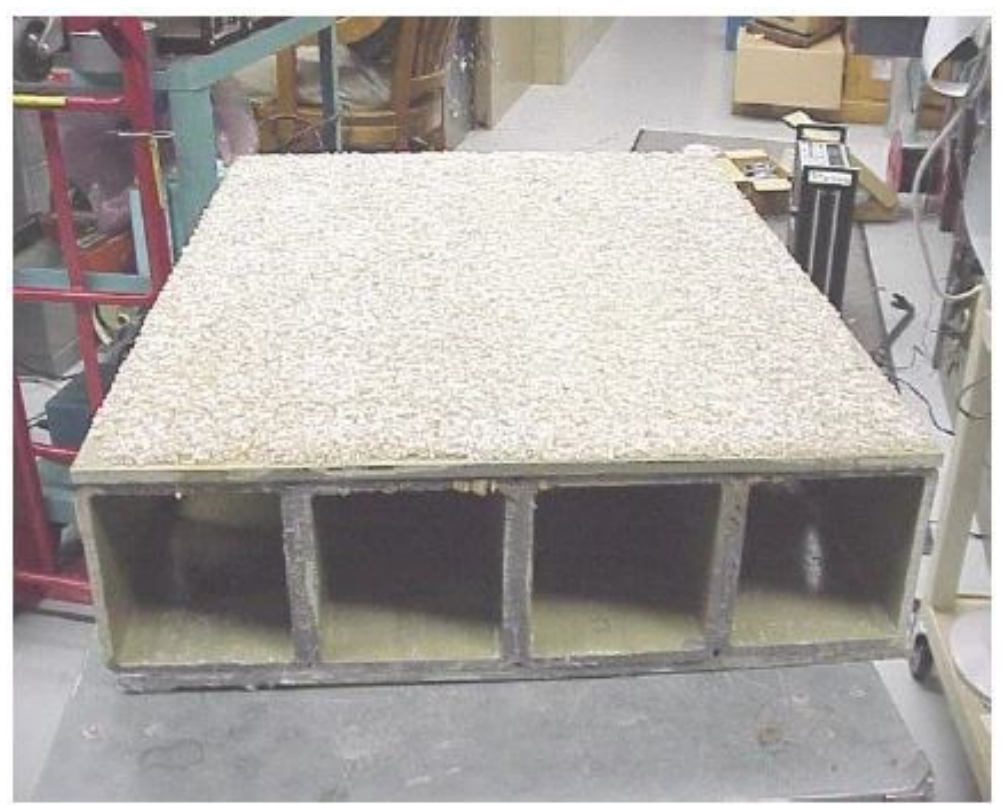

Figure 3-5: Model GFRP Bridge Deck (Miceli et al. 2003)

For laboratory testing, the GFRP bridge deck was heated with a hot convective air supply and still thermal infrared images were captured. The infrared camera, developed by Raytheon/Amber, was equipped with an Indium Antimonide detector array and operated at $3-5$ micron with a temperature range of $-20^{\circ} \mathrm{C}$ to $300^{\circ} \mathrm{C}$. The camera had a resolution of $256 \times 256$ pixel and an associated thermal analysis software was also used in conjunction. Figure 3-6 (left) shows the schematic diagram of model bridge deck with debonded area and Figure 3-6 (right) shows the thermal image of the deck captured after 6 minutes of heating. 

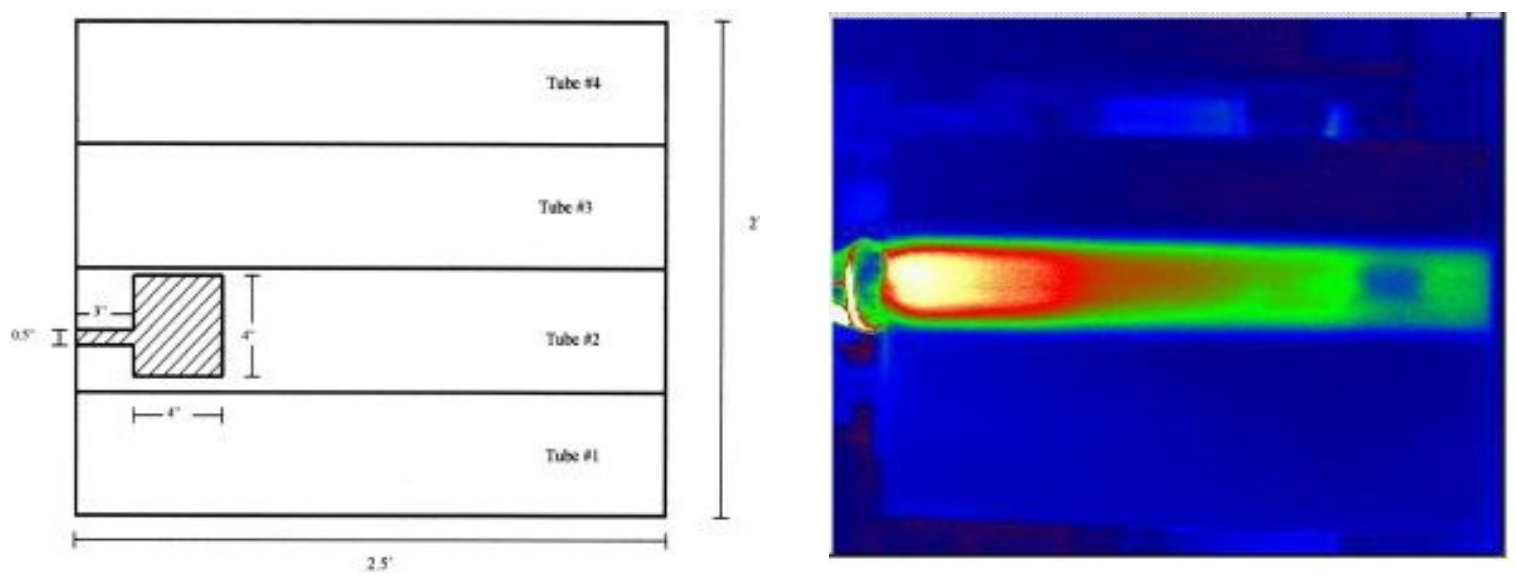

Figure 3-6: Schematic diagram of model GFRP bridge deck (left) and Thermal image of the bridge deck taken after 6 minutes of heating (right) (Miceli et al. 2003)

For field testing, two in situ bridge decks were installed on I-81 in Troutville, VA (Figure 3-7 (left)) and hot air was supplied through a piping system to heat the decks for testing. After the decks experienced some live traffic, the thermal images of the deck showed some unusual patterns due to the tire heat, as shown in Figure 3-7 (right).
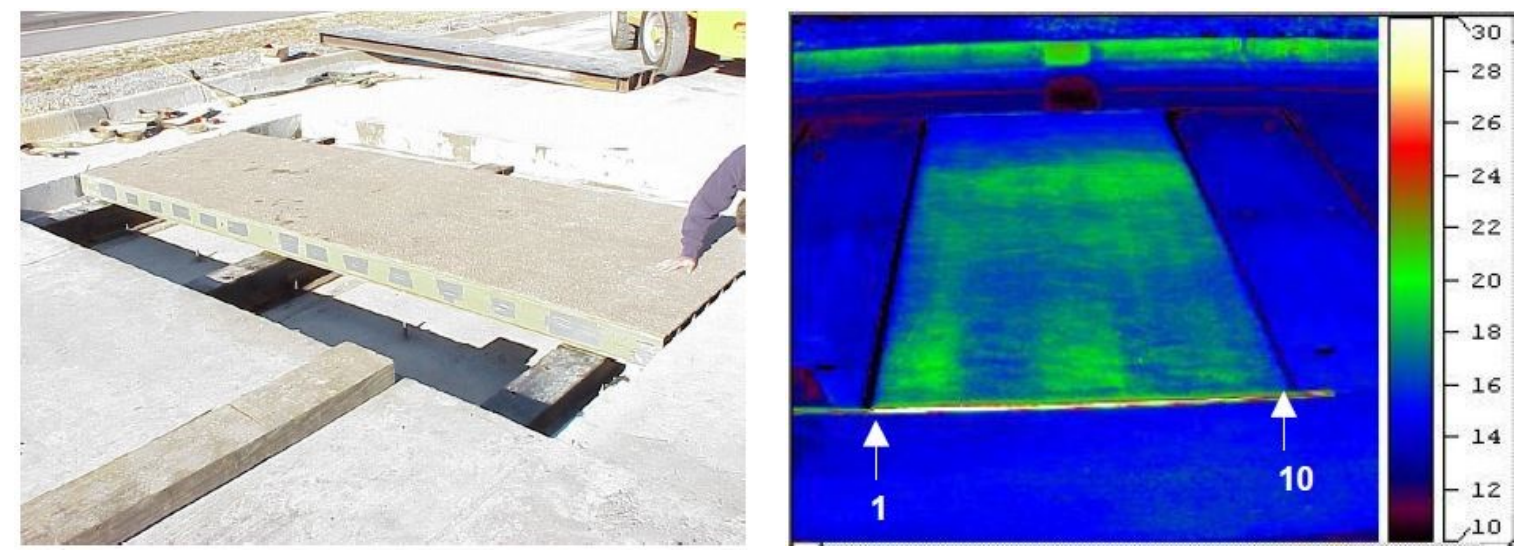

Figure 3-7: Full-size FRP bridge deck embedded in roadway (left) and Thermal image of the bridge deck showing tire heat at the top (right) (Miceli et al. 2003)

\section{Conclusion}

This paper concludes that the infrared testing method can be helpful in monitoring of in-service GFRP bridge deck condition. The technique helps to detect the debonds in the FRP layers of the bridge deck and provides proper evaluation for future repair or rehabilitation. The laboratory testing and field testing in this research show that infrared testing is an easy and rapid method of nondestructive testing of composite materials for both laboratory experiments and field application. 


\subsubsection{Nondestructive Evaluation of FRP Strengthening Systems Bonded on RC Structures using Pulse Stimulated Infrared Thermography (Taillade et al. 2012)}

\section{Introduction}

This paper discusses about the application of pulsed stimulated infrared thermography in detection and characterization of the defects between FRP wrap and underlying concrete. The subsurface defects can be detected by analyzing images obtained from pulsed infrared thermography (Ibarra-Castanedo et al. 2004). The pulse infrared thermography was used to test a sample with different defects in laboratory. A field inspection of an FRP strengthened concrete was also conducted using a handheld heating device and an uncooled infrared camera.

\section{Laboratory Testing and Results}

The laboratory experiment included a $400 \times 300 \times 15 \mathrm{~mm}^{3}$ concrete slab reinforced with three layers of pultruded FRP plates of thickness $1.2 \mathrm{~mm}$ with intermediate glue layers (1 mm thick), as shown in Figure 3-8. For the purpose of experimentation, the defects in the form of polytetrafluoroethylene (PTFE) discs were placed either between concrete surface and lower FRP plate or between two adjacent FRP plates. The discs of diameters 10,20 and $30 \mathrm{~mm}$ were placed at depths of 1.2, 3.4 and $5.6 \mathrm{~mm}$.

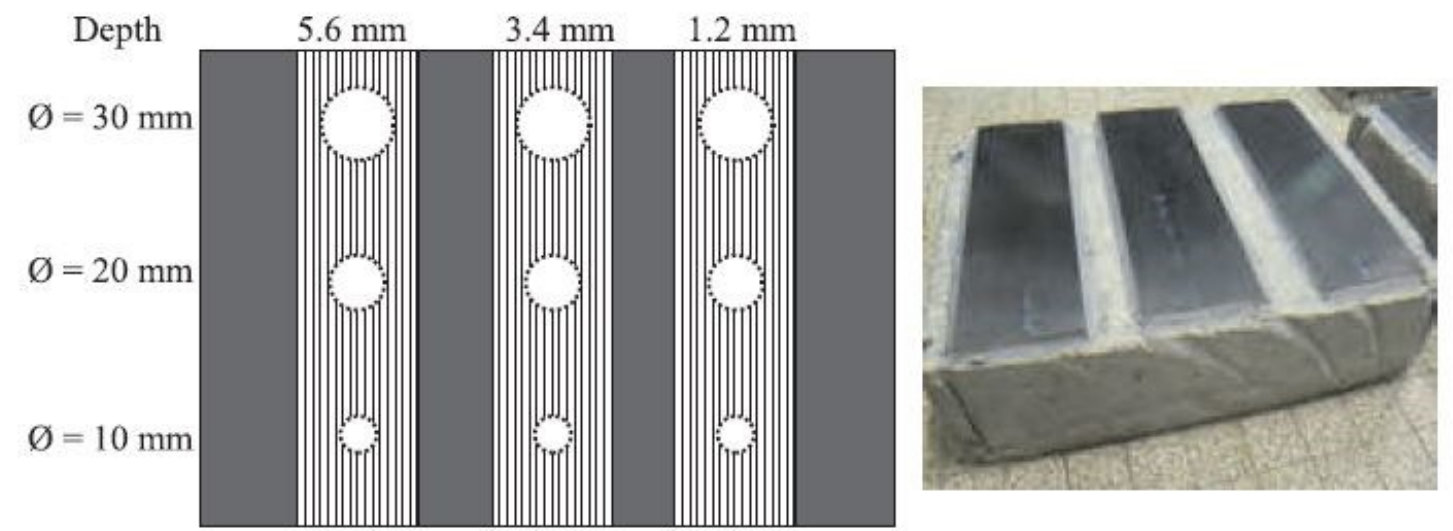

Figure 3-8: Concrete Slab Reinforced with Bonded FRP Plates along with Defects (Taillade et al. 2012) 
The surface of the reinforced slab was heated for 50 seconds using a $1000 \mathrm{~W}$ flexible electric cover. The heated surface was tested using uncooled microbolometer infrared camera (temperature range of $-40^{\circ} \mathrm{C}$ to $+2000^{\circ} \mathrm{C}$ with accuracy of $\pm 0.2^{\circ} \mathrm{C}$ and spectral range of 7.5 to 13 micron). The thermal images produced by the infrared camera had a resolution of $320 \times 240$ pixels. Figure 3-9 shows the thermal images of the specimen at beginning of the thermal relaxation (left) and 52 seconds after heating (right). It can be seen that at the beginning, the defects aren't clear and this is due to non-homogeneity of the heating. But after some time of heating, some, but not all, of the defects can be seen clear in the captured thermal image.
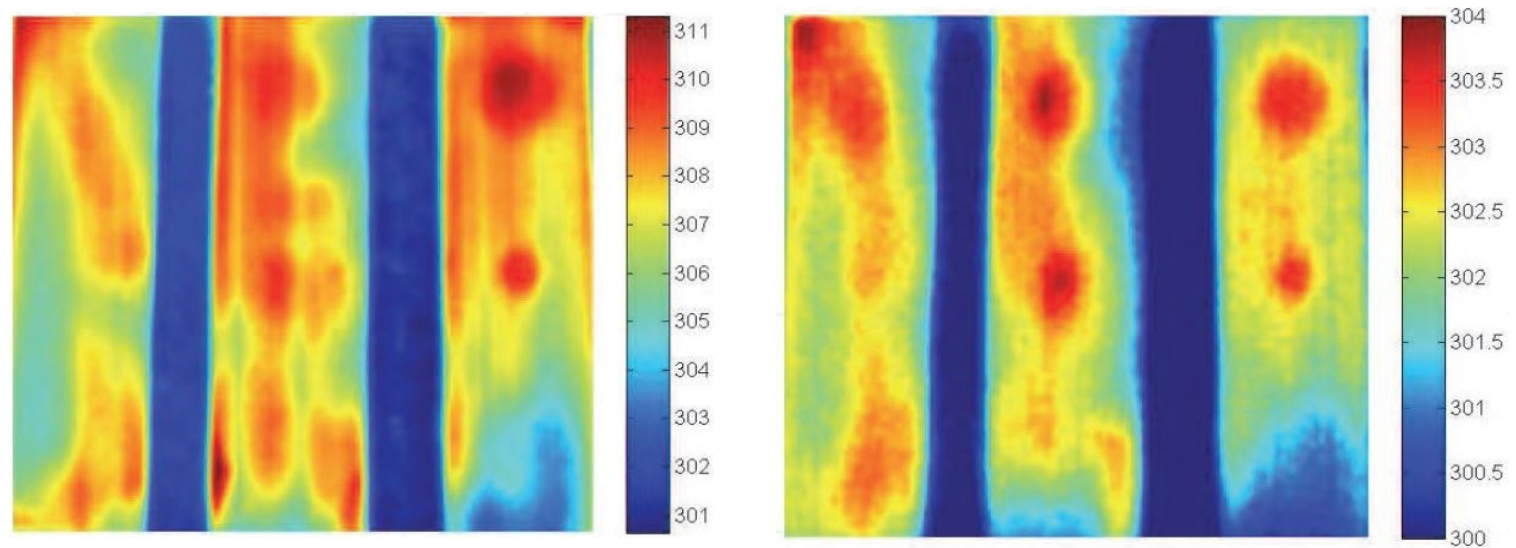

Figure 3-9: Thermal Image at the beginning of thermal relaxation (left) and after 52 seconds after heating (right) (Taillade et al. 2012)

\section{Field Inspection}

The pulsed infrared thermography was used for routine inspection of a FRP strengthened reinforced concrete bridge. The field test was conducted to detect the bonded defects in FRP fabric on the bridge girder. Built in the 1960's, the bridge is located near Besancon in France, over the Doubs river. The main central portion of the bridge, which is divided into three spans, is made of two prestressed concrete box-girders. After a visual inspection done in the 90 's, the lower slabs of the box girders were found to be cracked at mid-span as a result of inadequate design of longitudinal prestressed reinforcement in lower slabs. Following a study to optimize the rehabilitation design with respect to shear stress distribution, the deteriorated box-girders were repaired by bonding carbon FRP (CFRP) to the lower slabs and installing composite reinforcements at the outer side of the web of the girders as shown in Figure 3-10. 


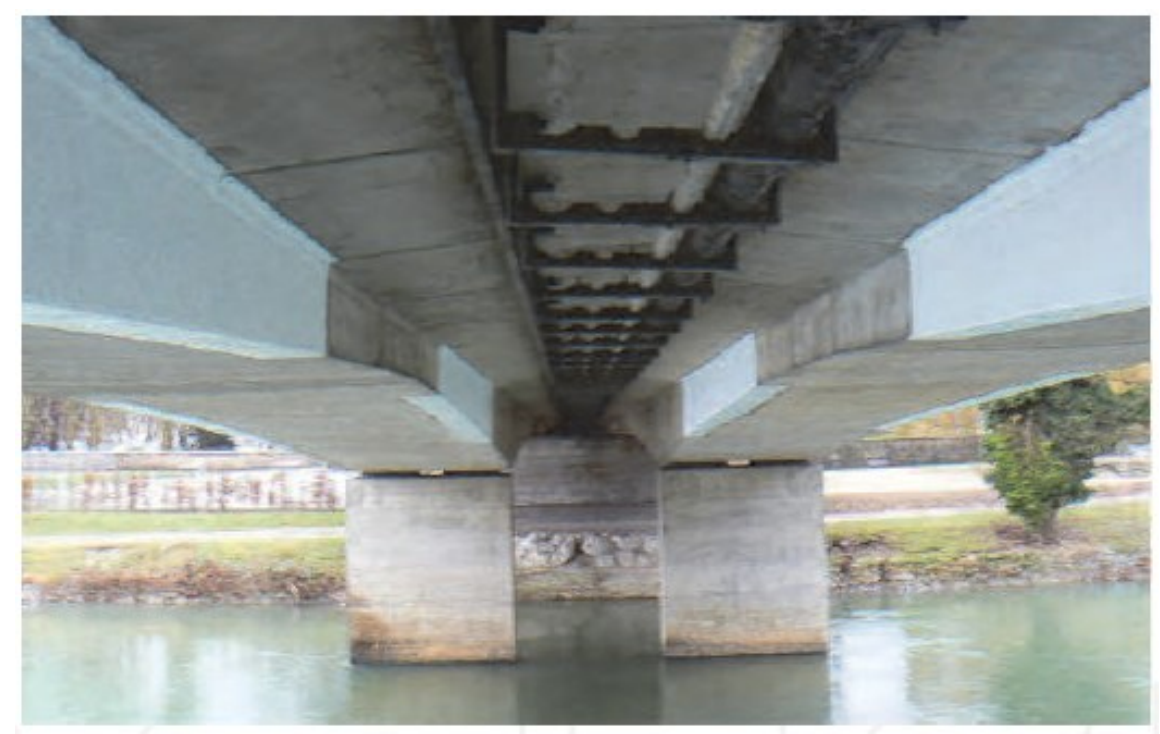

Figure 3-10: FRP Strengthened Box-Girders of the Bridge (Taillade et al. 2012)

The thermographic inspection of the carbon FRP wrapped girders was done before installing the external composite reinforcement on the web. To assess the CFRP bonded areas, a truck mounted lift-platform was used since this area was underneath the bridge. The surface was thermally excited with an infrared lamp and the thermal images were captured with an uncooled infrared camera. This portable setup of infrared camera and heating source made it possible to test the repaired box-girders with relative ease.

Figure 3-11 (left) shows the schematic diagram of pulsed infrared thermography test on the CFRP wrapped girder, conducted to detect any possible wrapping defect. The result of the infrared testing showed two small gluing debonds on the wraps (Figure 3-11 (right)), which was also confirmed with hammer tapping later.
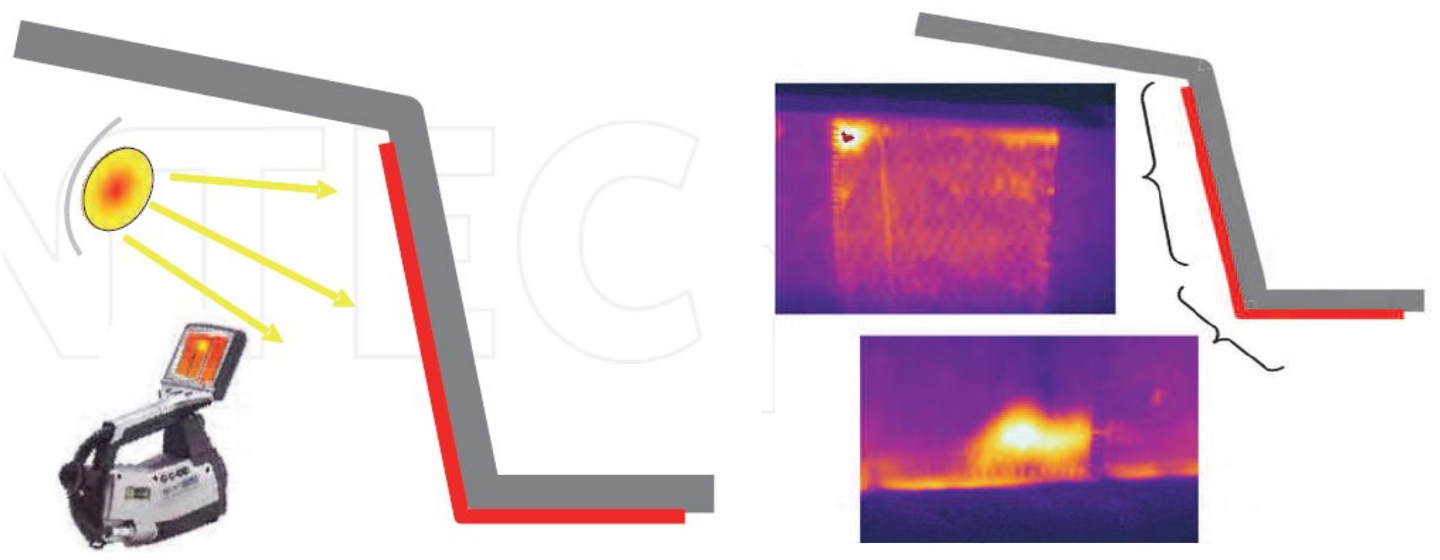

Figure 3-11: Schematic diagram of infrared thermography on the bridge (left) and thermal images showing defects on the wrap (right) (Taillade et al. 2012) 


\section{Conclusion}

This paper offers sufficient evidence to prove that the nondestructive evaluation (NDE), in the form of pulsed infrared thermography, is feasible in rapid evaluation of FRP wrapped bridges. The laboratory experimentation showed that this method of evaluation is very effective in detecting the debonds in FRP wraps. The simple setup of the infrared thermography equipment has proved to be capable of assessing FRP wrapped girders of a bridge efficiently, which makes it suitable for field testing application. The field testing presents NDE as an effective tool for routine inspection of FRP repaired bridges.

\subsection{ADVANCED INFRARED THERMOGRAPHY}

The advancement in the field of infrared thermography has improved the ability to detect subsurface defects to greater heights. The modern infrared testing method includes heavy-duty infrared camera and high image processing power, which helps to identify hidden detects by amplifying signals and reducing noises in the thermal data. The advanced infrared thermography is fairly new to the nondestructive testing industry. The following section discusses some of the works done recently in the field of advanced infrared technology.

\subsubsection{Thermographic Characterization of Composites (Shepard 2013)}

\section{$\underline{\text { Introduction }}$}

In the nondestructive testing (NDT) of structures, infrared thermography is the inspection method where the surface of the structure is thermally excited and observed with an infrared camera. The subsurface condition is then studied from the surface temperature differential. However, when compared to other NDT methods like ultrasound, a low-cost infrared camera and unprocessed infrared image output from the camera are insufficient for many NDT field applications. Thus, a high-performance infrared camera and a strong signal processing system have been very efficient in most NDT applications in recent days (Maldague 2001). Thermographic Signal Reconstruction (TSR) is one of the modern approaches to processing of thermal data, where the behavior of logarithmic temperature vs. time plot is studied. It includes taking derivatives of the logarithmic signal with respect 
to logarithmic time that helps in amplifying signal and reducing noise. Figure 3-12 shows the logarithmic surface temperature plot of a flaw-free slab with the first and second derivatives.
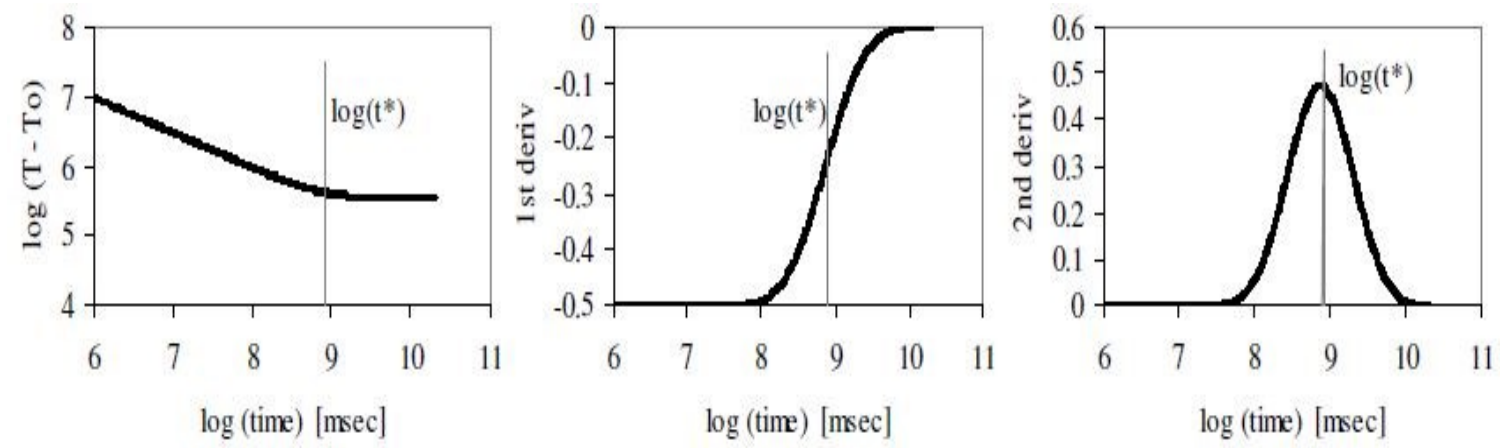

Figure 3-12: Logarithmic Surface Temperature vs Time plot (left), first derivative (center) and second derivative (right) with respect to logarithmic time (Shepard 2013)

\section{$\underline{\text { Experimentation }}$}

A 12-ply graphite epoxy sample with built-in flaws was examined with flash thermography to demonstrate image contrast method for detecting the flaws. Eight polymer inserts of thickness 0.1 " were embedded between two plies of the sample. Along with that, two flat bottom holes were cut into the sample, as shown in Figure 3-13.

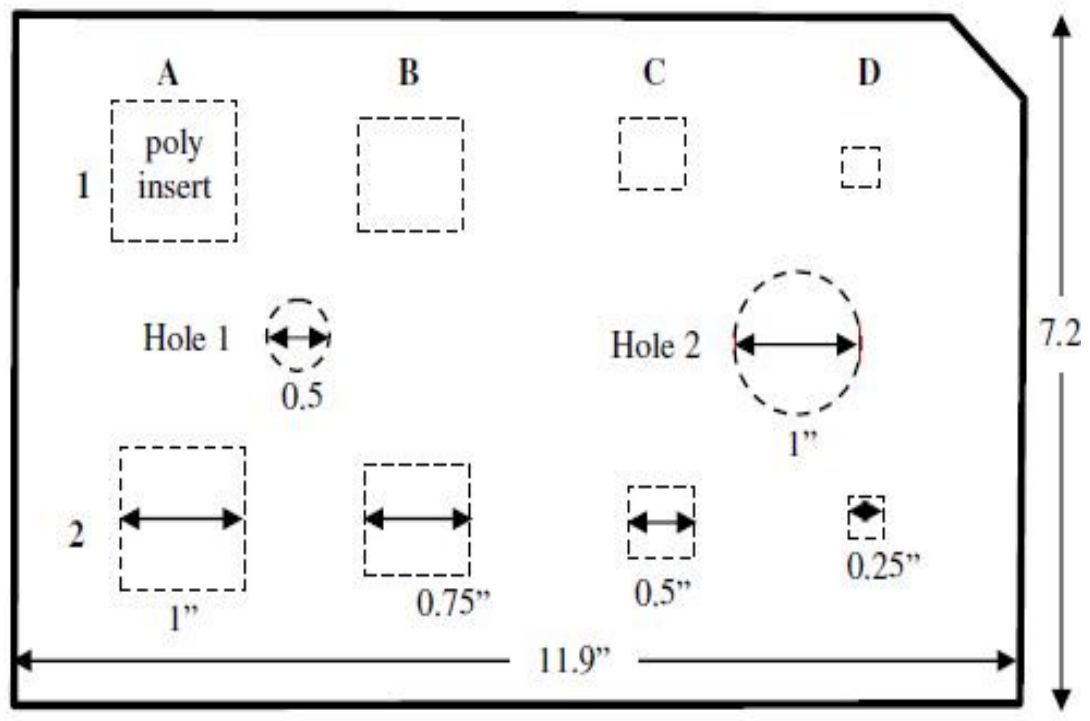

Figure 3-13: 12-ply graphite epoxy sample with embedded polymer inserts and flat bottom holes (Shepard 2013) 
The sample was tested with a thermography system with 2 quartz-xenon flash lamps and a $640 \times 480$ pixel infrared camera. The digital data is captured in real-time and temperature-time sequence is immediately processed using TSR in the associated software program. The program displays the reconstructed signal, $1^{\text {st }}$ and $2^{\text {nd }}$ logarithmic derivatives. The sample was placed at a distance of 12" from the camera and heated by a 3 millisecond flash pulse. The data was collected for 30 seconds after the flash pulse at a frame rate 30 Hz. Figure 3-14 shows the results of flash thermography on the sample. TSR method on the digital data gave clear images which can be seen in $1^{\text {st }}$ and $2^{\text {nd }}$ derivative images. The $2^{\text {nd }}$ derivative and $2 \mathrm{~d} \mathrm{t}_{\text {peak }}$ images show the eight polymer inserts as well.
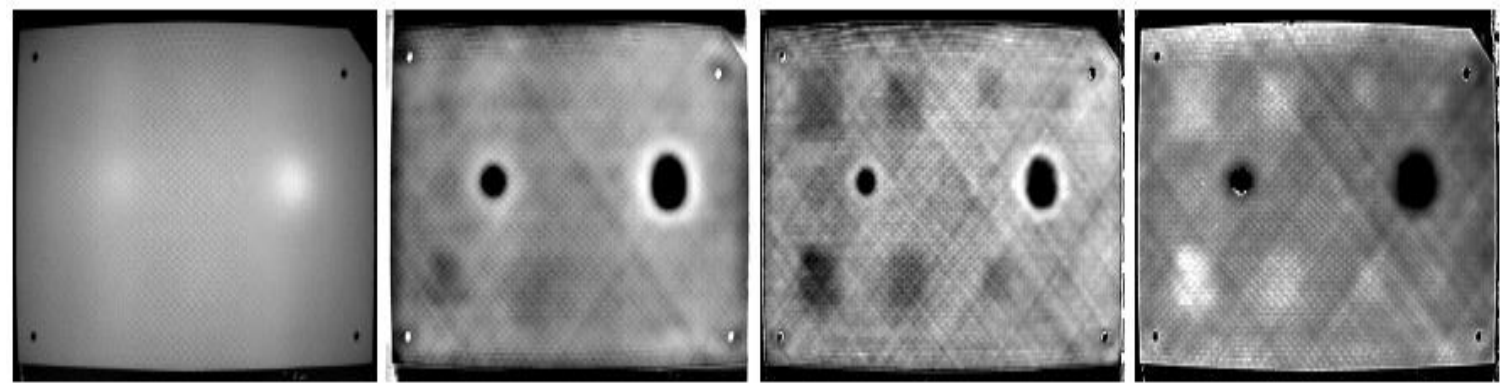

Figure 3-14: Contrast images (left to right) for raw, $1^{\text {st }}, 2^{\text {nd }}$ derivative and $2 d t_{\text {peak }}$ (Shepard 2013)

\section{Conclusion}

When the flaws in the sample get fuzzier, like the polymer inserts, direct viewing of the infrared image gives poor result. In such cases, TSR processing provides clear image of the flaws in the form of $1^{\text {st }}$ and $2^{\text {nd }}$ derivatives as the contrast between flaws and the background is enhanced.

\subsubsection{Defect Depth Determination in a CFRP Structure using TSR Technique (Oswald-Tranta et al. 2014)}

\section{Introduction}

In this paper, Thermographic Signal Reconstruction (TSR) technique has been used to analyze the response of a CFRP sample to pulse heating. After fitting the logarithmic temperature function into a polynomial equation, the derivatives of the temporal temperature change provide a method for early detection of defects. 


\section{$\underline{\text { Experimentation }}$}

The CFRP specimen is made using Vacuum Infusion Molding process and consists of 5 carbon fiber layers rotated to each other with Teflon inserts as defects between the layers, as shown in Figure 3-15. A flash heating pulse from xenon flash lamp and a commercially available cryogenically cooled 320 x 256 pixel InSb camera were used to test the specimen.
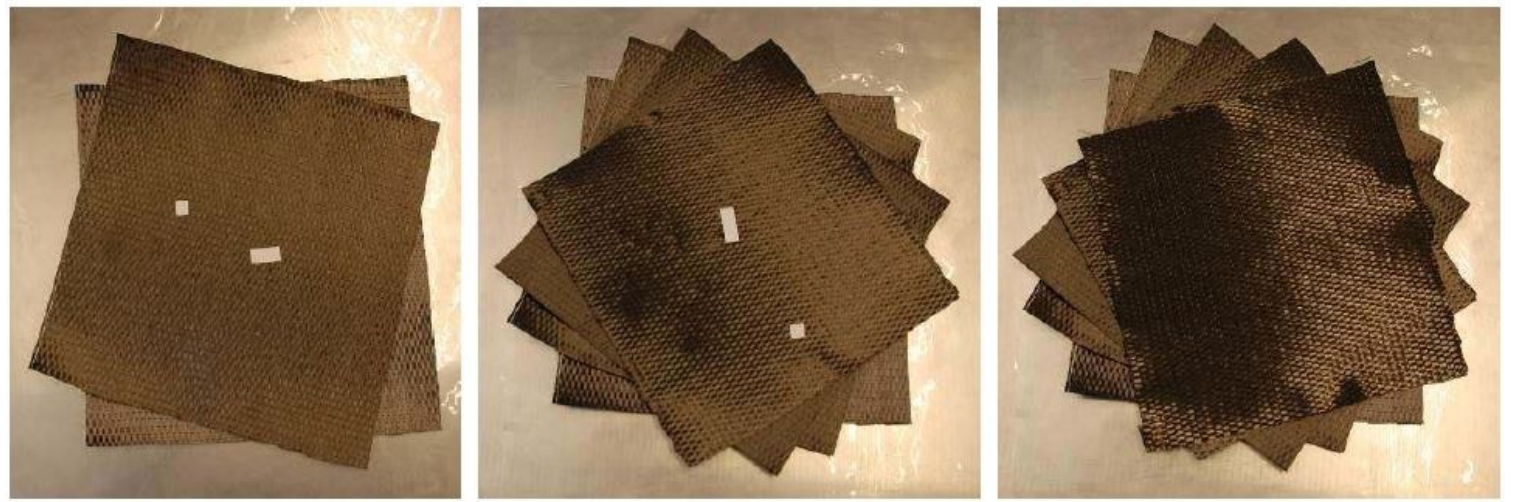

Figure 3-15: CFRP layers with Teflon inserts in the sample before applying vacuum infusion molding process (Oswald-Tranta et al. 2014)

Figure 3-16 shows the 3D map of the transmission measurement created using TSR technique where the Teflon inserts act as a barrier to the heat flow and occur as being thicker than the sample. The TSR method provides noise reduction by polynomial fitting of the measured temperature functions to determine the $2^{\text {nd }}$ derivative image. Figure 3-17 shows the $2^{\text {nd }}$ derivative image calculated after the polynomial fitting of the TSR method.

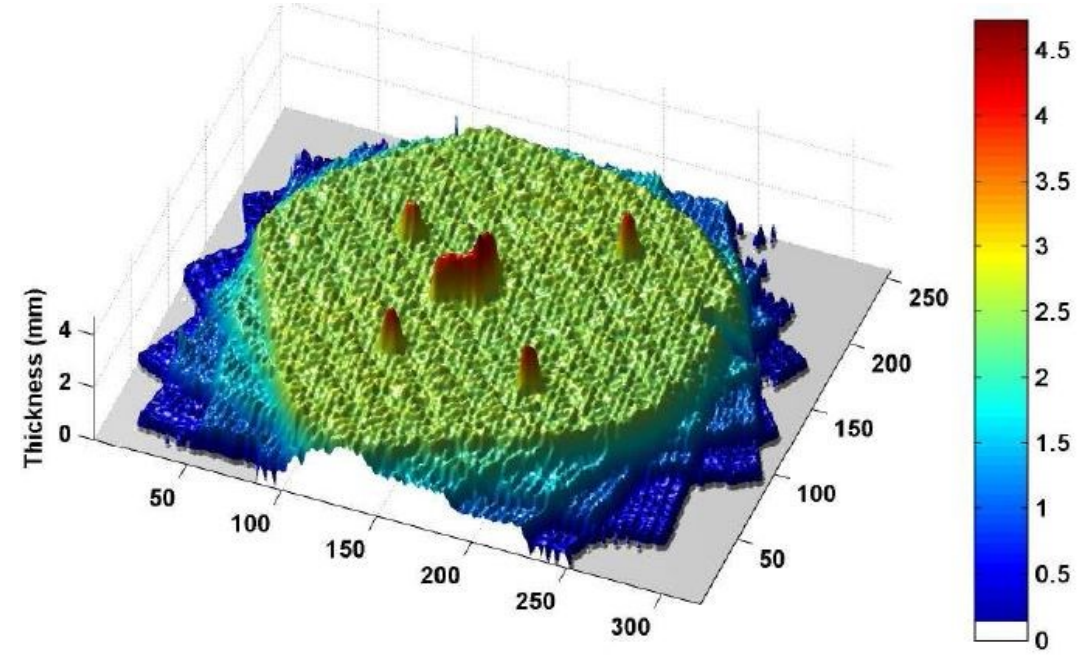

Figure 3-16: 3D map of the transmission measurement of the CFRP sample with Teflon inserts (Oswald-Tranta et al. 2014) 


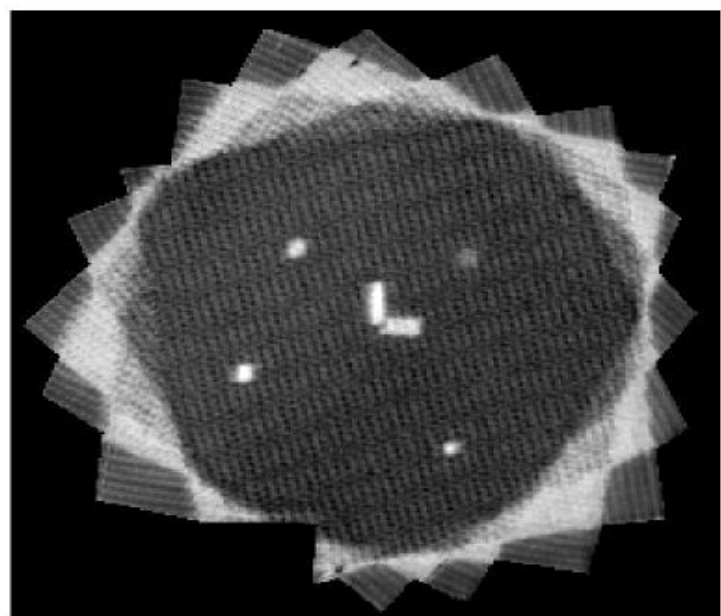

Figure 3-17: $2^{\text {nd }}$ derivative image of the CFRP specimen calculate after TSR fitting (Oswald-Tranta et al. 2014)

\section{Conclusion}

The TSR technique, with its ability to determine the location and depth of the defects to some extent, is a useful tool in evaluation of CFRP panels. The $2^{\text {nd }}$ derivative image offers a new approach to overcome the limitations of conventional thermal imaging methods.

\subsection{DIGITAL TAP TESTING}

The digital tap testing is the upgrade to the conventional coin tap testing method. The subjectivity in the traditional coin tap testing (based on user's hearing ability) is reduced in the digital tap testing method improving the sensitivity of the test. The following section discusses previous works and researches done to improve the method of tap testing as a nondestructive testing technique.

\subsubsection{Electronic Tap Hammer for Composite Damage Assessment (Georgeson et al. 1996)}

\section{$\underline{\text { Introduction }}$}

The Rapid Damage Detection Device $\left(\mathrm{RD}^{3}\right)$, developed by Boeing Defense and Space Group, is an electronic tap hammer that works on the basis of the accelerometer placed in the head of the hammer. The accelerometer translates the force-time pulse 
generated from each tap into a voltage pulse and the pulse width at half-amplitude in microseconds is computed and displayed as a number on the digital display. Any debond or delamination will produce wider force-time pulse than defect-free area (Figure 3-18), thus the number displayed for debond is larger than that for defect-free area (Georgeson et al. 1996).
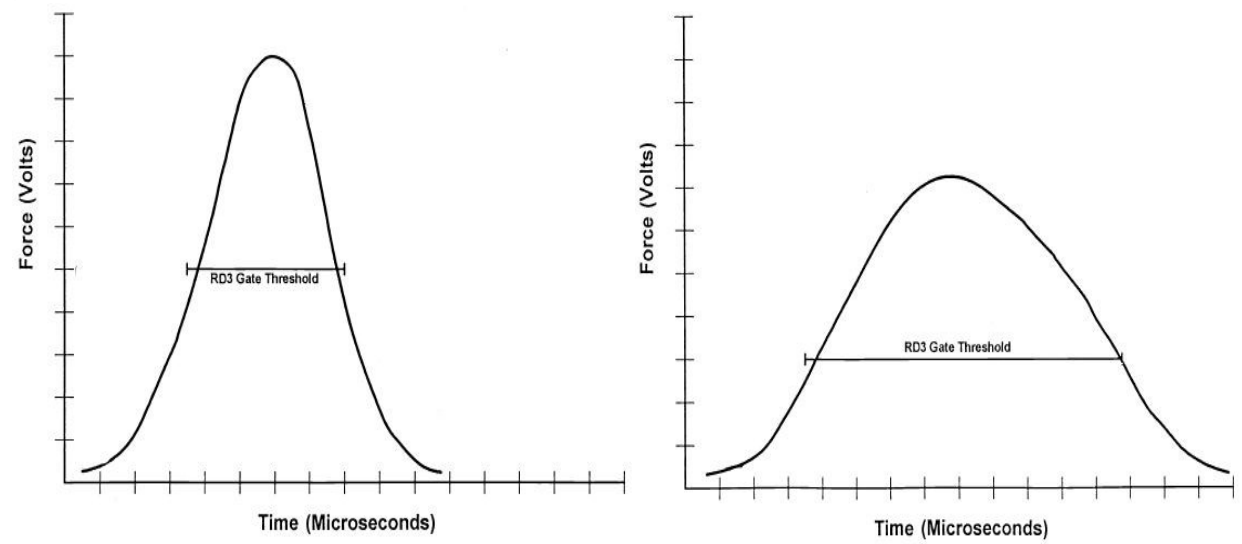

Figure 3-18: Typical $\mathbf{R D}^{3}$ force-time pulse for good area (left) and debond (right) (Georgeson et al. 1996)

\section{Experimentation}

The $\mathrm{RD}^{3}$ was used to test a step wedge made of 7 fiberglass/epoxy skins bonded to 1 "Nomex honeycomb core which has a portion of each skin disbonded from the core. After the tap testing on the step wedge, the measured pulse width for disbonded area was observed to be significantly greater than that for good areas, as shown in Figure 3-19. A $10 \%$ difference in the pulse width was taken as the threshold for discerning debonds from good areas. It should be noted that with the increase in the skin thickness, the change in the pulse width caused by the debond decreases.

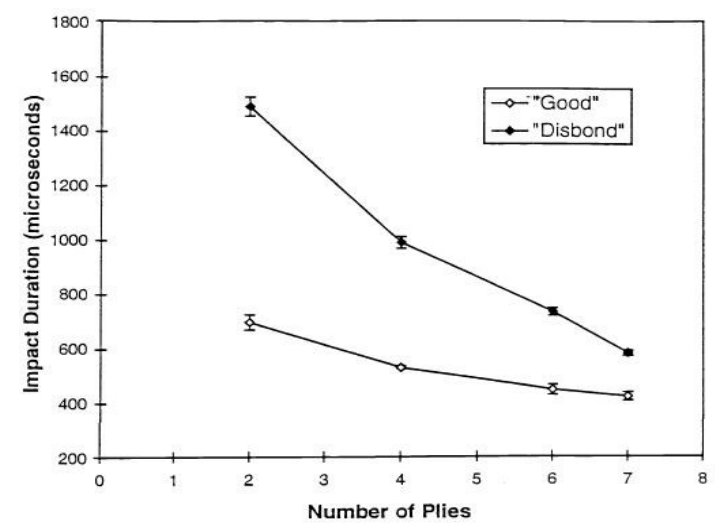

Figure 3-19: $\mathrm{RD}^{3}$ results on fiberglass/epoxy skin, Nomex honeycomb core test panel (Georgeson et al. 1996) 


\section{$\underline{\text { Conclusion }}$}

The digital tap testing method offered by the $\mathrm{RD}^{3}$ device is very useful in providing a clear evaluation of composite structures, reducing the subjectivity of the conventional tapping method. The $\mathrm{RD}^{3}$ is a low cost, convenient device that can be very essential in the field of Nondestructive Testing. However, the fact, that the difference in good areas and debonds gets smaller as the skin thickness increases, proves to be a drawback in this method.

\subsubsection{Applicability of a Tapping Method to Nondestructive Inspection of Carbon Fiber Reinforced Thermoplastics (Lyu et al. 2015)}

\section{Introduction}

Carbon Fiber Reinforced Thermoplastics (CFRTP) are very useful in manufacturing industry because of the light weight, high specific modulus and strength, short molding time, excellent recyclability and low processing cost, compared to Carbon Fiber Reinforced Thermosetting Resins (CFRTS) (Caba 2005). Hence nondestructive inspection of CFRTP is very essential to ensure no defect is present for mass production. This paper talks about a tapping method as the nondestructive testing method for CFRTP, where a force transducer is built into the head of the instrumented hammer. The force transducer, along with microphone and accelerometer, was used to acquire signals. The tapping method included global method and local method to identify the internal defects.

\section{Experimentation}

The specimens for this study were unidirectional CFRTP, ultra-thin chopped CFRTP and carbon fiber mat reinforced thermoplastics (CMT) that were fabricated by hot compression molding process. The CMT sheets had resin-rich defects while the other specimens had delaminations made by applying tensile load on both ends.

Both the global and local methods were applied to test these specimens. In the global method, the specimens were suspended by thin nylon filament and the resonant frequency and damping were analyzed to evaluate the health condition. In the local method, the specimens were placed on table and the hammer was dropped from certain height. The 
force was adjusted through the dropping height of the hammer and the peak and contact duration of the force profile were evaluated. Figure 3-20 shows the experimental setups for global method and local method for tap testing.
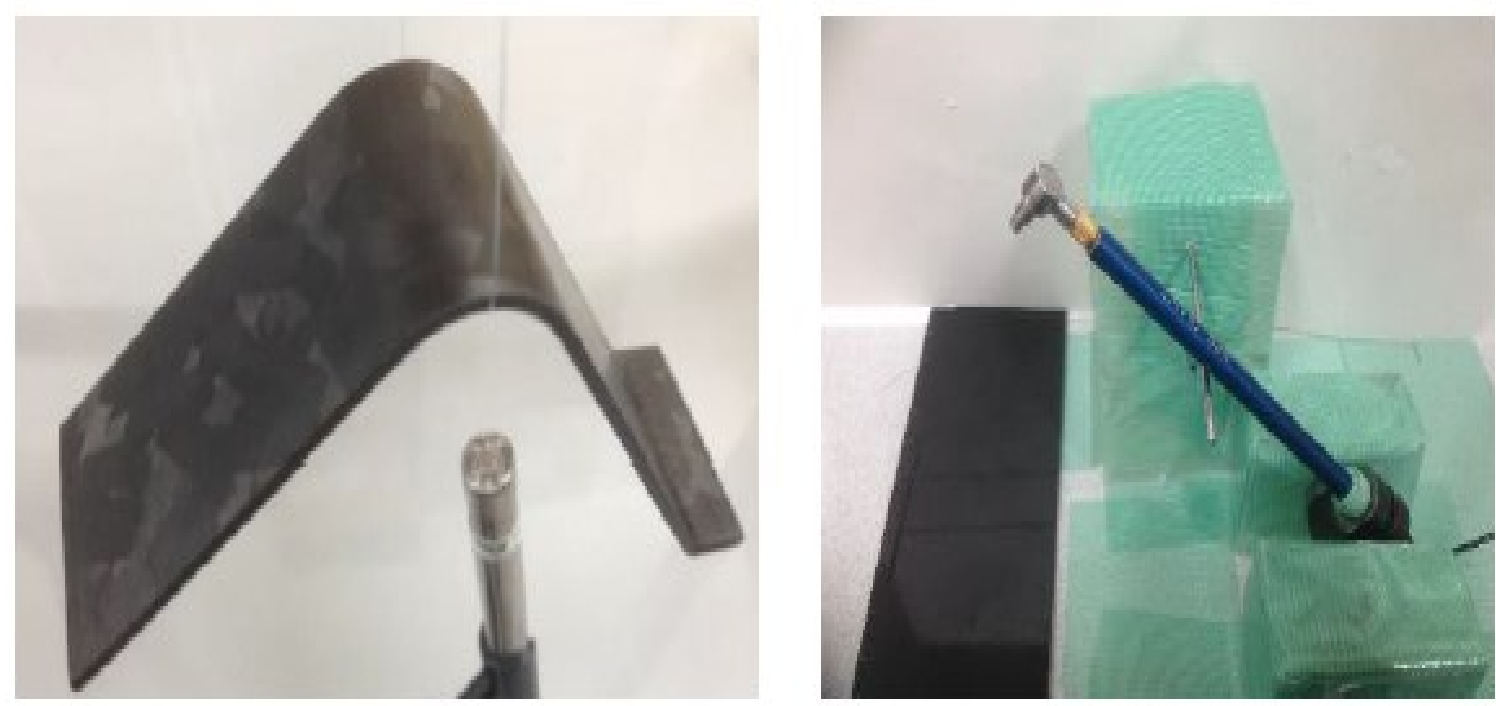

Figure 3-20: Experimental setups for tapping method: Global method (left) and Local method (right) (Lyu et al. 2015)

For the global method, the modal damping of the specimen post-destruction was slightly greater than that of the specimen pre-destruction but the model frequency of the specimen decreased significantly after the test (Figure 3-21). For the local method, the peak of the force applied on defective area was lower than that of defect-free area and the contact duration was longer in defective area than defect-free area (Figure 3-22).
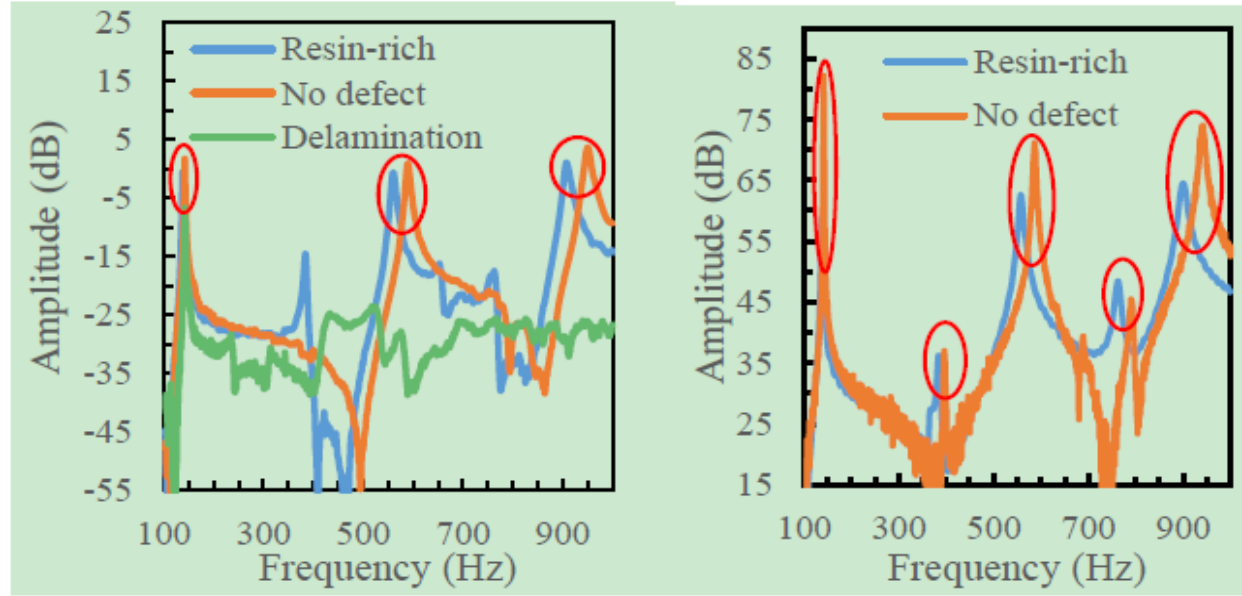

Figure 3-21: Damping and frequency analysis of the specimens for global method: Signal form microphone (left) and accelerometer (right) (Lyu et al. 2015) 


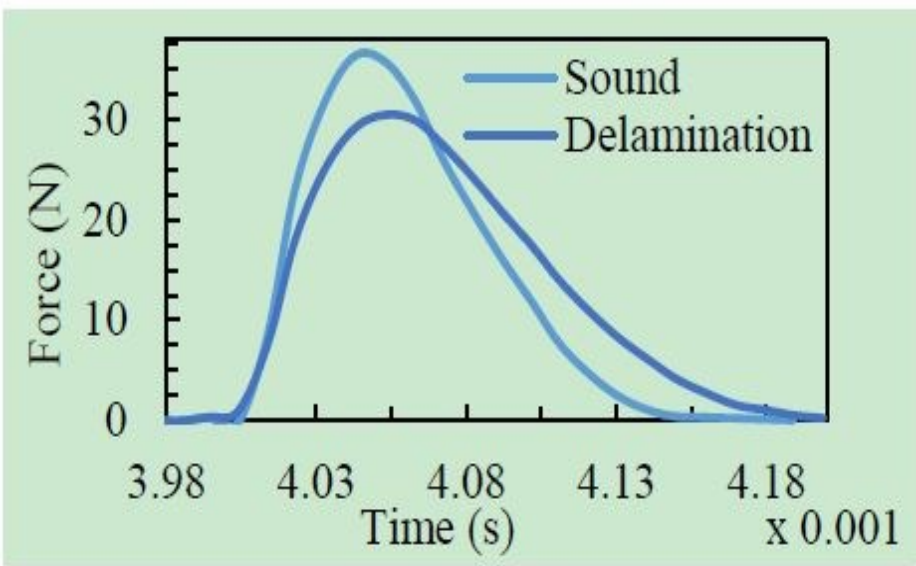

Figure 3-22: Force-profile of the specimens for local method (Lyu et al. 2015)

\section{Conclusion}

The tapping method in this paper presents global method and local method to analyze CFRTP specimens. The global method provides damping and frequency analysis which helps to distinguish delaminations from sound areas. Meanwhile, the local method focuses on comparison between the peaks of the forces applied and the contact durations on delaminations and sound areas. This principle is similar to the Digital Tap Testing device used in this problem report. 


\section{IRT AND DIGITAL TAP TESTING LABORATORY RESULTS}

\subsection{INTRODUCTION}

Reinforced concrete (RC) is the major construction material when it comes to bridge decks. RC decks are cheap and easy to install when compared to steel, timber and other materials used in the field. However, RC bridge decks are not durable since they are prone to corrosion due to exposure to moisture from the surrounding environment. The cracks in concrete in tension lead the way to corrosion in the reinforcing steel. The strength of the RC deck is significantly reduced and this calls for either rehabilitation of the bridge or replacement of the bridge. The replacement of the deteriorated bridge is an expensive and time-consuming procedure. An alternative to this is the use of fiber reinforced polymer (FRP) composite bridge decks.

The recent development of FRP bridge decks can be very useful in solving the problem of deteriorating RC bridges. The high stiffness and strength-to-weight ratio, high fatigue and corrosion resistance in addition to the light weight and rapid manufacturing and transportation activities are the benefits offered by the FRP decks. Despite high initial cost of FRP decks, their minimal life-cycle cost helps in substantial cost savings (Mara et al. 2014). FRP decks provide a sustainable solution to the degrading bridges, owing to the durability and cost-efficiency of FRP composite.
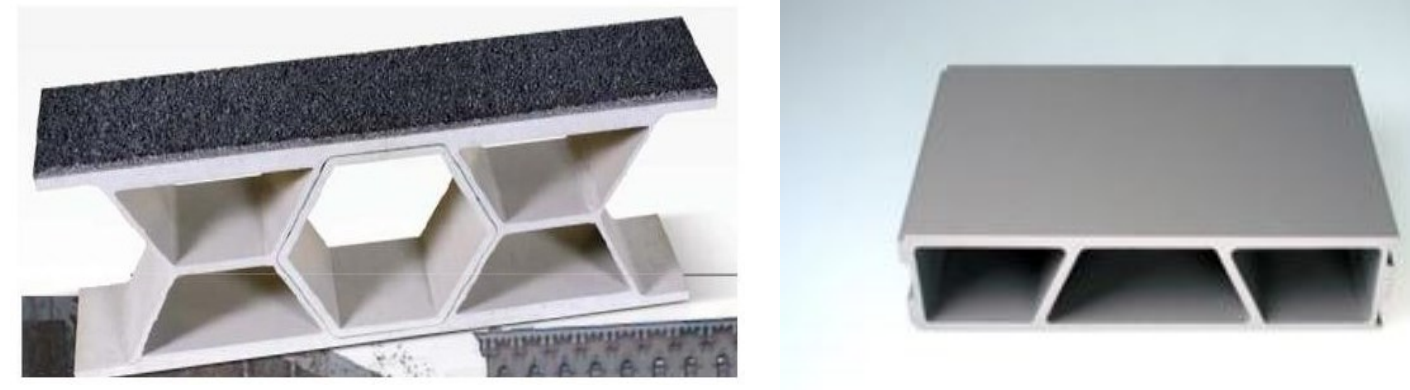

Figure 4-1: Fiber Reinforced Polymer (FRP) bridge deck samples -left (www.thomasnet.com) and right (www.materialstoday.com) 
In the manufacturing of FRP deck, some subsurface defects, such as cracks, debonds, delaminations, and voids, could be formed. They may be formed even in the construction process or during service life of the bridge decks. These subsurface defects affect the strength of the deck in an adverse way. Also, in the field, moisture can get into these subsurface defects and contribute to the freeze-thaw damage. Thus, it is important to evaluate the FRP decks, and locate and rectify any defect found in the subsurface. Nondestructive Testing techniques have been very effective in inspection of FRP composites. Techniques like infrared thermography and digital tap testing have proved to be successful in providing excellent results in terms of subsurface anomalies. Infrared Thermography helps to identify defects in composites through thermal images captured by infrared camera after the surface is thermally excited. Meanwhile, Digital Tap Testing helps to locate defects through pulse width of the signal generated by tapping the hammer on the surface.

This laboratory experiment is a study of the efficiency of the advanced and conventional methods of infrared thermography in locating the subsurface defects in GFRP components. Along with that, the effectiveness of digital tap testing on GFRP bridge decks is also evaluated. In addition to the GFRP bridge decks, this study also includes a FRP square-tube section and concrete specimens wrapped with FRP fabric. This chapter talks about the preparation of defects in specimens, experimental setup and infrared testing and digital tap testing results.

\subsection{PREPARATION OF FRP BRIDGE DECKS WITH DEFECTS}

The GFRP bridge deck specimens, along with embedded defects (debonds and delaminations), were prepared in the laboratory as part of previous research studies (Vasudevan 2004, Roy 2004). The debonds were created by placing artificial defects between the wearing surface and the GFRP bridge deck. The delamination in the specimen was simulated by placing the defects within the flange-to-flange junction of connecting deck components (Vasudevan 2004, Roy 2004).

The defects placed in the specimens were either air-filled or water-filled. The airfilled defects were made by gluing two polypropylene sheets with air pocket in between 
while the water-filled defects were created by entrapping water inside high-strength plastic sheets (Vasudevan 2004). Air-filled and water-filled defects of different sizes (1" x 1", 2" $\mathrm{x} 2$ " and 3" x 3") were prepared for insertion into the GFRP specimens (Figure 4-3).

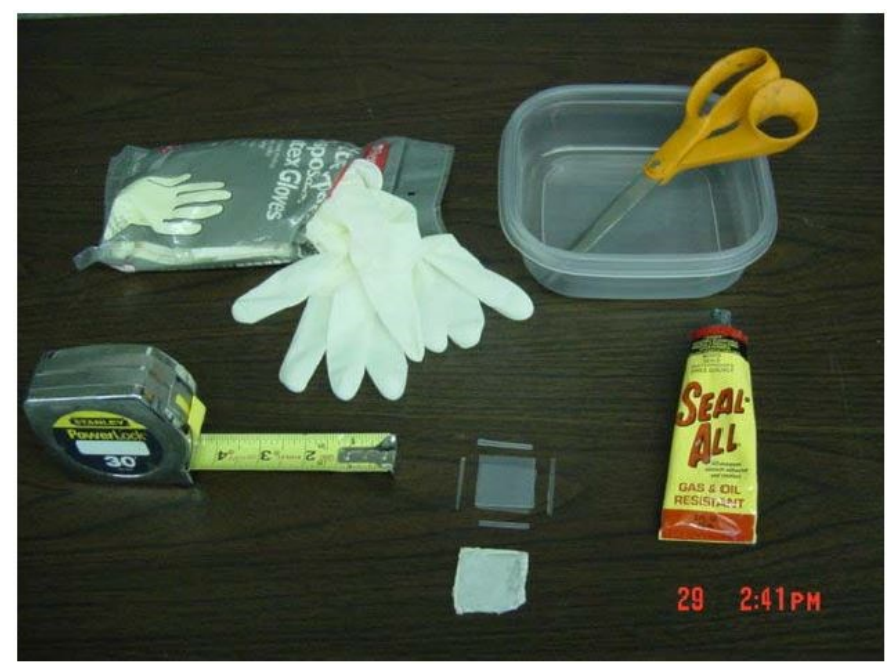

Figure 4-2: Materials used to prepare air-filled defects to be inserted into the GFRP bridge deck specimen (Vasudevan 2004)

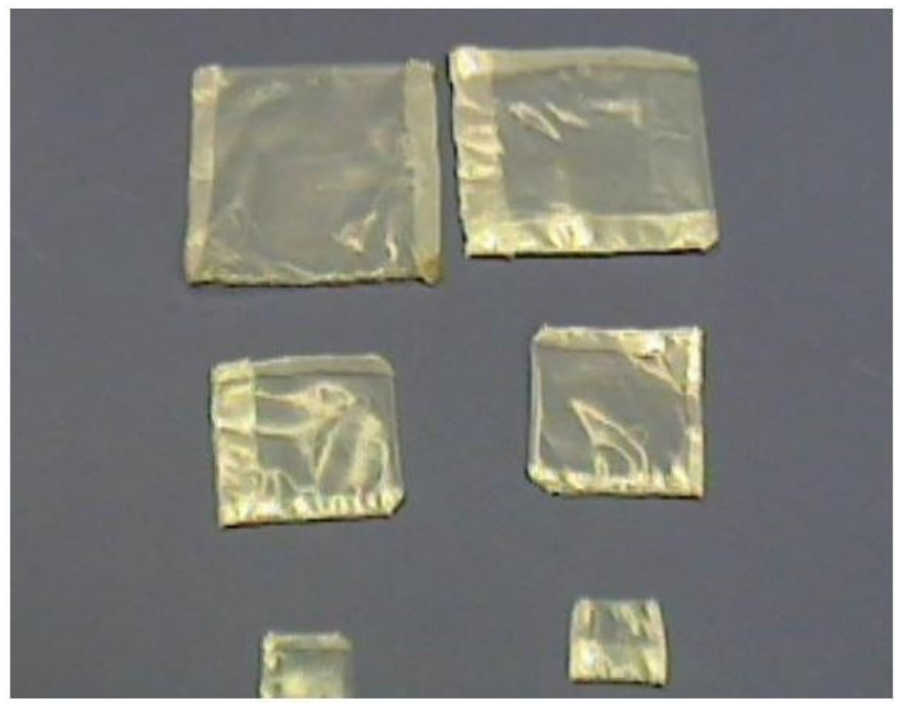

Figure 4-3: Water-filled defects of sizes 3" x 3", 2" x 2" and 1" x 1" to be inserted into the GFRP bridge deck specimen (Roy 2004)

The bridge deck specimens were prepared by cutting proper sizes of FRP bridge deck module using a milling machine. The defects were placed in the middle of the flange joint area. Wax paper was used to cover the defects to keep them intact and a structural adhesive called 'Pliogrip' was used to join the two flanges of the bridge deck system resulting in the average depth of 0.32 " from the top surface. 


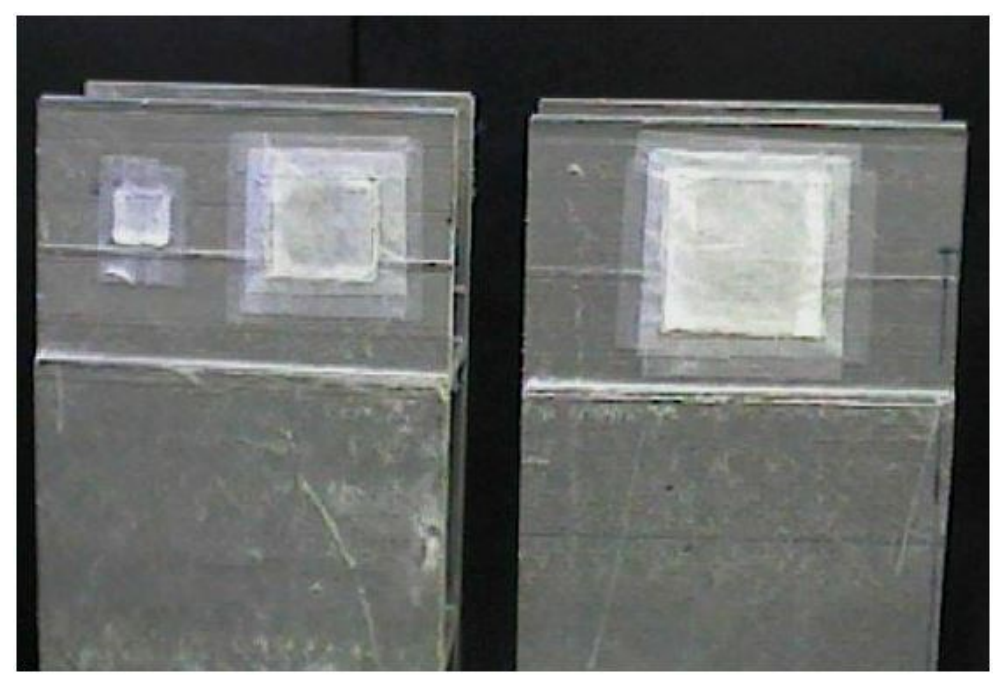

Figure 4-4: Water-filled defects embedded in the flanges of the FRP bridge deck specimens (Roy 2004)

\section{BD1}

The specimen BD1 was made of E-glass fibers and polyester resin (Figure 4-5). Its overall size was 24 " $\mathrm{x} 12$ " with an overall depth of 8 ". The thickness of the flanges was 0.5 " while that of the web was 0.35 " and of the diagonal members was 0.25 ". The debonds were placed in between the wearing surface and the underlying FRP deck surface. The wearing surface was $3 / 8$ " thick and made of specially selected blend of aggregates, i.e., Glacial Gravel - Basalt, Quartzite and Granite, mixed with two-part liquid polymer system.
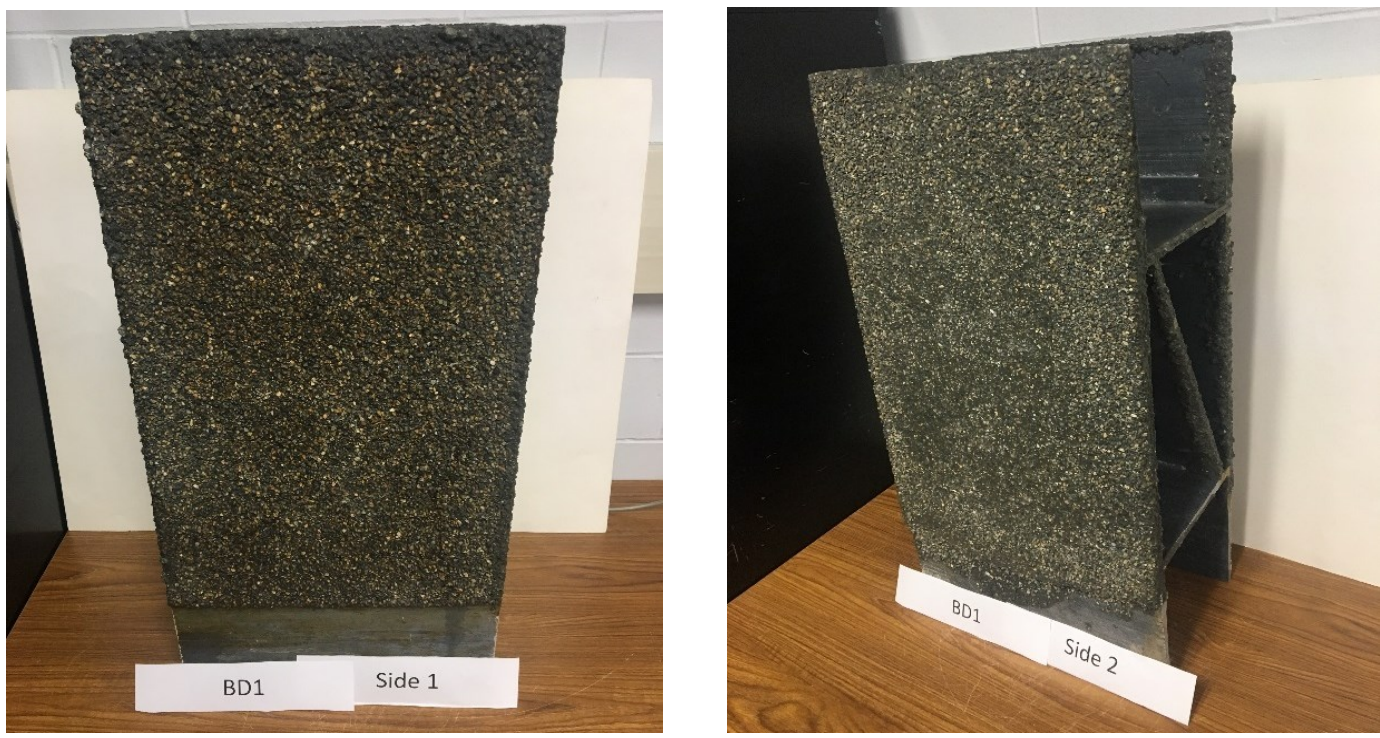

Figure 4-5: Side 1 (left) and Side 2 (right) of the GFRP deck specimen BD1 
There were two air-filled debonds of sizes 2" x 2" and 3" x 3" on Side 1 of the specimen and two air-filled debonds of sizes 1" x 1" and 1/2" x 1/2" on Side 2 (Figure 4-6). All the debonds on specimen BD1 were 1/16" thick.

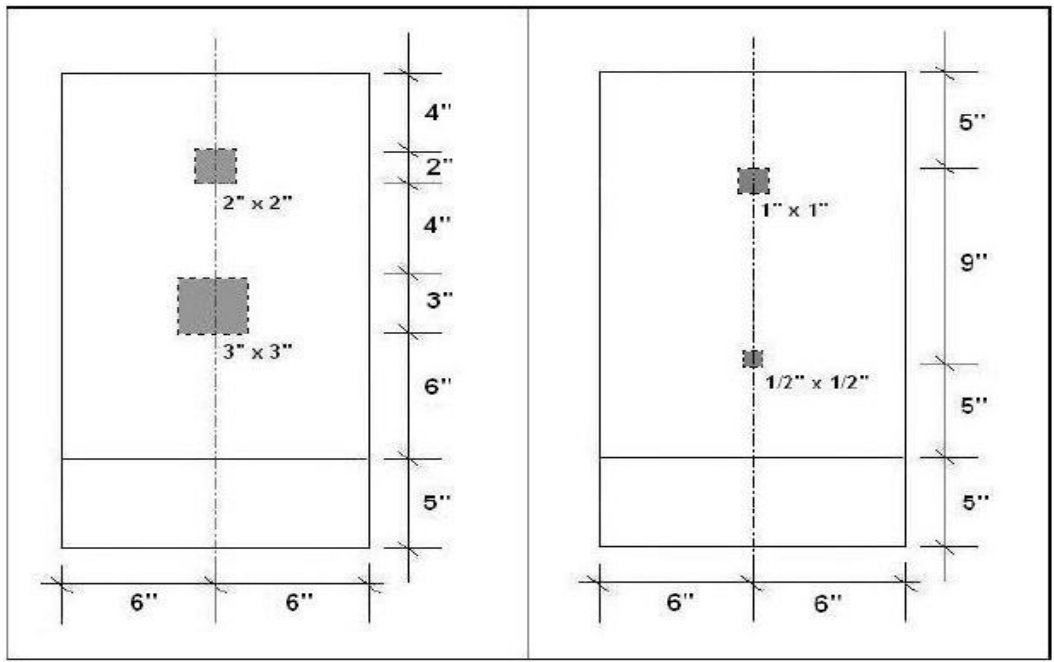

Figure 4-6: Schematic diagram of debonds on Side 1 (left) and Side 2 (right) of the GFRP deck specimen BD1 (Vasudevan 2004)

$\underline{\text { JD1 }}$

The specimen JD1 was a low-profile GFRP deck made of E-glass fiber and vinylester resin (Figure 4-7). The size of the specimen was 15" x 8" and the flange thickness was 0.45 ". It had no wearing surface on both sides. A delamination of size 3 " x 3" and thickness 1/20" was simulated in the middle of the flange joint on Side 1 of specimen JD1 (Figure 4-8 (left)). Side 2 had two delaminations of sizes 2" x 2" and 1" x 1" with thickness of 1/16" (Figure 4-8 (right)).
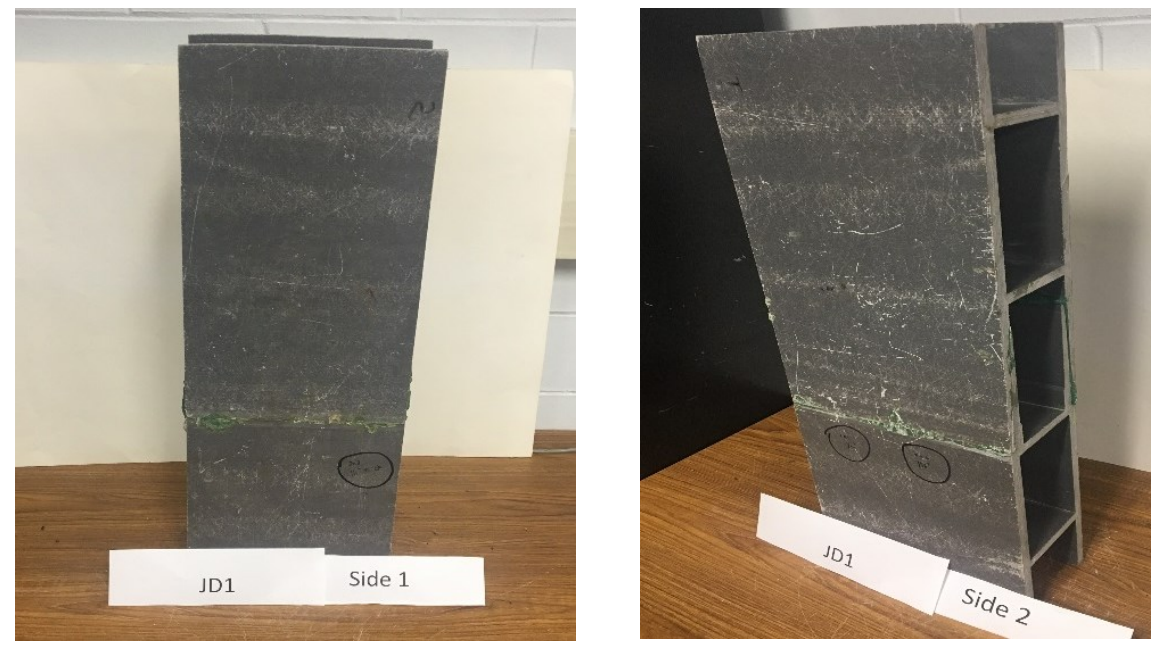

Figure 4-7: Side 1 (left) and Side 2 (right) of the GFRP deck specimen JD1 

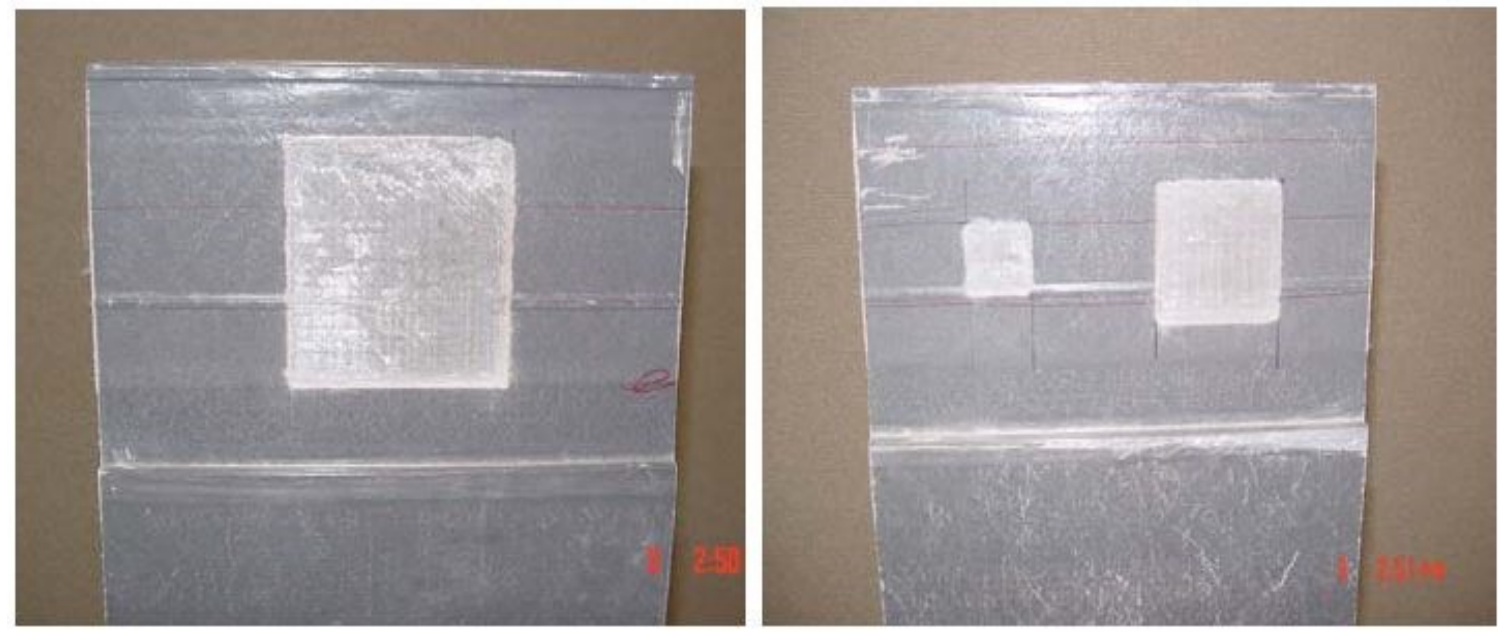

Figure 4-8: Delamination of size 3" $x$ 3" on Side 1 (left) and of sizes 2" $x 2$ " and 1" $x$ 1" on Side 2 (right) of GFRP deck specimen JD1 (Vasudevan 2004)

$\underline{\text { JD2 }}$

The specimen JD2, similar to JD1, was a low-profile GFRP deck too, with a size of $15 " \times 8$ " and flange thickness of $0.45 "(0.6 "$ at the flange junction), as shown in Figure 4-9. Both sides of the specimen were covered with $3 / 8$ " thick wearing surface made of the same materials as used for the specimen BD1. On Side 1, there was a 1/8" thick debond of size 3" x 3" in the mid-flange junction (Figure 4-10). Meanwhile, Side 2 didn't have any defect.
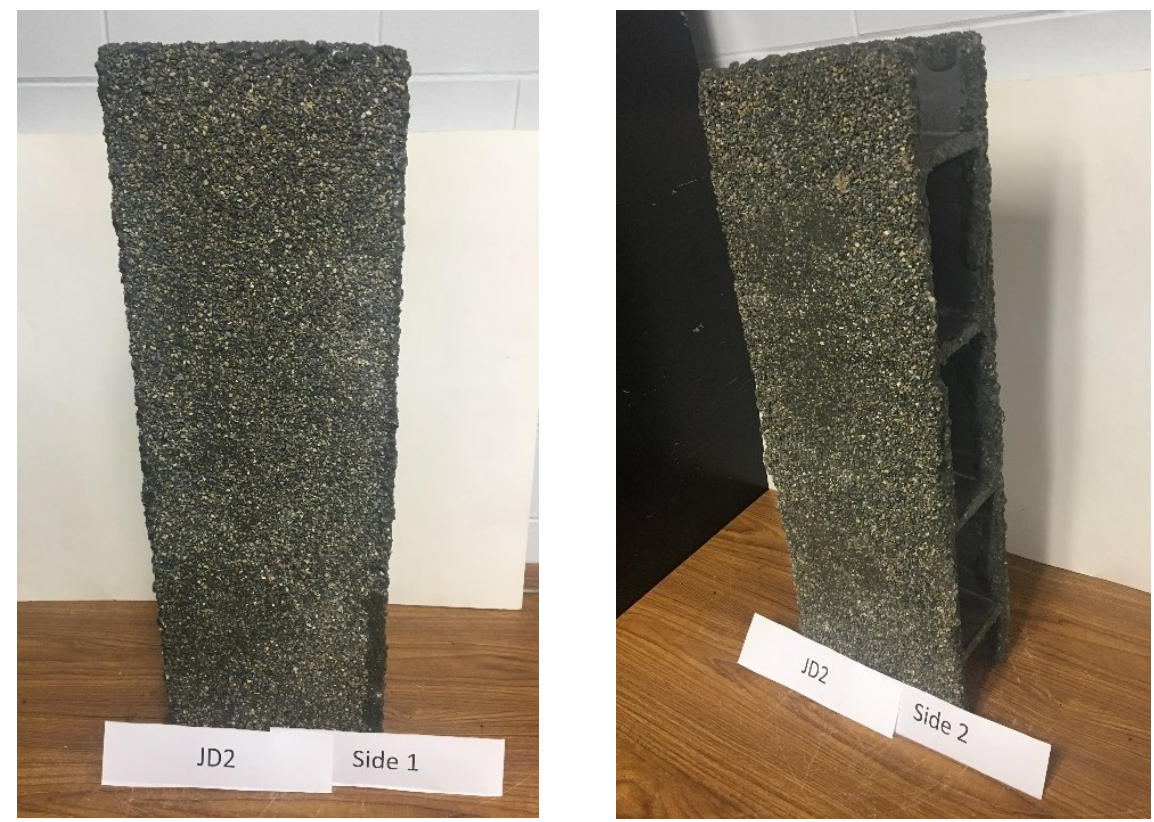

Figure 4-9: Side 1 (left) and Side 2 (right) of the GFRP deck specimen JD2 


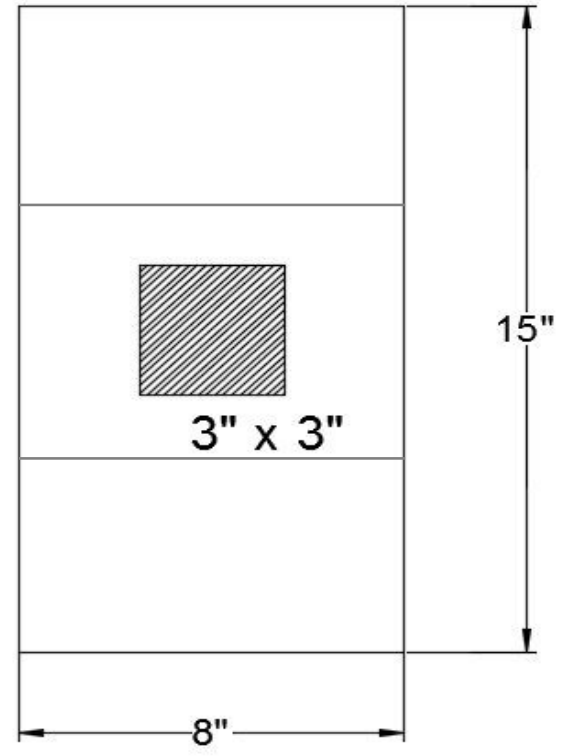

Figure 4-10: Schematic diagram of 3" $x$ 3" sized debond on Side 1 of the GFRP deck specimen JD2

\section{$\underline{\text { WJD2 }}$}

WJD2 was another low-profile GFRP bridge deck specimen made of E-glass fiber and vinyl-ester resin. The plan size of WJD2 was 24 " x 8 " and the thickness of the flange was 0.45 " with a thickness of 0.6 " at the flange-to-flange junction. A $3 / 8$ " thick wearing surface, consisting of a two-component polysulphide epoxy based overlay system, was applied on Side 2 of the specimen.
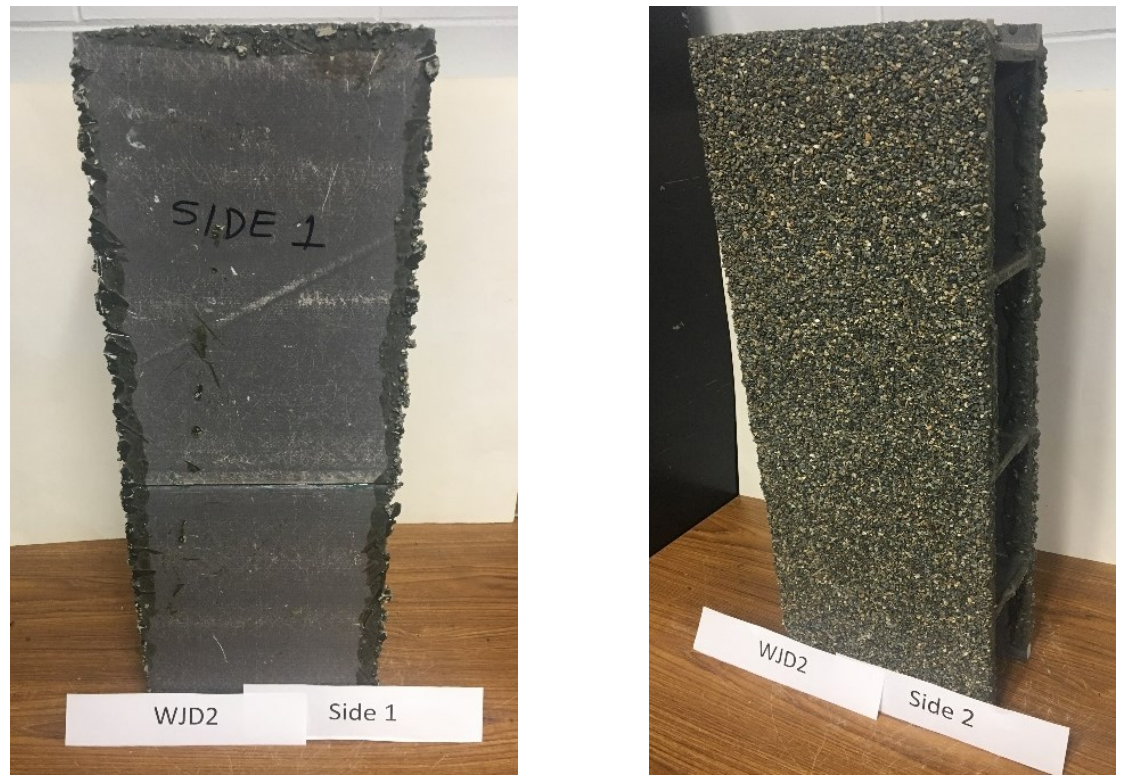

Figure 4-11: Side 1 (left) and Side 2 (right) of the GFRP deck specimen WJD2 
Both sides of the specimen WJD2 had a water-filled debond of size 3" x 3 " placed centrally in the flange junction (Figure 4-12). They were located at 0.32 " from the top of the GFRP deck surface on both sides but Side 2 also had 3/8" thick wearing surface overlay.

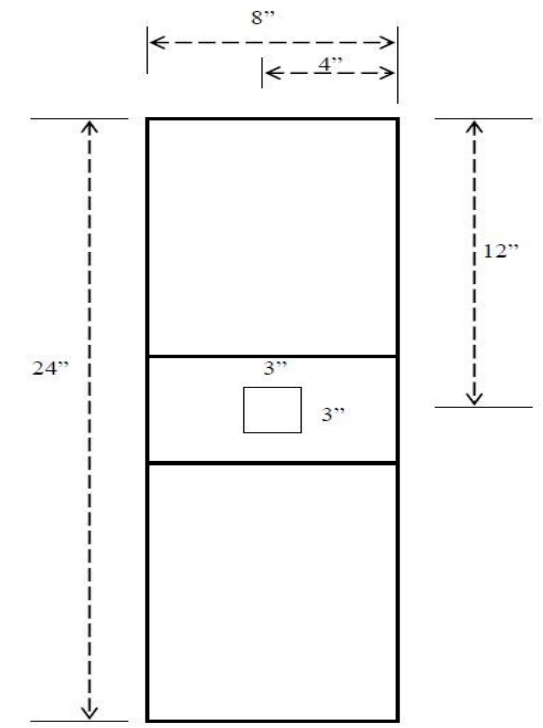

Figure 4-12: Schematic diagram of 3" x 3" sized debond on both sides of the GFRP deck specimen WJD2 (Roy 2004)

\section{$\underline{\text { WJD3 }}$}

Similar to WJD2, the specimen WJD3 was a low-profile GFRP bridge deck of plan size 24 " $x$ " "with flange thickness of 0.45 " (0.6" at the flange junction), as shown in Figure $4-13$. Side 1 of the specimen had a wearing surface of thickness $3 / 8$ ". The wearing surface was made of similar material used in WJD3.
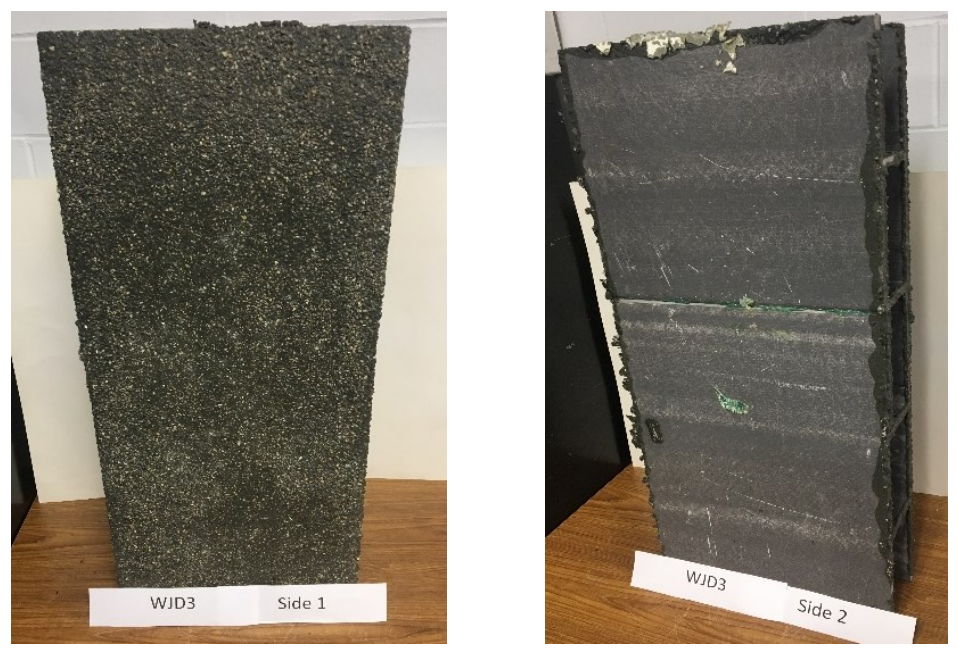

Figure 4-13: Side 1 (left) and Side 2 (right) of the GFRP deck specimen WJD3 
There was a water-filled debond of size 3" x 3" and thickness 1/16" on Side 1 of WJD3, similar to WJD2 (Figure 4-12). On Side 2, two 1/16" thick water-filled debonds of sizes 2" x 2" and 1" x 1" were placed in the flange-to-flange junction (Figure 4-14).

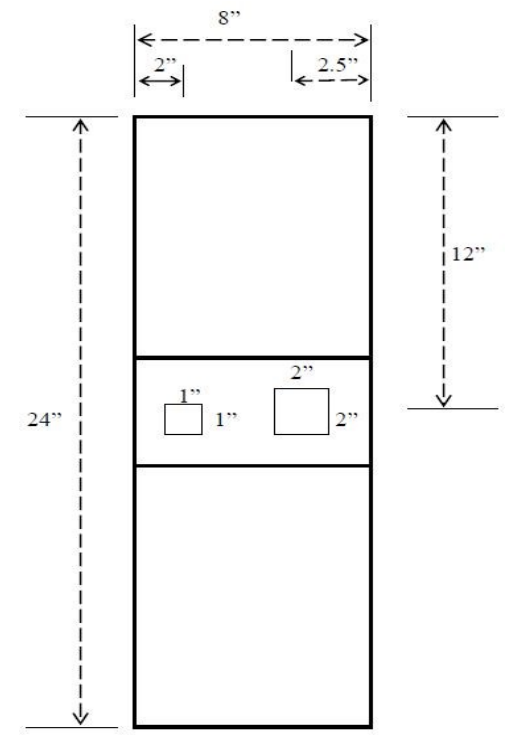

Figure 4-14: Schematic diagram of debonds on Side 2 of the GFRP deck specimen WJD3 (Roy 2004)

\section{$\underline{\mathrm{AS2}}$}

The specimen AS2 was a GFRP bridge deck with no wearing surface on any side (Figure 4-15). It was made of E-glass fiber and vinyl-ester resin and had a plan size of 24" $\mathrm{x} 12$ ". Side 1 of AS2 had two 1/16" thick delaminations of sizes 2 " x 2" and 1" x 1" in the flange junction (Figure 4-16). There was no delamination in Side 2 of the specimen.
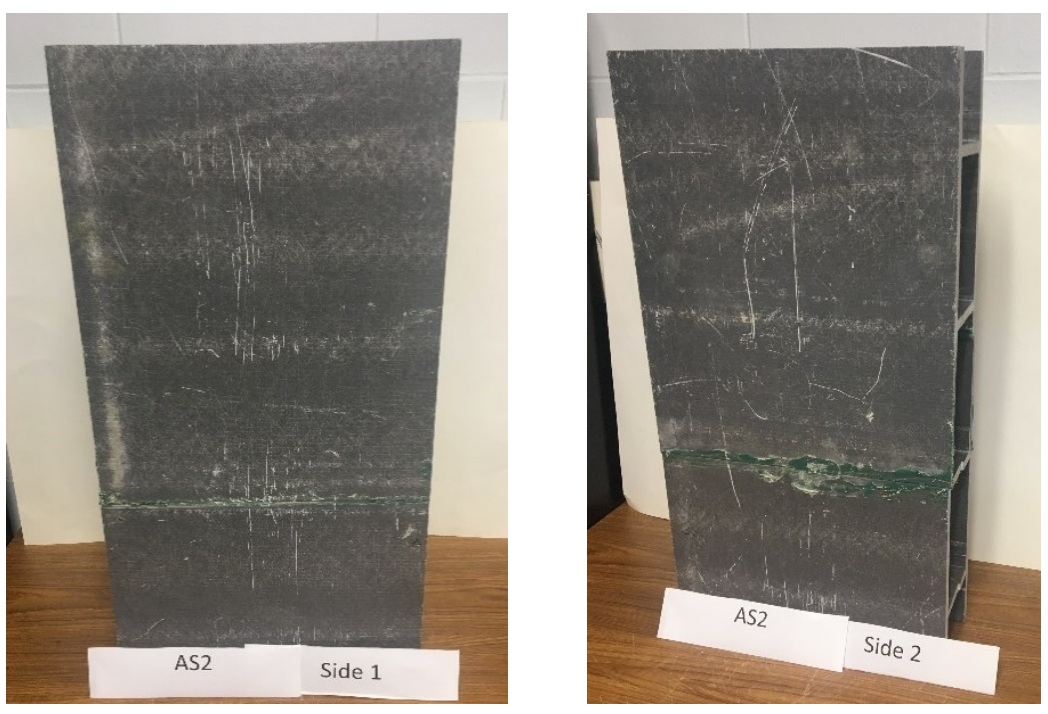

Figure 4-15: Side 1 (left) and Side 2 (right) of the GFRP deck specimen AS2 


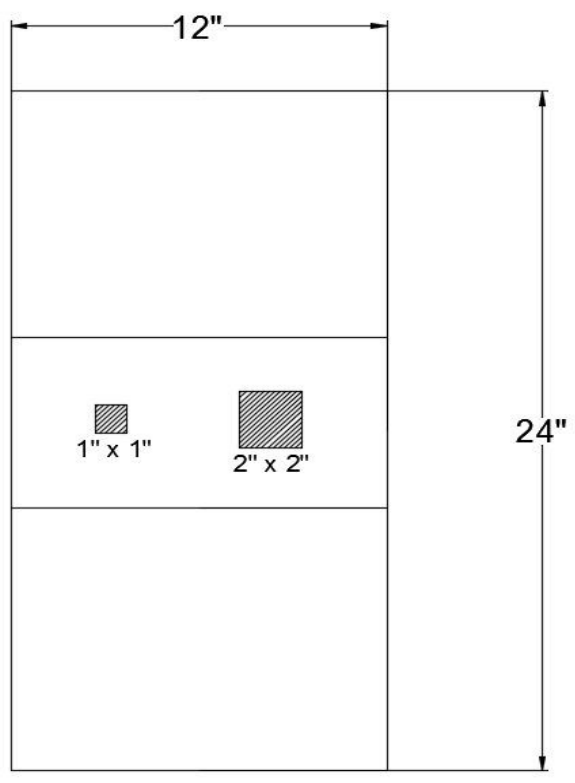

Figure 4-16: Schematic diagram of debonds on Side 1 of the GFRP deck specimen AS2

\section{$\underline{\mathrm{AS3}}$}

With similar material properties as AS2, the specimen AS3 was another GFRP bridge deck of plan size 24" x 12" (Figure 4-17). Side 1 of the specimen had 3/8" thick wearing surface which consisted of two-component polysulphide epoxy based overlay system. A 3" x 3" sized debond of thickness 1/16" was placed in between wearing surface and the underlying deck on Side 1 (Figure 4-18). Side 2 did not have any wearing surface. There was a 1/16" thick delamination of size 3" x 3" on Side 2 in the flange-to-flange junction.
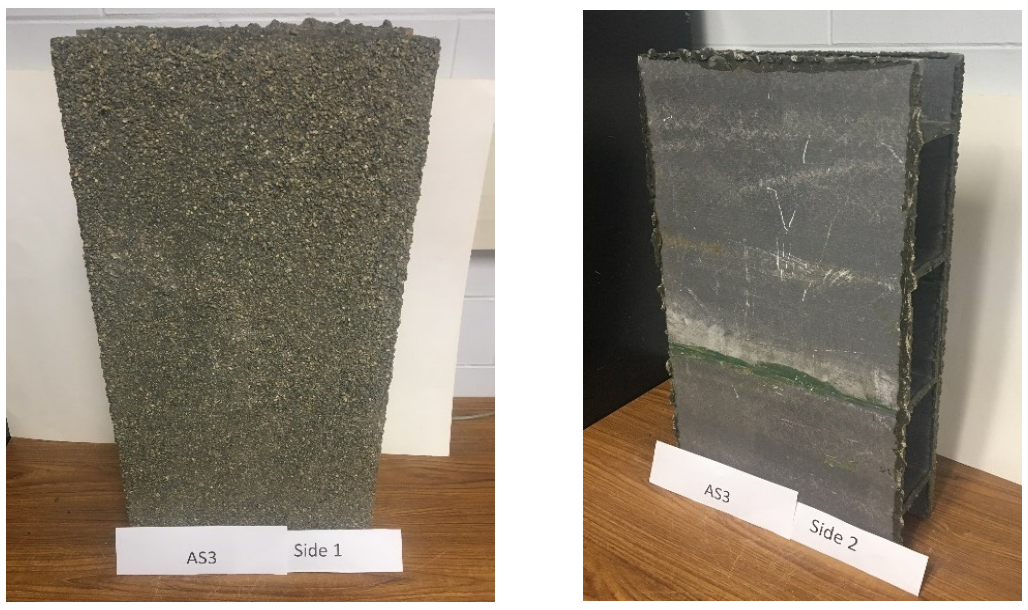

Figure 4-17: Side 1 (left) and Side 2 (right) of the GFRP deck specimen AS3 


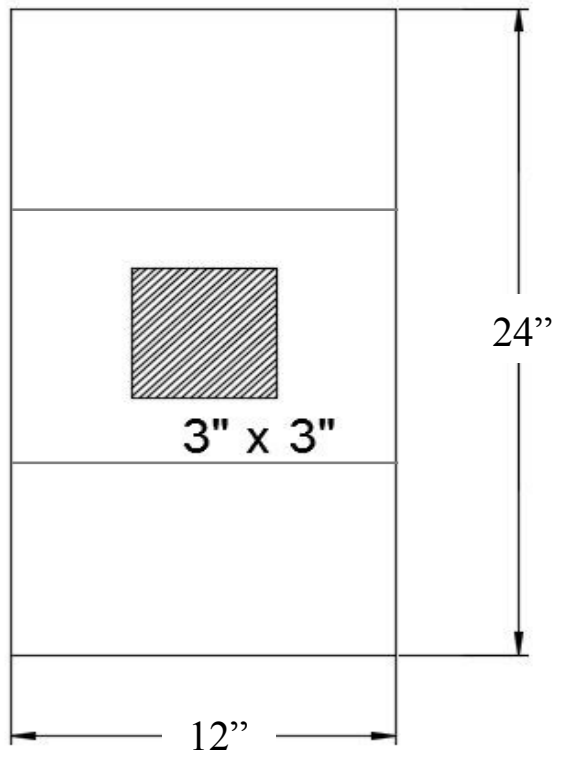

Figure 4-18: Schematic diagram of debonds on both sides of the GFRP deck specimen AS3

\section{Defect-free Cylinder}

The concrete cylinder used in this study had a compressive strength of $3000 \mathrm{psi}$. The size of the cylinder was 6" x 12", which is the standard size for testing as per ASTM/ACI (Dutta 2010). After curing for 28 days and drying for another 7 days, the cylinder was wrapped using 3 layers of GFRP fabric. An epoxy resin was used as the matrix to bind the wraps. This defect-free cylinder, as shown in Figure 4-19, did not have any defect and was prepared to compare with other specimens containing air-filled and waterfilled defects.
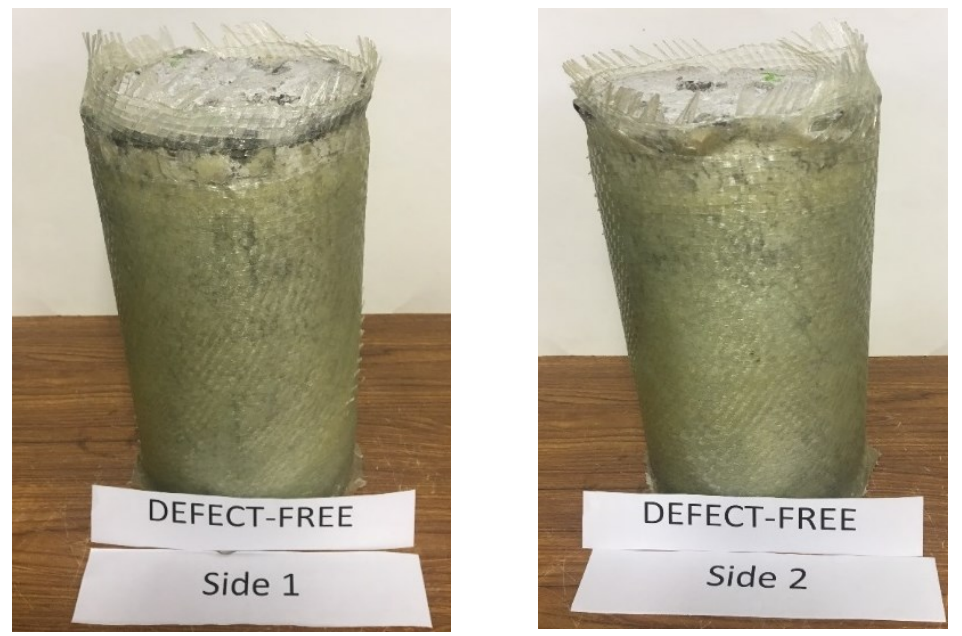

Figure 4-19: Side 1 (left) and Side 2 (right) of the defect-free GFRP-wrapped concrete cylinder 


\section{$\underline{\text { Air-filled Cylinder }}$}

Similar to the defect-free cylinder, the 6" x 12" sized concrete cylinder with airfilled defect also had a compressive strength of 3000 psi. A single layer of GFPR fabric was used with epoxy resin to wrap this cylinder. A 2" x 2" air-filled defect was placed on Side 1 of the specimen before wrapping (Figure 4-20 (left)). Side 2 of the wrapped cylinder did not have any defect (Figure 4-20 (right)).
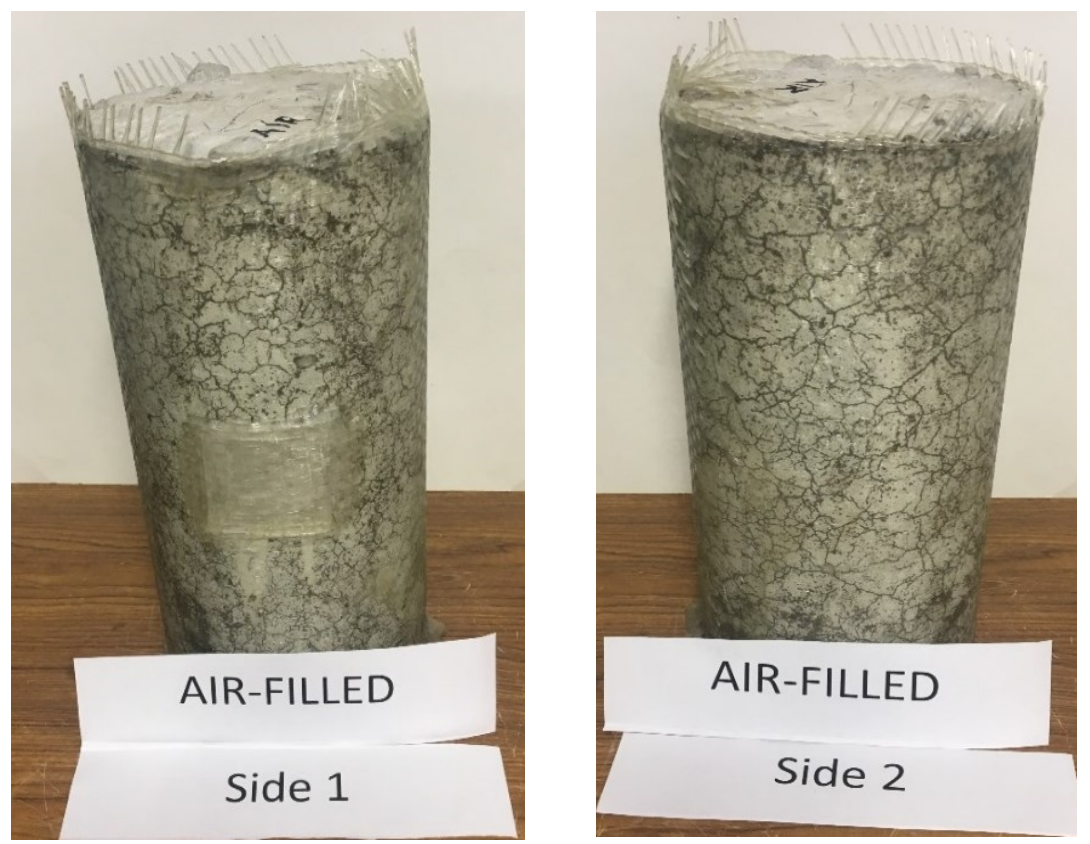

Figure 4-20: Side 1 containing air-filled defect (left) and defect-free Side 2 (right) of the GFRP-wrapped concrete cylinder

\section{Water-filled Cylinder}

Like other cylinders, the size of the concrete cylinder with water-filled defect was 6 " $\mathrm{x} 12$ " and its compressive strength was 3000 psi. The wrapping was done using 3 layers of GFRP fabric and epoxy resin. Both sides of the specimen had a 1" x 1" sized waterfilled defect in between the GFRP wrap and the underlying concrete surface, as shown in Figure 4-21. 

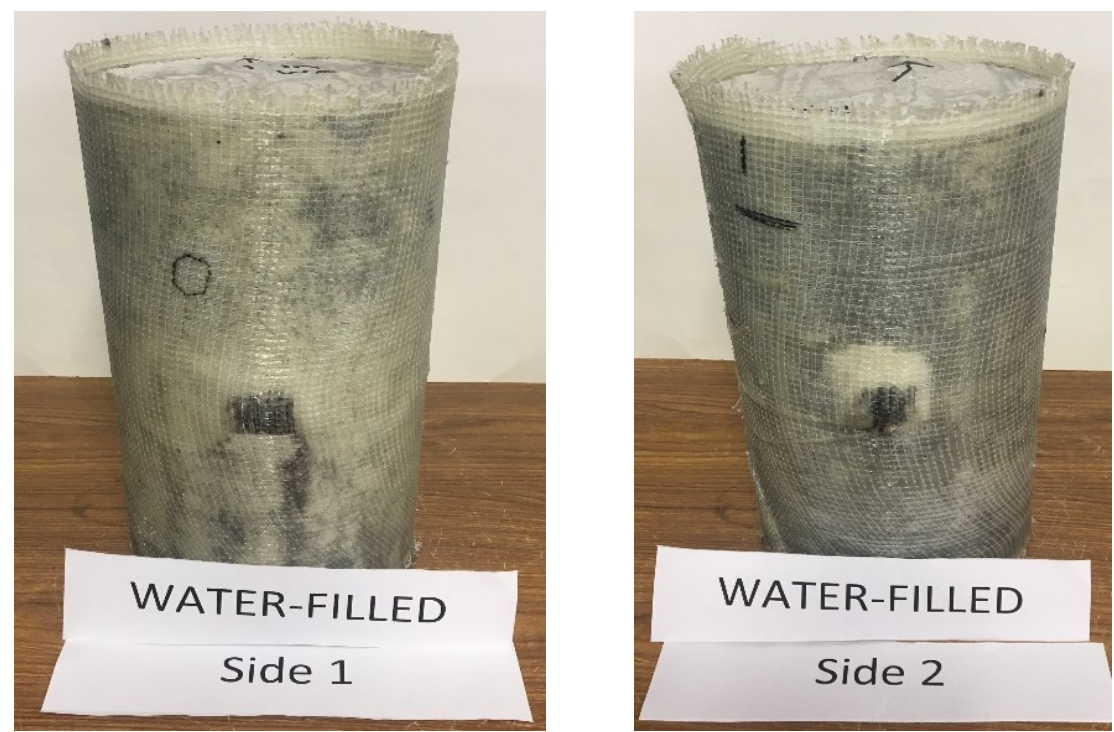

Figure 4-21: Side 1 (left) and Side 2 (right) of the GFRP-wrapped concrete cylinder, both containing 1" $x$ 1" water-filled defect

\section{Square Tube}

The composite tube, made of Glass Fiber Reinforced Polymer (GFRP), had external size of $5 \frac{1 / 4}{4}$ " $5 \frac{1}{4}$ " and a thickness of $3 / 8$ " on all sides (Figure 4-22). The specimen was part of a support column which underwent failure in the field due to inadequate support leading to eccentric loading. As a result, Side 1 failed with delaminations and cracks extending along the edges. Other sides, including Side 2, did not show signs of defect or delamination. NDT testing of the failed Side 1 was done in this study.
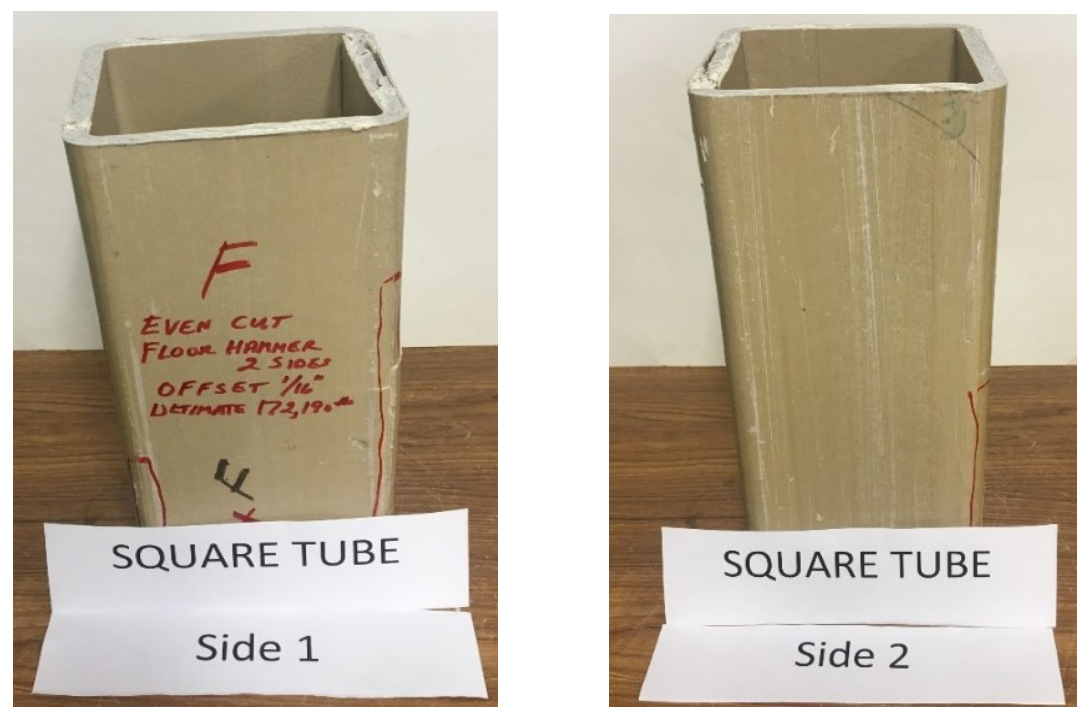

Figure 4-22: Side 1 (left) and Side 2 (right) of the GFRP composite square tube 


\subsection{EXPERIMENTAL SETUP}

The laboratory experiment consisted of different setups for infrared thermography and digital tap testing. Within the infrared thermography testing method, advanced and conventional infrared techniques were implemented using the heat source from VoyageIR Pro while only conventional infrared testing was conducted in the case of halogen lamp heater. Digital Tap Testing included tapping on the surface of the specimen to identify the defects, reflected through the number on the digital display.

The fundamental idea of both advanced and conventional infrared thermography is always the same, i.e., to study the thermal image of the surface after its thermal excitation to locate the defects based on the temperature differential. While using the VoyageIR Pro, its advanced system allowed to heat the surface and record the thermal data simultaneously. The specimens were placed on the table and the VoyageIR Pro was set up on a tripod stand such that the surface of the specimen was at a distance of 24 " from the IR camera on the VoyageIR Pro system, as shown in Figure 4-23 and Figure 4-24. The IR camera was maintained at a height of 42 " from the ground to get proper testing setup. The system also had a 9" long shield on the front to prevent any disturbance from the surrounding while the thermal data was being captured. The surface of the specimen was heated for different time durations $(50 \mathrm{~s}, 100 \mathrm{~s}$, and 200s) to determine the optimal heating interval for the VoyageIR Pro. The processing system in the VoyageIR Pro system captured the thermal data throughout the heating period and for 30 seconds after the heating stopped. After VoyageIR Pro captured the thermal data and the surface was still in thermally excited state, the FLIR InfraCAM SD was used as conventional infrared equipment to capture still thermal images of the surface. This was done to compare between advanced and conventional infrared testing methods on same heating source. The specimen was allowed to cool before heating it for another testing duration. The associated software in the VoyageIR Pro system was then used to process the thermal data captured in the experiment and obtain TSR, $1^{\text {st }}$ and $2^{\text {nd }}$ derivative images. Profiles of TSR, $1^{\text {st }}$ derivative and $2^{\text {nd }}$ derivative along a line in the images were also obtained using the software. 


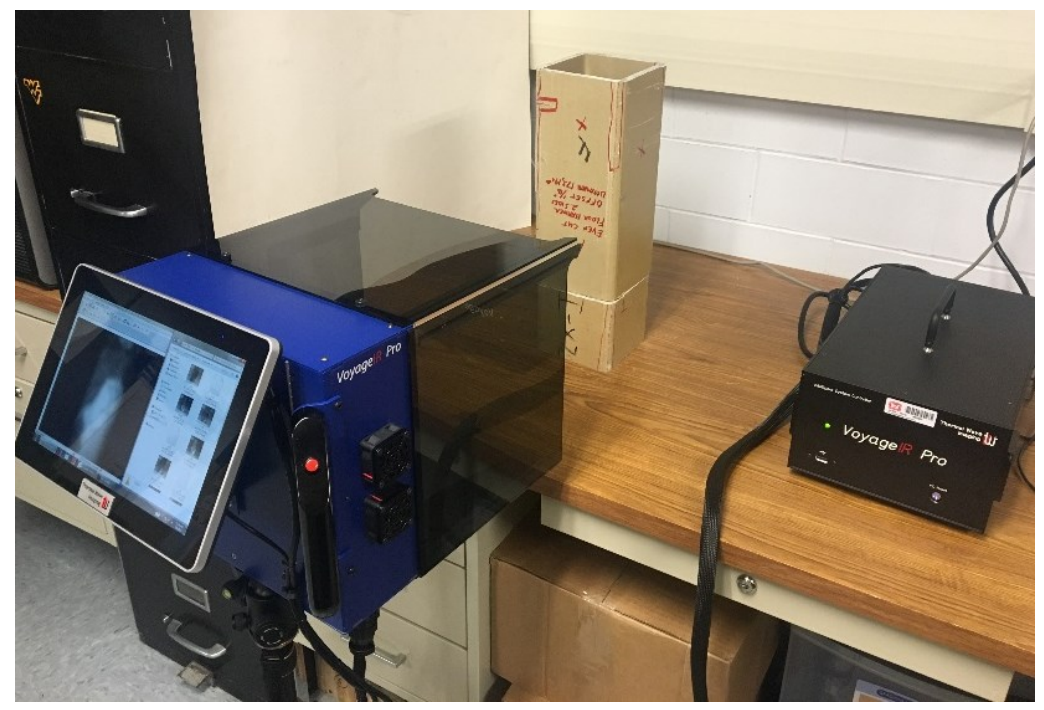

Figure 4-23: Laboratory setup of advanced infrared thermography on FRP specimens using VoyageIR Pro
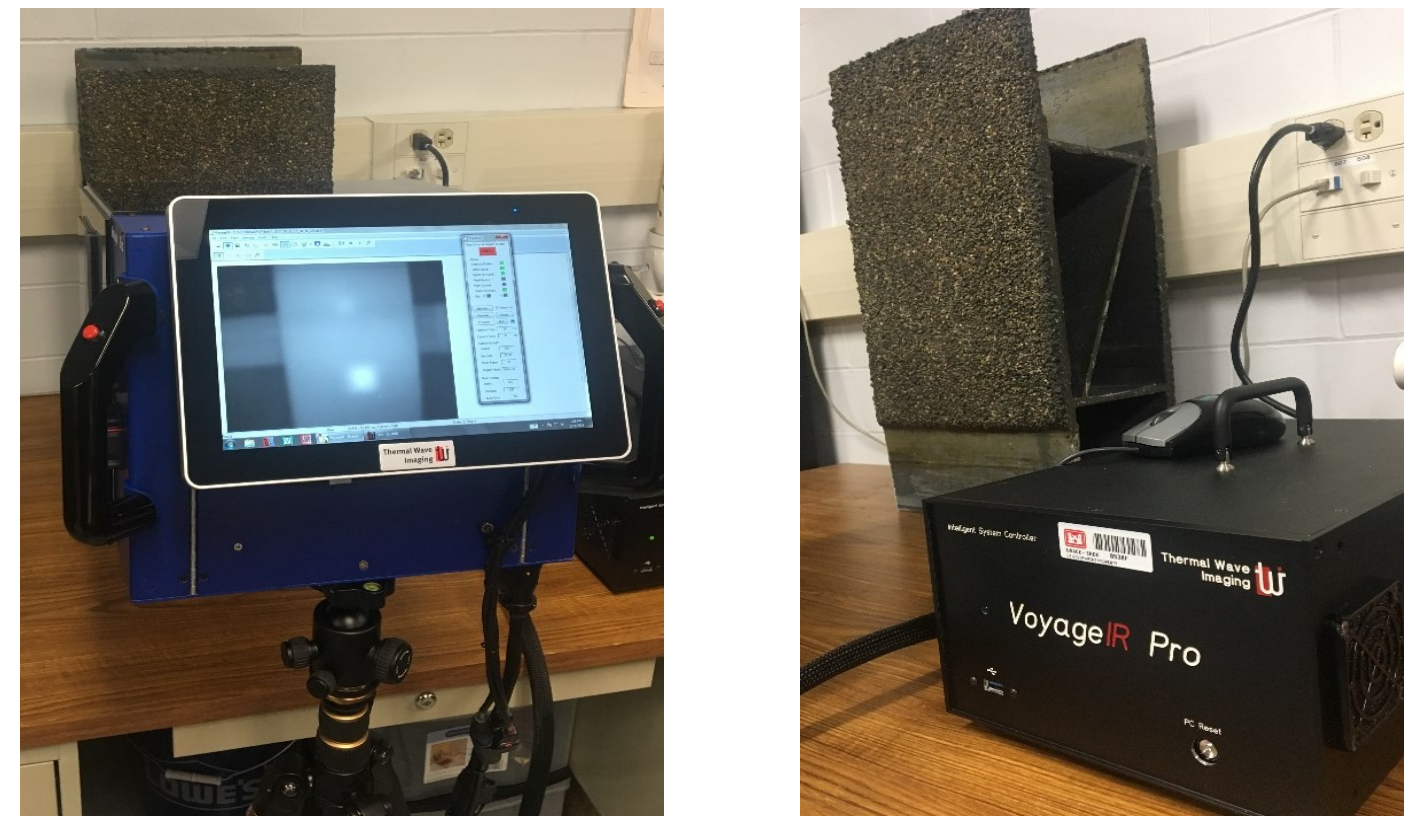

Figure 4-24: Components of VoyageIR Pro used in the laboratory experiment for advanced infrared thermography

The conventional infrared thermography conducted using FLIR InfraCAM SD gave still images of the heated surface (Figure 4-25). These images can be studied directly to locate the defects. In addition, the associated software (QuickReport) can be used which provides other information, such as minimum, maximum, and average temperatures of selected areas in the image. 


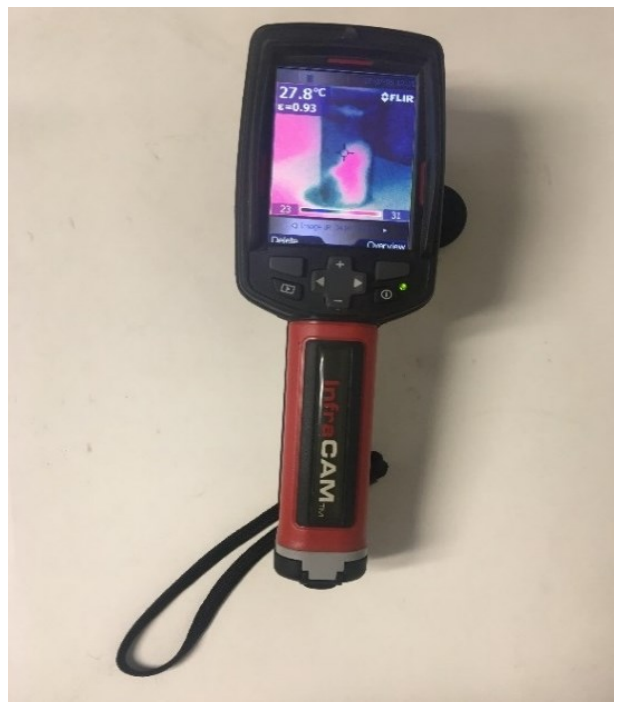

Figure 4-25: FLIR InfraCAM SD showing thermal image of a specimen in laboratory experiment

All the specimens were also heated using a halogen lamp heater with just one lamp turned on, as described in the previous chapter. But, in this case, only FLIR InfraCAM SD was used to capture thermal images. This part of the experiment helped to compare the efficiencies of the heating system on the VoyageIR Pro and the conventional heater. With a similar setup as VoyageIR Pro, the halogen lamp heater on tripod stand was placed 24" off the surface of the specimen. As previously carried out, the test proceeded with heating the surface for different time intervals and infrared images were recorded with FLIR InfraCAM SD. Heating was done using only one of the halogen lamp bulbs (500W), as shown in Figure 4-26 (right).
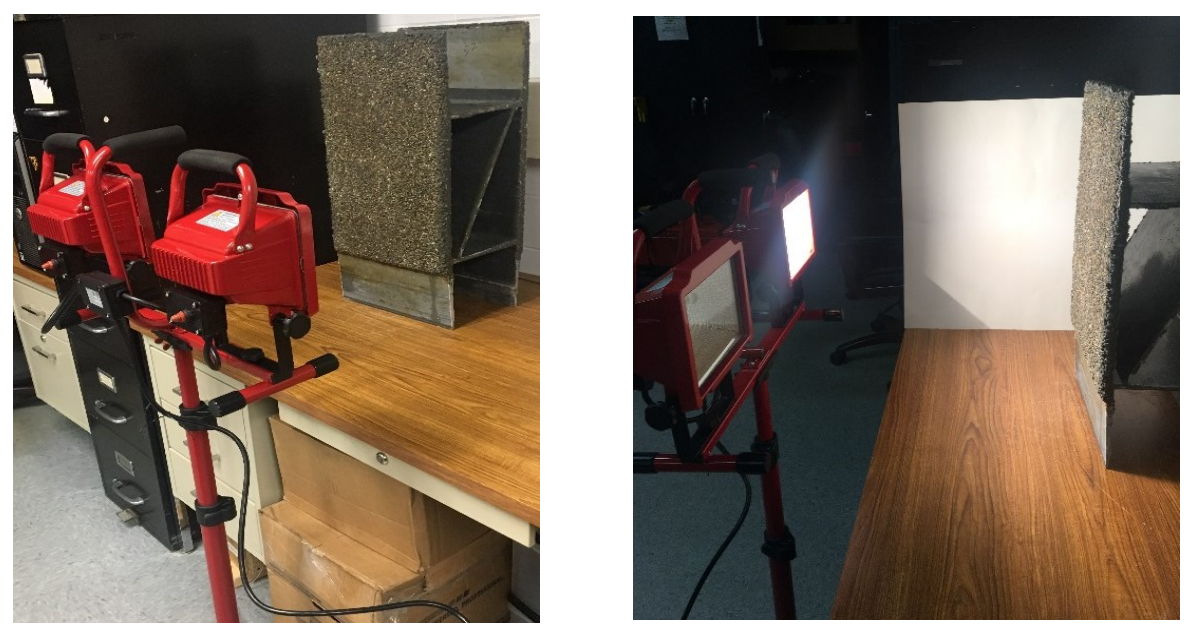

Figure 4-26: Laboratory setup of conventional infrared thermography using a halogen lamp heater 
Digital Tap Testing could only be performed on smooth surfaces, such as FRP wrapped cylinders and bridge decks with no wearing surface. The sharp, pointy surface of the wearing course can damage the head of the hammer and tapping on this surface would not provide any useful result. So, digital tap testing was limited to specimens with smooth surface and the GFRP-wrapped specimens. The test procedure included tapping the surface with hammer attached to the handheld module. The $\mathrm{RD}^{3}$ displayed corresponding number for each tap and variation in this number helped determine defective areas from good areas. First, a tap testing number range is defined for good areas. Then, rest of the area is tapped and any number that is $10 \%$ greater than that of good areas is considered as defective area.

\subsection{IRT AND DIGITAL TAP TESTING RESULTS}

The results from the advanced infrared testing were obtained after processing the thermal data in the associated software in the VoyageIR Pro system. The raw, TSR, $1^{\text {st }}$ and $2^{\text {nd }}$ derivative images for each specimen, along with their profiles, are presented in this section of the chapter. The conventional infrared testing results include the thermal images from FLIR InfraCAM SD after processing through its related software. The digital tap testing results give the numbers displayed on the device for each defect as compared to the defect-free areas. Since the output of the experiment included numerous infrared images and profile-plots, only significant ones are included in this chapter and the remaining results can be found in Appendix A.

\section{BD1}

The specimen BD1 on advanced infrared testing gave results in the form of raw images, TSR images, $1^{\text {st }}$ and $2^{\text {nd }}$ derivative images along with profiles for different time intervals. For 20 seconds of heating, raw images obtained from VoyageIR Pro are shown in Figure 4-27, with Side 1 indicating unclear boundaries for 2" x 2" and 3" x 3" sized debonds and Side 2 unclear with 1" x 1" and 1/2" x 1/2" sized debonds. The unclear boundaries from the raw images were processed through the software in VoyageIR Pro. The indistinct raw images, after processing, gave clear images for the debonds. The $1^{\text {st }}$ derivative images of Sides 1 and 2 of BD1 are shown in Figure 4-28, where the debonds on both sides can be identified. Similar results were obtained for heating duration of 50 seconds (Figures 4-29 and 4-30) and 100 seconds (Figures 4-31 and 4-32). 

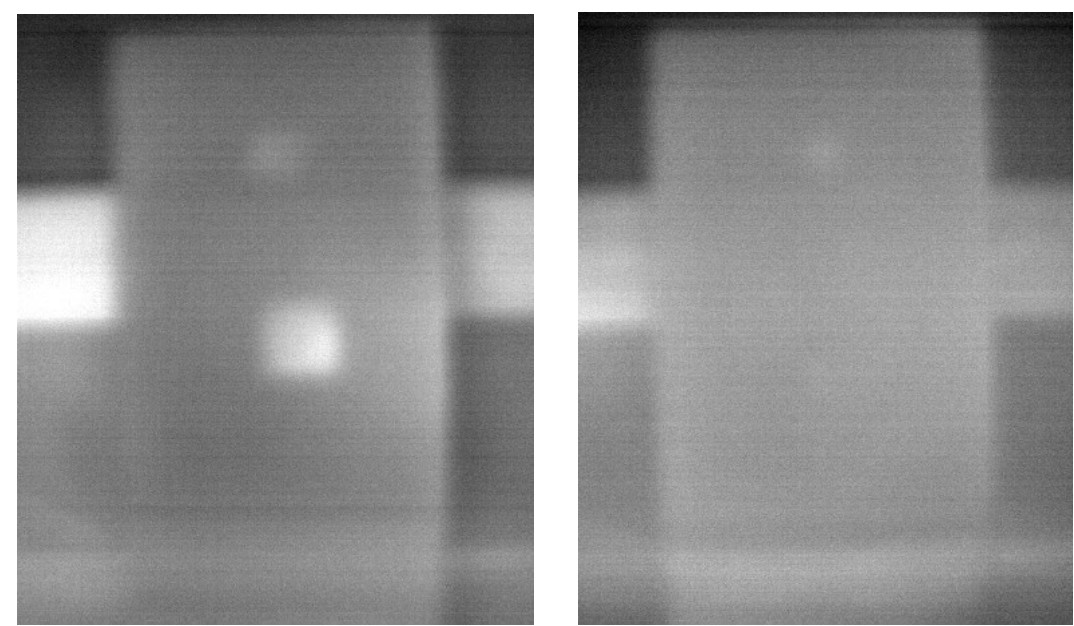

Figure 4-27: Raw thermal images of Side 1 (left) and Side 2 (right) of the deck specimen BD1 after 20 seconds of heating
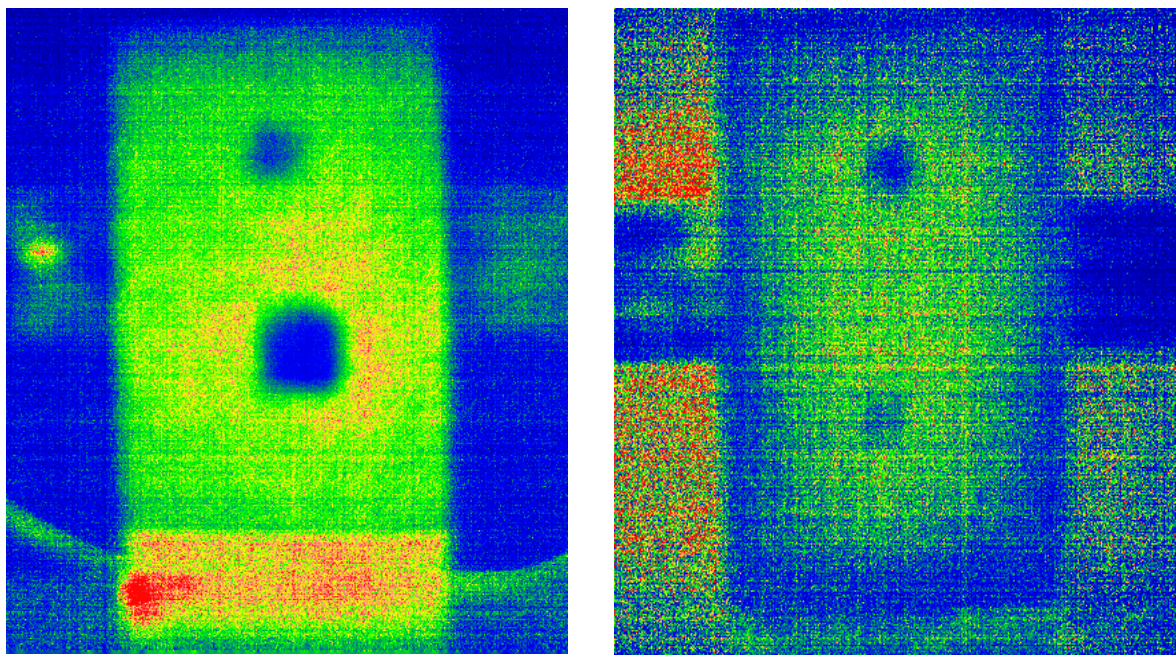

Figure 4-28: 1st derivative images of Side 1 (left) and Side 2 (right) of the deck specimen BD1 after 20 seconds of heating
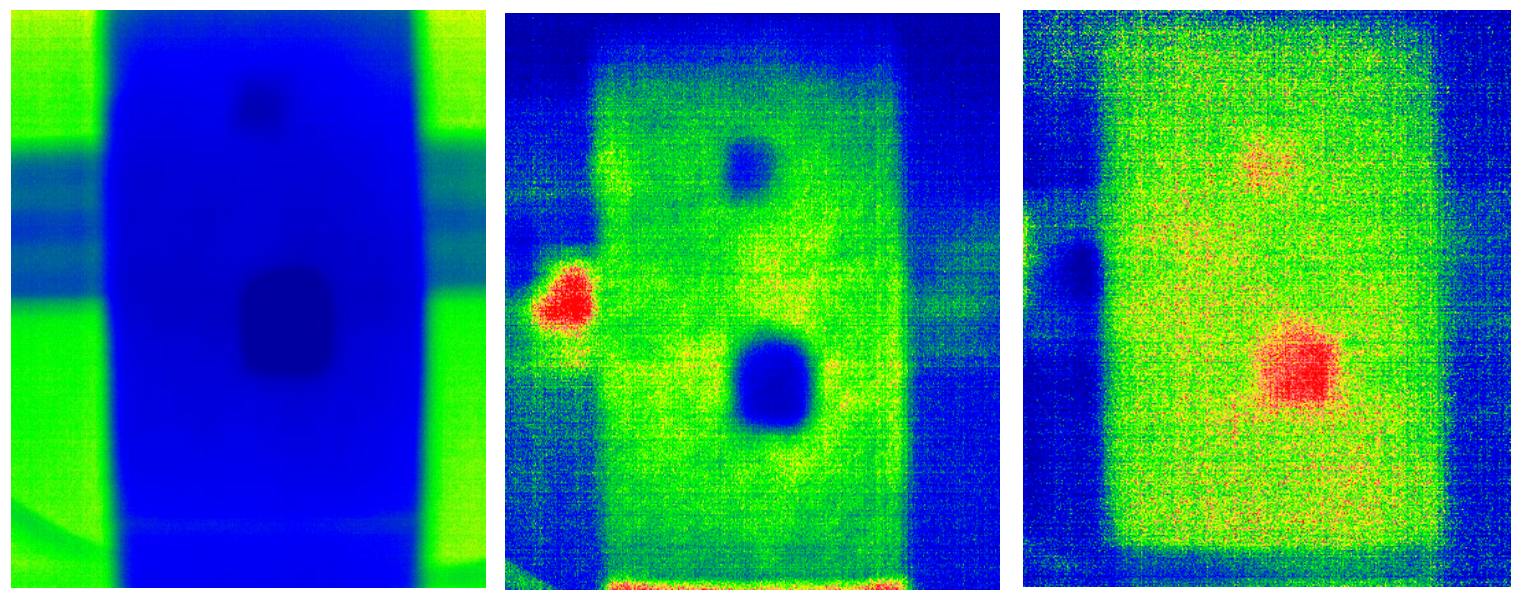

Figure 4-29: TSR image (left), $1^{\text {st }}$ derivative image (center), and $2^{\text {nd }}$ derivative image (right) of Side 1 of the deck specimen BD1 after 50 seconds of heating 

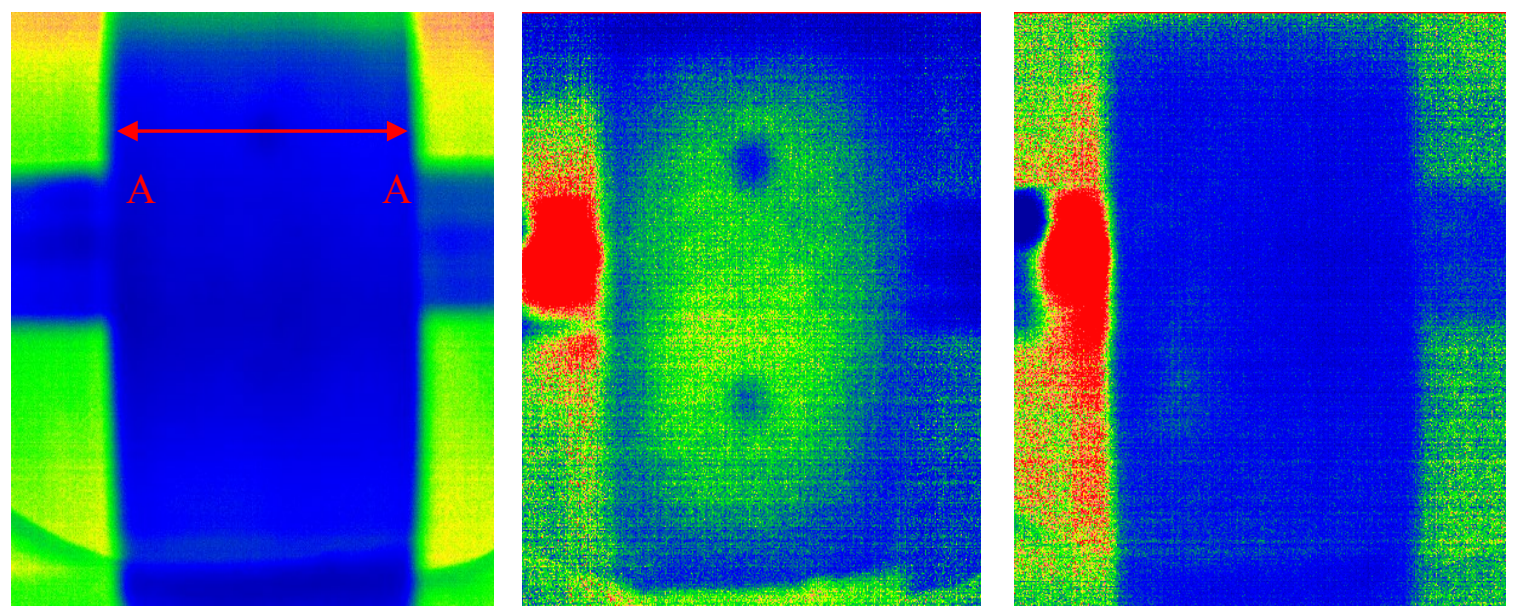

Figure 4-30: TSR image (left), $1^{\text {st }}$ derivative image (center), and $2^{\text {nd }}$ derivative image (right) of Side 2 of the deck specimen BD1 after 50 seconds of heating
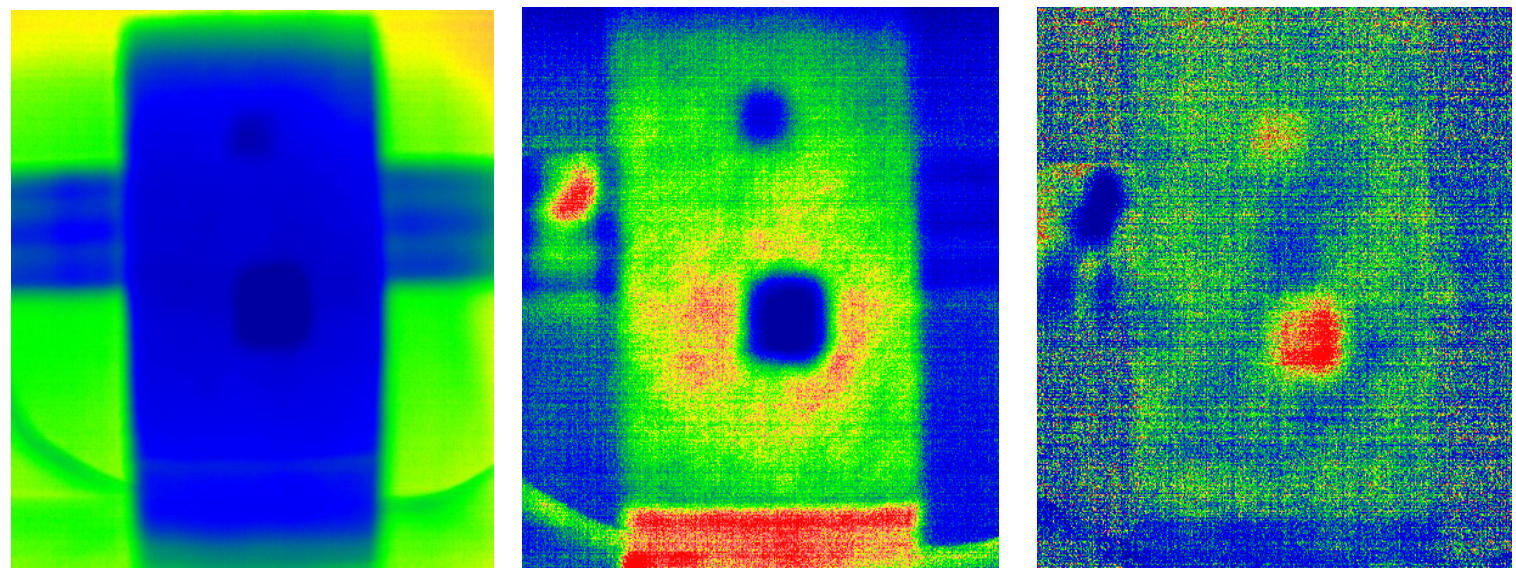

Figure 4-31: TSR image (left), $1^{\text {st }}$ derivative image (center), and $2^{\text {nd }}$ derivative image (right) of Side 1 of the deck specimen BD1 after 100 seconds of heating
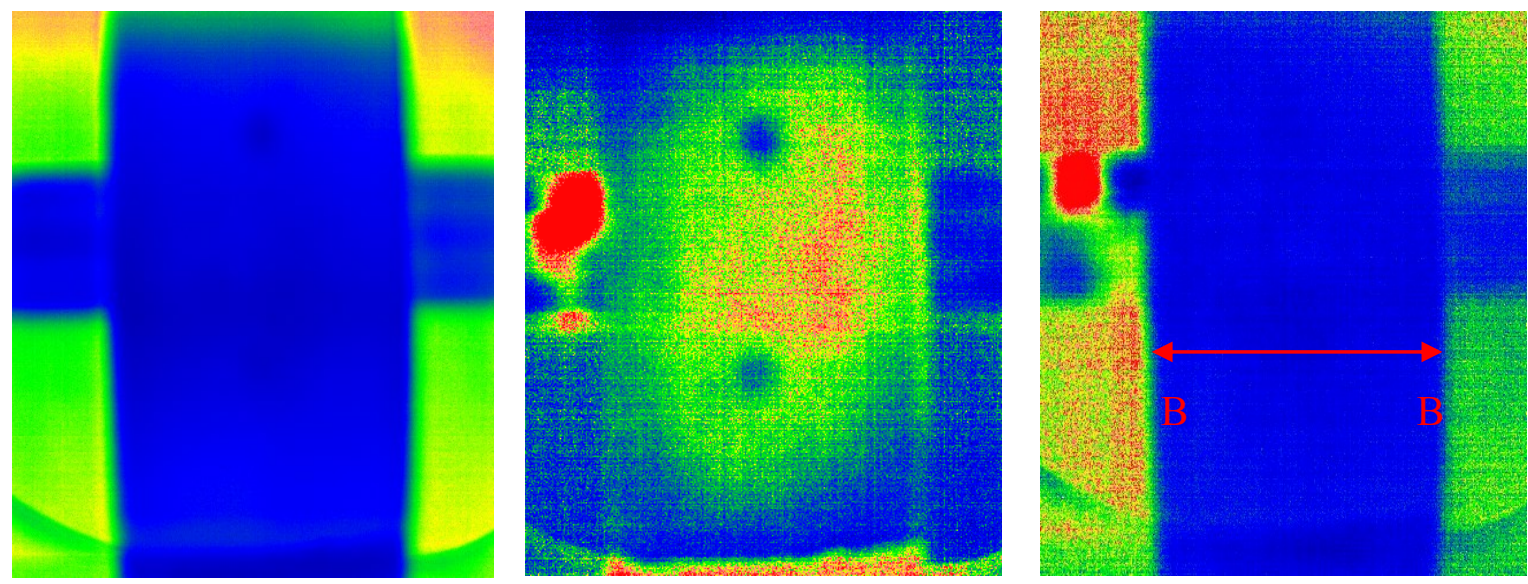

Figure 4-32: TSR image (left), $1^{\text {st }}$ derivative image (center), and $2^{\text {nd }}$ derivative image (right) of Side 2 of the deck specimen BD1 after 100 seconds of heating 
From the above observations, it can be noted that the optimum heating duration was 50 seconds as this heating duration was sufficient enough to detect the defects clearly and any longer duration would increase the testing time. It can also be seen that the $1^{\text {st }}$ derivative image is the clearest and the most reliable processed image in different heating durations.

The processed images did not show clear images of the debonds in all cases. For example, Side 2 with smaller debonds were difficult to detect in TSR and $2^{\text {nd }}$ derivative images even for 50 secs and 100 secs of heating, as shown in Figure 4-30. However, the profiles of the images against the pixels in the images provide better understanding of the debonds in the specimen. Figure 4-33 (left) shows the plot of intensity of the TSR image along the line A-A shown in Figure 4-30 (left), where the debonded area can be easily distinguished from good areas with the rise in the intensity. Similarly, Figure 4-33 (right) represents the line B-B of Figure 4-32 (right) with the debonds having higher $2^{\text {nd }}$ derivative image intensity than the good areas.
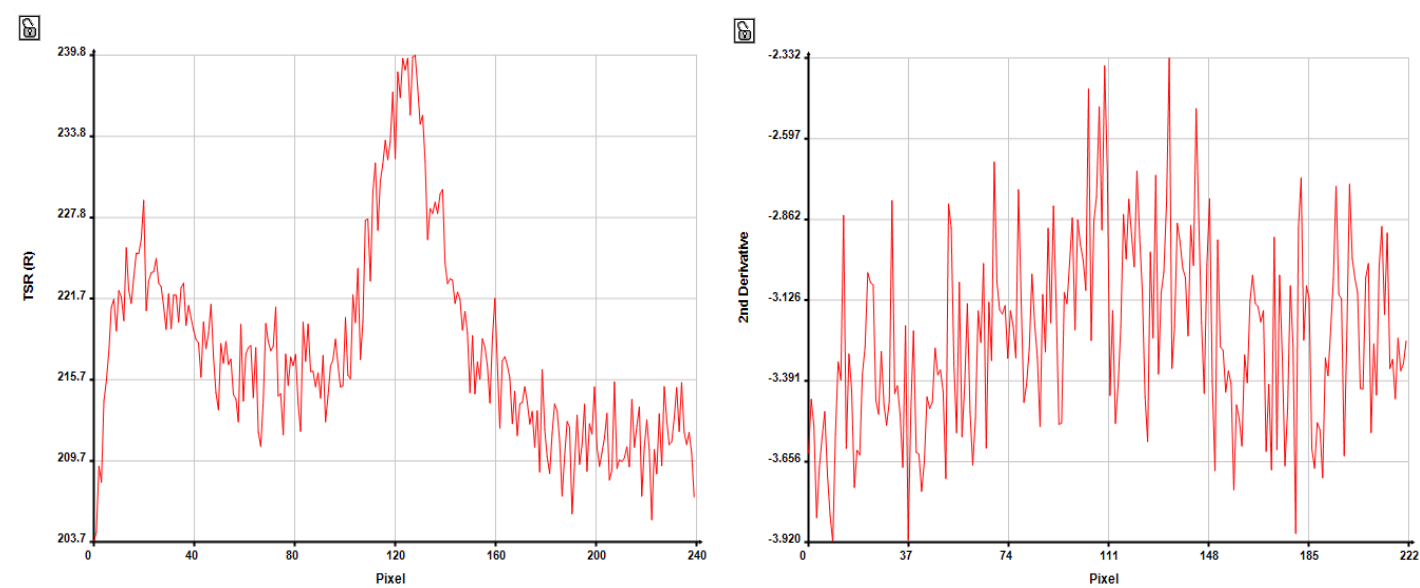

\section{Figure 4-33: Plot of TSR intensity along line A-A (left) and of $2^{\text {nd }}$ derivative intensity along line B-B (right)}

The FLIR InfraCAM SD captured thermal images of BD1 after heating the specimen for different time durations using VoyageIR Pro heating system. For 20 seconds of heating, the infrared images did not give a clear indication of the debonds on either side of the deck specimen BD1 (Figure 4-34). With the temperature difference of about $1{ }^{\circ} \mathrm{C}$ (debonded area with temperature of $25.7^{\circ} \mathrm{C}$ and surrounding area $24.7^{\circ} \mathrm{C}$ ), the debonds could not be located precisely. 

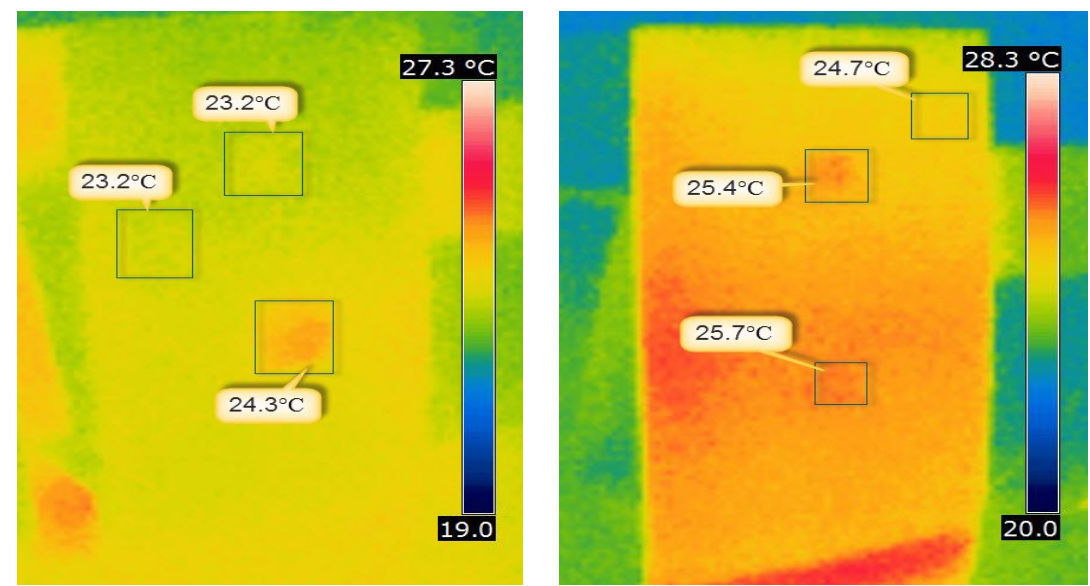

Figure 4-34: Thermal images of Side 1 (left) and Side 2 (right) of BD1 taken from FLIR InfraCAM SD after 20 seconds of heating from VoyageIR Pro system

However, with 50 seconds of heating, the debonds were easily identified in the still images captured from FLIR InfraCAM SD. Figure 4-35 (left) shows Side 1 of BD1 with a temperature differential of about $2^{\circ} \mathrm{C}$ to $3^{\circ} \mathrm{C}$. Side 2, as shown in Figure 4-35 (right), had a temperature difference of about $1.5^{\circ} \mathrm{C}$ but did not indicate the smaller debonds distinctly. This is because the size of the debond was small and for 50 seconds of heating, the surrounding was also heated evenly and there was not much temperature differential between the surrounding and the small debond. For other heating intervals, similar results were obtained for infrared testing on Sides 1 and 2 of the specimen BD1 using FLIR InfraCAM SD, which can be found in Appendix A. Thus, it has to be acknowledged that the advanced infrared data processing helps identify the smaller debonds, as seen previously for BD1. From infrared imaging on this specimen, it can be noted that the optimum heating duration for the specimen was 50 seconds, like previously stated.
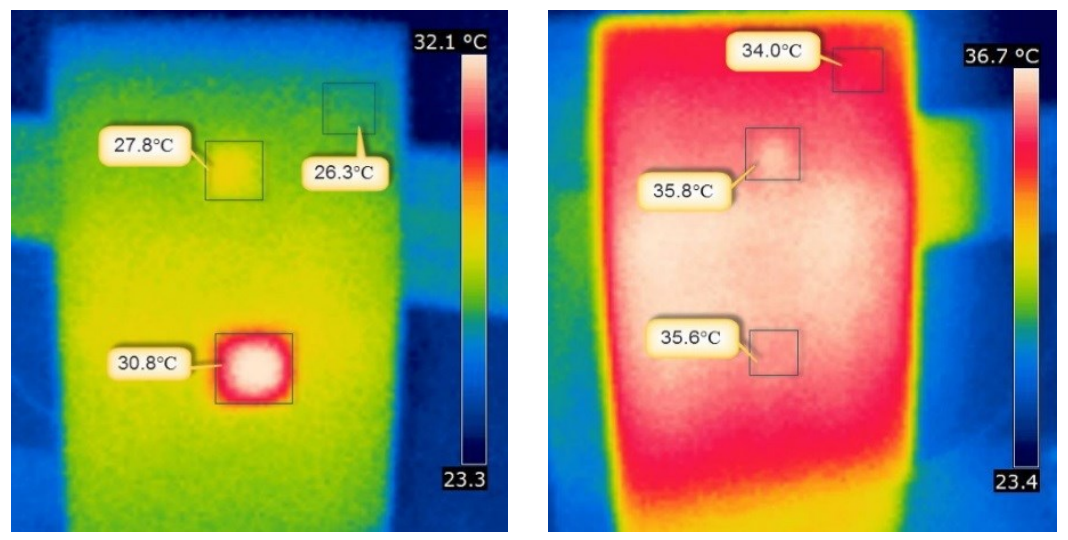

Figure 4-35: Thermal images of Side 1 (left) and Side 2 (right) of BD1 taken from FLIR InfraCAM SD after 50 seconds of heating from VoyageIR Pro system 
The halogen lamp heater was then used as the heating source. Infrared images after heating for 50 seconds were taken by FLIR InfraCAM SD, as shown in Figure 4-36. Side 1 of BD1 had two debonds with temperatures of $31.0^{\circ} \mathrm{C}$ and $31.9^{\circ} \mathrm{C}$ while the surrounding temperature was $29.5^{\circ} \mathrm{C}$. Side 2 was not that clear after 50 seconds of heating in terms of temperatures with only around $1{ }^{\circ} \mathrm{C}$ difference. Figure 4-37 shows Side 2 of BD1 after 100 seconds of heating. The results obtained are similar to the previous case in which the heating source was VoyageIR Pro system.
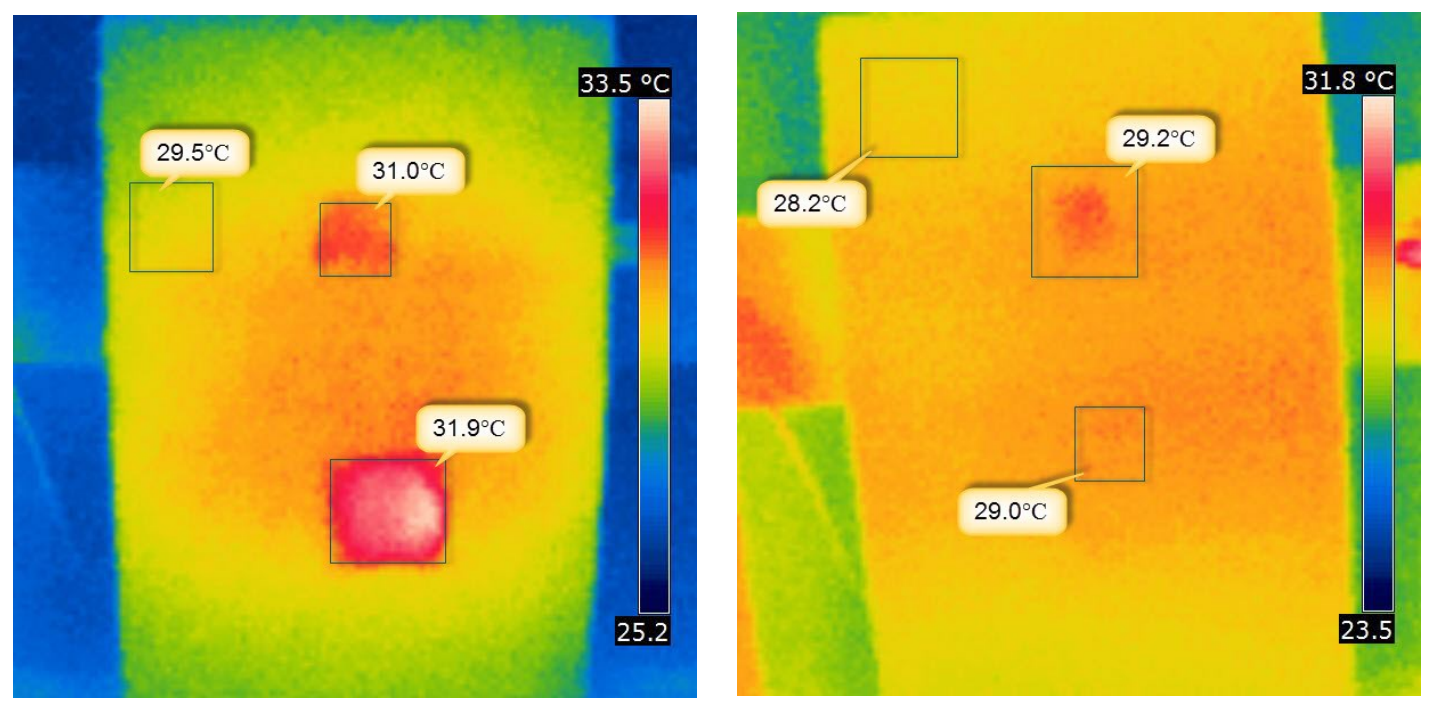

Figure 4-36: Thermal images of Side 1 (left) and Side 2 (right) of BD1 taken from FLIR InfraCAM SD after 50 seconds of heating from halogen lamp heater

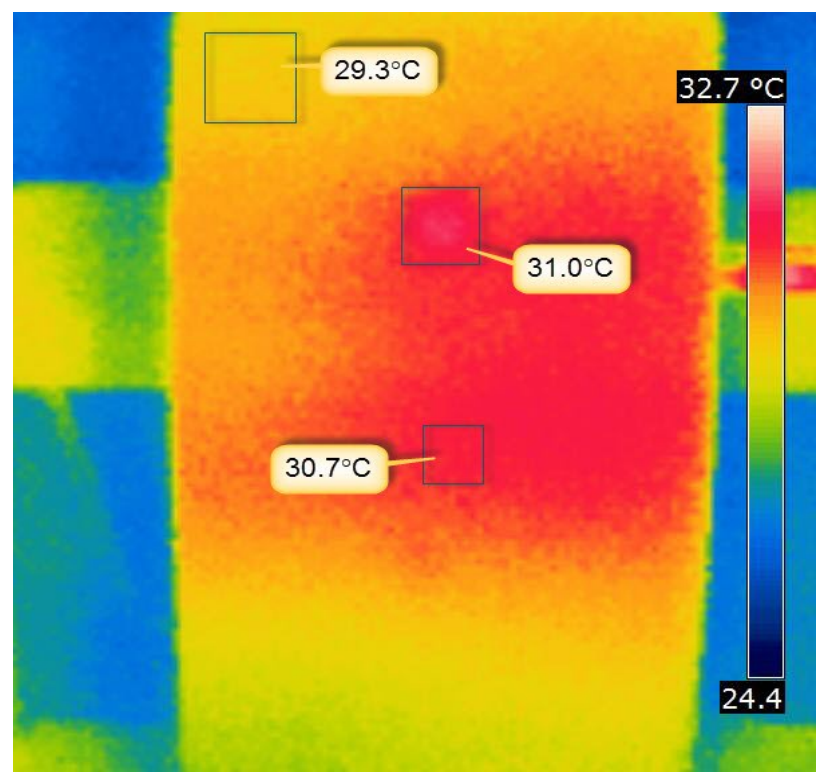

Figure 4-37: Thermal image of Side 2 of BD1 taken from FLIR InfraCAM SD after 100 seconds of heating from halogen lamp heater 
The raw images of bridge deck specimen JD1 after 50 seconds of heating are shown in Figure 4-38. The 3" x 3" sized debond on Side 1 could be detected in the raw image. Also, 2" x 2" and 1" x 1" sized debonds on Side 2 were also seen in the raw image. Though no data processing was required to detect debonds in this case, the advanced infrared system was utilized to get higher order images. Figure 4-39 shows $1^{\text {st }}$ derivative images of JD1 for 200 seconds of heating from VoyageIR Pro system, since the 50 seconds and 100 seconds $1^{\text {st }}$ derivative images were not that clear (Appendix A).

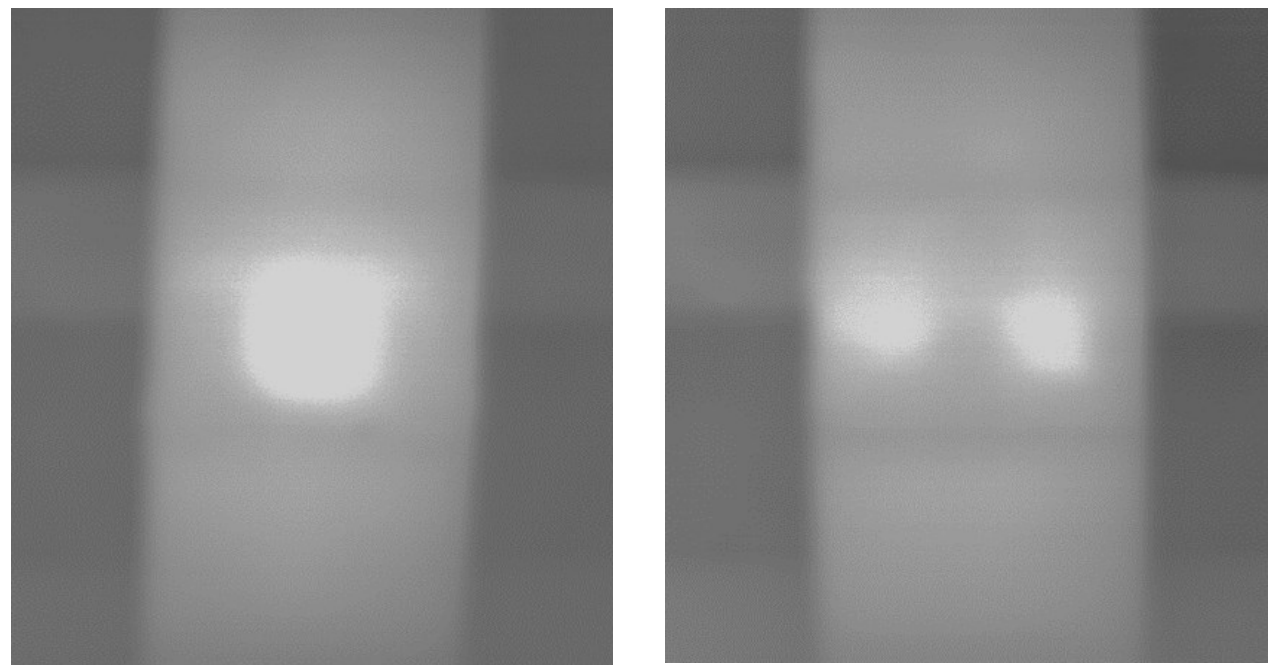

Figure 4-38: Raw thermal images of Side 1 (left) and Side 2 (right) of the deck specimen JD1 after 50 seconds of heating
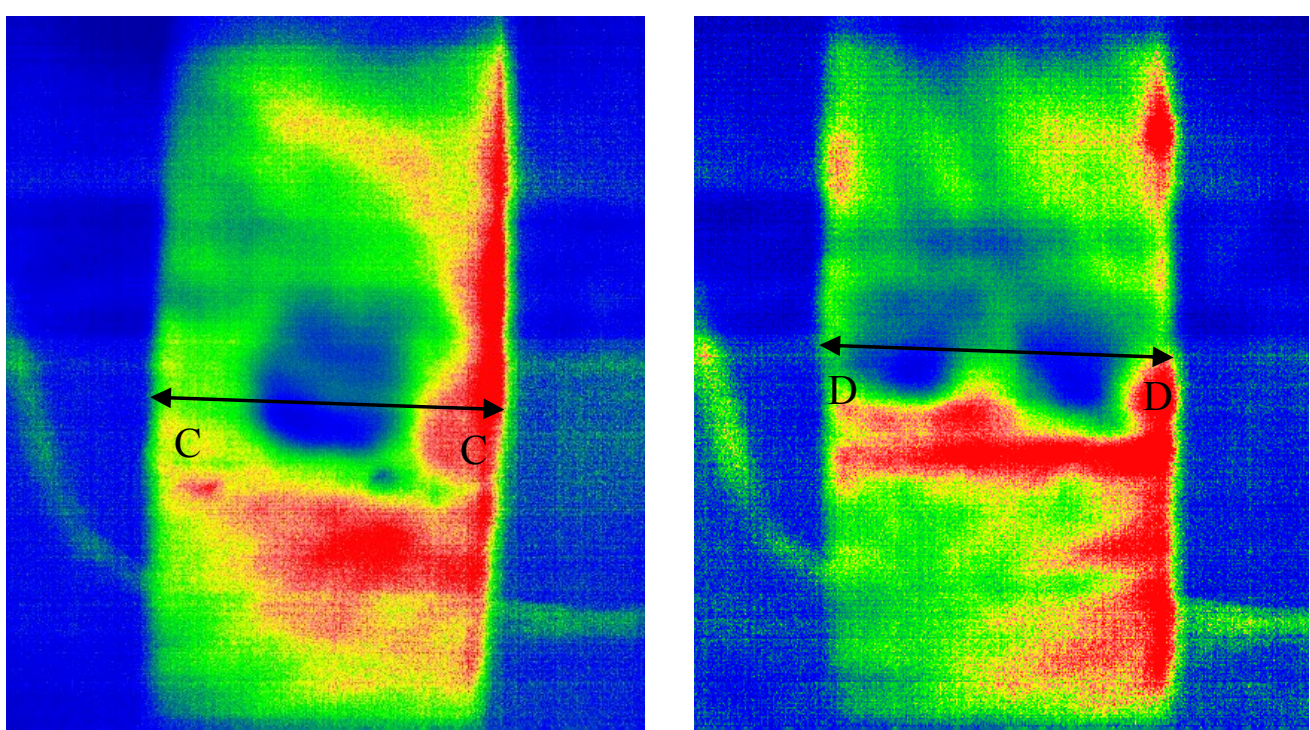

Figure 4-39: $1^{\text {st }}$ derivative images of Side 1 (left) and Side 2 (right) of the deck specimen JD1 after 200 seconds of heating 
Figure 4-40 (left) shows the profile along line C-C on Side 1 of the specimen JD1. The 3" $\mathrm{x} 3$ " sized debond is represented by the increase in the $1^{\text {st }}$ derivative intensity in the profile. The two debonds on Side 2 of JD2 can be identified from the two peaks in the profile along the line D-D, as shown in Figure 4-40 (right).

圆

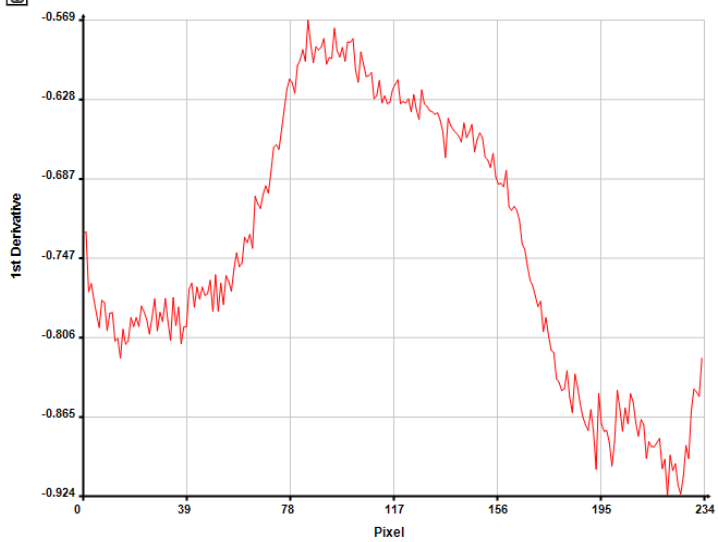

圆

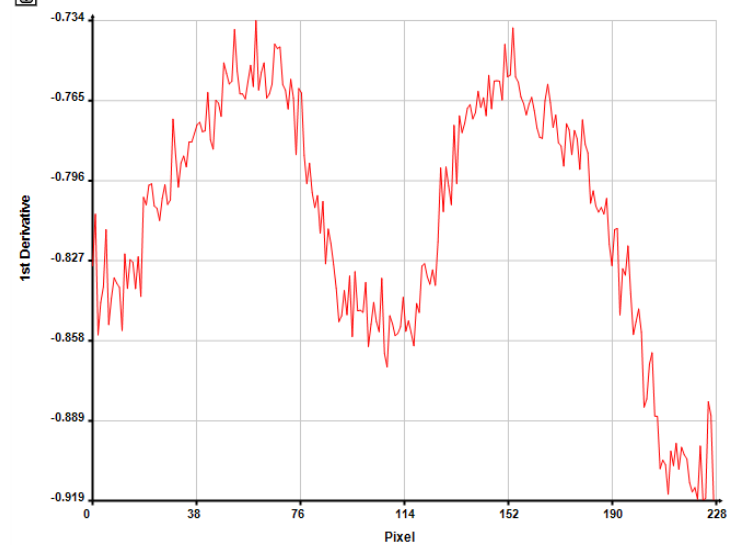

Figure 4-40: Plot of $1^{\text {st }}$ derivative intensity along the line $\mathrm{C}-\mathrm{C}$ (left) and along the line D-D (right)

The infrared images of JD1 captured from the FLIR InfraCAM SD after 50 seconds of heating are shown in Figure 4-41. The debonds on Sides 1 and 2 of JD1 could be located from the conventional thermal images. The temperature difference between debonds and surrounding area was about $1.5^{\circ} \mathrm{C}$ to $3^{\circ} \mathrm{C}$. Similar results were obtained for other heating durations (e.g., 100s), which are shown in Appendix A.
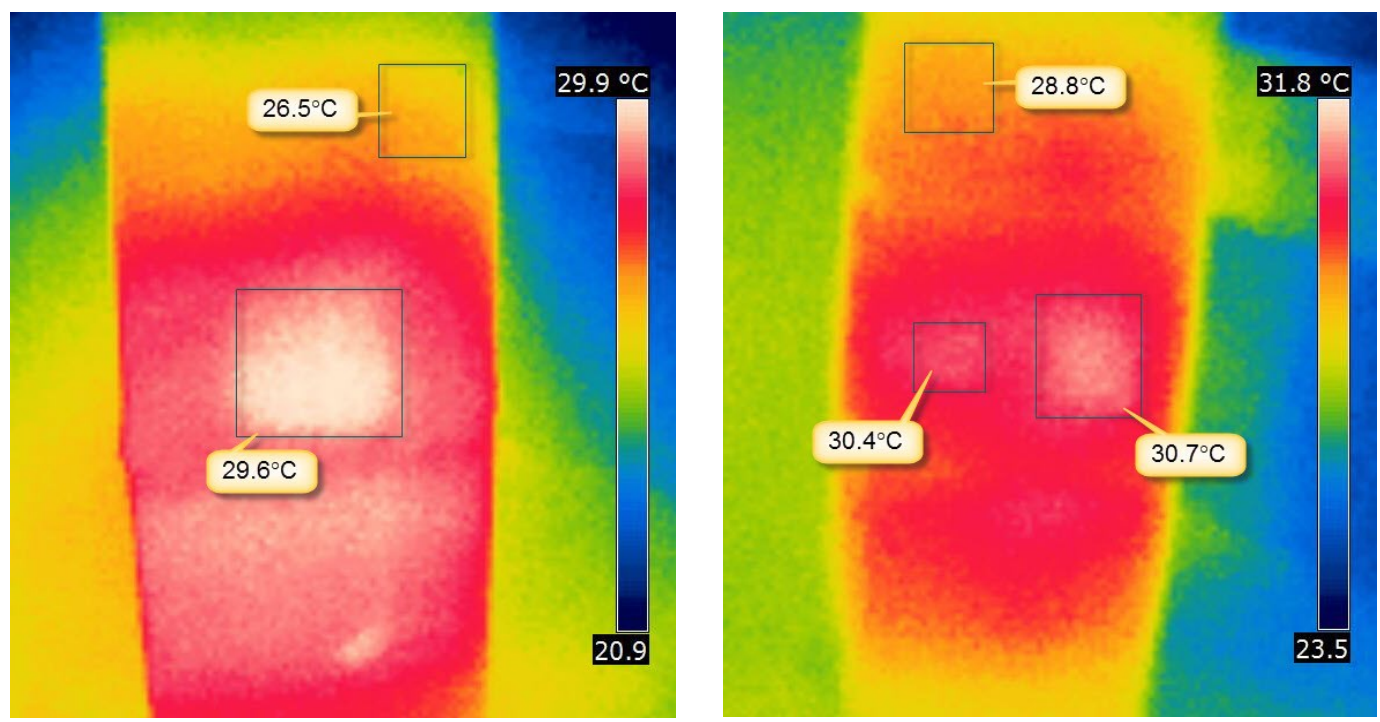

Figure 4-41: Thermal images of Side 1 (left) and Side 2 (right) of JD1 taken from FLIR InfraCAM SD after 50 seconds of heating from VoyageIR Pro system 
Figure 4-42 shows the FLIR InfraCAM SD images taken after heating the specimen JD1 for 100 seconds using the halogen lamp heater. The temperature difference of around $2.5^{\circ} \mathrm{C}$ to $3^{\circ} \mathrm{C}$ could be seen in the thermal image of Sides 1 and 2 of the deck specimen JD1. The result from 50 seconds of heating was not satisfactory with unclear thermal images of JD1 (Appendix A).
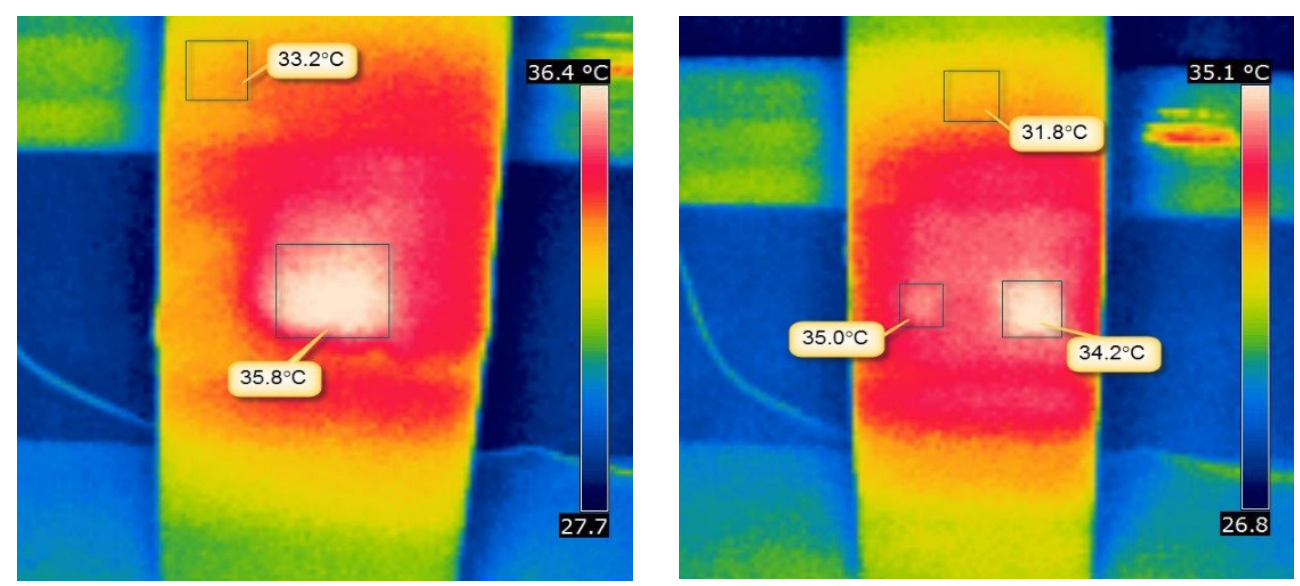

Figure 4-42: Thermal images of Side 1 (left) and Side 2 (right) of JD1 taken from FLIR InfraCAM SD after 100 seconds of heating from halogen lamp heater

\section{$\underline{\text { JD2 }}$}

The bridge deck specimen JD2, with a 3" x 3" sized debond on Side 1 and no debond on Side 2, was heated using the VoyageIR Pro system. The raw image of Side 1 for 50 seconds of heating did not show the debond. The raw image after heating for 100 seconds could not detect the debond either, as shown in Figure 4-43 (left). But, for 200 seconds of heating, the debond could be detected in the raw image itself (Figure 4-43 (right)).
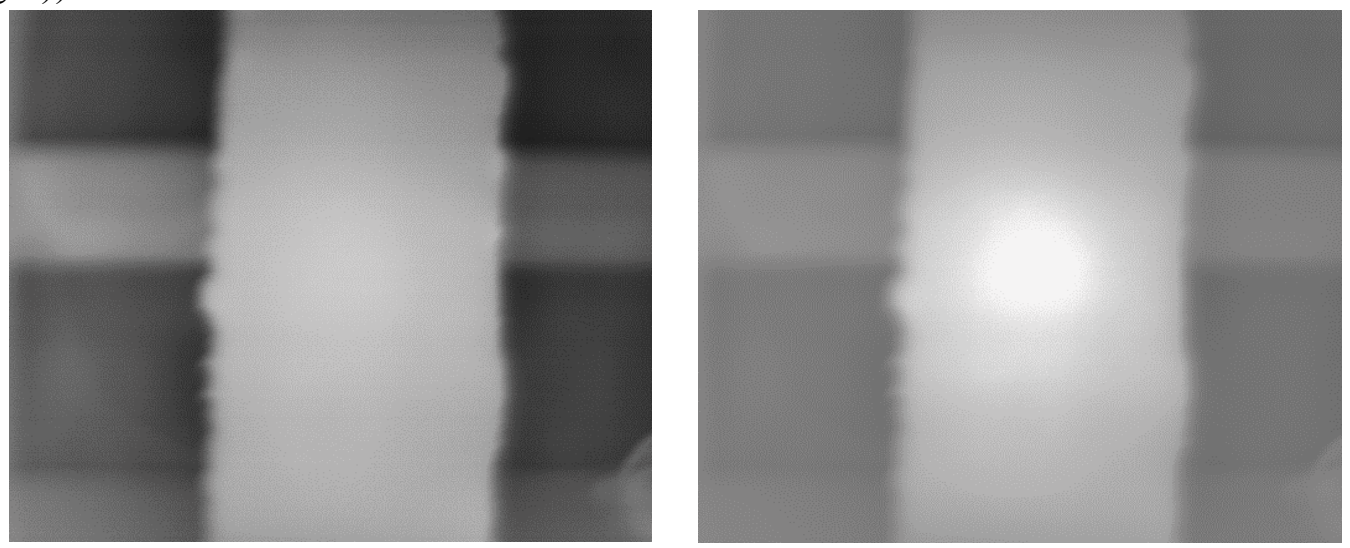

Figure 4-43: Raw thermal images of Side 1 of the deck specimen JD2 after 50 seconds of heating (left) and 200 seconds of heating (right) 
After the raw images of the specimen JD2 were processed through the associated software in the VoyageIR Pro system, the debond could be seen even for 100 seconds of heating. The $2^{\text {nd }}$ derivative image of Side 1 for 100 seconds of heating indicated the debond as a hot spot (Figure 4-44 (left)). The profile drawn along the line E-E is shown in Figure 4-44 (right), where the 3" 3 " sized debond is represented by the rise in the $2^{\text {nd }}$ derivative intensity. Some of the processed images were not as clear as the $2^{\text {nd }}$ derivative image for 100 seconds. This is because of the deeper depth of the defect, which could not be seen in most of the processed images. The total depth of the defect was around 0.7 " (3/8" wearing course plus the half of thickness of flange-to-flange junction, which was 0.3 ”).
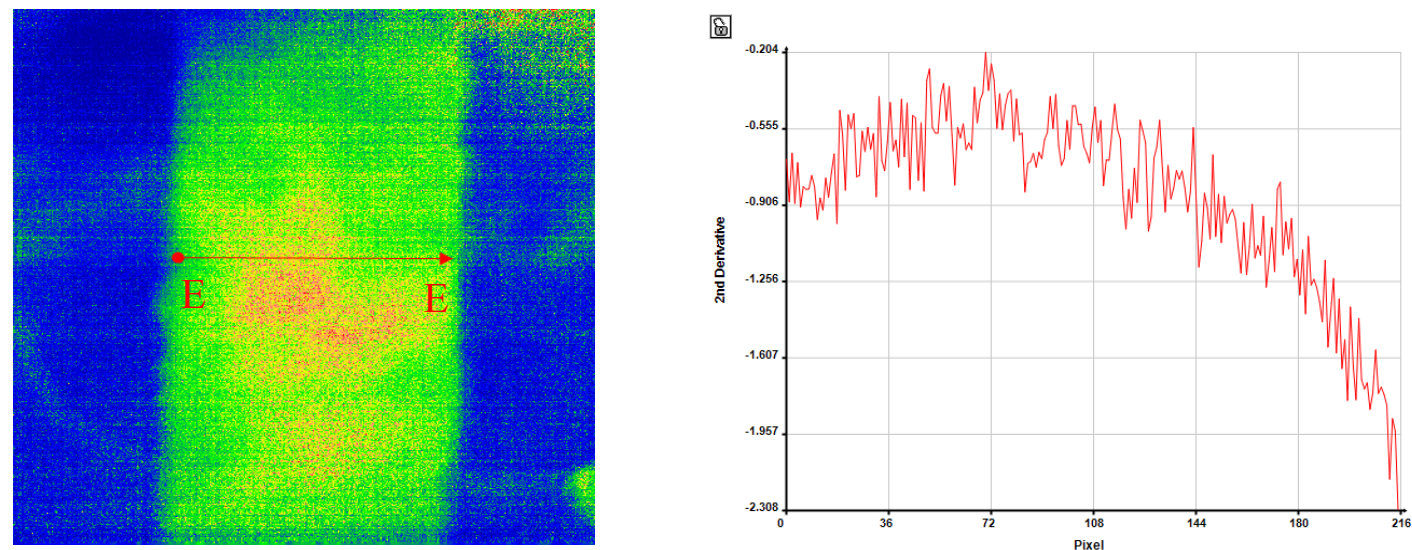

Figure 4-44: $2^{\text {nd }}$ derivative image of Side 1 of the deck specimen JD2 after 100 seconds of heating (left) and plot of $2^{\text {nd }}$ derivative intensity along the line E-E (right)

The FLIR InfraCAM SD image of Side 1 of JD2 taken after 50 seconds of heating from VoyageIR Pro system is shown in Figure 4-45. The debond had a temperature of $29.7^{\circ} \mathrm{C}$ while the surrounding temperature was $28.1^{\circ} \mathrm{C}$. The thermal image for 100 seconds of heating also displayed similar results (Appendix A).

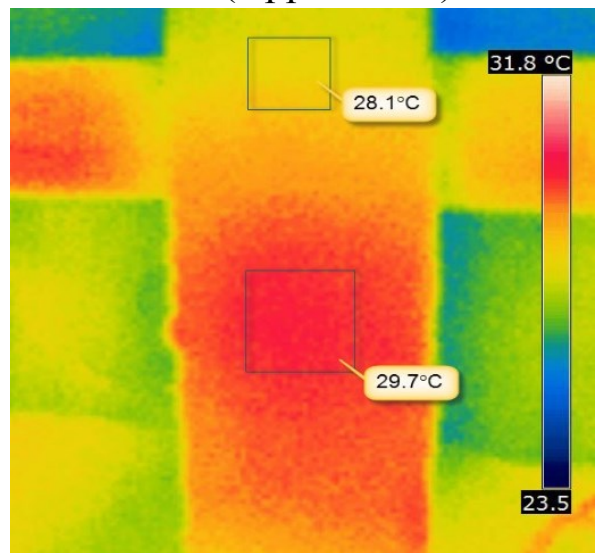

Figure 4-45: Thermal image of Side 1 of JD2 taken from FLIR InfraCAM SD after 50 seconds of heating from VoyageIR Pro system 
Figure 4-46 shows the infrared images taken by FLIR InfraCAM SD after heating Side 1 of JD2 for 200 seconds using the halogen lamp heater. The images for 50 seconds and 100 seconds of heating could not distinguish between the debond and good areas (Appendix A). The image for 200 seconds of heating provides some information on the debond but is not completely satisfactory. Though the temperature difference is about $2.5^{\circ} \mathrm{C}$, the heated surrounding proves to be unreliable.

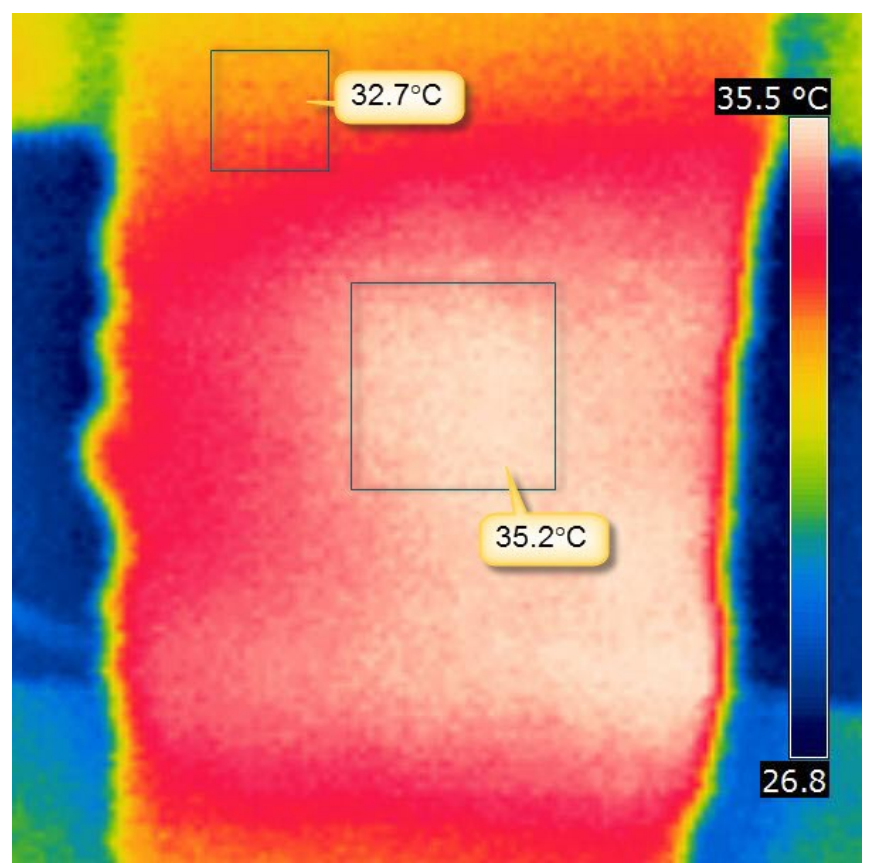

Figure 4-46: Thermal images of Side 1 of JD2 taken from FLIR InfraCAM SD after 200 seconds of heating from halogen lamp heater

\section{WJD2}

The bridge deck specimen WJD2 had a 3" x 3" sized debond on both of its sides and under 50 seconds of heating from VoyageIR Pro system, the obtained raw images are shown in Figure 4-47. The images displayed the debond in the uncovered Side 1 (left), however, the debond within the wearing-surface-covered Side 2 could not be detected (right). The debond in Side 2 could not be located in raw images for other heating durations too (Appendix A). After processing the images, there was clear indication of defects in $1^{\text {st }}$ derivative images of both sides after 50, 100 and 200 seconds of heating, as shown in Figures 4-48 and 4-49. 

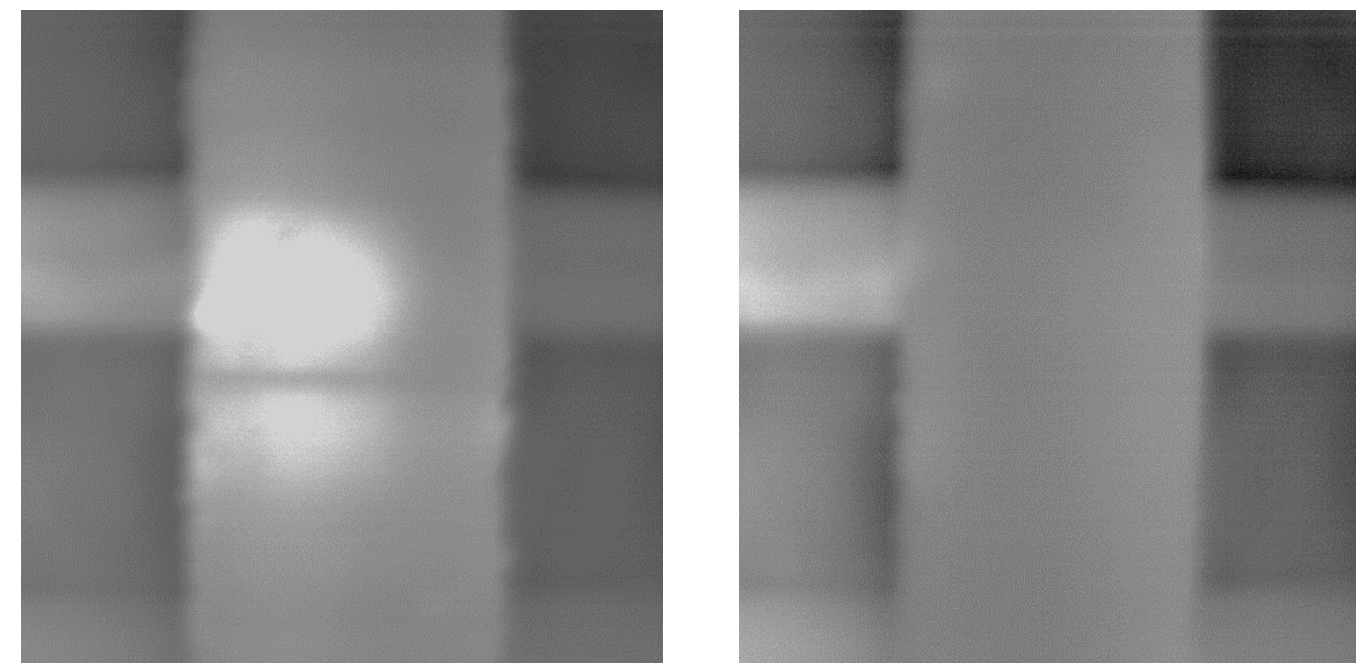

Figure 4-47: Raw thermal images of uncovered Side 1 (left) and covered Side 2 (right) of the deck specimen WJD2 after 50 seconds of heating
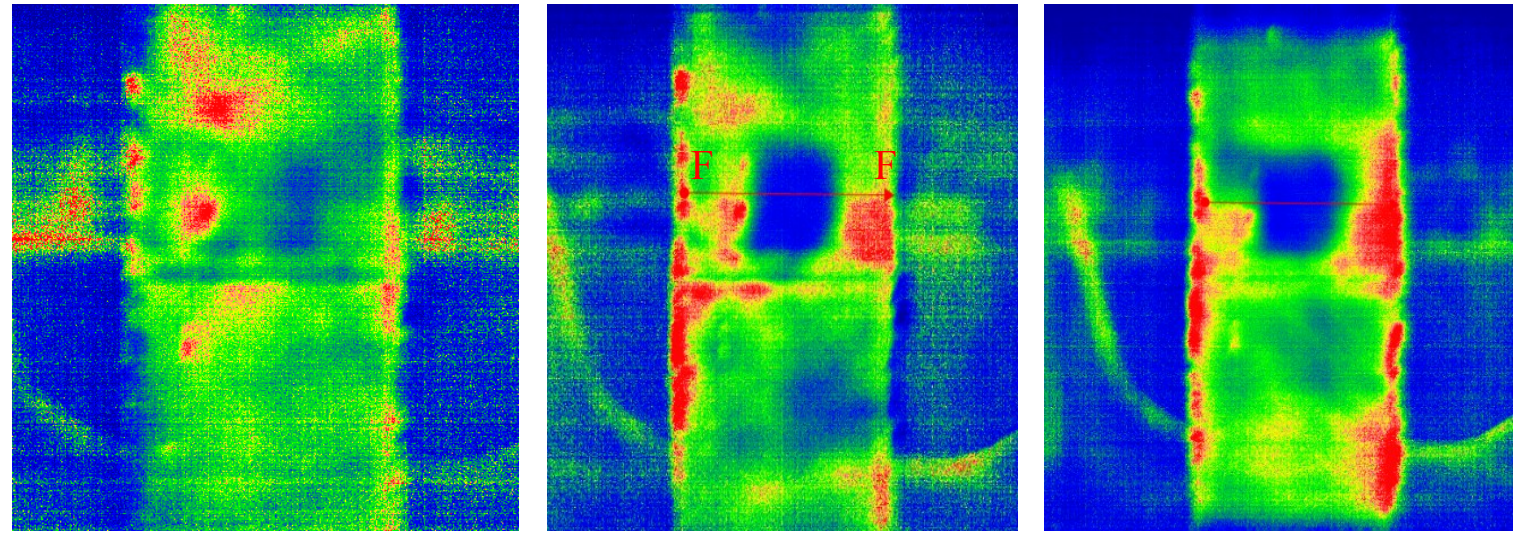

Figure 4-48: $1^{\text {st }}$ derivative images of uncovered Side 1 of the deck specimen WJD2 after 50 seconds (left), 100 seconds (center), and 200 seconds (right) of heating
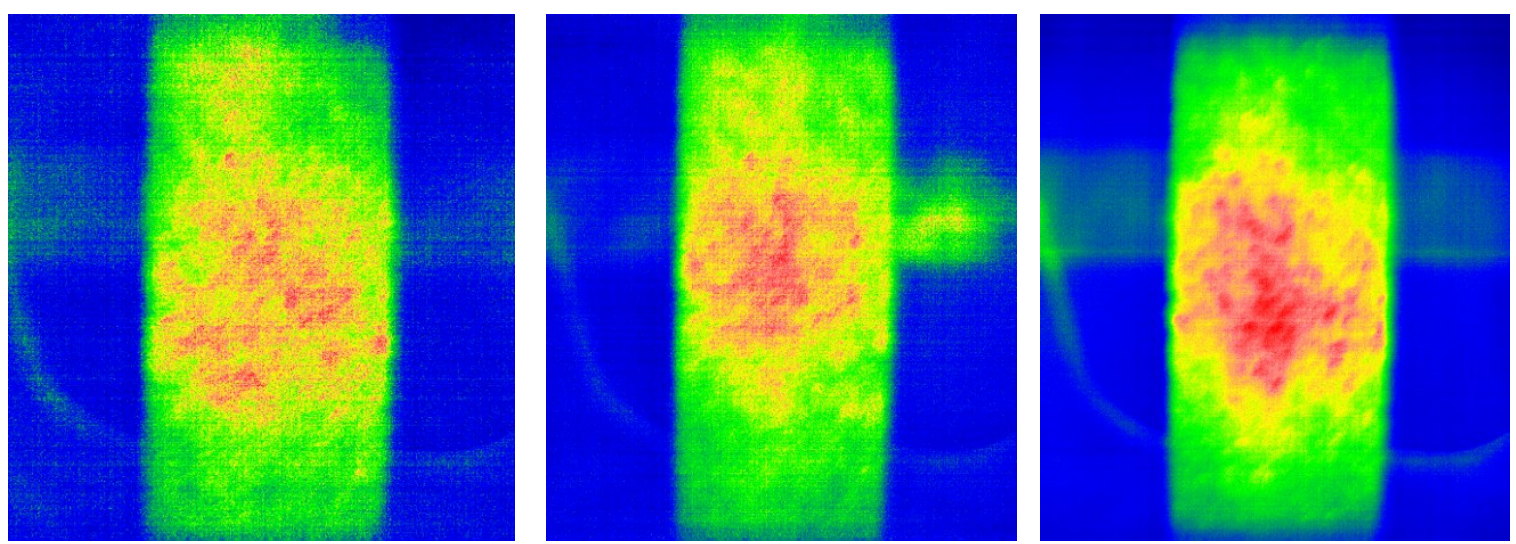

Figure 4-49: $1^{\text {st }}$ derivative images of covered Side 2 of the deck specimen WJD2 after 50 seconds (left), 100 seconds (center), and 200 seconds (right) of heating 
From the above images, it can be seen that the defects at deeper depths require longer duration of heating. The delamination on uncovered Side 1 was at the depth of around 0.3 ", which can be seen in the $1^{\text {st }}$ derivative image after 50 seconds of heating. On the other hand, the delamination on covered Side 2 was at the depth of around 0.7', which can only be seen in the $1^{\text {st }}$ derivative image after 100 seconds of heating.

The line F-F on Figure 4-48 (center) represents the profile for the intensity of the $1^{\text {st }}$ derivative image of the Side 1 after 100 seconds of heating. This profile-plot is shown in Figure 4-50, where the 3" x 3" sized debond can be identified through the rise in the intensity along the profile line F-F. Similar results were obtained for Side 1 for other heating durations and processed images. However, Side 2 did not give clear indication of debond in any processed image or profile-plot. Figure 4-51 shows the thermal images taken from FLIR InfraCAM SD of the deck specimen WJD2 after 100 seconds of heating from VoyageIR Pro system. Heating duration of 50 seconds did not give reliable information on the defects. The 3" x 3" debond on Side 1 of WJD2 could be located with FLIR InfraCAM SD image. The debond on Side 2 was still unclear on the conventional thermal image, though there was significant temperature difference (around $2^{\circ} \mathrm{C}$ ) between the debond area and surrounding.

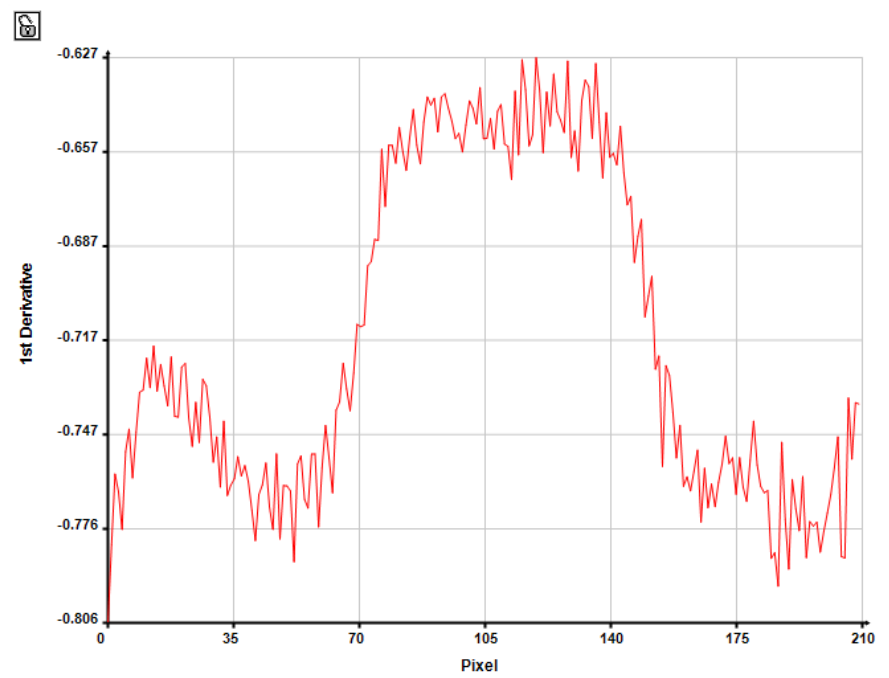

Figure 4-50: Plot of $1^{\text {st }}$ derivative intensity along the line F-F on Side 1 of the deck specimen WJD2 

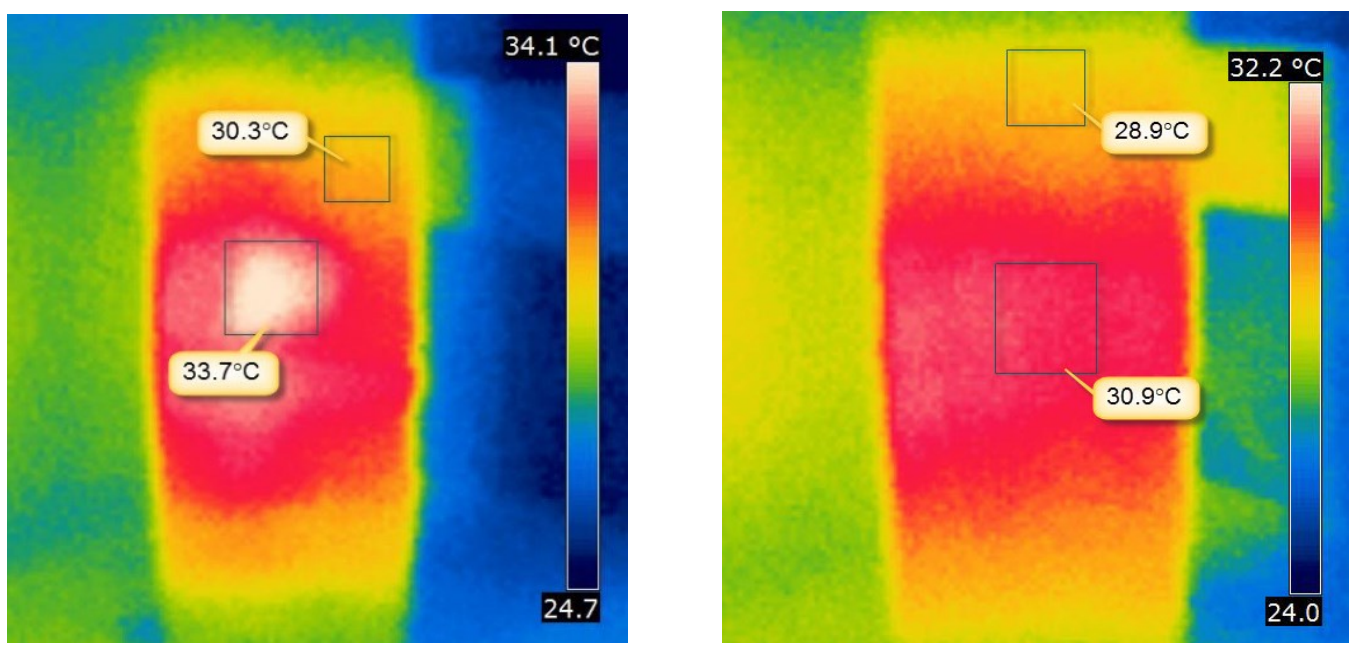

Figure 4-51: Thermal images of Side 1 (left) and Side 2 (right) of WJD2 taken from FLIR InfraCAM SD after 100 seconds of heating from VoyageIR Pro system

The halogen lamp heater was then used to the specimen WJD2 and the images taken from FLIR InfraCAM SD after 100 seconds of heating are shown in Figure 4-52. The results from heater as heating source were similar to the VoyageIR Pro heating system. The debond on Side 1 was clear for detection while on Side 2 (which had overlay), it was difficult to identify the debond based on the thermal images.
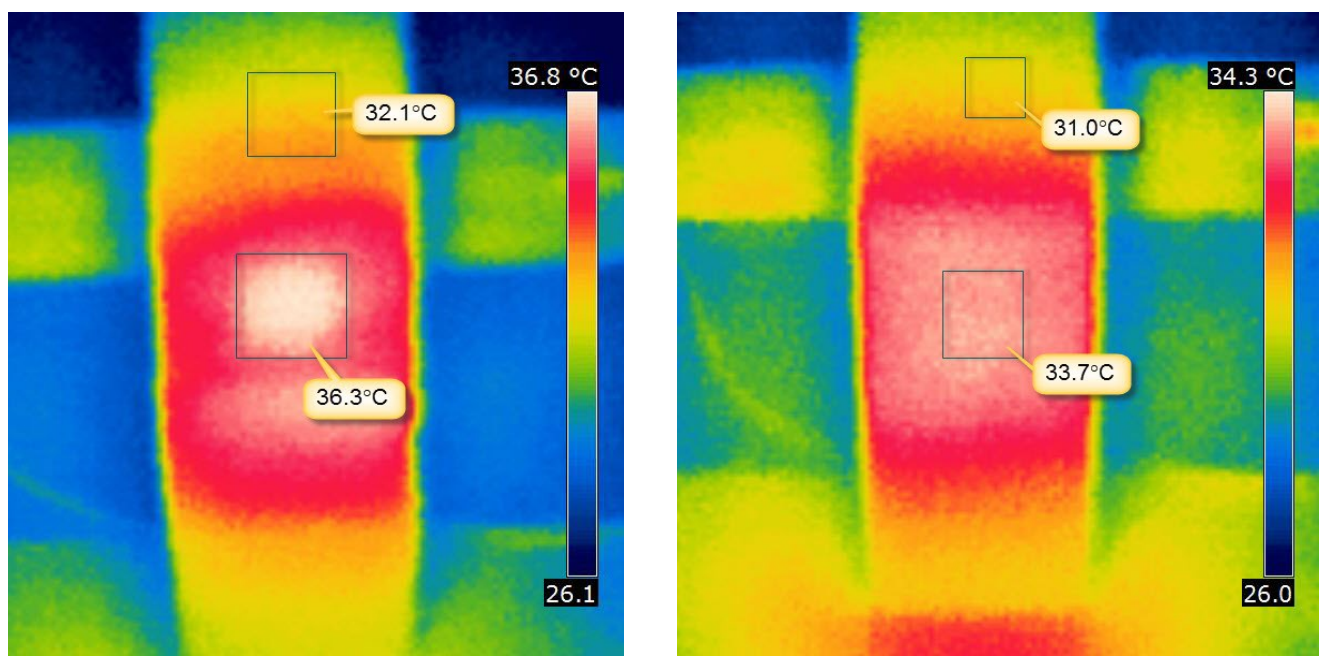

Figure 4-52: Thermal images of Side 1 (left) and Side 2 (right) of WJD2 taken from FLIR InfraCAM SD after 100 seconds of heating from halogen lamp heater 


\section{WJD3}

The specimen WJD3 had a 3" x 3" sized debond on Side 1 but it could not be detected in the raw image (Figure 4-53 (left)) after 50 seconds of heating from VoyageIR Pro system, mainly because this side was covered with a wearing surface. The two debonds on Side 2 of the specimen WJD3 could be seen in the raw image but they were still not so distinct (Figure 4-53 (right)). The processed image in the form of $1^{\text {st }}$ derivative after 100 seconds of heating was able to show the debond on Side 1 (Figure 4-54). The $1^{\text {st }}$ derivative image of Side 2 gave good results after 200 seconds of heating, which was much better than 100 seconds of heating (Figure 4-55). The line G-G on Figure 4-55 (right) is a profile that crosses the two debonds on Side 2 of WJD3. The plot of this profile is shown in Figure 4-56, where the intensity of $1^{\text {st }}$ derivative image of Side 2 displays the two debonds as two peaks in the graph.
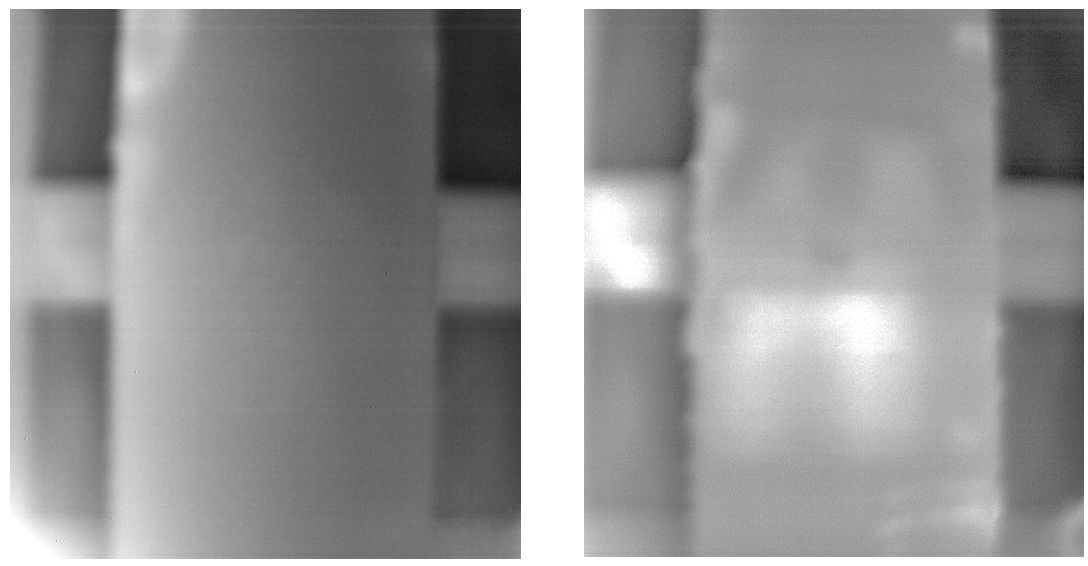

Figure 4-53: Raw thermal images of covered Side 1 (left) and uncovered Side 2 (right) of the deck specimen WJD3 after 50 seconds of heating

Figure 4-54: $1^{\text {st }}$ derivative image of Side 1 of the deck specimen WJD3 after 100 seconds of heating 

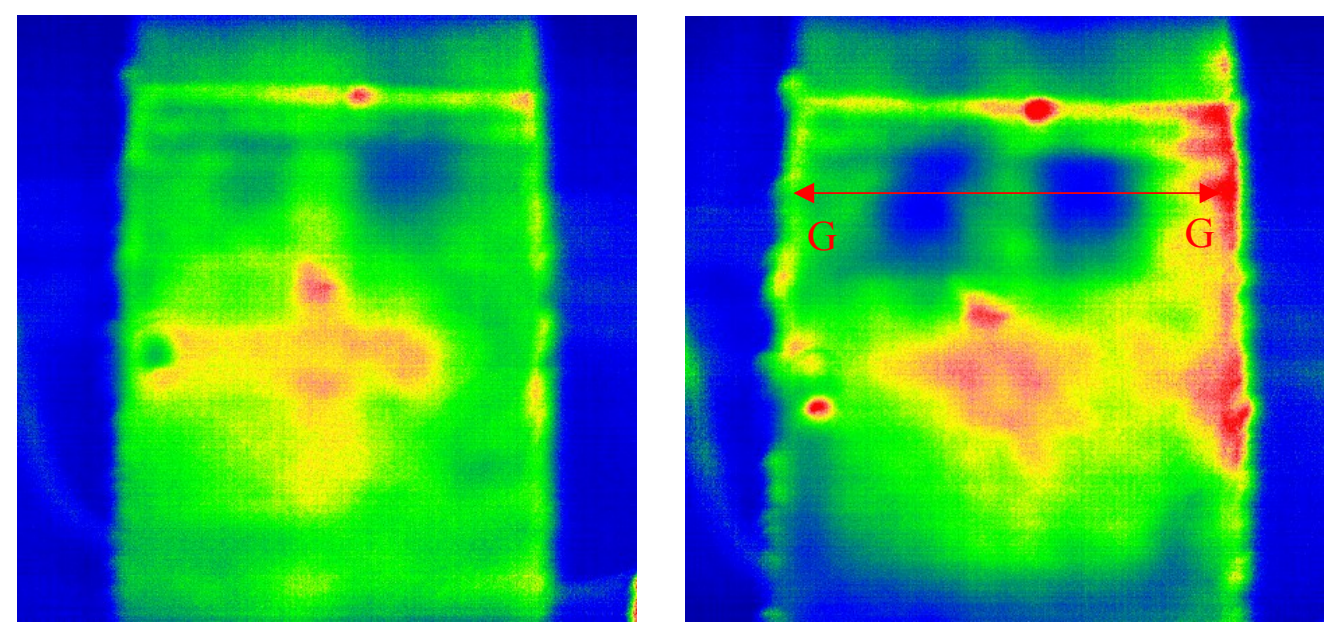

Figure 4-55: $1^{\text {st }}$ derivative images of Side 2 of the deck specimen WJD3 after 100 seconds of heating (left) and after 200 seconds of heating (right)

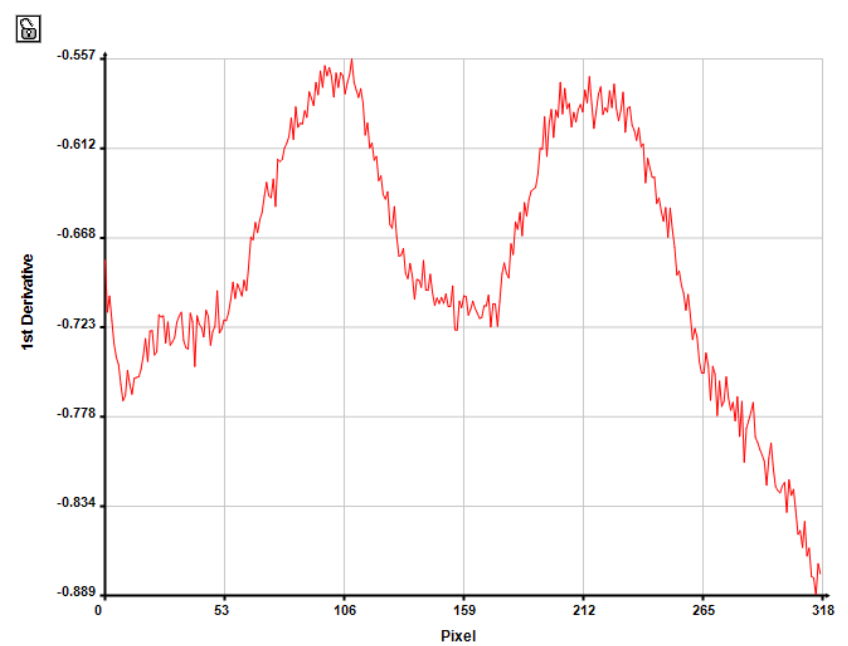

Figure 4-56: Plot of $1^{\text {st }}$ derivative intensity along the line G-G on Side 1 of the deck specimen WJD3

The heating durations of 50 seconds and 100 seconds could not produce good infrared results for WJD3 using the FLIR InfraCAM SD (Appendix A). The conventional thermal images of Sides 1 and 2 of WJD3 after 200 seconds of heating are shown in Figure 4-57. The debond on Side 1 could not be detected even with 200 seconds of heating. The whole surrounding got heated to high temperature so the 3 " $\mathrm{x} 3$ " sized debond could not be located. For Side 2, the two debonds could be seen in the image as two hot spots with temperature difference in the range of $4^{\circ} \mathrm{C}$ to $5^{\circ} \mathrm{C}$. 

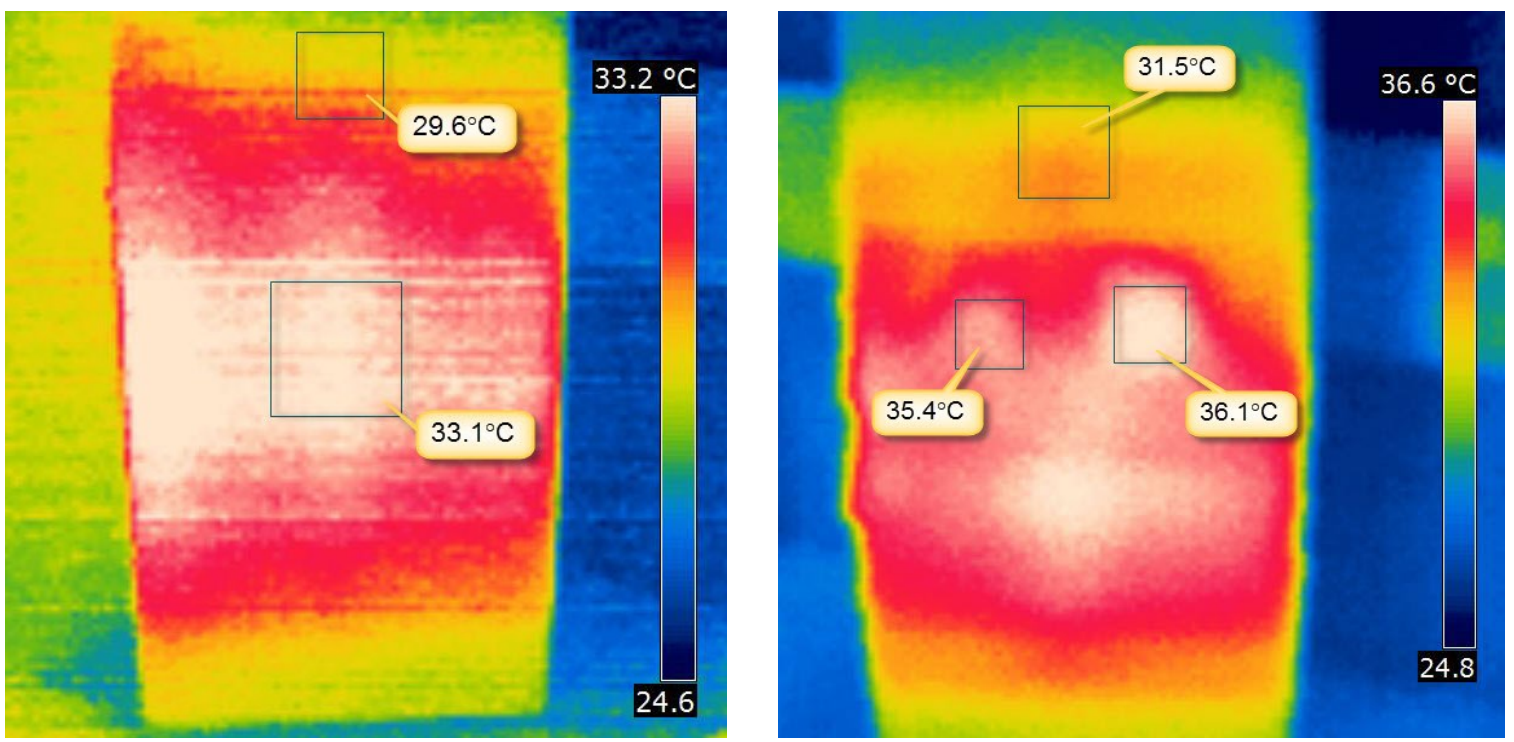

Figure 4-57: Thermal images of Side 1 (left) and Side 2 (right) of WJD3 taken from FLIR InfraCAM SD after 200 seconds of heating from VoyageIR Pro system

Figure 4-58 shows the conventional thermal images of WJD3 for halogen lamp heater. 100 seconds of heating did show clear indication of debonds on both sides of the specimen. Temperature difference of about $1.5^{\circ} \mathrm{C}$ to $2.5^{\circ} \mathrm{C}$ could be seen between the debonds and the surrounding area.
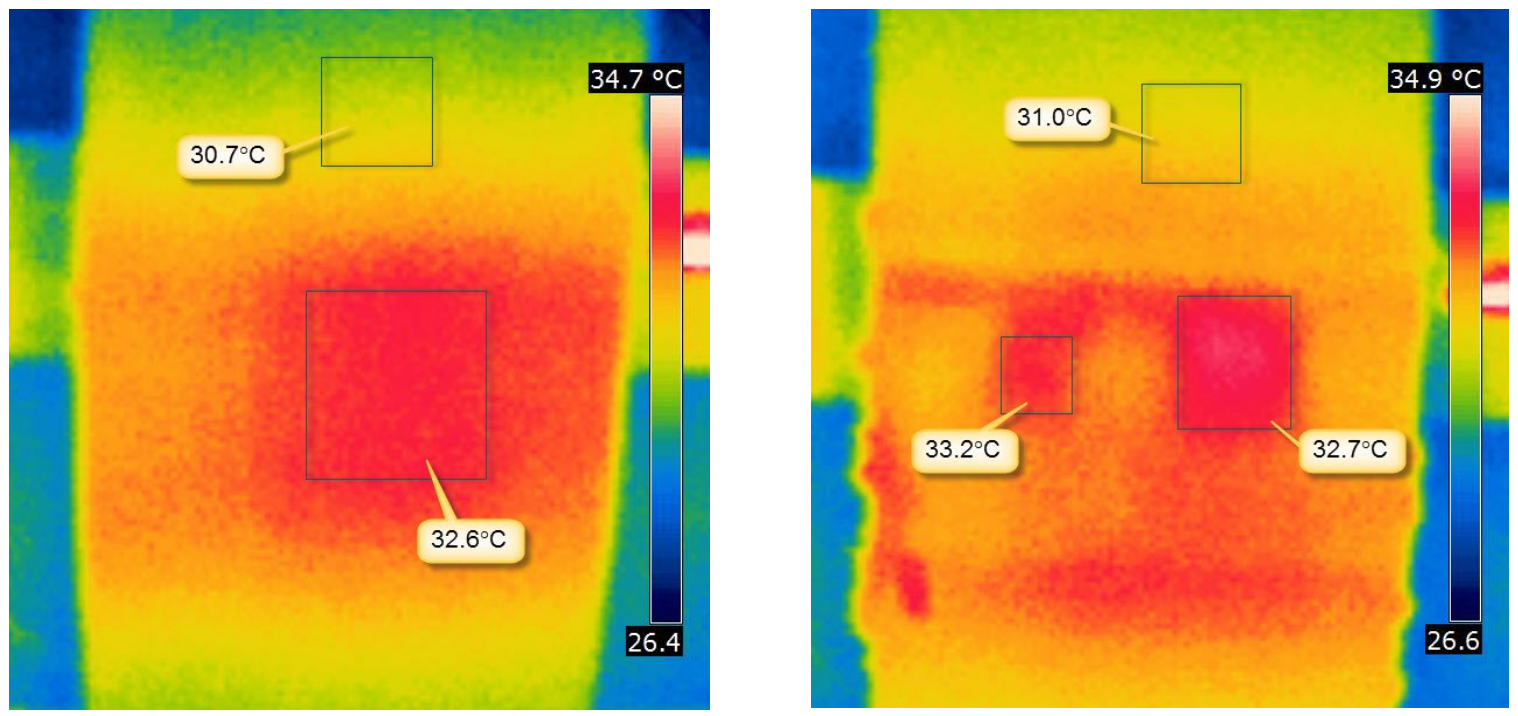

Figure 4-58: Thermal images of Side 1 (left) and Side 2 (right) of WJD3 taken from FLIR InfraCAM SD after 100 seconds of heating from halogen lamp heater 
The deck specimen AS2 had two debonds of size 2" x 2" and 1" x 1" on Side 1 and no debond on Side 2. The raw images from VoyageIR Pro, after heating for 50 seconds, detected these debonds on Side 1, as shown in Figure 4-59.

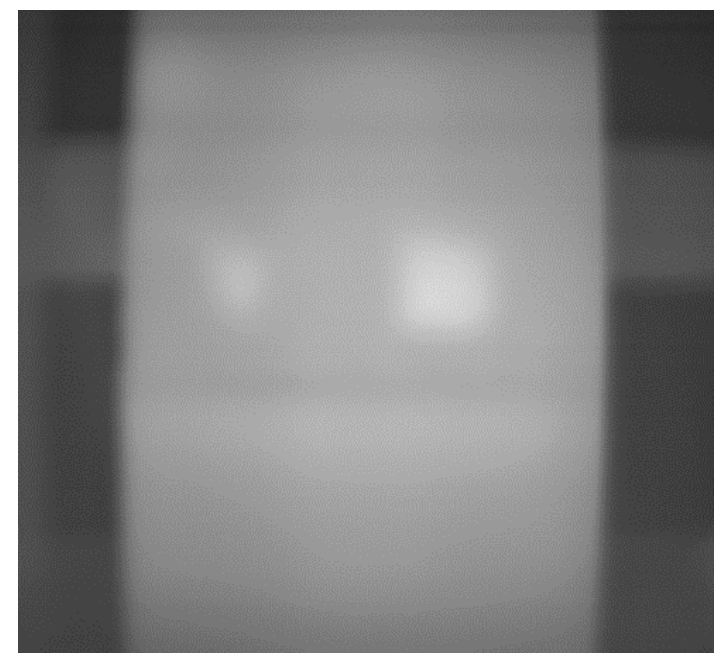

Figure 4-59: Raw thermal image of Side 1 of the deck specimen AS2 after 50 seconds of heating

Figure 4-60 (left) shows the $1^{\text {st }}$ derivative image of the specimen AS2 after 100 seconds of heating, where the defects can be clearly identified. The plot of profile along line $\mathrm{H}-\mathrm{H}$ is shown in Figure 4-60 (right), where the two peaks of $1^{\text {st }}$ derivative intensity represent the two debonds on Side 1 of AS2.
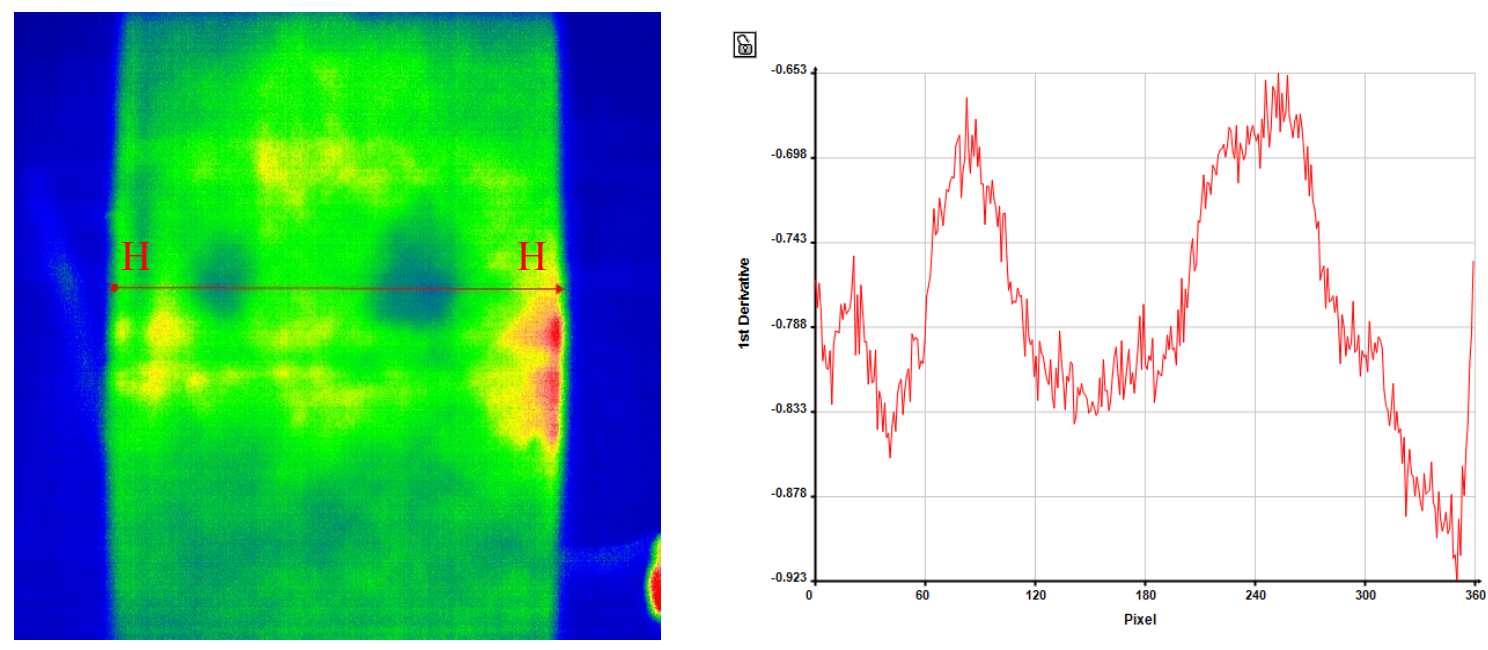

Figure 4-60: $1^{\text {st }}$ derivative image of Side 1 of the deck specimen AS2 after 100 seconds of heating (left) and plot of $1^{\text {st }}$ derivative intensity along the line $\mathrm{H}-\mathrm{H}$ (right) 
After heating the specimen AS2 for 50 seconds using VoyageIR Pro system, the thermal images from FLIR InfraCAM SD was not satisfactory but for 100 seconds, the two debonds on Side 1 could clearly be distinguished from surrounding area (Figure 4-61). The temperature difference between the debonds and the surrounding was in the range of $2{ }^{\circ} \mathrm{C}$ to $3^{\circ} \mathrm{C}$.
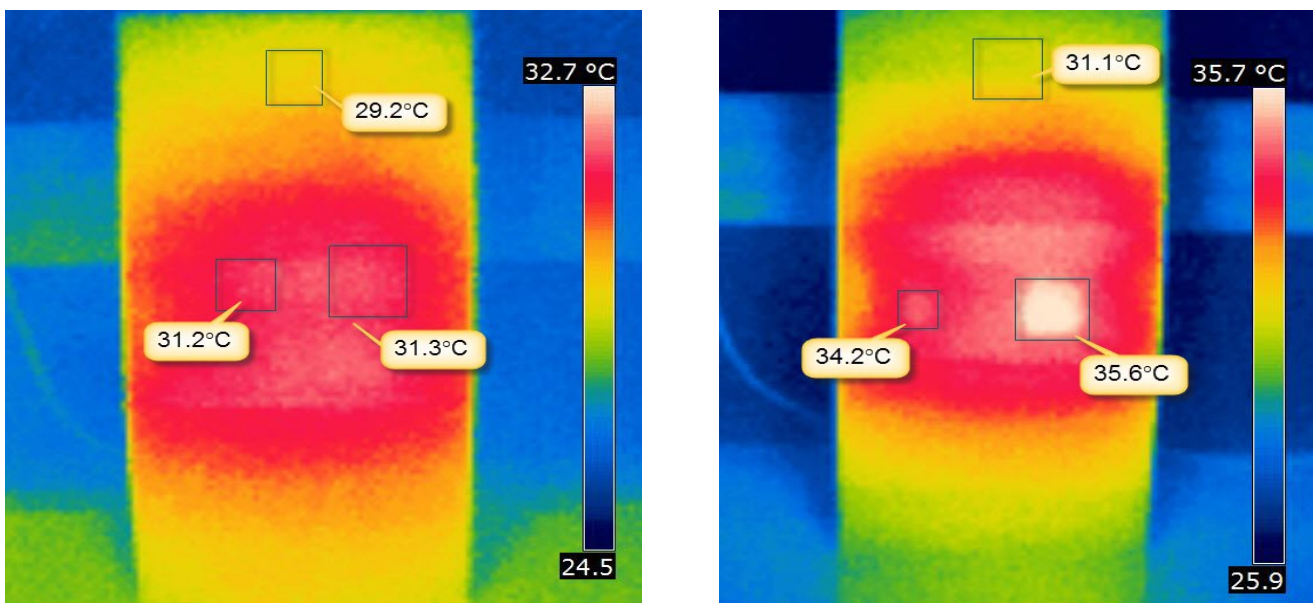

Figure 4-61: : Thermal images of Side 1 of AS2 taken from FLIR InfraCAM SD after 50 seconds (left) and 100 seconds of heating (right) from halogen lamp heater

The halogen lamp heater was then used to heat the specimen AS2 and Figure 4-62 show the results from FLIR InfraCAM SD. Similar to the VoyageIR Pro system, the thermal images for 50 seconds of heating from the heater could not detect the debonds on Side 1 (left). Heating duration of 100 seconds, however, produced thermal images showing the two debonds of size 1" x 1" and 2" x 2" (right).
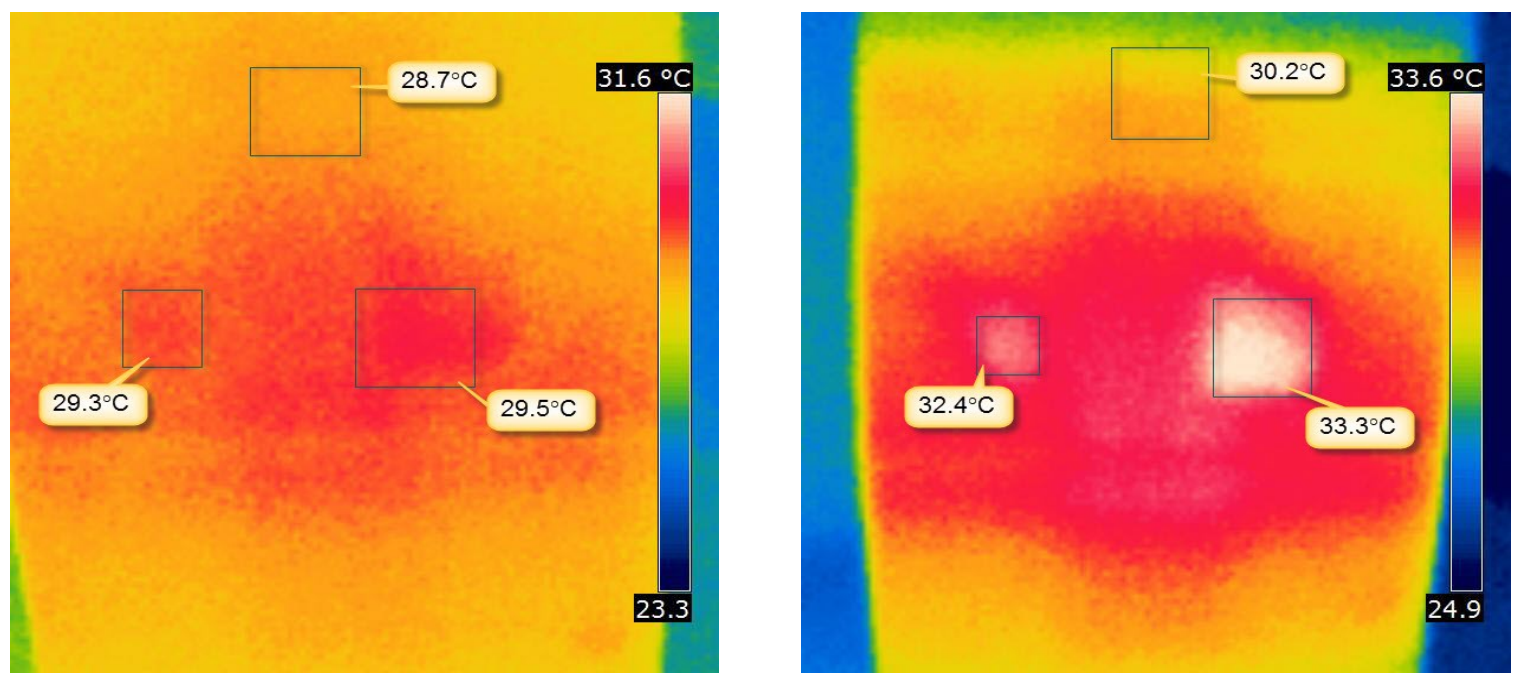

Figure 4-62: Thermal images of Side 1 of AS2 taken from FLIR InfraCAM SD after 50 seconds (left) and 100 seconds of heating (right) from VoyageIR Pro system 
The bridge deck specimen AS3, after heating with VoyageIR Pro system, did not show defects on both sides for 50 seconds duration in the raw images (Appendix A). But, the defects were clearly visible in the raw images for 100 seconds of heating, as shown in Figure 4-63. The 3" x 3" sized debond in flange-to-flange junction on Side 1 and the samesized debond between wearing surface and deck surface on Side 2 were clearly indicated in the raw images of the specimen.
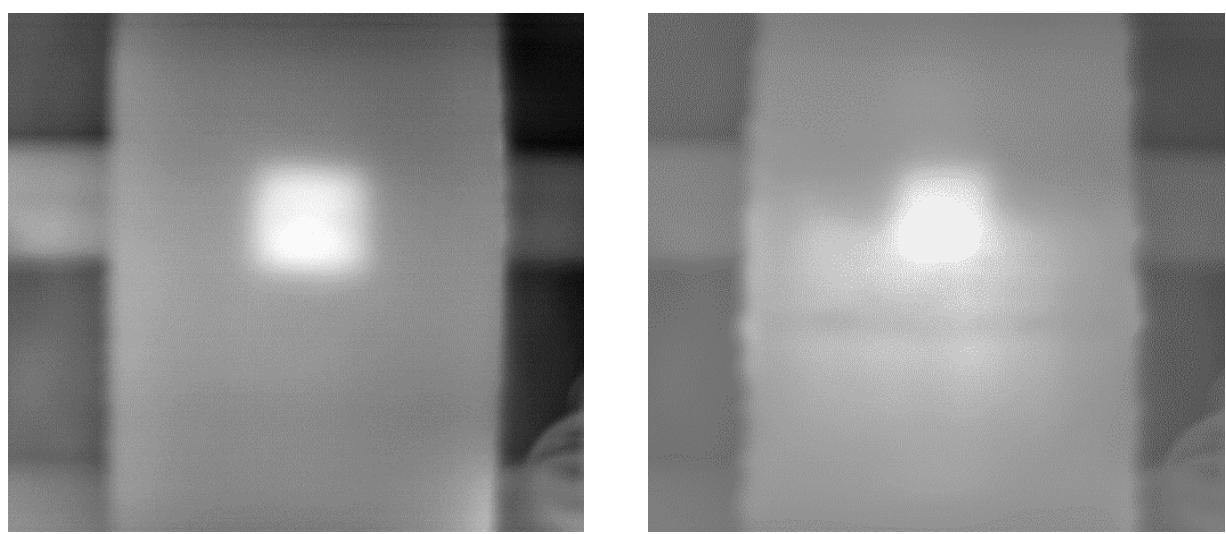

Figure 4-63: Raw thermal images of Side 1 (left) and Side 2 (right) of the deck specimen AS3 after 100 seconds of heating

Though the raw images of AS3 after 50 seconds of heating did not give good results, the processed $1^{\text {st }}$ derivative images for 50 seconds were very clear showing the 3 " $\mathrm{x} 3$ " sized debonds on both sides of the specimen AS3 (Figure 4-64). The profile-plots along line I-I on Side 1 and line J-J on Side 2 of AS3 are shown in Figure 4-65. The rise in the $1^{\text {st }}$ derivative intensity in both profiles indicate the debonds. Similar $1^{\text {st }}$ derivative images along with profile-plots were obtained for other heating durations (100s), which are shown in Appendix A.
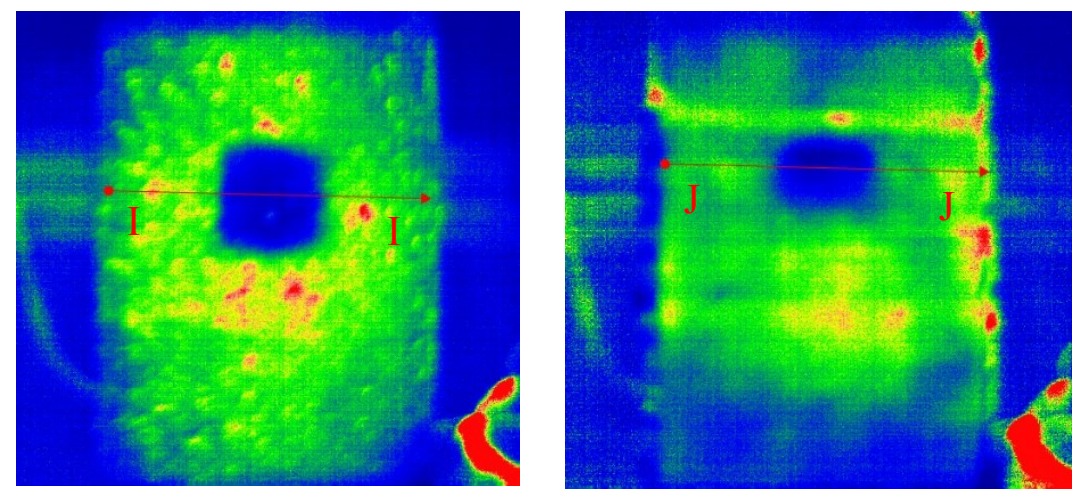

Figure 4-64: $1^{\text {st }}$ derivative images of Side 1 (left) and Side 2 (right) of the deck specimen AS3 after 50 seconds of heating 

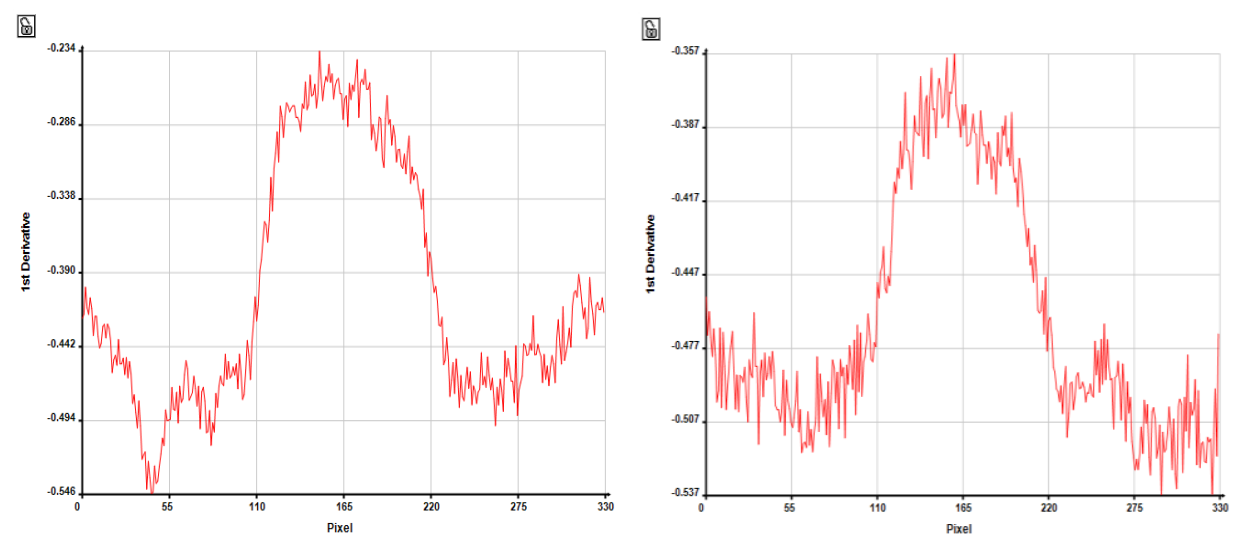

Figure 4-65: Plot of $1^{\text {st }}$ derivative intensity along the line I-I (left) and along the line J-J (right)

Figure 4-66 shows the thermal images of AS3 captured by FLIR InfraCAM SD after 50 seconds of heating from VoyageIR Pro system. The debonds on both sides are clearly visible on the images with the temperature of debonds greater than the surrounding temperature by around $1.5^{\circ} \mathrm{C}$ to $2^{\circ} \mathrm{C}$. Similar results were obtained for other heating intervals (Appendix A).
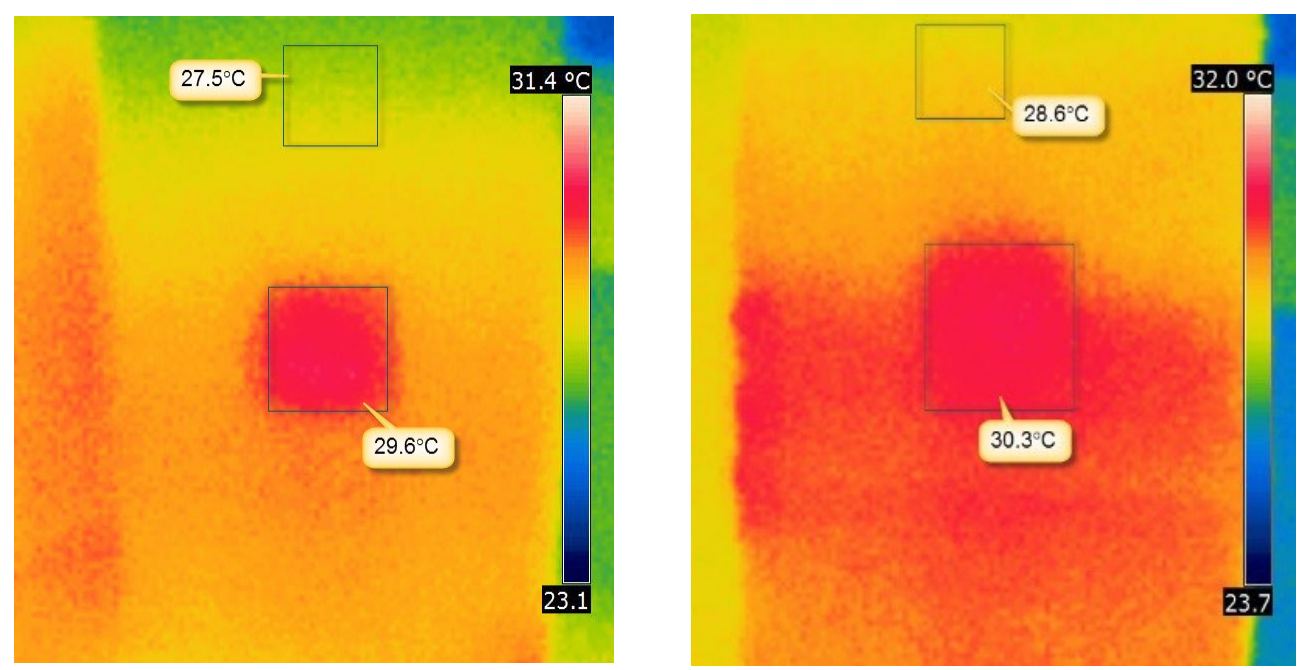

Figure 4-66: Thermal images of Side 1 (left) and Side 2 (right) of AS3 taken from FLIR InfraCAM SD after 50 seconds of heating from VoyageIR Pro system

The infrared testing done using FLIR InfraCAM SD for halogen lamp heater as heating source gave good results for 50 seconds of heating (Figure 4-67). The images showed clear indication of the debonds with temperature difference of around $2^{\circ} \mathrm{C}$. Heating durations of 100 s and 200s also provided distinct thermal images of the specimen AS3. 

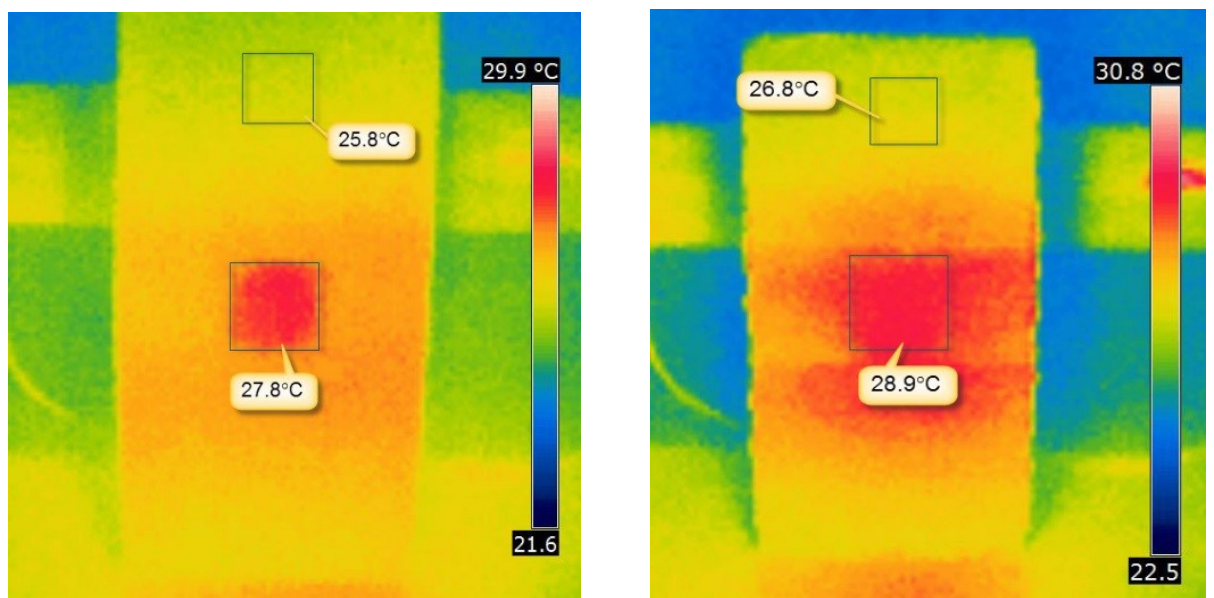

Figure 4-67: Thermal images of Side 1 (left) and Side 2 (right) of AS3 taken from FLIR InfraCAM SD after 50 seconds of heating from halogen lamp heater

\section{Defect-free Cylinder}

After testing all the bridge deck specimens, the GFRP wrapped cylinder specimens (with 3 layers of wrap) were tested. Among the cylinder specimens, the defect-free cylinder on advanced infrared testing gave raw thermal images for 50 seconds of heating, as shown in Figure 4-68. The Sides 1 and 2 had no underlying defects; however, both sides indicated hot regions in the images. This is because of the wrapping method. The outer layers of FRP wrap end at the region where the hot area begins in both Side 1 and Side 2. The processed $2^{\text {nd }}$ derivative image did not show the hot region on both sides (Figure 4-69). Since the specimen was defect-free, there was no sign of any other defect in the processed images as well.
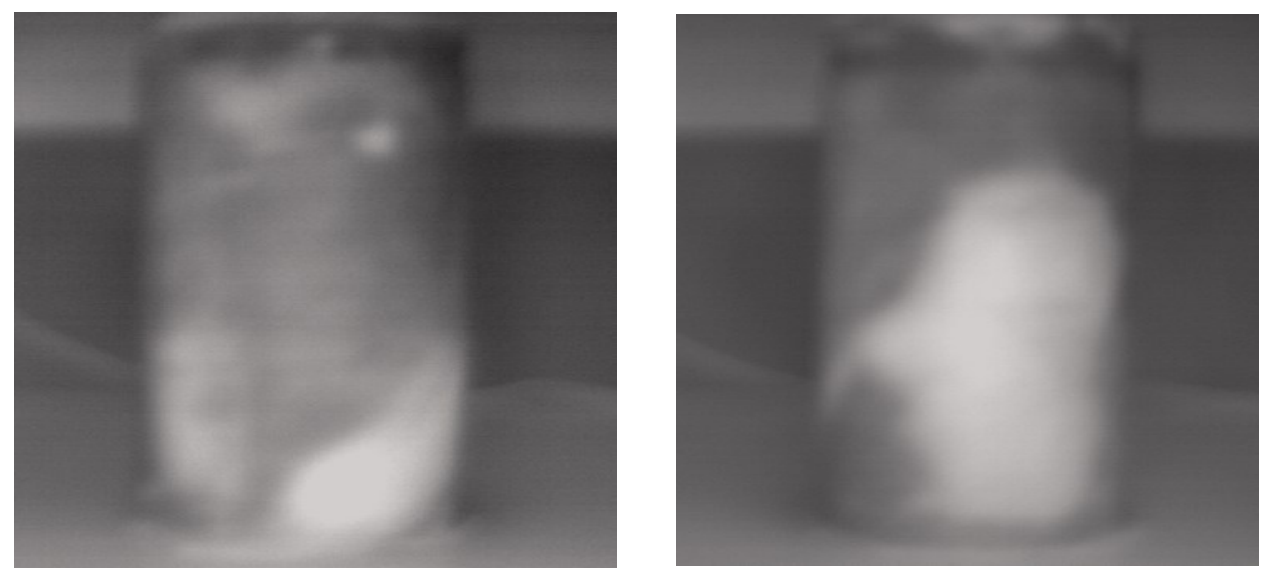

Figure 4-68: Raw thermal images of Side 1 (left) and Side 2 (right) of the defect-free cylinder specimen after 50 seconds of heating 

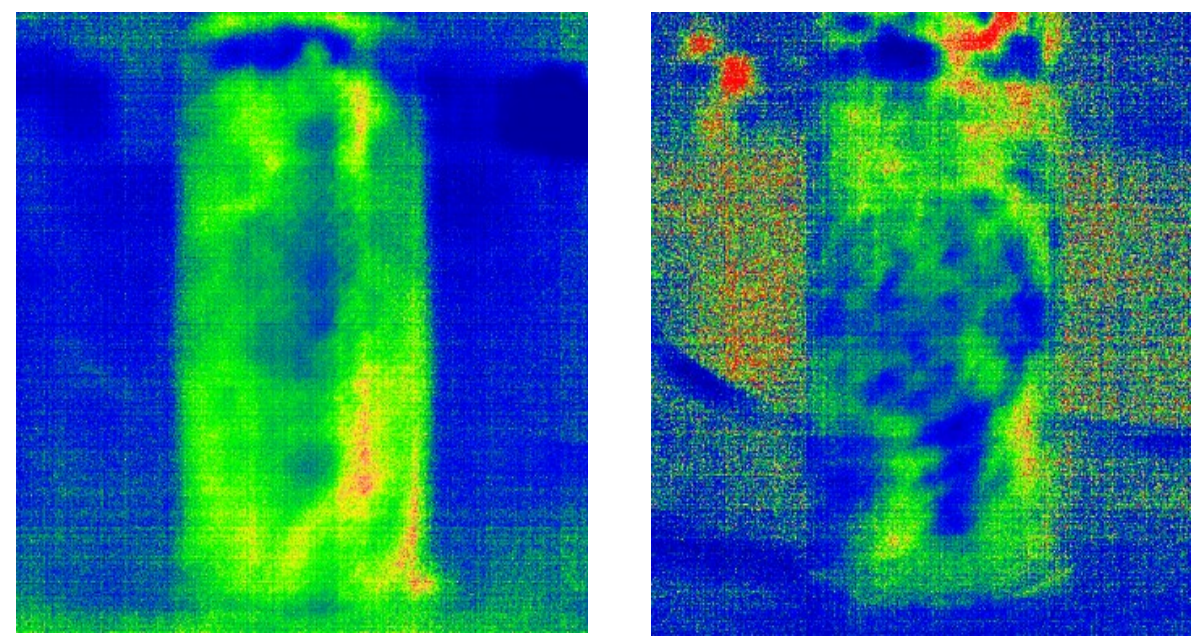

Figure 4-69: $2^{\text {nd }}$ derivative images of Side 1 (left) and Side 2 (right) of the defect-free cylinder specimen after 50 seconds of heating

Figure 4-70 shows the thermal images taken from FLIR InfraCAM SD after heating the defect-free cylinder for 50 seconds. Similar to the VoyageIR Pro raw images, the hot regions could be seen in the still images from conventional infrared testing too. The temperature of these hot areas were around $2^{\circ} \mathrm{C}$ to $3.5^{\circ} \mathrm{C}$ greater than surrounding area.
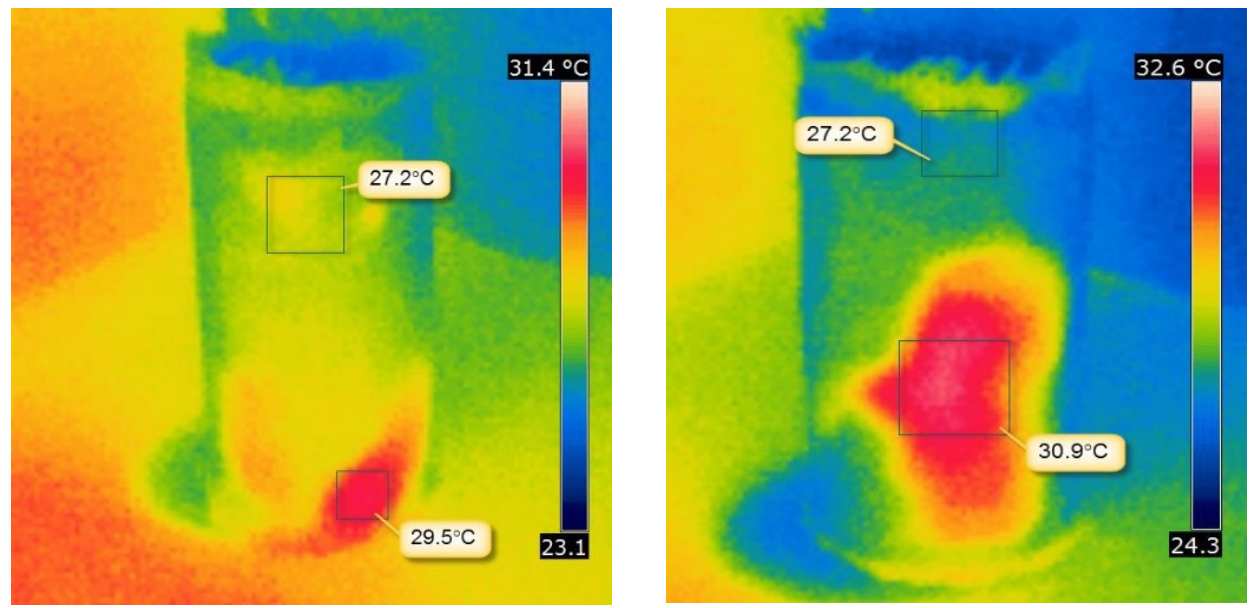

Figure 4-70: Thermal images of Side 1 (left) and Side 2 (right) of defect-free cylinder taken from FLIR InfraCAM SD after 50 seconds of heating from VoyageIR Pro system

The FLIR InfraCAM SD images of the defect-free cylinder after 50 seconds of heating from halogen lamp heater are shown in Figure 4-71. The results for halogen lamp heater were similar to the VoyageIR Pro system. The thermal images showed the hot regions, like in the previous case. The temperature difference between the hot area and surrounding was in the range of $1^{\circ} \mathrm{C}$ to $4^{\circ} \mathrm{C}$. 

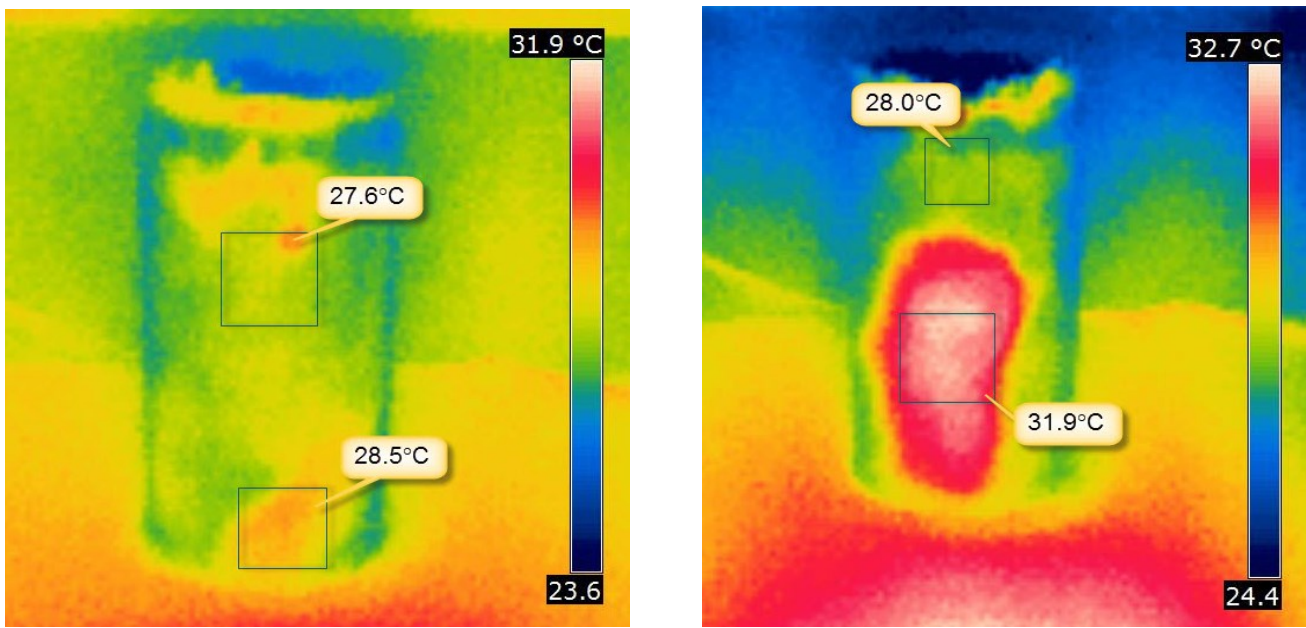

Figure 4-71: Thermal images of Side 1 (left) and Side 2 (right) of defect-free cylinder taken from FLIR InfraCAM SD after 50 seconds of heating from halogen lamp heater

\section{$\underline{\text { Air-filled Cylinder }}$}

The concrete cylinder specimen with a 2" x 2" sized air-filled debond on Side 1 gave infrared results, as shown in Figure 4-72. The heating duration was 50 seconds and the air-filled debond within the single layer of GFRP wrap was clearly visible in the raw image taken from the VoyageIR Pro system. The debond was also distinct in the processed images. Figure 4-73 shows the $1^{\text {st }}$ derivative image and $2^{\text {nd }}$ derivative image of Side 1 of the cylinder with the debond, after 50 seconds of heating.

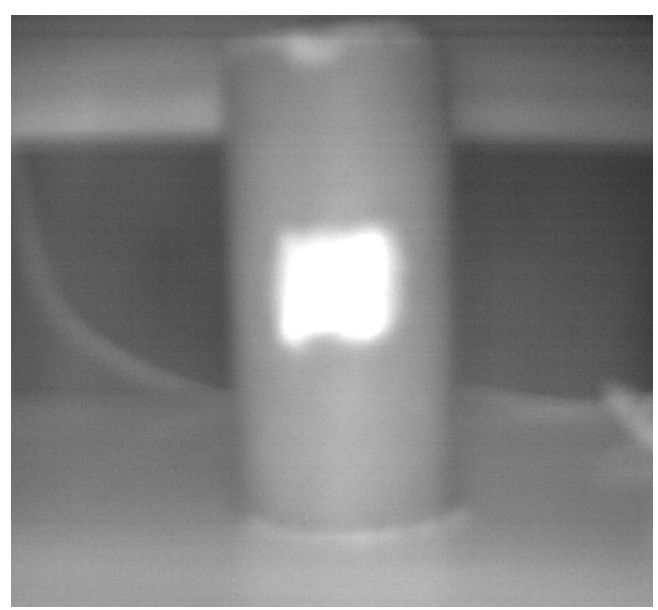

Figure 4-72: Raw thermal image of Side 1 of the GFRP-wrapped concrete cylinder specimen with 2 " $x$ 2" sized air-filled debond after 50 seconds of heating 

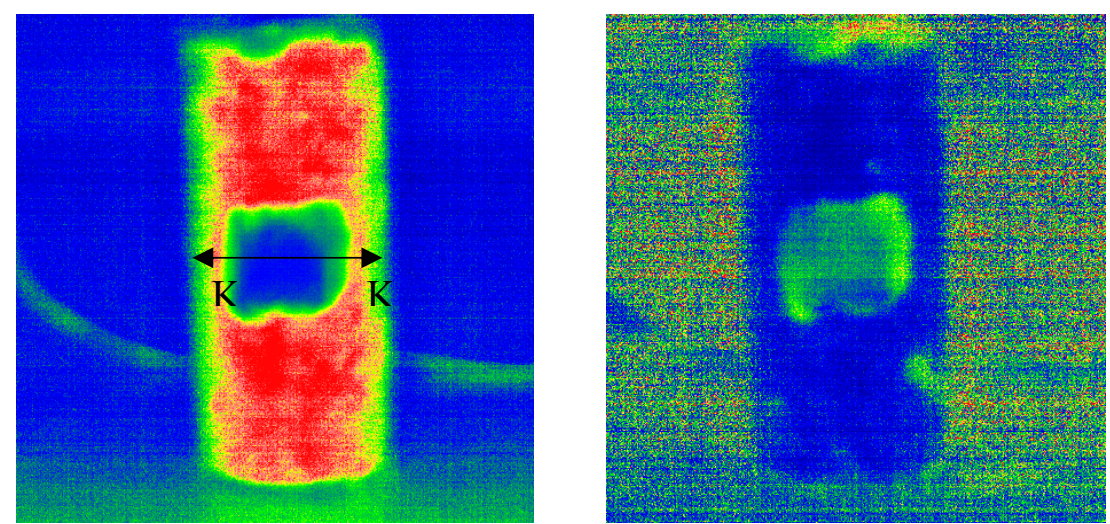

Figure 4-73: $1^{\text {st }}$ derivative (left) and $2^{\text {nd }}$ derivative (right) images of Side 1 of the GFRP-wrapped concrete cylinder specimen with 2 " $x 2$ " sized air-filled debond after 50 seconds of heating

The plot of the profile along the line K-K on $1^{\text {st }}$ derivative image of Side 1 of the specimen is shown in Figure 4-74. The $1^{\text {st }}$ derivative intensity rises where the debond is located on the cylinder and the peak on the graph explains the presence of debond within the GFRP wrap.

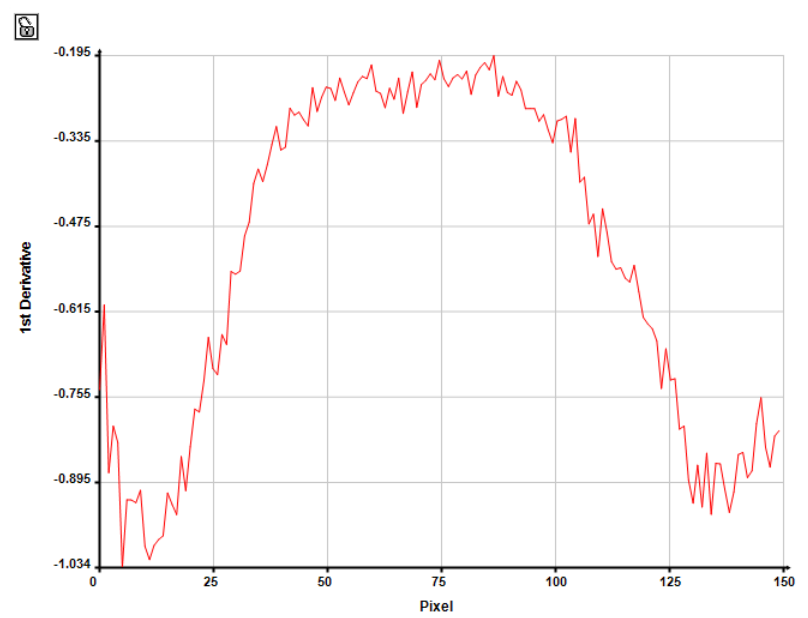

Figure 4-74: Plot of $1^{\text {st }}$ derivative intensity along the line K-K

Figure 4-75 shows the FLIR InfraCAM SD image of Side 1 of the concrete cylinder specimen with the air-filled debond after heating for 50 seconds using the VoyageIR Pro system. The temperature of the debond was $29.8^{\circ} \mathrm{C}$, compared to the surrounding temperature of $27.1^{\circ} \mathrm{C}$. 


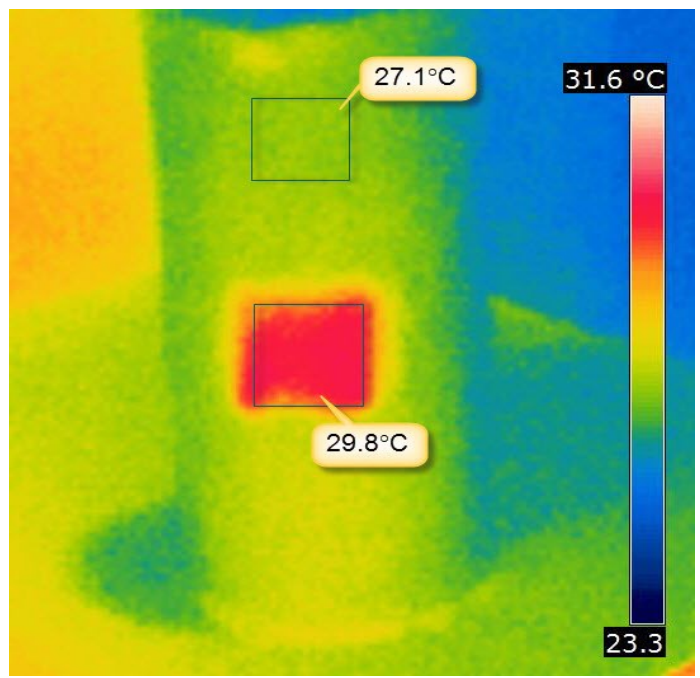

Figure 4-75: Thermal image of Side 1 of the cylinder with air-filled debond taken from FLIR InfraCAM SD after 50 seconds of heating from VoyageIR Pro

The result from infrared testing of Sldem 1 of the concrete cylinder specimen using the halogen lamp heater is shown in Figure 4-76. The thermal image taken from FLIR InfraCAM SD after 50 seconds of heating displayed the 2" x 2" sized air-filled debond with a temperature difference of about $3^{\circ} \mathrm{C}$.

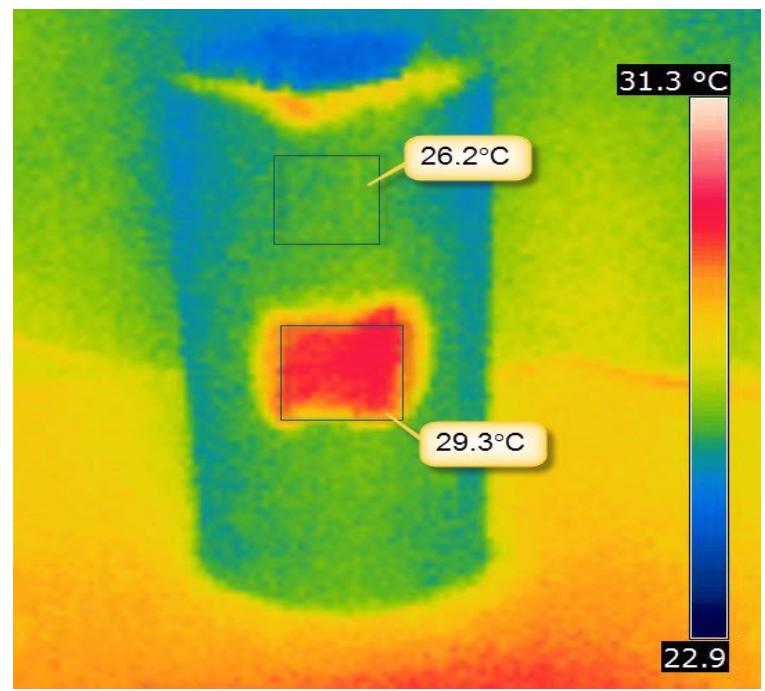

Figure 4-76: Thermal image of Side 1 of the cylinder with air-filled debond taken from FLIR InfraCAM SD after 50 seconds of heating from halogen lamp heater 


\section{Water-filled Cylinder}

The 1" $\mathrm{x}$ 1" sized water-filled debonds on the two sides of the concrete cylinder were detected in the raw thermal image after 50 seconds of heating from VoyageIR Pro system, as shown in Figure 4-77. The processed $1^{\text {st }}$ derivative images of the specimen also gave satisfactory results in detection of the water-filled debonds (Figure 4-78).
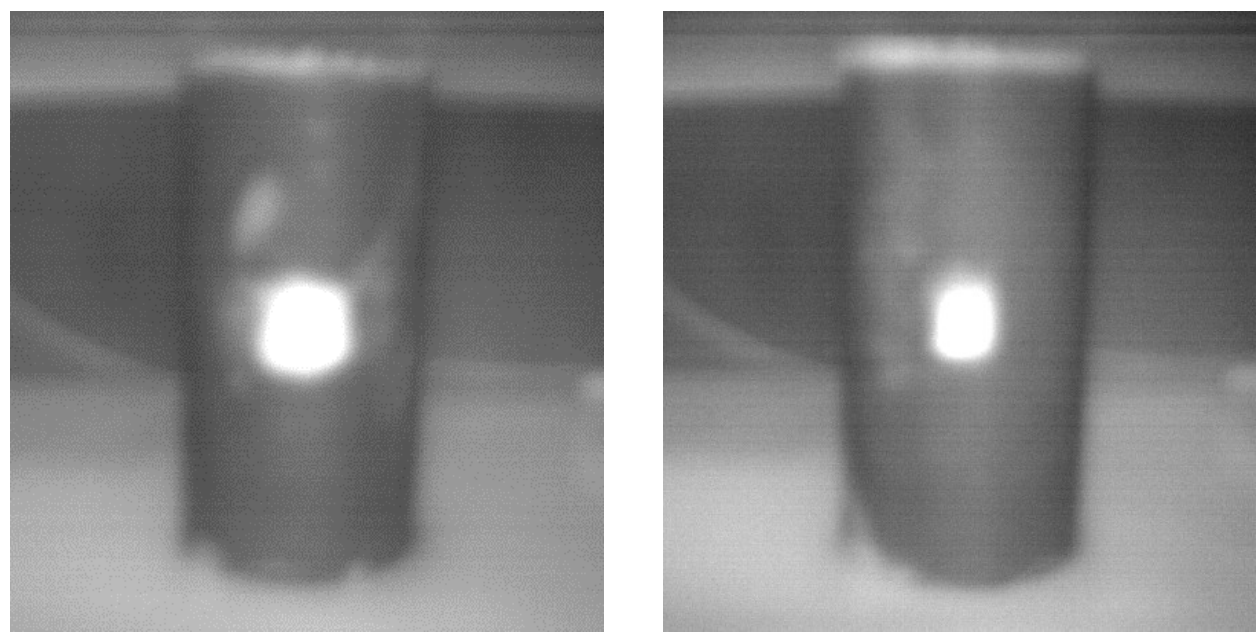

Figure 4-77: Raw thermal images of Side 1 (left) and Side 2 (right) of the cylinder specimen with water-filled debonds after 50 seconds of heating
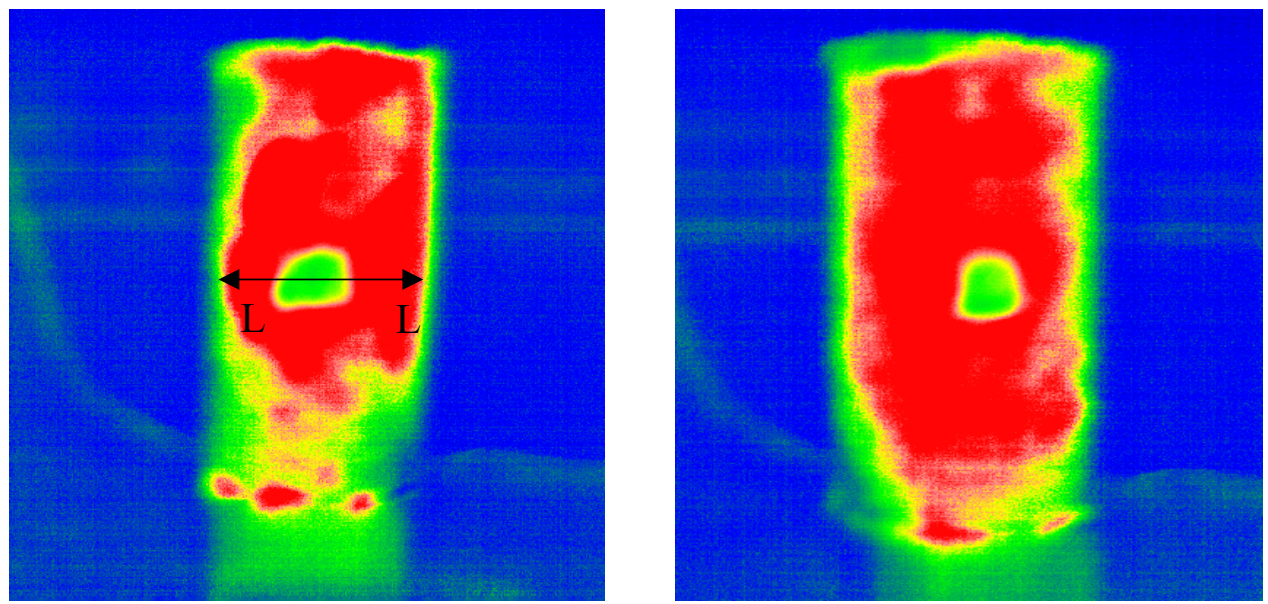

Figure 4-78: $1^{\text {st }}$ derivative images of Side 1 (left) and Side 2 (right) of the cylinder specimen with water-filled debonds after 50 seconds of heating

The line L-L on $1^{\text {st }}$ derivative image of Side 1 of the cylinder specimen is a profile crossing the water-filled debond and the plot of this profile is shown in Figure 4-79. The peak in the $1^{\text {st }}$ derivative intensity in the plot represents the debond between the GFRP wrap and the underlying concrete surface. 


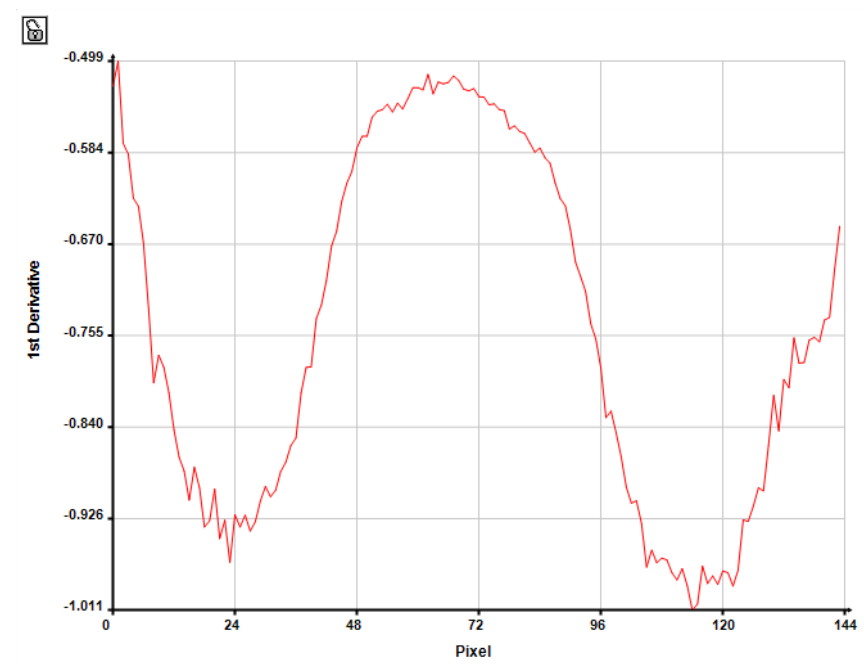

Figure 4-79: Plot of $1^{\text {st }}$ derivative intensity along the line $\mathrm{L}-\mathrm{L}$

Figure 4-80 shows the FLIR InfraCAM SD images of Sides 1 and 2 of the concrete cylinder specimen with water-filled debonds after 50 seconds of heating from VoyageIR Pro system. The temperature of debonds were around $3^{\circ} \mathrm{C}$ greater than the surrounding temperature. The specimen was then heated with halogen lamp heater. The conventional infrared images of the two sides of the cylinder specimen with water-filled debonds after 50 seconds of heating are shown in Figure 4-81. The temperature difference between the debonds and the surrounding area was in the range of $5^{\circ} \mathrm{C}$ to $7^{\circ} \mathrm{C}$.
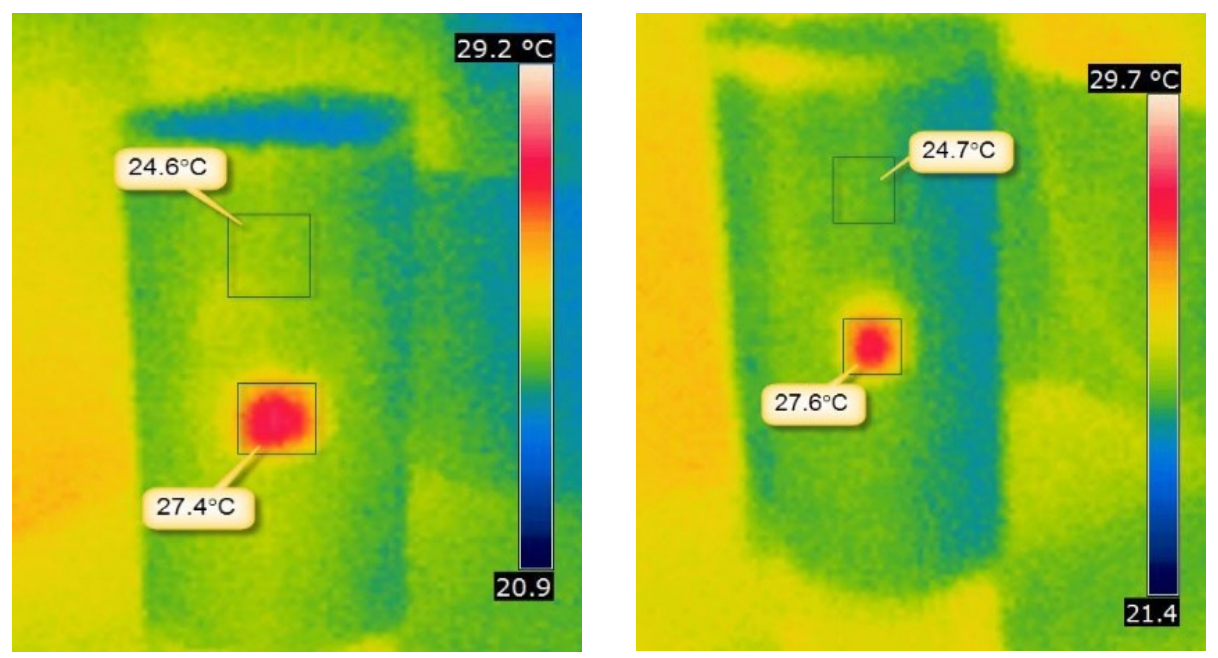

Figure 4-80: Thermal images of Side 1 (left) and Side 2 (right) of the cylinder with water-filled debonds taken from FLIR InfraCAM SD after 50 seconds of heating from VoyageIR Pro system 

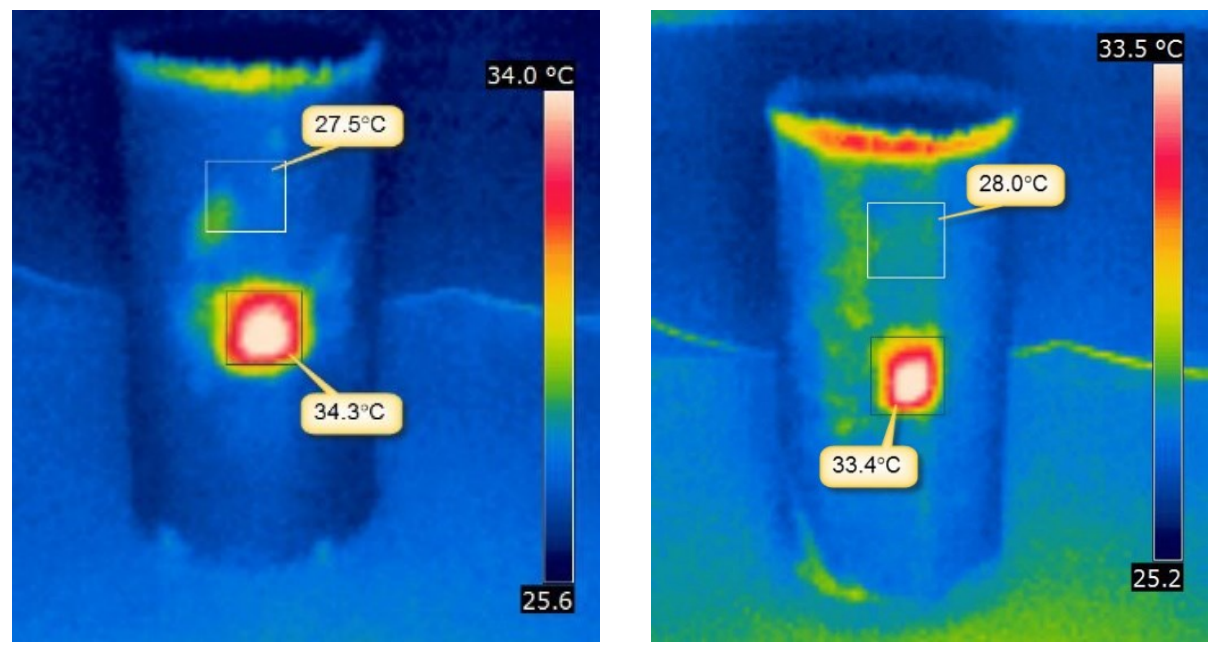

Figure 4-81: Thermal images of Side 1 (left) and Side 2 (right) of the cylinder with water-filled debonds taken from FLIR InfraCAM SD after 50 seconds of heating from halogen lamp heater

\section{$\underline{\text { Square Tube }}$}

The failed Side 1 of the GFRP composite square tube specimen, on heating for 50 seconds using VoyageIR Pro system, produced raw image as shown in Figure 4-82. The delamination on Side 1 could be seen as the hot spot region. The processed $1^{\text {st }}$ derivative image also showed the delaminated area on Side 1 with the peak in the profile plot along line M-M representing the delamination on Side 1 (Figure 4-83).

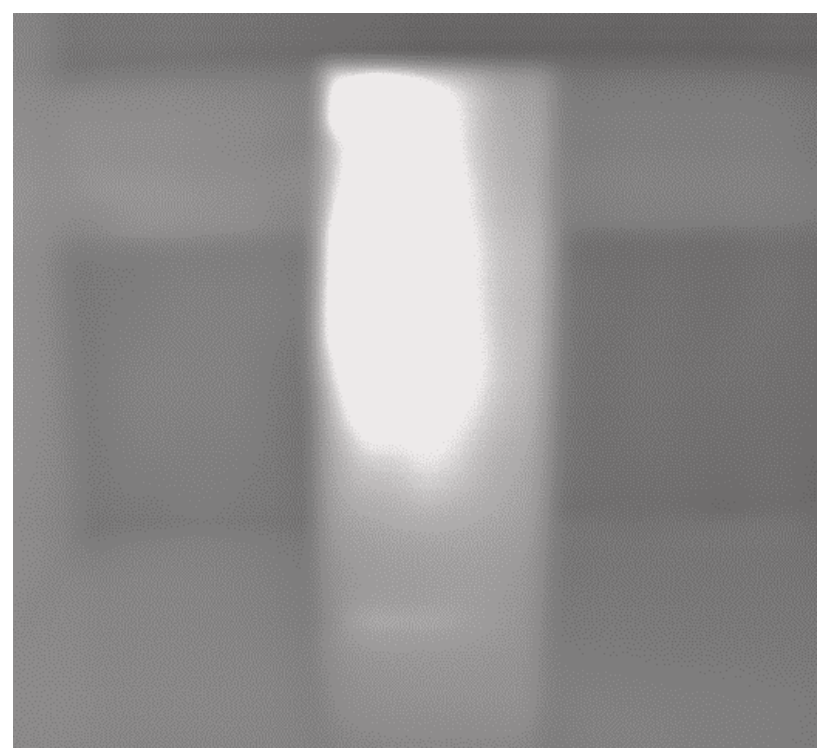

Figure 4-82: Raw thermal image of Side 1 (left) of the GFRP composite square tube specimen after 50 seconds of heating 

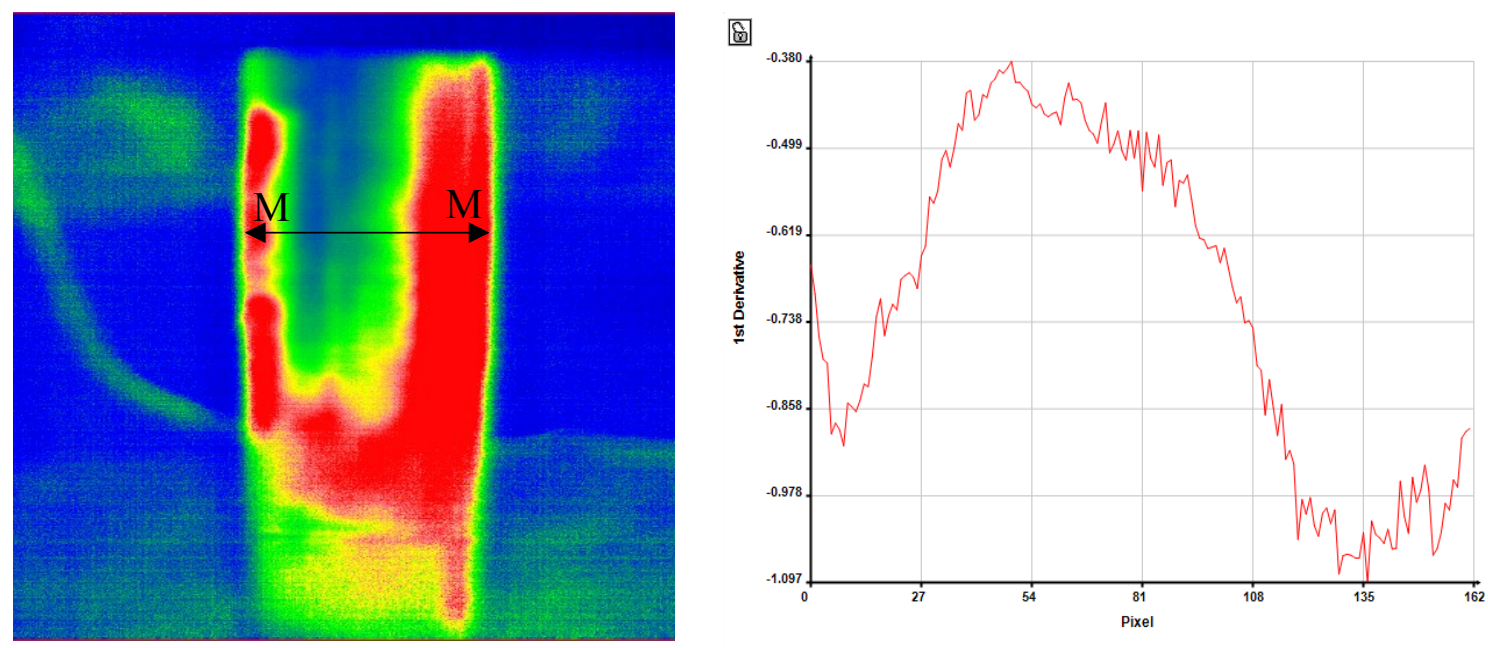

Figure 4-83: $1^{\text {st }}$ derivative thermal image of Side 1 of the GFRP composite square tube specimen after 50 seconds of heating (left) and plot of $1^{\text {st }}$ derivative intensity along the line M-M (right)

Figure 4-84 shows the FLIR InfraCAM SD image of Side 1 of the specimen after 50 seconds of heating from VoyageIR Pro system. The delamination on Side 1 could be seen as hot region in the thermal image with a temperature difference of around $6^{\circ} \mathrm{C}$ compared to the surrounding area. The GFRP square tube specimen, after heating for 50 seconds using the halogen lamp heater, gave similar results with delamination on Side 1 (Figure 4-82). The temperature of the delaminated area was $34.6^{\circ} \mathrm{C}$ while the surrounding temperature was $30.6^{\circ} \mathrm{C}$.
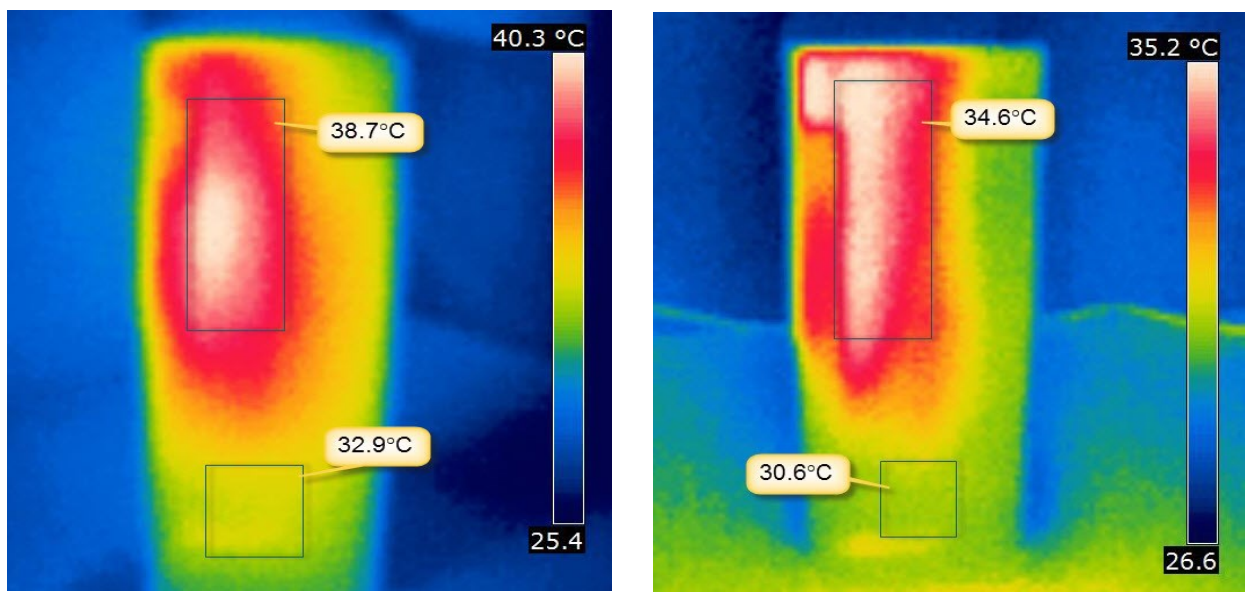

Figure 4-84: Thermal image of Side 1 of the GFRP composite square tube taken from FLIR InfraCAM SD after 50 seconds of heating from VoyageIR Pro (left) and halogen lamp heater (right) 


\section{Digital Tap Testing Results}

The Digital Tap Testing on the FRP composite bridge deck specimens was limited to the ones with no wearing surface. The pointy surface of the wearing course could damage the hammer head and thus, digital tap testing could not be done on such surfaces. The concrete cylinders with GFRP wraps were also tested, along with the square tube specimen.

The deck specimen JD1, with no wearing surface on either side, was tapped using the digital tap hammer. Side 1 gave tap testing number in the range of 1097 - 1113 (microseconds) for good areas and in between 1120 - 1148 for the 3" x 3" sized defect. The tap testing numbers for the defect was not significantly higher than the good areas, therefore digital tap testing did not produce satisfactory results for the bridge deck specimen. Similarly, the results for Side 2 showed the tap testing number for defective areas as $1093-1111$ against the good area which had number in the range of $1084-1101$. The specimen WJD2 had Side 1 with no wearing course and the digital tap testing could be done on this side. The defect-free area had tap testing number in between $1090-1109$ while over the defect, it was around 1116 - 1135. These numbers also do not suggest good results for digital tap testing on FRP bridge deck specimens. Likewise, Side 2 of the specimen WJD3 also gave similar results with numbers for good areas as $1101-1116$ compared to $1098-1128$ for defects.

The bridge deck specimen AS2 had two defects of sizes 2" x 2" and 1" x 1" on Side 1 and no defect on Side 2. The specimen AS2 had no wearing surface on either side. The defect-free number for AS2 was in between 1093 - 1110 while for the defects on Side 1, it was in the range of $1094-1125$. This also showed that the digital tap testing was not effective for FRP composite bridge deck specimens of considerable thickness (around 0.3" from outer surface to the defect, which is half of the thickness of flange junction). For bridge deck specimen AS3, the uncovered Side 2 had a 3" x 3" sized debond which gave tap testing numbers as 1109 - 1130. The tap testing number for good areas on Side 2 of AS3 was in the range of 1083 - 1114, which shows the numbers for debonds are not $10 \%$ greater than good areas. Thus, AS3 is another specimen that provides unsatisfactory results for digital tap testing. 
Digital Tap Testing, on the other hand, proved very effective when the GFRP wrapped concrete cylinders were tested. The air-filled and water-filled debonds gave numbers significantly higher than the surrounding good areas. Since the wraps were pretty thin (1 layer and 3 layers), the digital tap testing gave satisfactory results for these specimens. The defect-free areas on cylinder with air-filled defect had tap testing numbers in the range of $1075-1151$ while the air-filled defect had $1801-2104$. These numbers show that the defects within the wraps can be easily detected using digital tap hammer. Similarly, the water filled defects gave numbers in between $1380-1475$, which when compared to 1108 - 1130 for good areas could clearly be distinguished as defects. The composite square tube specimen gave numbers in between $2848-3178$ for the delaminated area while the good area had numbers in the range of $1108-1128$.

Table 4-1 gives a summary on the results of digital tap testing on bridge deck specimens, FRP wrapped cylinders and the square tube specimen.

Table 4-1: Digital Tap Testing Results for Laboratory Experiment

\begin{tabular}{|c|c|c|}
\hline \multirow{2}{*}{ Specimen } & \multicolumn{2}{|c|}{ Digital Tap Testing Numbers (microseconds) } \\
\cline { 2 - 3 } & Good (Defect-free) Area & Defective (Debond) Area \\
\hline JD1 - Side 1 & $1097-1113$ & $1120-1148$ \\
\hline JD1 - Side 2 & $1084-1101$ & $1093-1111$ \\
\hline WJD2 - Side 1 & $1090-1109$ & $1116-1135$ \\
\hline WJD3 - Side 2 & $1101-1116$ & $1098-1128$ \\
\hline AS2 - Side 1 & $1093-1110$ & $1094-1125$ \\
\hline AS3 - Side 2 & $1083-1114$ & $1109-1130$ \\
\hline Air-Filled Cylinder & $1075-1151$ & $1801-2104$ \\
\hline Water-Filled Cylinder & $1108-1130$ & $1380-1475$ \\
\hline Square Tube & $1108-1128$ & $2848-3178$ \\
\hline
\end{tabular}




\subsection{CONCLUSIONS}

The NDT evaluation of the laboratory specimens using infrared thermography and digital tap testing allowed us to detect the simulated debonds and thus, assess the effectiveness of these methods in different types of specimens. The advanced infrared thermography is a fairly new technique for nondestructive testing of civil infrastructure, so this experimental study proved very essential in defining the efficiency of the method. The use of two types of heating source also helped compare the effectiveness between them. The results of digital tap testing showed the extent and limitation of application of the NDT method in FRP composites.

The VoyageIR Pro system was very useful as an infrared thermography equipment in terms that the heating source was in the same unit as the infrared camera and the processing capability was high. In the case when the raw images could not detect the defects, the processed images were able to identify the defects. The results from the laboratory experiments showed that the TSR images were not helpful in evaluation of defects; however, $1^{\text {st }}$ derivative and $2^{\text {nd }}$ derivative images could locate the defects in most

of the cases. There were few exceptions where raw, $1^{\text {st }}$, and $2^{\text {nd }}$ derivative images could not evaluate the specimens with defects. This is mainly due to the specimens being thicker and covered by wearing surface. The advanced infrared thermography was mostly able to produce satisfactory results, even in situations where conventional thermography was unsatisfactory. The VoyageIR Pro system proved to be essential, owing to its excellent heating system and superior processing abilities over FLIR InfraCAM SD system. The conventional thermography required external heat source which is its major drawback when compared to the VoyageIR Pro system. The results also helped decide the optimum heating duration to be 50 seconds, which gave the best output in almost all cases of the specimens tested in this study. In a few cases, longer duration heating (up to 200 seconds) was needed.

The results from laboratory experiments facilitated in determining the effectiveness of heating source from VoyageIR Pro against conventional heaters. The ideal heating time of 50 seconds produced the best results for both VoyageIR Pro and halogen lamp heater. 
The VoyageIR Pro system also permitted recording thermal data while heating. The associated software, then, could be simultaneously used to process the data to obtain reconstructed thermal data. It can be concluded that the heating system of VoyageIR Pro was easy to handle and operate, thus the use of VoyageIR Pro as heating source demonstrated its advantages over conventional heater.

Digital Tap Testing is a quick and convenient method of nondestructive testing but it had its limitations when the thicker bridge deck specimens were involved. The method was unable to detect delaminations at 0.3 " depth within the flange of deck specimens. Another downside of this method was that it could not be used on specimens with wearing surface. But, the digital tap testing method was capable in detecting defects underneath thin layers of FRP fabric wraps. The concrete cylinders wrapped by GFRP composite fabric were successfully evaluated using tap testing method. The delamination in FRP square tube specimen was also detected by digital tap hammer. Therefore, digital tap testing is an effective NDT method in FRP composite wraps used in rehabilitation of structural components; however, it fails in inspection of thicker composite structural members like FRP bridge decks. It should be noted that defects at shallow depth under FRP wraps were also effectively detected by infrared thermography. Thus infrared thermography is a more robust technique, useful for both shallow and deep defects, while digital tap testing only works at shallow depth such as debonds under FRP composite wraps. The major advantage of digital tap testing is that it is very simple to use and is a low cost device. 


\section{FIELD TESTING OF WHITEDAY CREEK BRIDGE}

\subsection{INTRODUCTION}

The concrete bridges in the US are deteriorating every day and the ones built 50 years and before are in urgent need for maintenance and/or rehabilitation. The concrete cover over rebars in beams and columns are spalling due to the moisture from water in the case of bridges. As the concrete cover degrades, the steel rebars and prestressing strands are exposed to water and chlorides which leads to corrosion of steel in the beams and columns. The corrosion of steel reinforcement leads to the loss of strength of the concrete member and thus is clearly not favorable. Fiber Reinforced Polymer (FRP) composite is a well-known reinforcing material that not only strengthens the damaged structural member but also prevents further corrosion in steel by acting as a jacket to the member. In the process of repairing the weak beam or column, a proper bond between FRP fabric laminate and the underlying concrete has to be guaranteed to get maximum desired strength after the repair works. Any debond, formed between the fabric and concrete, needs to be identified and repaired so that the bridge can function properly after the rehabilitation.

This chapter talks about the field testing done on a concrete box-beamed bridge over the Whiteday Creek, West Virginia. The box beams of the Whiteday Bridge, which had significant corrosion damage, were repaired using Carbon Fiber Reinforced Polymer (CFRP) fabric. Digital Tap Testing and Infrared Thermography tests were conducted on

the bonded beams to locate debonds, if any, between the CFRP fabric laminate and the concrete surface. The chapter discusses in detail about the location of the bridge, field test setup, digital tap testing and infrared test results and challenges faced during the field tests.

\subsection{DESCRIPTION OF THE BRIDGE}

The Whiteday Bridge, built in 1964, crosses over the Whiteday Creek and provides for the public-access road to the Opekiska Lock and Dam, which is located 13.3 miles downstream from Fairmont, WV on the Monongahela River (Figure 5-1). 


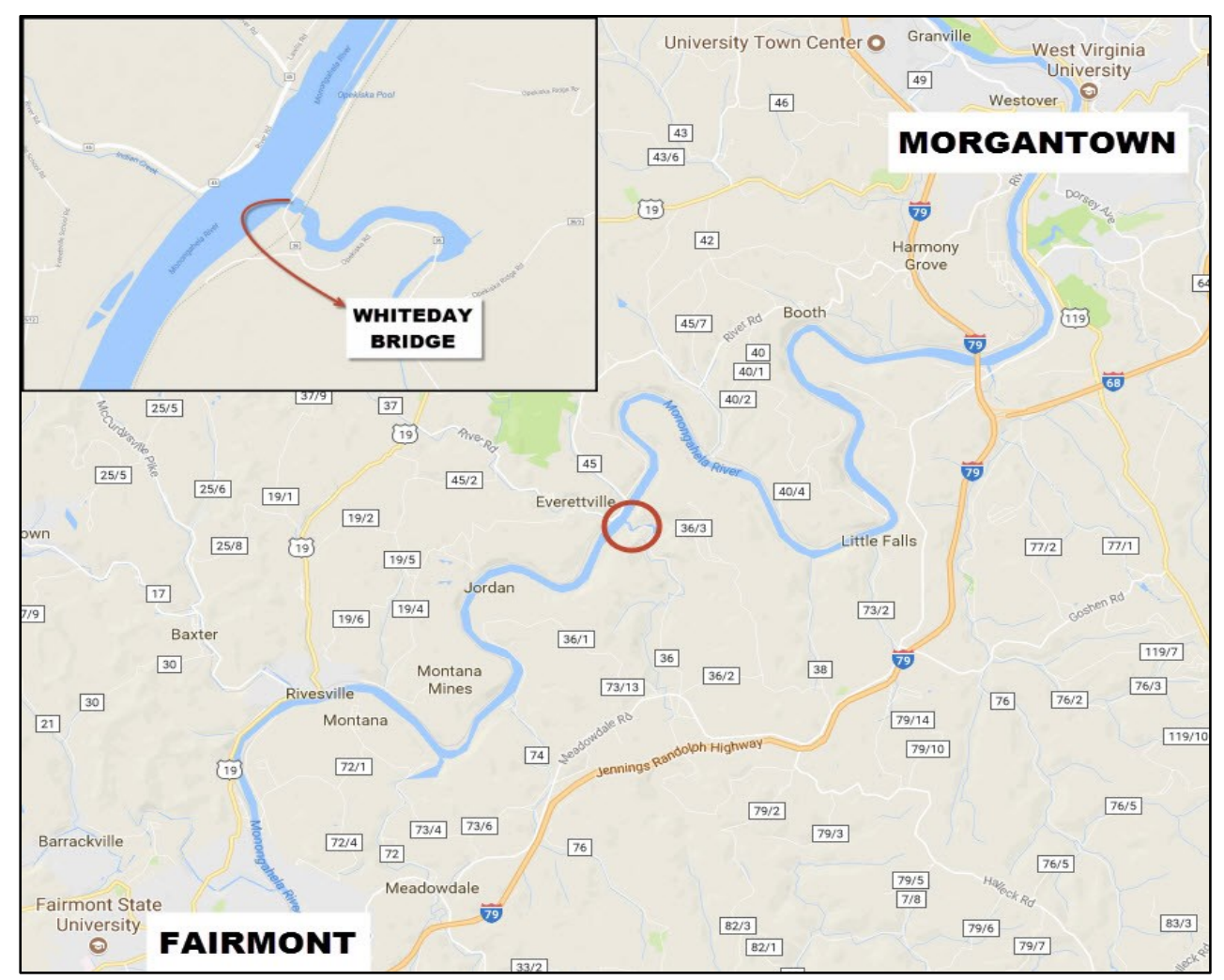

Figure 5-1: Location of Whiteday Bridge, WV

The bridge consists of eight adjacent precast prestressed concrete box beams placed over three spans. The two end-spans are 50'-0" each, between the pier centerlines and the abutment bearing, while the center-span (Main Span) is $100^{\prime}-0$ "' between the two pier centerlines which totals to 200'-0" as the length of the bridge (Figure 5-2).

The main span beams were in severely corroded condition with the prestressing strands exposed at the underside and at other undesirable locations, i.e., at the center line of the span where bending stresses are maximum (Figure 5-3). Since the exposed prestressing strands affected the structural strength of the box beams, they were of great concern and required immediate attention. Also, the bituminous wearing surface had heaving and longitudinal cracks throughout the span, which could be because of excessive deflection (Figure 5-4). The wearing surface was under repair as shown in Figure 5-6. The extreme erosion of concrete piers including spalling of concrete and snapping of rebar could also be seen at the water level (Figure 5-7). To prevent the high cost of replacing the bridge, the affected box beams were repaired with Carbon Fiber Reinforced Polymer (CFRP) composite fabric laminates (Figure 5-5). 


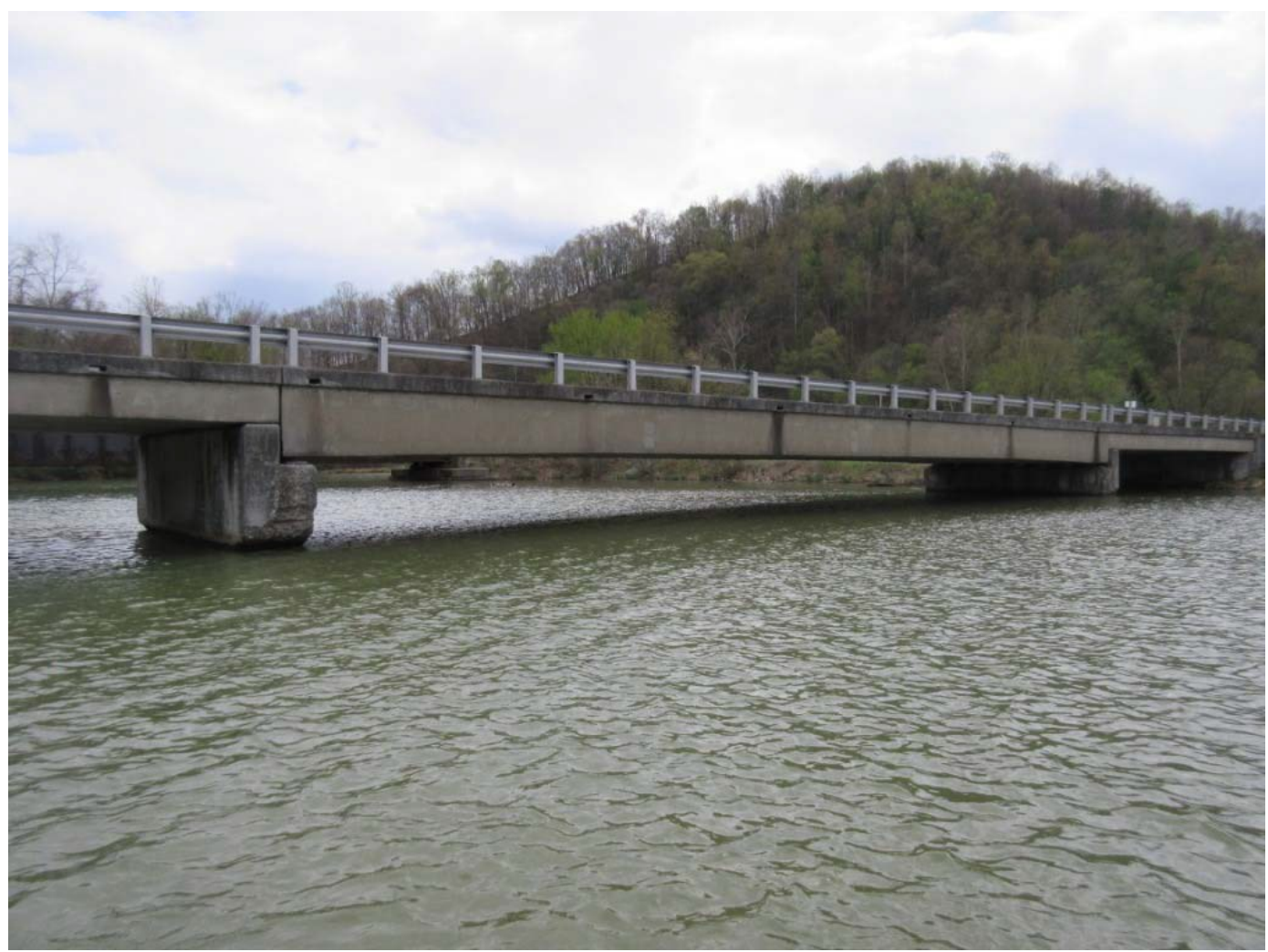

Figure 5-2: West Elevation of the Whiteday Bridge

(Kollias 2015)

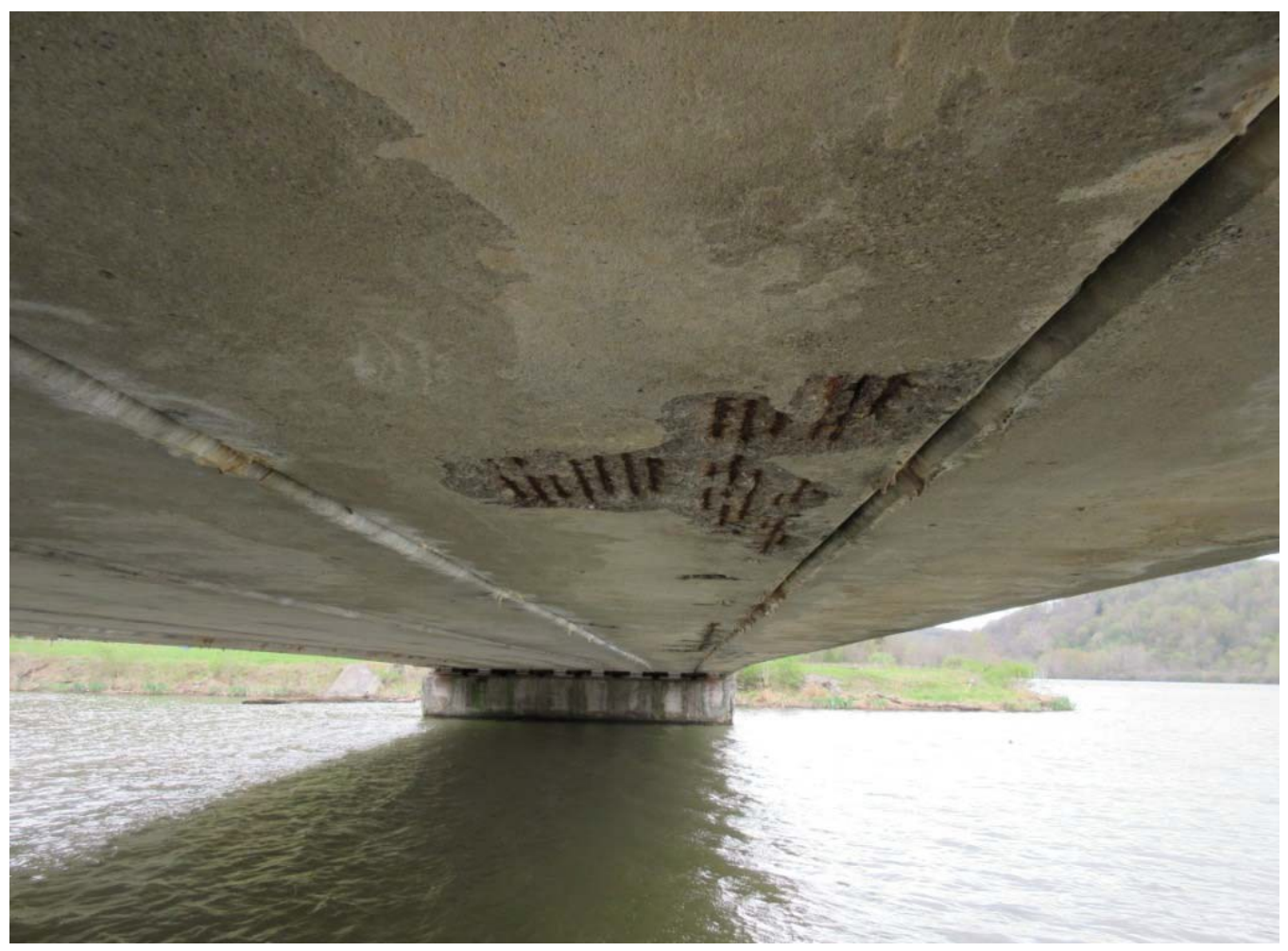

Figure 5-3: Main Span Beam - Exposed Strands

(Kollias 2015) 

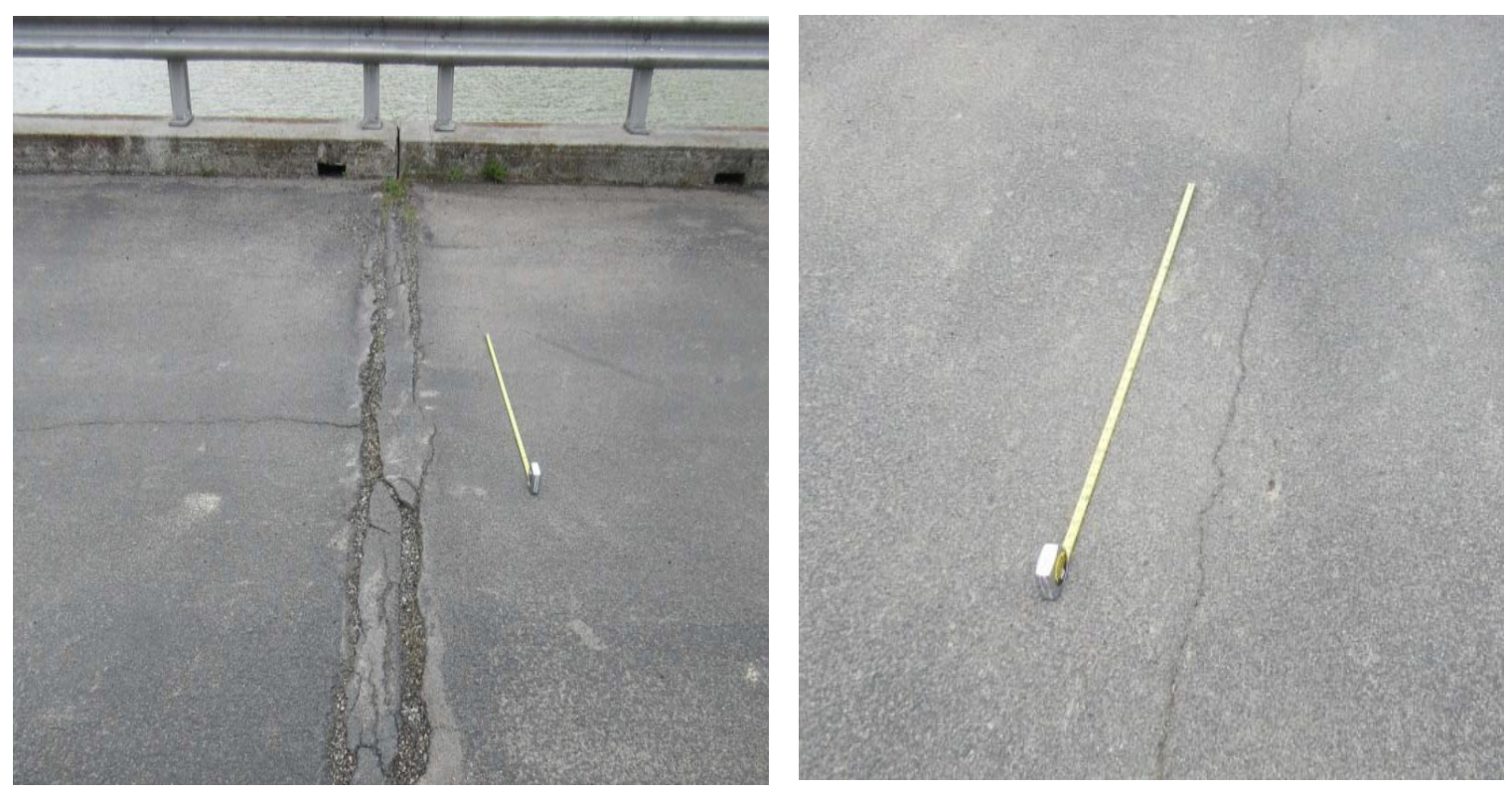

Figure 5-4: Heaving on the wearing surface at Pier 2 deck joint (left) and Longitudinal cracks (right)

(Kollias 2015)

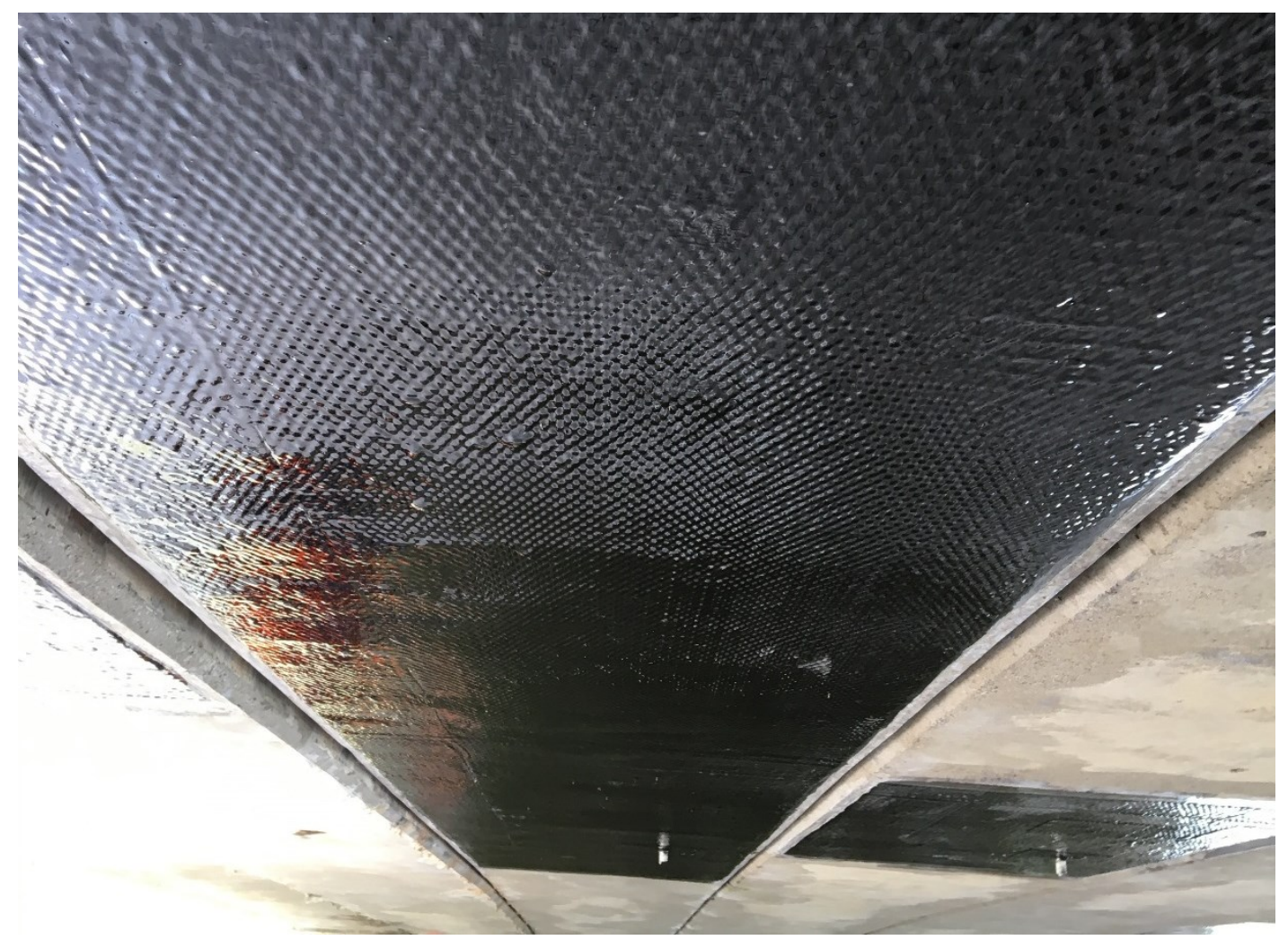

Figure 5-5: Main Span Beam repaired with CFRP fabric 


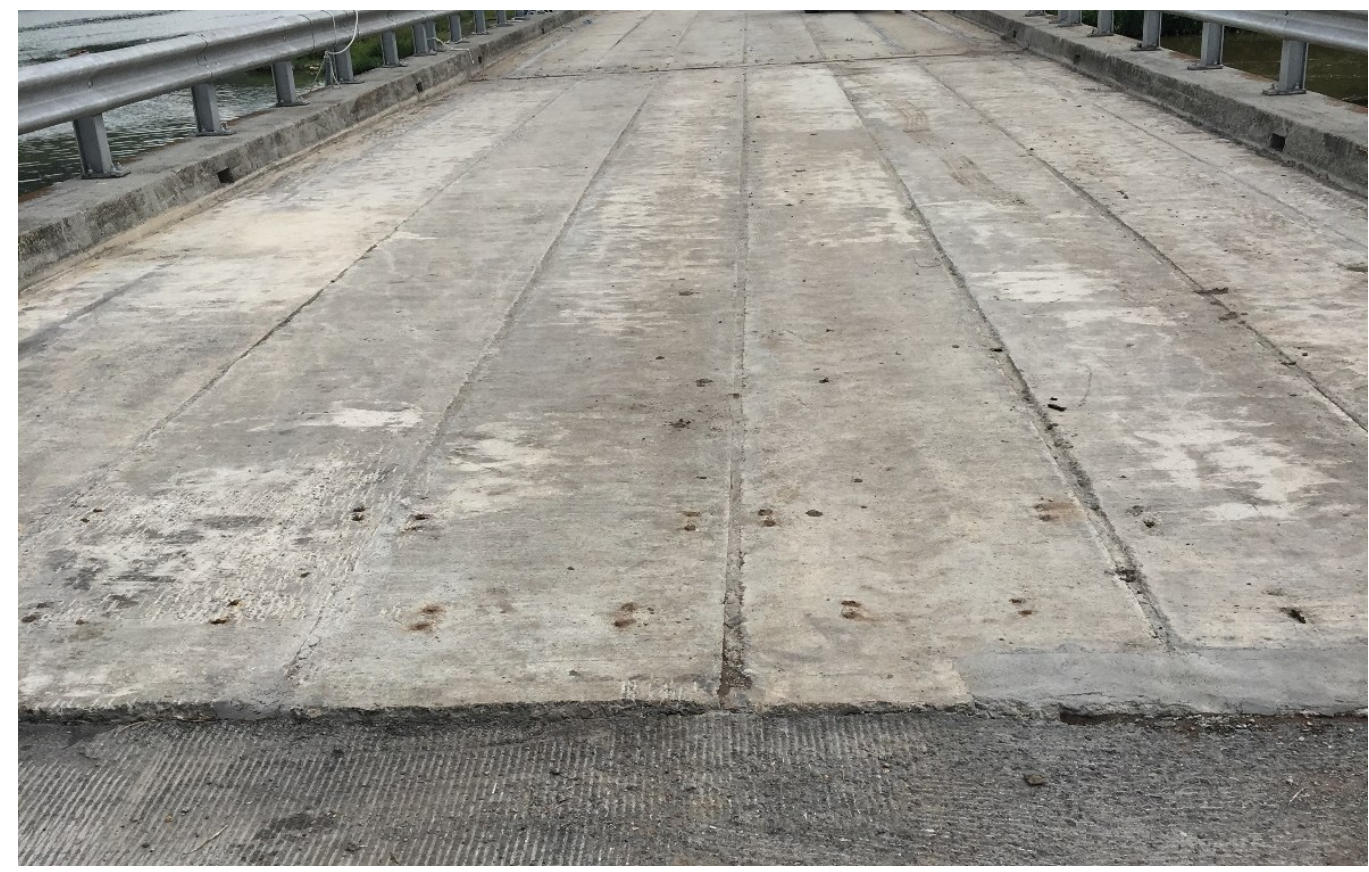

Figure 5-6: Wearing surface of the Whiteday Bridge under repair work

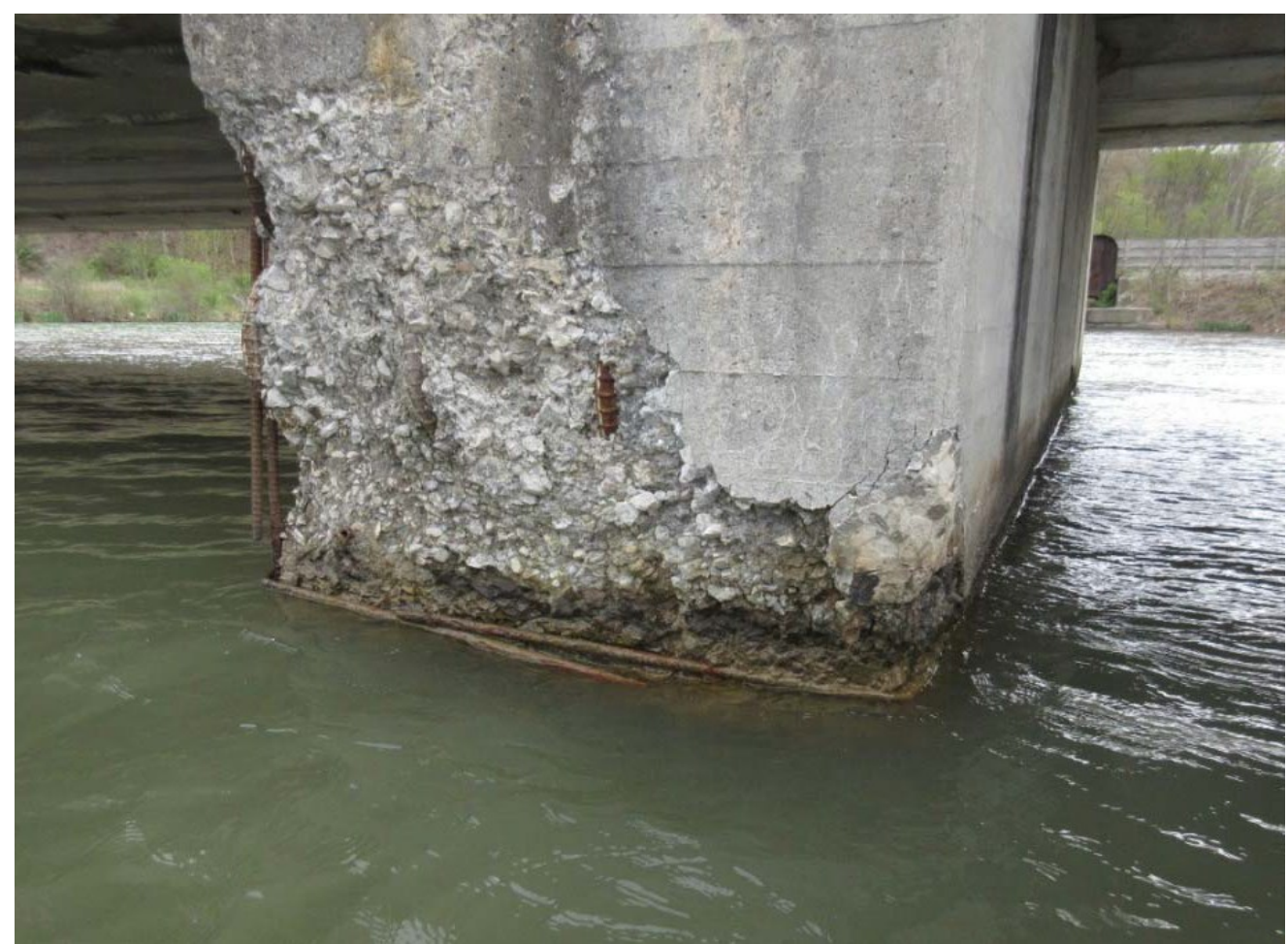

Figure 5-7: Concrete spalling at the surface of contact with water in Pier 1 (Kollias 2015) 


\subsection{FIELD TESTS}

The nondestructive tests conducted on the CFRP bonded box beams of the Whiteday Bridge are discussed in this section. This section explains the setup for the tests and the results from digital tap testing and infrared thermography. The beams were numbered 1 to 8 from east to west and the delaminated areas of the beams were repaired with CFRP fabric laminates (Figure 5-8). Most of the repair was done with 2 layers of CFRP fabric. Beams 7 and 8 had 3 layers of CFRP fabric in most areas (Figure 5-9). However, it was of utmost importance to ascertain that there was proper bond between the fabric and the underlying concrete. For testing the bond integrity, the nondestructive tests were carried out.

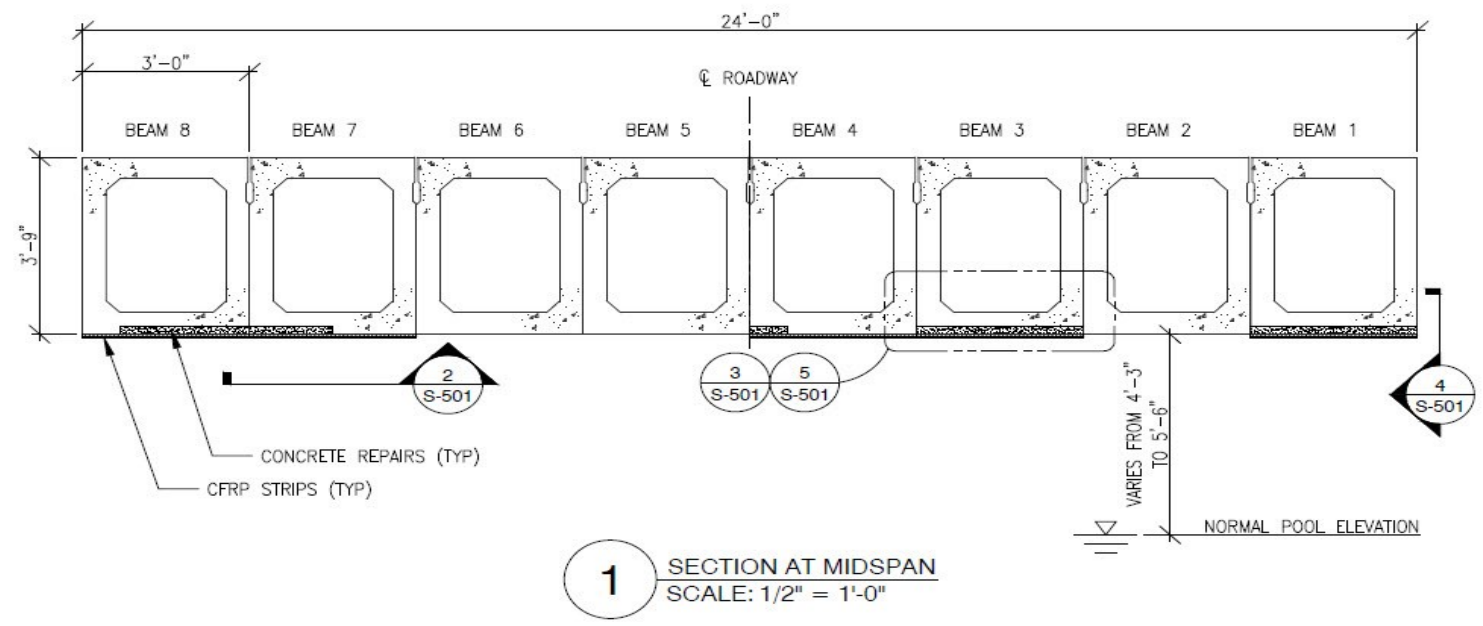

Figure 5-8: Cross-section at mid-span of the Whiteday Bridge (courtesy of USACE - Philadelphia District)

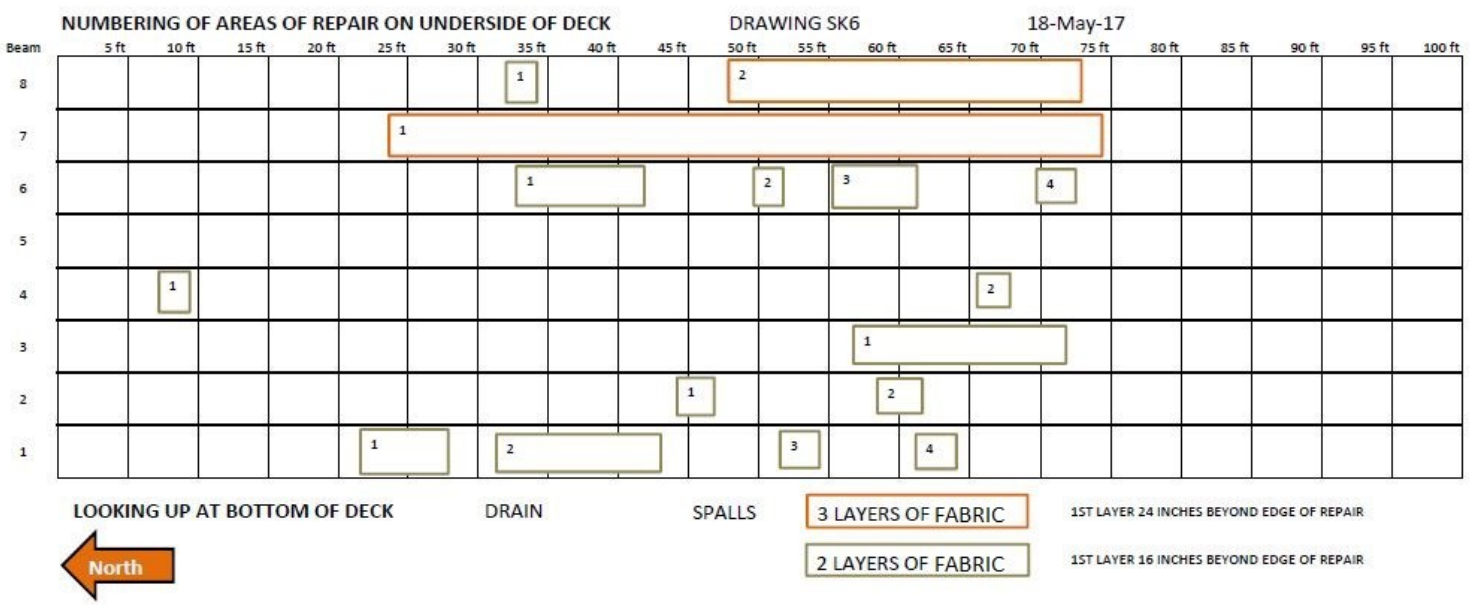

Figure 5-9: Plan of the Main Span of the Whiteday Bridge with numbering of the beams and positioning of the CFRP fabric laminates (courtesy of USACE Contractor) 


\subsection{TEST SETUP AND PROCEDURE}

Most of the structural damage in the beams of the Whiteday Bridge were seen at the bottom of the bridge. Since the beams needed to be repaired at the bottom which required special provisions for access, an array of barges was set up, that could be moved along the length of the bridge. The barges allowed a clearance of 53" under the bridge. The test included two major steps: first, the digital tap testing along the length of the bonded beam members and second, infrared thermography on the defective spots identified through tap testing. The digital tap testing is a quick method of identifying the defective spots which gives a rapid assessment of the bonded areas of the beam. Infrared Thermography, being relatively slower than tap testing, is able to give detailed information of the defect area map under the fabric. The Infrared Thermography test was done using both of the previously mentioned devices. The Advanced Infrared data was collected using the VoyageIR Pro. Similarly, the FLIR InfraCAM SD was used to capture the thermal image of the heated spot. The entire field NDT testing was conducted on July 15, 2017.

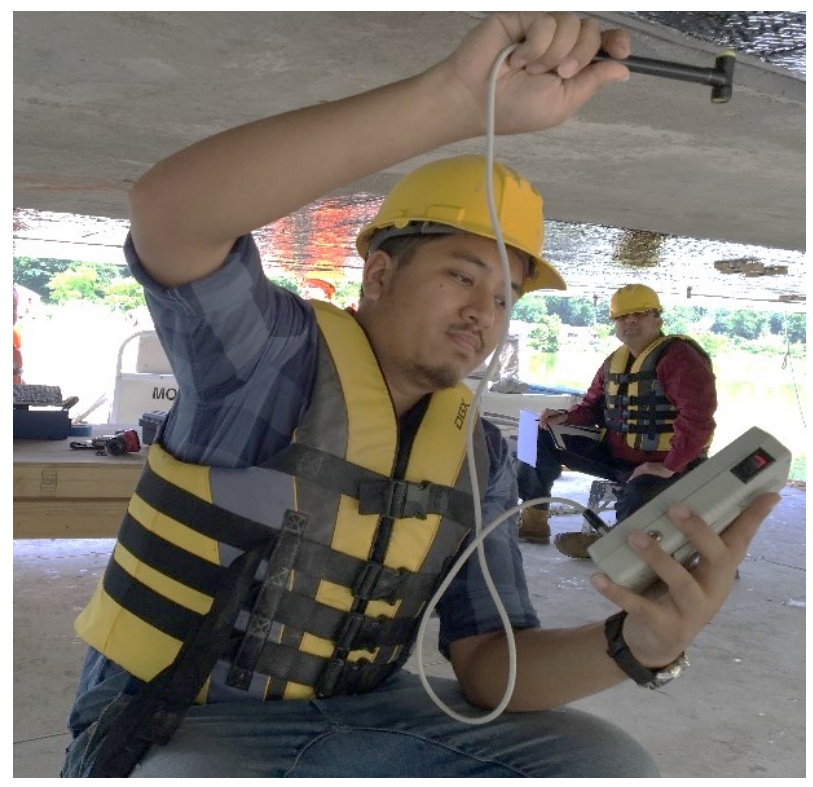

Figure 5-10: Digital Tap Testing with Rapid Damage Detection Device $\left(\mathrm{RD}^{3}\right)$ on the
Whiteday Bridge

The digital tap testing was conducted throughout the CFRP bonded areas of the beam. This test indicated spots with debonds underneath CFRP fabric in the beam. Some of these spots were then heated with the heating source from the VoyageIR Pro. The VoyageIR Pro also recorded the data after heating. The heating of the area with the spot 
needed to be uniform as well as fast. Considering the heating distance was also affected by the clearance available under the bridge, the heating distance from the source to the beam was set to be 10 ". It should be noted that the heating of the spots for infrared thermography through solar radiation was not possible as the test areas were under the bridge and the heating source needed to be quick and handy in terms of operation. This was the main reason why VoyageIR Pro with integrated heating system was used for the bridge testing.

The Digital Tap Testing on the bonded surface followed the procedure of tapping with Rapid Damage Detection Device $\left(\mathrm{RD}^{3}\right)$. The striking force should be high enough to give desired numbers on the digital display on the device. However, it should be noted that very strong strikes can cause harm to the thin layer of the carbon composite members as well as to the tapping sensor. The areas of the beam that were bonded with the CFRP laminates were tapped throughout. The number for good areas were set for each beam by tapping on consistently good areas, which was in the range of 1000 to 1175 . As mentioned in the previous chapter, a debond can be distinguished by the number that differs over $10 \%$ from the number for the good area. Thus, the spots with numbers over 1200 were considered as bad spots. The debonded areas identified from the tap testing were marked and numbered for each beam as shown in Figure 5-11. The size of each spot was also recorded. The digital tap testing was done for all the bonded areas of the main span beams of the bridge and this was done by moving the barges along the length of the beams.
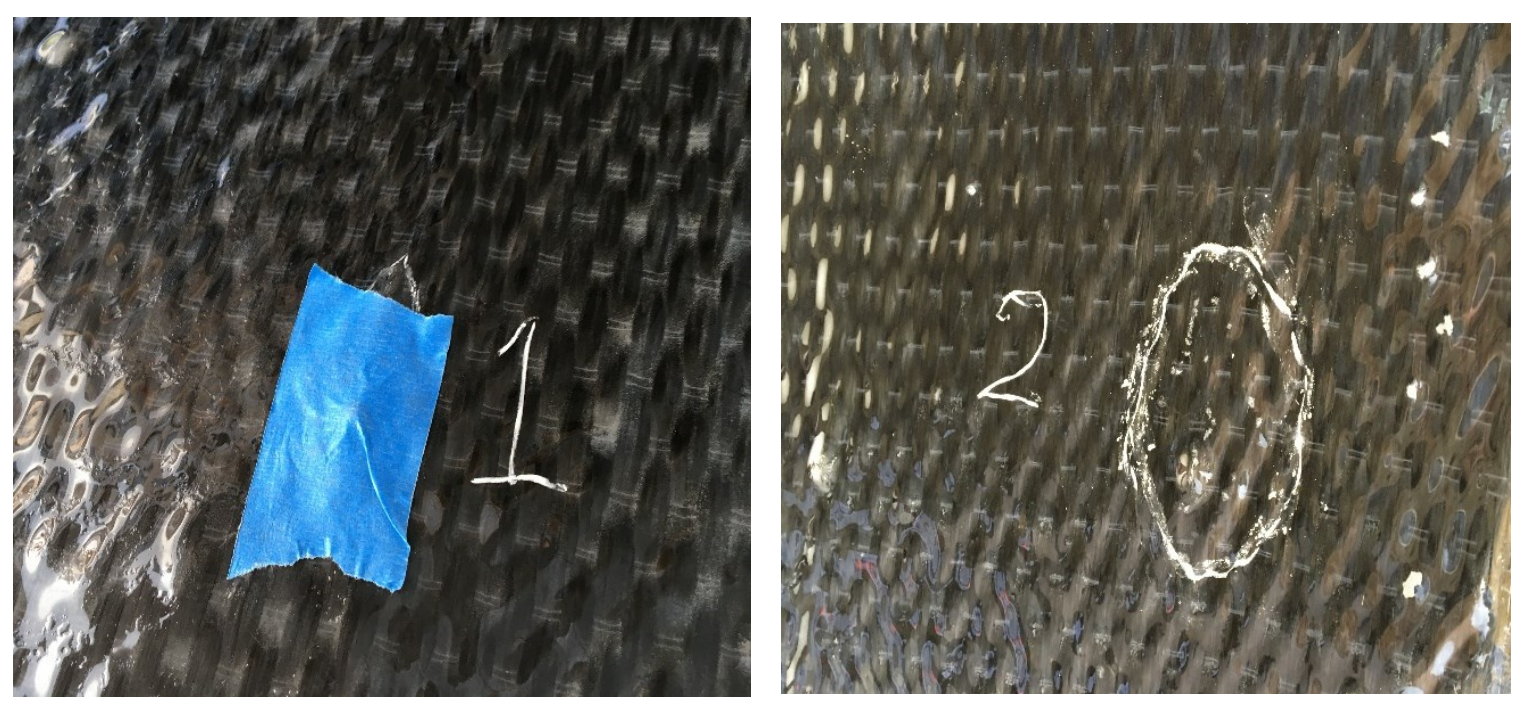

Figure 5-11: Marks and Labels on the Debonded Areas of the repaired beams 
The test setup was not favorable for conventional infrared testing. The conventional bulky heaters and infrared cameras would have been very difficult to set up and operate in the limited space available under the bridge. The VoyageIR Pro, however, was just the right fit for such constricted test environment with its easy-to-use integrated heating source and advanced thermal data capture capability. The heating from the VoyageIR Pro was uniform and quick, thus this also helped to collect conventional thermal image using FLIR InfraCAM. So, the infrared data was collected by both the methods: advanced infrared thermography as well as conventional infrared thermography. Since running infrared test throughout the span of the beam required moving the barges time-to-time, this wasn't the ideal process for the test. So, after the digital tap testing was done within an area, the infrared test was done immediately over the defects detected by the tap testing in that area. The defective spots from Beam 1 through Beam 8 were tested using VoyageIR Pro and FLIR InfraCAM (Figure 5-12).

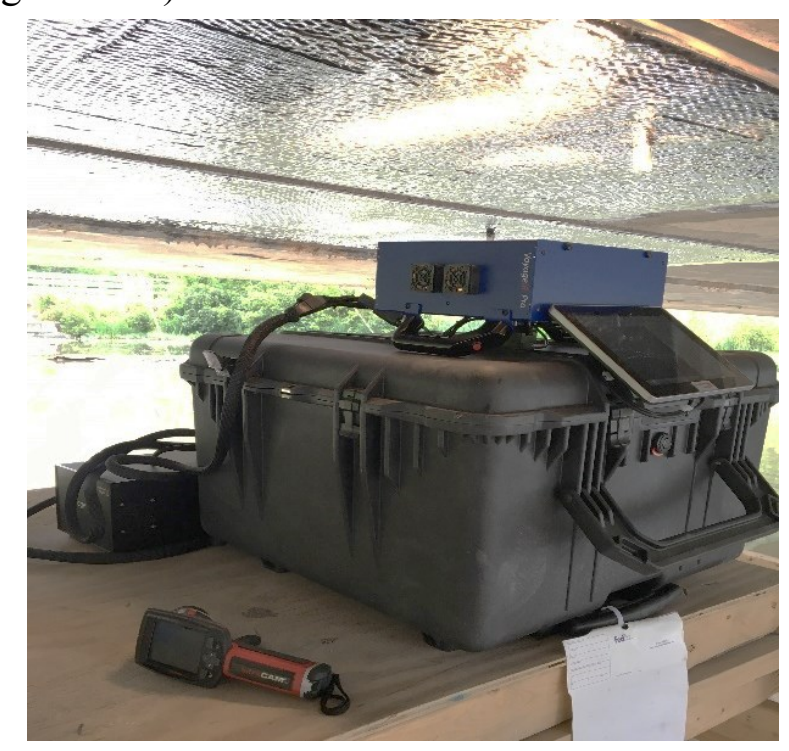

Figure 5-12: Infrared Test Setup with VoyageIR Pro and FLIR InfraCAM

The VoyageIR Pro was set up under the defective spots (Figure 5-12). The heating time was set to be 50 seconds, which the lab tests concluded as the optimum heating time. The VoyageIR Pro system allowed capturing thermal data of the defect after the heating stopped and simultaneously the FLIR InfraCAM was also used to collect thermal image. The spots on Beams 1 through 8 were tested this way and the barge was moved along the beam span to locate the defective spots throughout the span of the beams using digital tap testing and infrared testing. 


\subsection{DIGITAL TAP TESTING RESULTS}

The Digital Tap Testing was conducted throughout the length of the CFRP bonded areas of the box beams. The tap testing results gave debond with sizes ranging from 1.5 " $\mathrm{x}$ 0.75 " to 4 " x 3 ". Spots of size less than $1.5 "$ x 0.75 " ( 1.1 sq. in.) were also located but these do not require any special attention. According to ACI 440.2R-17, debonds of size less than 2 sq. in. are permissible as long as the area with debond is less than $5 \%$ of the total bonded area. In our field test, however, even the detected debonds of size as small as 1.5 " x 0.75 " ( $\sim 1.1$ sq. in.) was repaired using resin injection and the large ones (size $\sim 4$ " x 3") were repaired by cutting off the CFRP fabric and replacing them with new fabric.

Most of the repair work using CFRP fabric laminates was done on the central area of the main span beams as this area carried maximum loads and had correspondingly larger area of corrosion of prestressing strands and concrete spalling. Digital tap testing on Beam 1 identified two debonded spots between CFRP laminate and underlying concrete (Figure 5-13). Spot 1-1 of size 4" x 3" had tap test reading with range 1228 - 1269, compared to the range 1042 - 1189 of the good areas on Beam 1. Similarly, Spot 1-2 of size $2.25 " x 1$ " had reading in the range of $1260-1411$.
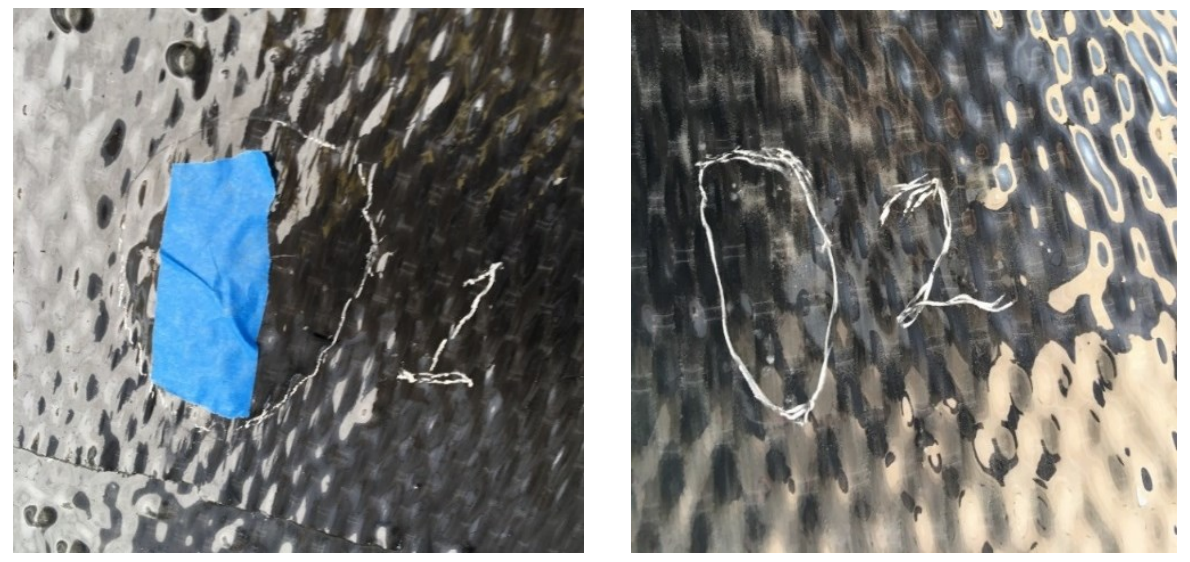

Figure 5-13: Defective Spots 1-1 (left) and 1-2 (right) on Beam 1 of the Whiteday Bridge

The tap test reading for good areas on Beam 2 was of the range 1033 - 1162. Beam 2 had only one defective spot (Figure 5-14), i.e., Spot 2-1, of size 2.5" x 1" that gave reading of range 1258 - 1380. Some defective spots of negligible size could be seen but they were just pocket of resins on the surface. Beam 3 turned out to be defect-free from the results of digital tap testing with readings throughout the beam in the range of $1027-1176$. 

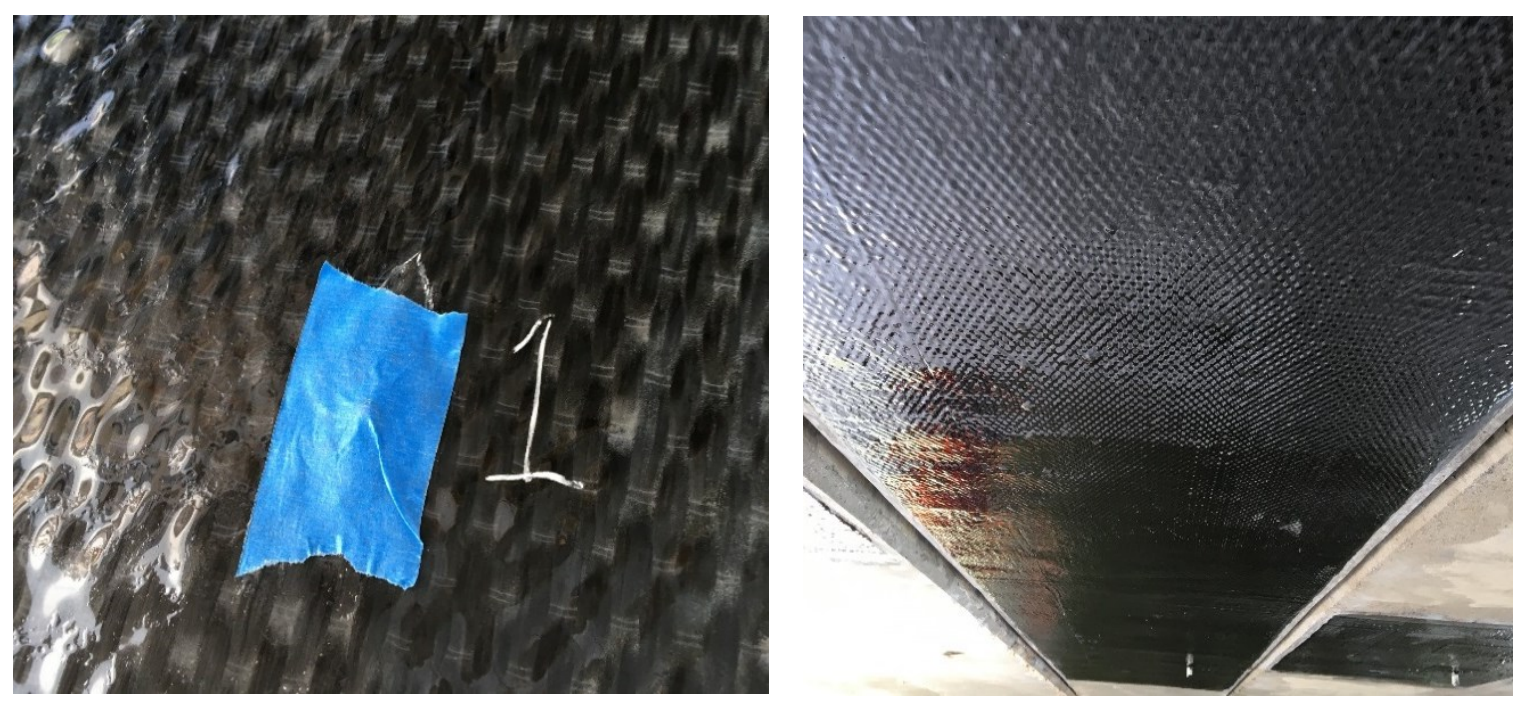

Figure 5-14: Debond 2-1 on Beam 2 (left) and Defect-free Beam 3 (right) of the Whiteday Bridge

The results of tap testing on Beam 4 showed there were two defective spots (Figure 5-15) that differed from the good areas, which had readings ranging from 1055 to 1168. Spot 4-1 with size 1.5" x 1" had tap readings in the range of 1205 - 1325 while Spot 4-2 with size 1.5 " x 3/4" had readings 1216 - 1365. These spots, according to ACI 440.2R-17, can be considered permissible, however, they were recorded to ensure that the main loadbearing span remained free from defects. Beam 5 was free of any damage and thus did not have any CFRP fabric repair. Beam 6 had some CFRP bonded areas which showed no signs of defects in the central area of the main span. The tap test readings for Beam 6 ranged from $1029-1136$.
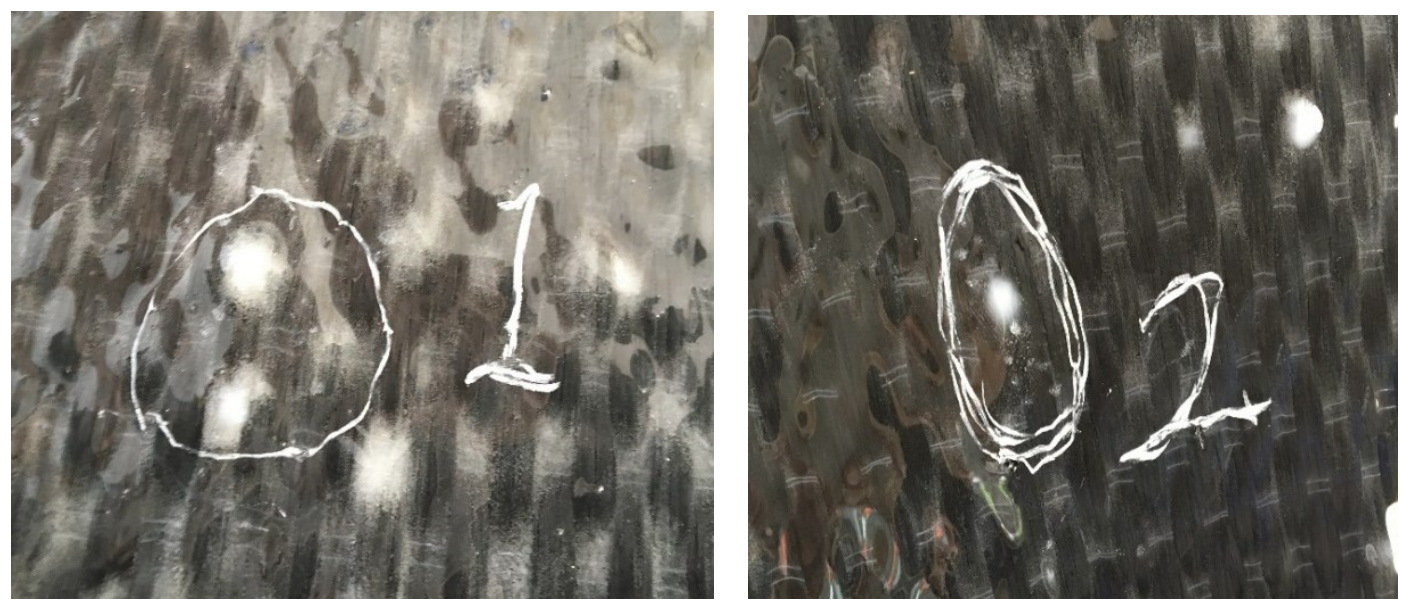

Figure 5-15: Defective Spots 4-1 (left) and 4-2 (right) on Beam 4 of the Whiteday Bridge 
A significant portion of Beam 7 was bonded with CFRP laminates and two debonds were detected through tap testing (Figure 5-16). Debond 7-1 of size 3" x 1.5" had tap test reading of range 1252 - 1339 against the good areas in Beam 7 with readings 1042 - 1172 . Debond 7-2 was of size 3" x 2" and the tap testing results gave readings in the range of 1432 - 1437.
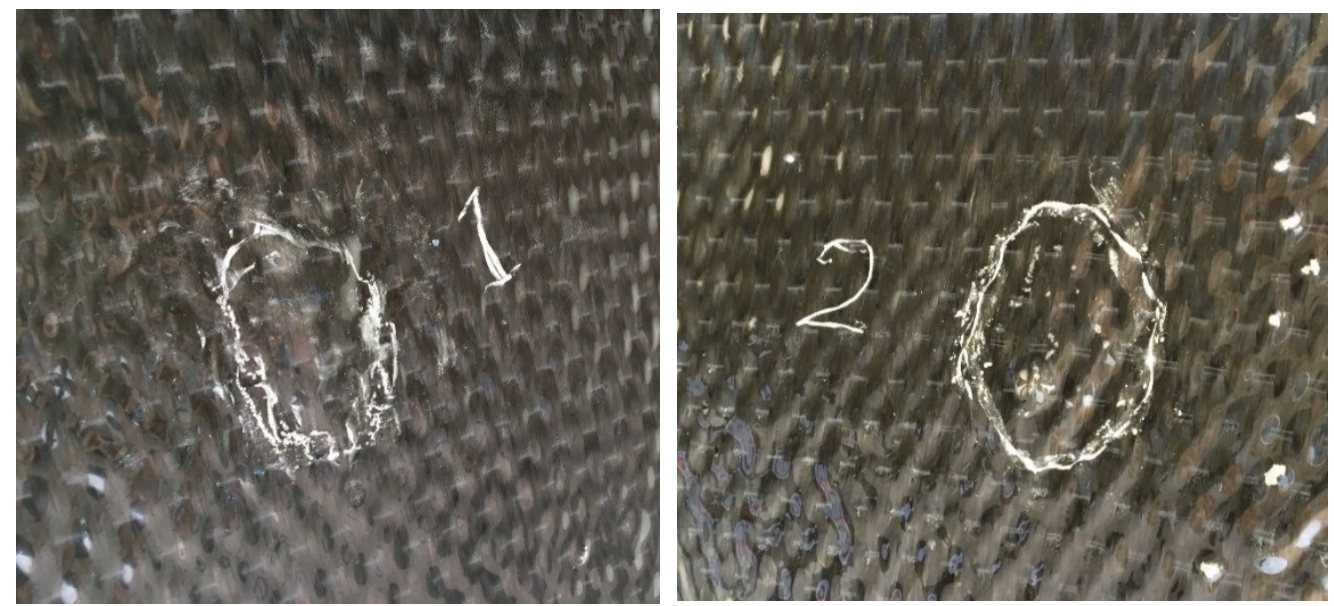

Figure 5-16: Debonds 7-1 (left) and 7-2 (right) on Beam 7 of the Whiteday Bridge

The good areas on Beam 8 had tap test readings ranging from 1041 - 1160. Tap testing indicated three debond spots on Beam 8 (Figure 5-17). Spot 8-1 of size 1.5" x 1" was again a code-permitted debond which gave a reading of range 1358 - 1422 on the digital tap testing device. The size of the debonded spot 8-2 was 4" x 3", which was a result of a bulge on the carbon fabric. This defect had a reading of $1211-1239$. In addition to these debonds, spot 8-3 on Beam 8 (Figure 5-18) actually had two closely spaced debonds of sizes 3" x 1" and 2" x 1", which had tap readings in the range of 1338 - 1390 .
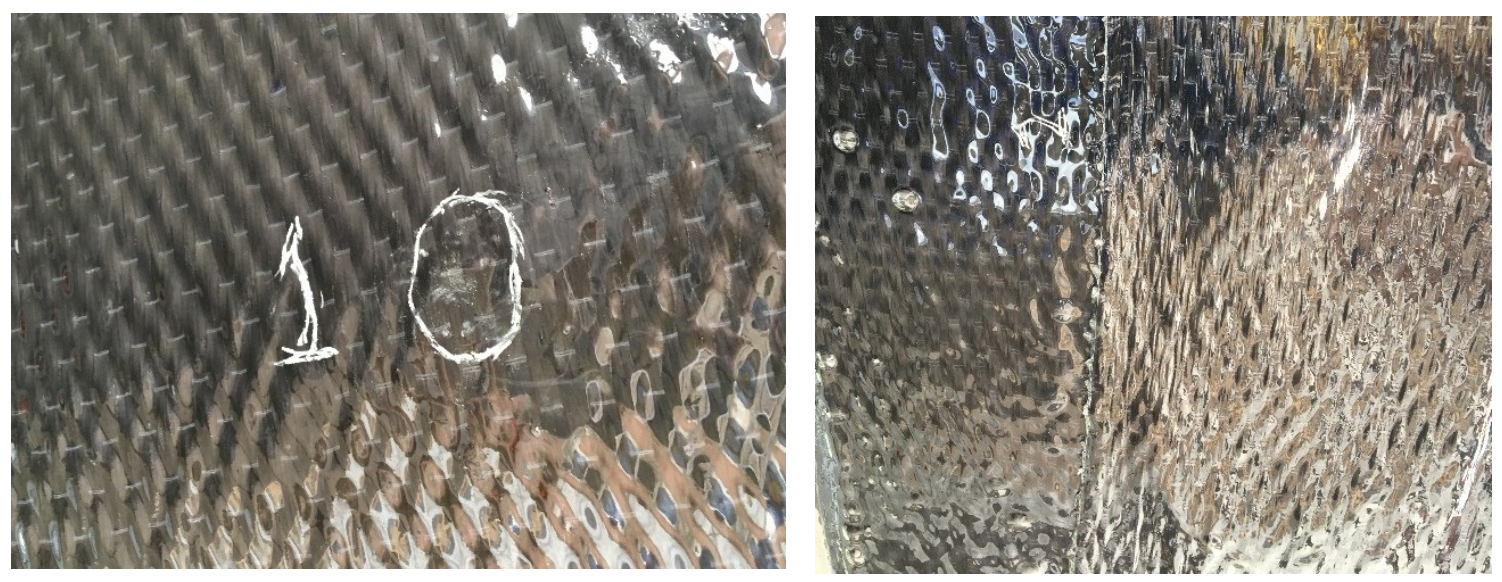

Figure 5-17: Defective Spots 8-1 (left) and 8-2 (right) on Beam 8 of the Whiteday Bridge 


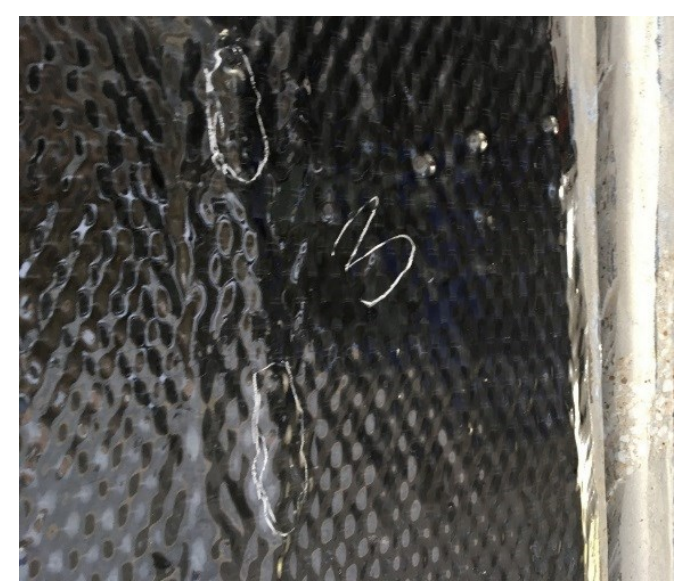

\section{Figure 5-18: Debond 8-3 with two small pockets on Beam 8 of Whiteday Bridge}

Along with the central area of the main span of the bridge, the south side and north side of the main span were also tested for debonds. Since these areas were not severely deteriorated, only certain areas were bonded with CFRP fabric. On the south side, Beams 6 through 8 were bonded with CFRP fabric laminates and thus tested with $\mathrm{RD}^{3}$. No debonds were found on these beams and the good areas had tap testing readings of $1021-1178$. Likewise, on the north side, only Beams 1, 4, 6, 7 and 8 were bonded with CFRP fabric laminates and tap testing showed that there were minimal debonds of insignificant sizes. Beams 1 and 4 had very tiny spots with size less 2 sq. in. These spots had reading in the range of 1336 - 1408. Beam 6 was debond-free throughout the CFRP bonded area on the north side. The north side of Beam 7, from tap testing results, indicated that there were tiny spots, some with dry resin on the surface, with readings between 1185 and 1492. Beam 8 had mostly good areas with readings in the range of $1008-1179$. There was a small spot $8-4$ of size $1.75 " \times 1.25$ " ( 2.2 sq. in.) and this spot had tap test reading in the order of 1215 - 1328. In addition, Beam 8 also had a small CFRP bonded area with a good bond and readings of $1114-1128$, but on tapping, a hollow sound from underlying concrete could be heard. This meant the bond between the FRP and concrete was good; however, the concrete underneath the surface could be spalling.

Table 5-1 shows the list of all the debonds detected by digital tap testing along with their sizes and their tap testing readings. The table includes the debonds from the central and northern areas of the main span of the bridge where the debonds were identified (the southern side did not have any debonds). The debonds of size ranging from 1.5 " $\mathrm{x} 0.75$ " to 4" x 3" were detected by Digital Tap Testing in central and northern areas. The readings 
for defect-free or good areas were in the range of 1033 - 1189 and the debonds were distinguished with readings greater than 1200. Figure 5-19 shows the plan of the main span with location of the debonds between CFRP fabric laminate and the underlying concrete.

Table 5-1: Digital Tap Testing Results on the Whiteday Bridge

\begin{tabular}{|c|c|c|c|c|c|}
\hline Beam & Spot & Location & Debond Size & $\begin{array}{l}\text { Tap Testing } \\
\text { Reading for } \\
\text { Debonds }(\mu s) \\
\end{array}$ & $\begin{array}{c}\text { Tap Testing } \\
\text { Reading for } \\
\text { Good Area }(\mu s) \\
\end{array}$ \\
\hline \multirow{4}{*}{1} & $1-1$ & Central Area & $4 " x$ 3" & $1228-1269$ & \multirow{4}{*}{$1042-1189$} \\
\hline & $1-2$ & Central Area & $2.25 " \times 1 "$ & $1260-1411$ & \\
\hline & $1-3$ & North Side & $2 " x 1 "$ & $1336-1408$ & \\
\hline & $1-4$ & North Side & $2 " x 1.5 "$ & $1238-1368$ & \\
\hline 2 & $2-1$ & Central Area & $2.5 \% \times 1 "$ & $1258-1380$ & $1033-1162$ \\
\hline 3 & \multicolumn{5}{|c|}{ NO DEBONDS DETECTED } \\
\hline \multirow{2}{*}{4} & $4-1$ & Central Area & $1.5 " \times 1 "$ & $1205-1325$ & \multirow{2}{*}{$1055-1168$} \\
\hline & $4-2$ & Central Area & $1.5 " \times 0.75 "$ & $1216-1365$ & \\
\hline 5 & \multicolumn{5}{|c|}{ NO DEBONDS DETECTED } \\
\hline 6 & \multicolumn{5}{|c|}{ NO DEBONDS DETECTED } \\
\hline \multirow{2}{*}{7} & $7-1$ & Central Area & $3 " x 1.5 "$ & $1252-1339$ & \multirow{2}{*}{$1042-1172$} \\
\hline & $7-2$ & Central Area & $3 " x 2 "$ & $1432-1437$ & \\
\hline \multirow{4}{*}{8} & $8-1$ & Central Area & $1.5 " \times 1 "$ & $1358-1422$ & \multirow{4}{*}{$1041-1160$} \\
\hline & $8-2$ & Central Area & $4 " x$ 3" & $1211-1239$ & \\
\hline & $8-3$ & Central Area & $3 " x$ 1" \& 2" x 1" & $1338-1390$ & \\
\hline & $8-4$ & North Side & $1.75^{\prime \prime} \times 1.25 "$ & $1215-1328$ & \\
\hline
\end{tabular}

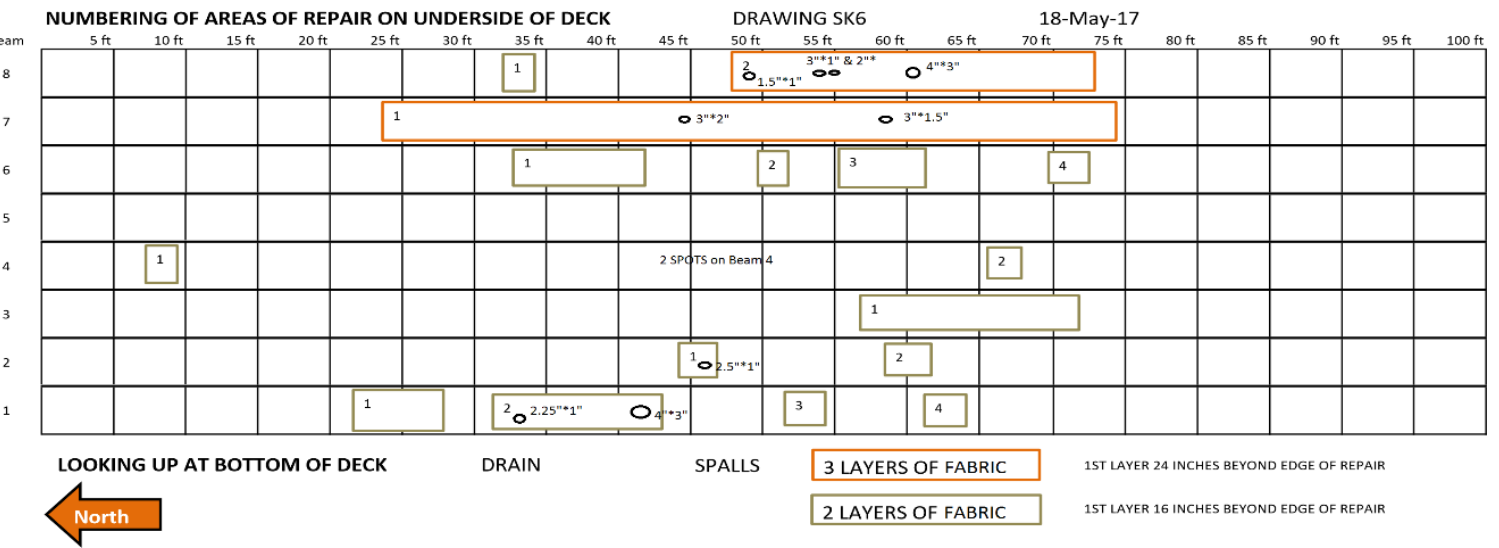

Figure 5-19: Plan of the Main Span of the Whiteday Bridge with numbering of the beams and positioning of the CFRP fabric laminates 


\subsection{INFRARED THERMOGRAPHY TESTING RESULTS}

The results from digital tap testing served as the base for the infrared thermography testing. The process of infrared testing throughout the CFRP bonded areas of the beams would be very tedious and time-consuming. Therefore, after getting the results from tap testing, some of the identified defective spots were tested with VoyageIR Pro and FLIR InfraCAM SD. Most of the debonds of size 2 sq. in. and greater were tested using infrared thermography. Also, infrared thermography testing was conducted on some of the smaller sized debonds. The uniform heating from the VoyageIR Pro and recording of thermal image using both VoyageIR Pro and conventional infrared camera (FLIR InfraCAM SD) allowed thorough study of these debonds.

The central area of the main span was found to have most of the significant defects. The north side and the south side of the main span beams had very few defective spots (mostly tiny ones) so these spots were not tested using infrared thermography. The central area, however, needed infrared testing based on the larger number and size of the debonds detected by tap testing. The two debonds on Beam 1 - namely spots 1-1 and 1-2 - could be seen as hot spots in the thermal images. Figure 5-20 shows the raw thermal image of the spot 1-1 as taken from the VoyageIR Pro and the thermographic image from the FLIR InfraCAM SD. The hot spot of the debond indicates an average temperature of $51.8^{\circ} \mathrm{C}$ as compared to $37.3^{\circ} \mathrm{C}$ of the defect-free area.
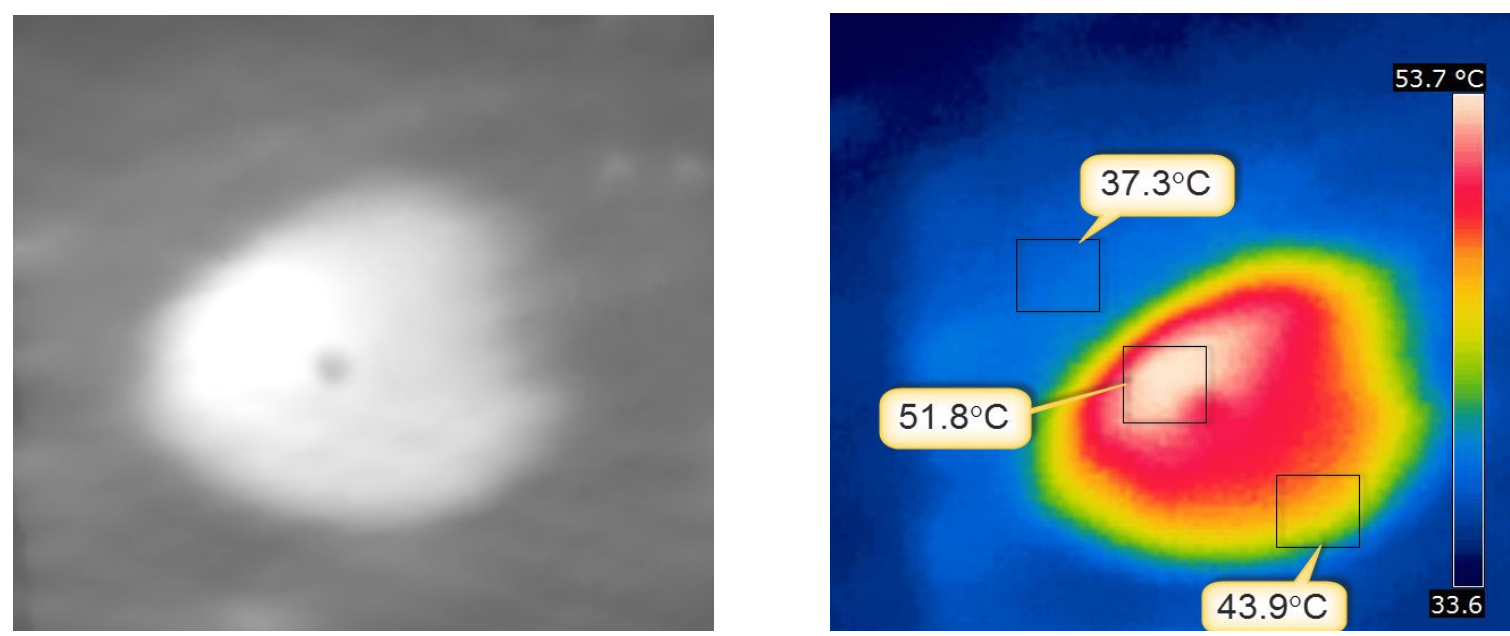

Figure 5-20: Raw Thermal Image from VoyageIR Pro (left) and Infrared Image from FLIR InfraCAM SD (right) of the Debond 1-1 on Beam 1 of the Whiteday Bridge 
Similarly, Figure 5-21 shows the thermal images of the debond 1-2 obtained from the VoyageIR Pro and FLIR InfraCAM SD. The images show the debond as a hot spot with an average temperature of $39.6^{\circ} \mathrm{C}$ against the surrounding temperature of $33.7^{\circ} \mathrm{C}$.
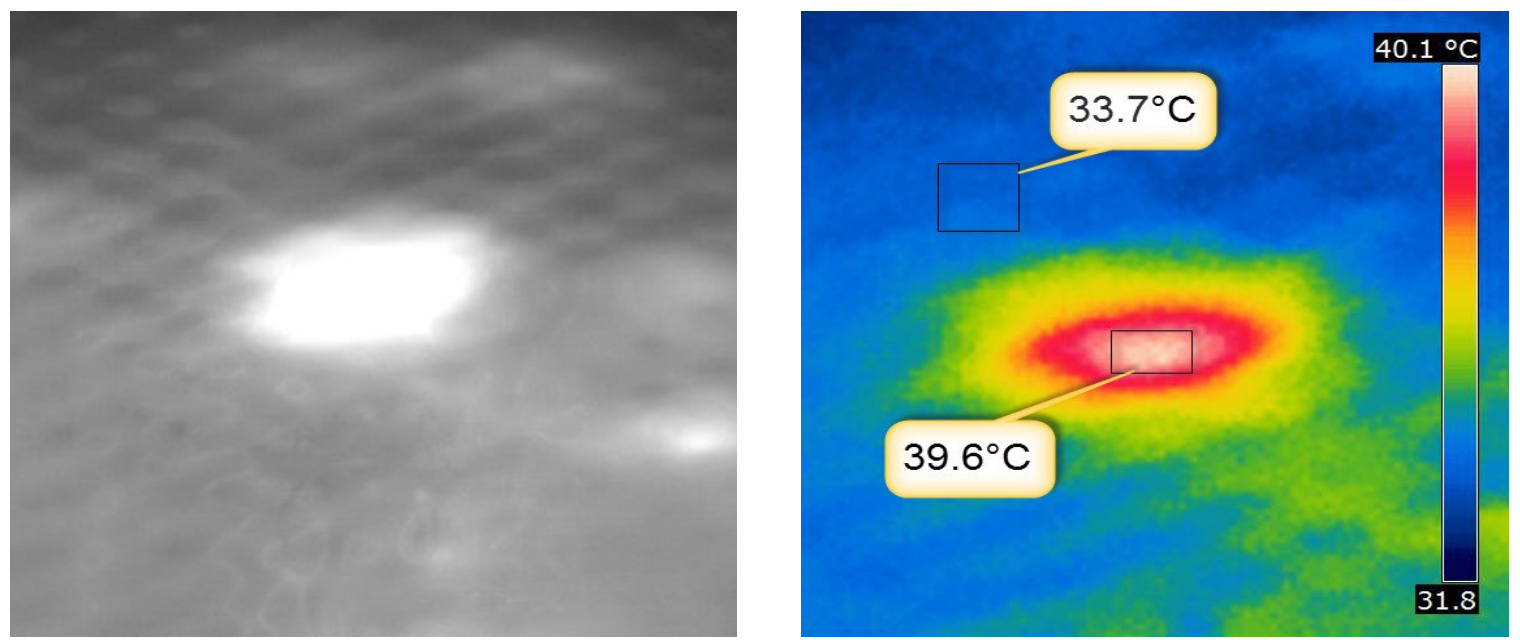

Figure 5-21: Raw Thermal Image from VoyageIR Pro (left) and Infrared Image from FLIR InfraCAM SD (right) of the Debond 1-2 on Beam 1 of the Whiteday Bridge

The infrared test on the spot 2-1 of Beam 2 gave the results as shown in Figure 522. The debond showed up as hot spot in both advanced and conventional infrared test results. For spot $2-1$, the average temperature was $40.5^{\circ} \mathrm{C}$ while the surrounding temperature was $33.7^{\circ} \mathrm{C}$. Figure $5-23$ shows the infrared test results for Beam 3 , which was defect-free and the average temperature difference within the test area was less than $0.5^{\circ} \mathrm{C}$.
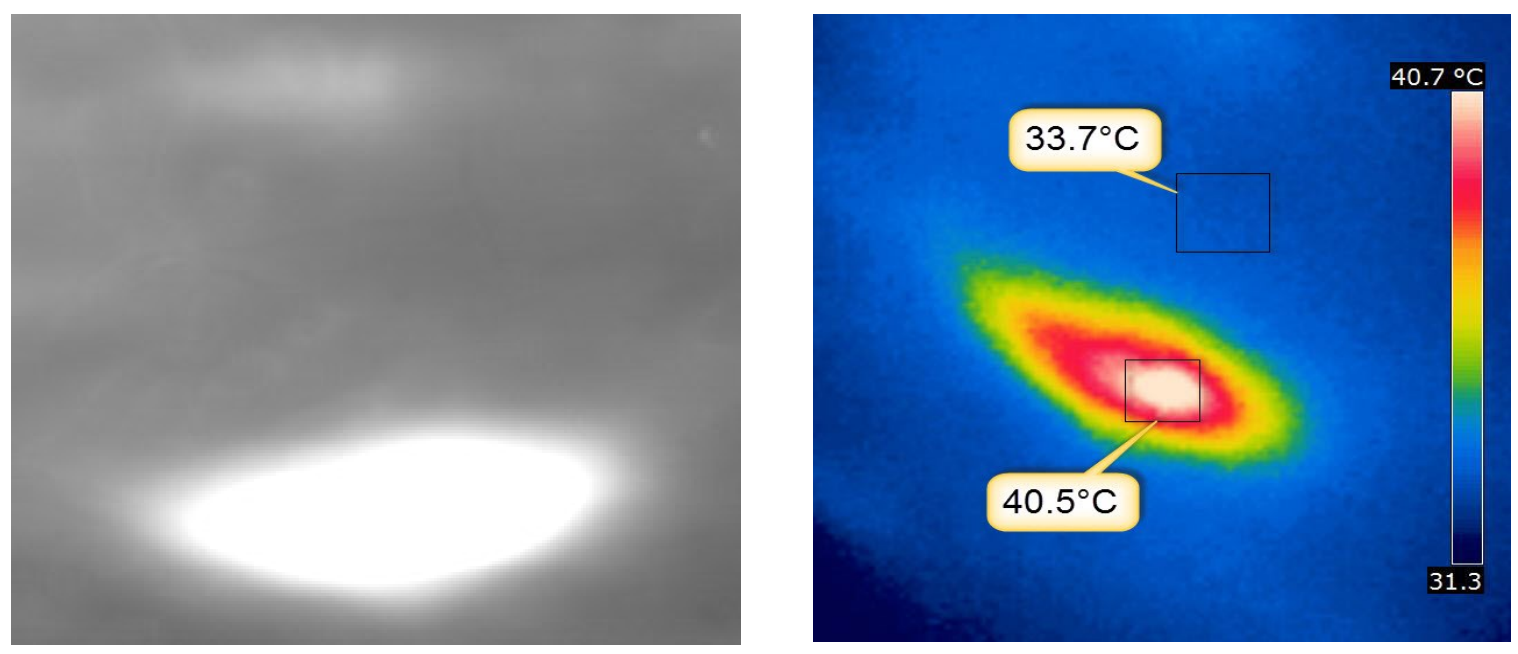

Figure 5-22: Raw Thermal Image from VoyageIR Pro (left) and Infrared Image from FLIR InfraCAM SD (right) of the Debond 2-1 on Beam 2 of the Whiteday Bridge 

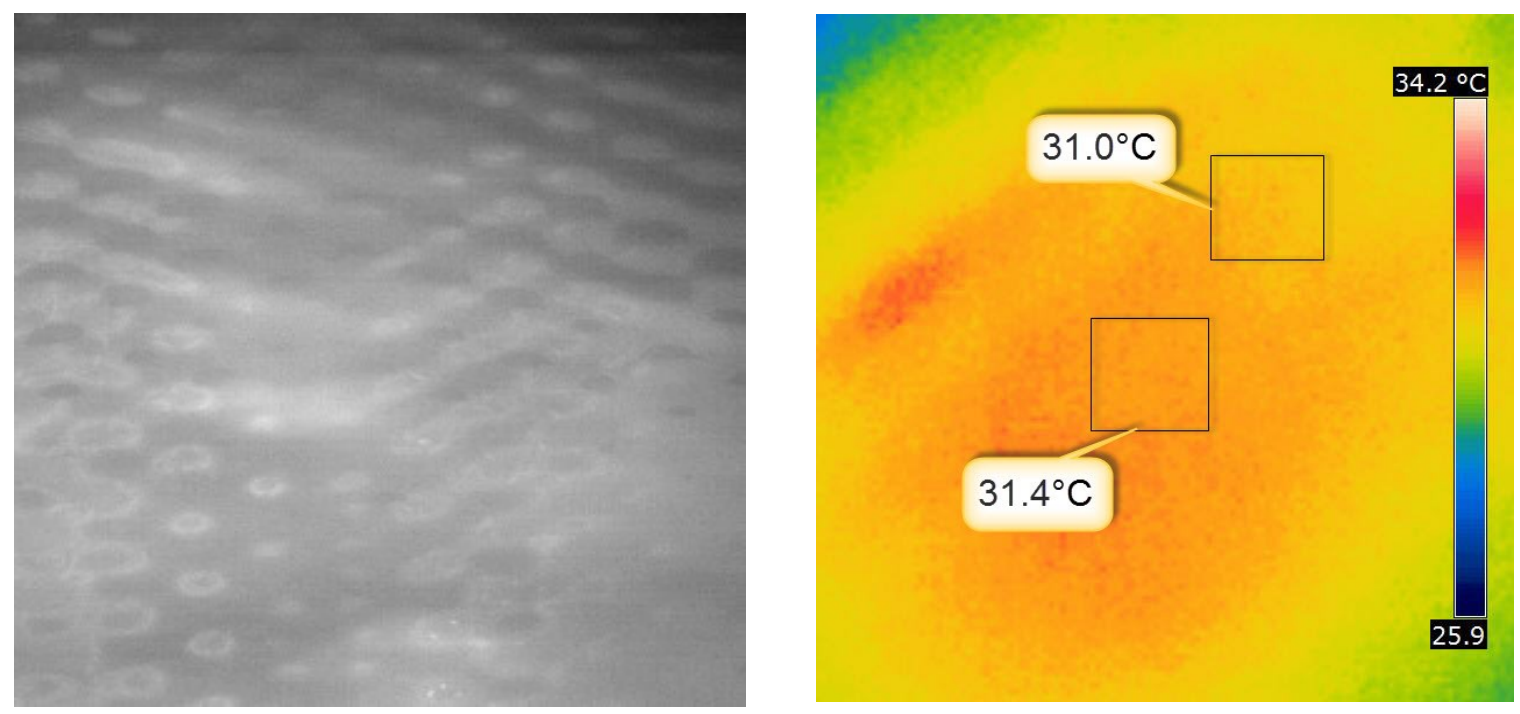

Figure 5-24: Raw Thermal Image from VoyageIR Pro (left) and Infrared Image from FLIR InfraCAM SD (right) of the Defect-free Beam 3 of the Whiteday Bridge

Figure 5-24 shows the thermal images obtained from VoyageIR Pro and FLIR InfraCAM SD for debond 4-1 on Beam 4. Both the devices showed the debond as hot spot with temperature greater than the surrounding area. The hot spot had the average temperature of $41.8^{\circ} \mathrm{C}$ while the surrounding temperature was $33.1^{\circ} \mathrm{C}$. Another debond on Beam 4, Spot 4-2, gave results on infrared testing as shown in Figure 5-25, with the average temperature of the debond as $38.1^{\circ} \mathrm{C}$ and the surrounding area temperature as $32.0^{\circ} \mathrm{C}$.
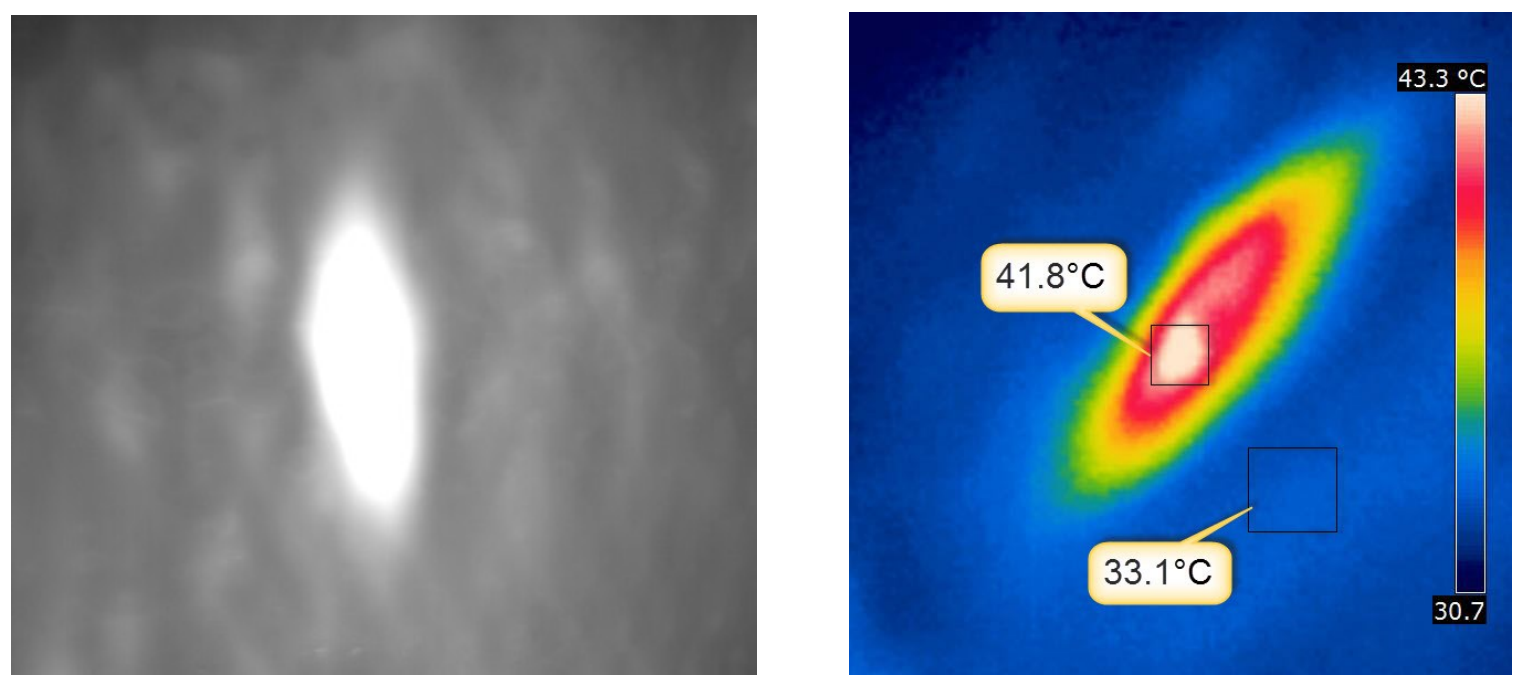

Figure 5-23: Raw Thermal Image from VoyageIR Pro (left) and Infrared Image from FLIR InfraCAM SD (right) of the Defective Spot 4-1 on Beam 4 of the Whiteday Bridge 

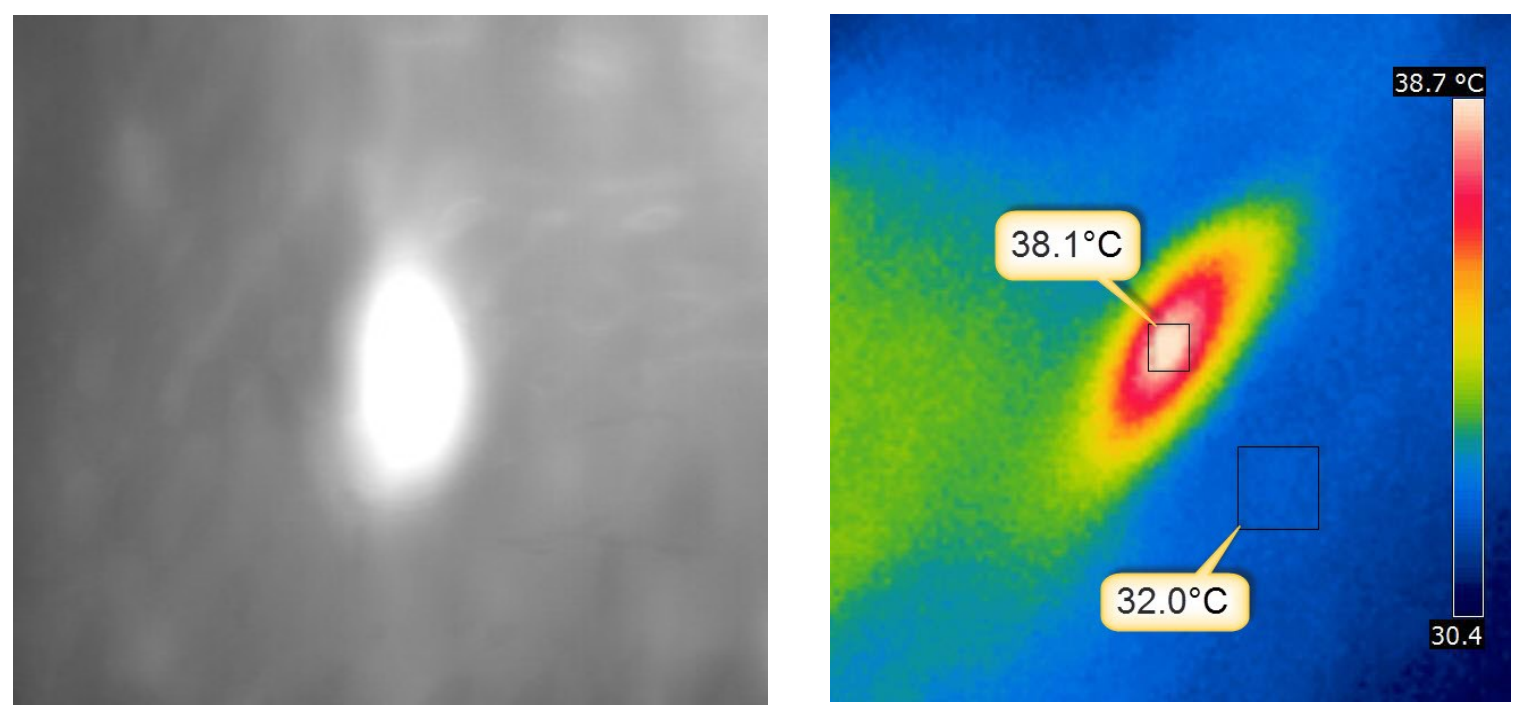

Figure 5-25: Raw Thermal Image from VoyageIR Pro (left) and Infrared Image from FLIR InfraCAM SD (right) of the Defective Spot 4-2 on Beam 4 of the Whiteday Bridge

Since Beam 5 did not have any CFRP fabric, no infrared testing needed to be done on Beam 5. Tap testing results for Beam 6 indicated that there was no debond on Beam 6 so infrared testing on Beam 6 was also not required. Beam 7, however, had two debonds and infrared images were taken for both the debonds. The raw image of the defective spot 7-1 taken from VoyageIR Pro along with the thermographic image with the temperatures taken from FLIR InfraCAM SD is shown in Figure 5-26. Average temperature of the debond was $42.2^{\circ} \mathrm{C}$ as compared to the surrounding area temperature of $31.0^{\circ} \mathrm{C}$.
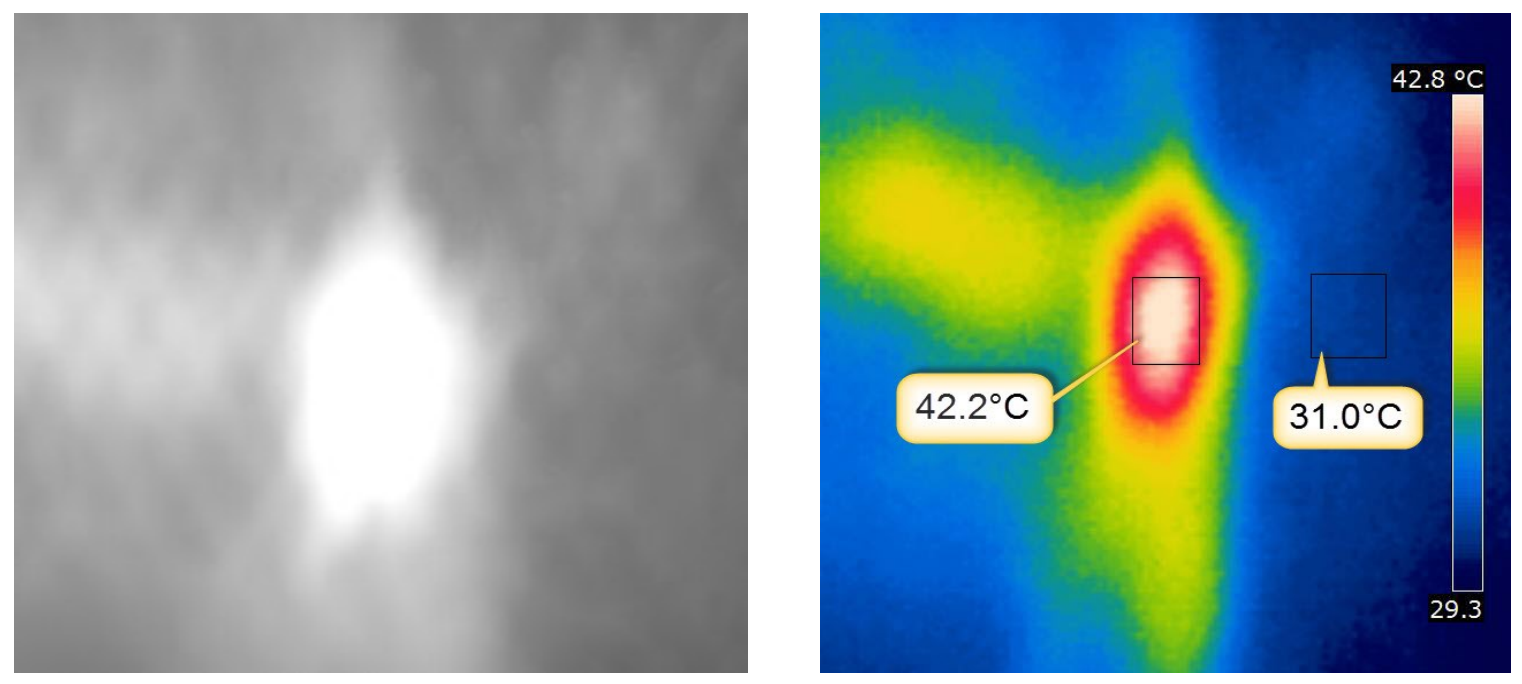

Figure 5-26: Raw Thermal Image from VoyageIR Pro (left) and Infrared Image from FLIR InfraCAM SD (right) of the Defective Spot 7-1 on Beam 7 of the Whiteday Bridge 
The infrared results of the second debond 7-2 on Beam 7, as shown in Figure 5-27, indicates a hot spot with an average temperature of $43.1^{\circ} \mathrm{C}$. The surrounding temperature was $31.0^{\circ} \mathrm{C}$. It can be seen that both advanced thermography and conventional thermography give similar results for any debond between CFRP fabric laminate and the underlying concrete.
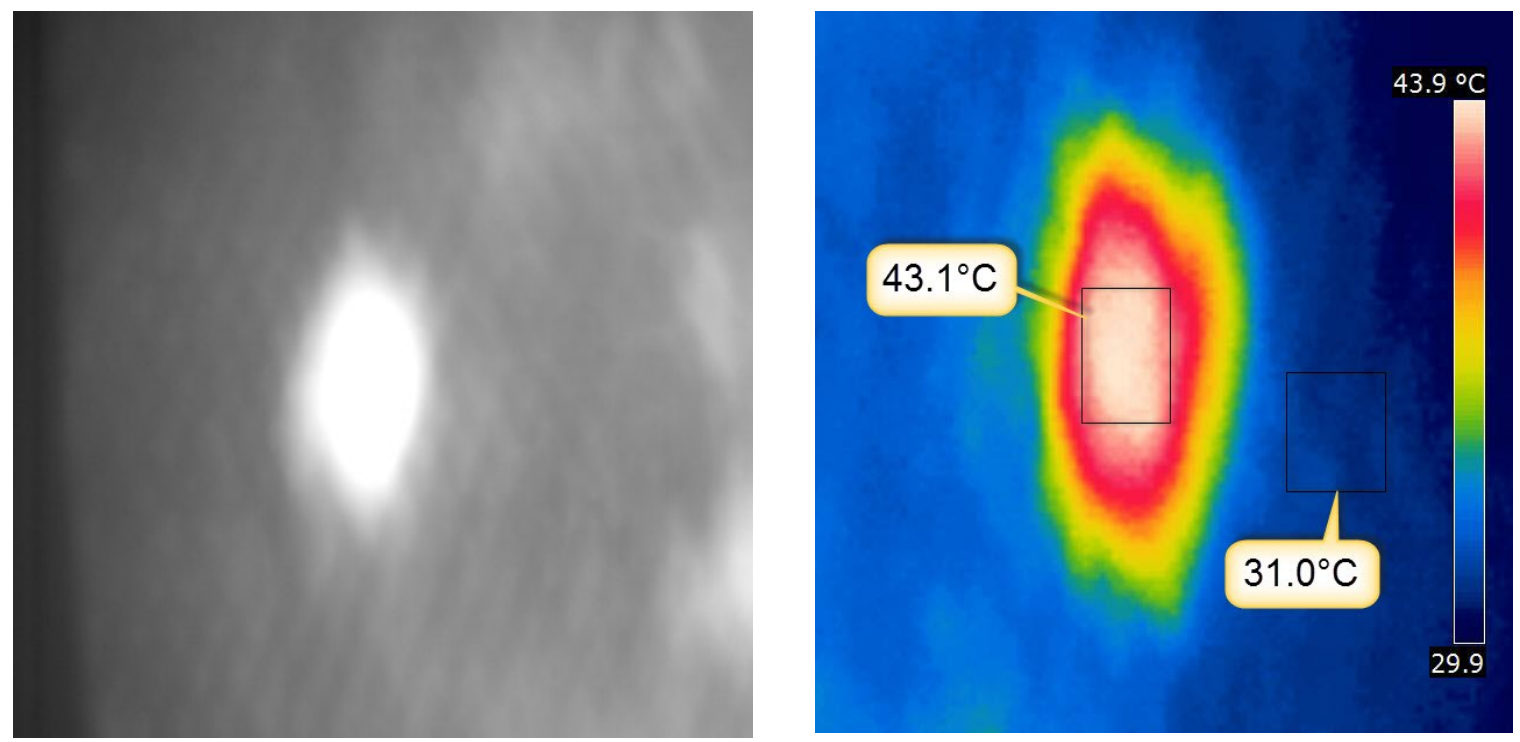

Figure 5-27: Raw Thermal Image from VoyageIR Pro (left) and Infrared Image from FLIR InfraCAM SD (right) of the Defective Spot 7-2 on Beam 7 of the Whiteday Bridge

Beam 8 had three defective spots as identified by the tap testing results. Defective spot 8-1 was not a significant one so heating this debond with VoyageIR Pro affected the temperature of the area surrounding the debond. This can be seen in Figure 5-28 where the surrounding FRP fabric also shows a significant increase in temperature. The hot spot had an average temperature of $39.6^{\circ} \mathrm{C}$ while FRP fabric in the vicinity had temperature of $38.7^{\circ} \mathrm{C}$. Temperature of the unaffected surrounding area was $32.3^{\circ} \mathrm{C}$. This gives us an idea of how insignificant debonds can show up in the results of the infrared thermography tests - both advanced and conventional, and care should be taken not to classify these areas as debonds. Debonded areas typically result in hot spots with the highest temperature. Figure 5-29 shows the infrared results of the second debond 8-2 on Beam 8, which is a clear hot spot, formed as a result of a 4" x 3" sized bulge. The average temperature of the hot spot was $38.9^{\circ} \mathrm{C}$ as compared to the surrounding temperature of $30.9^{\circ} \mathrm{C}$. 

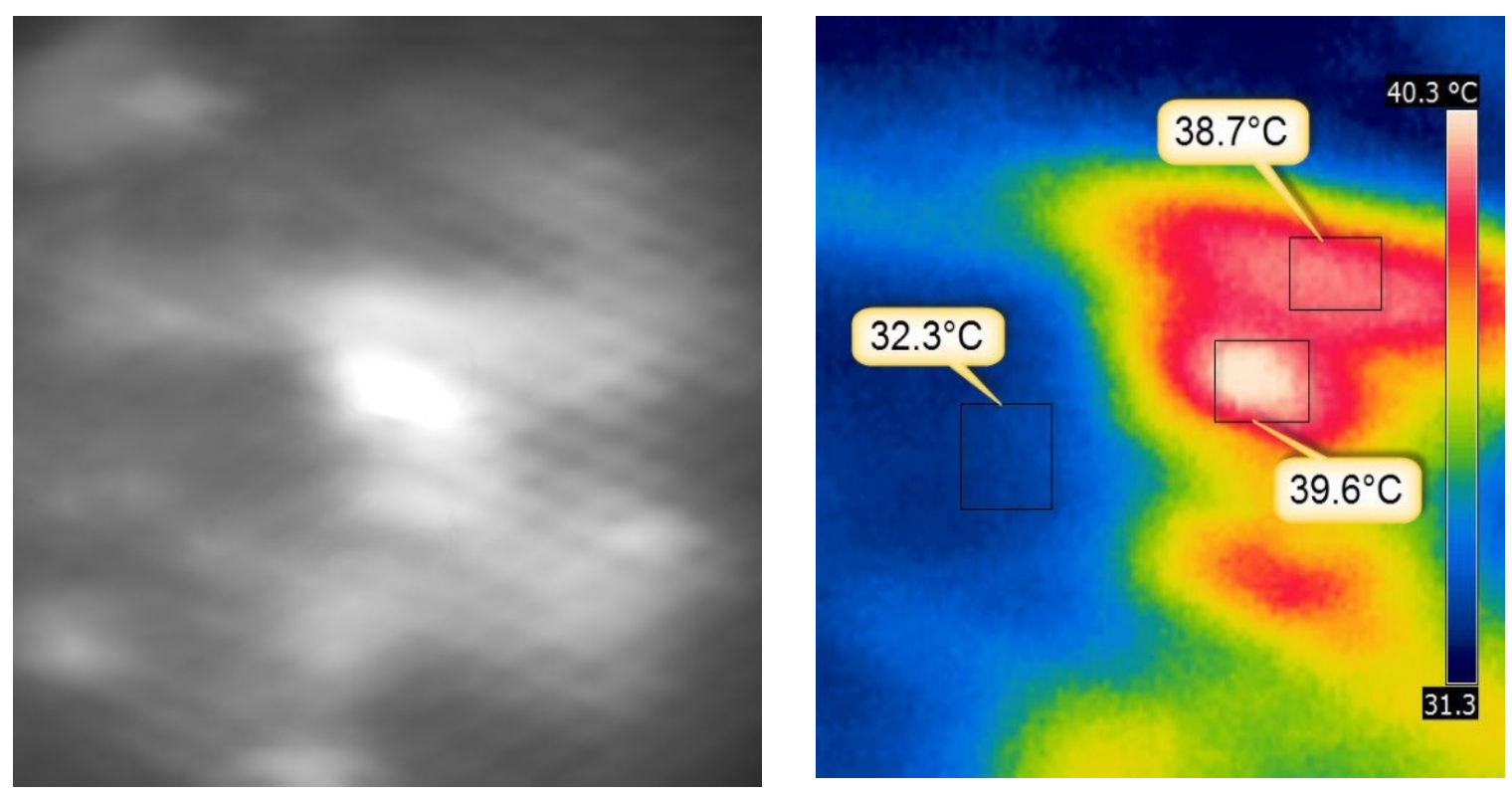

Figure 5-28: Raw Thermal Image from VoyageIR Pro (left) and Infrared Image from FLIR InfraCAM SD (right) of the Defective Spot 8-1 on Beam 8 of the Whiteday Bridge
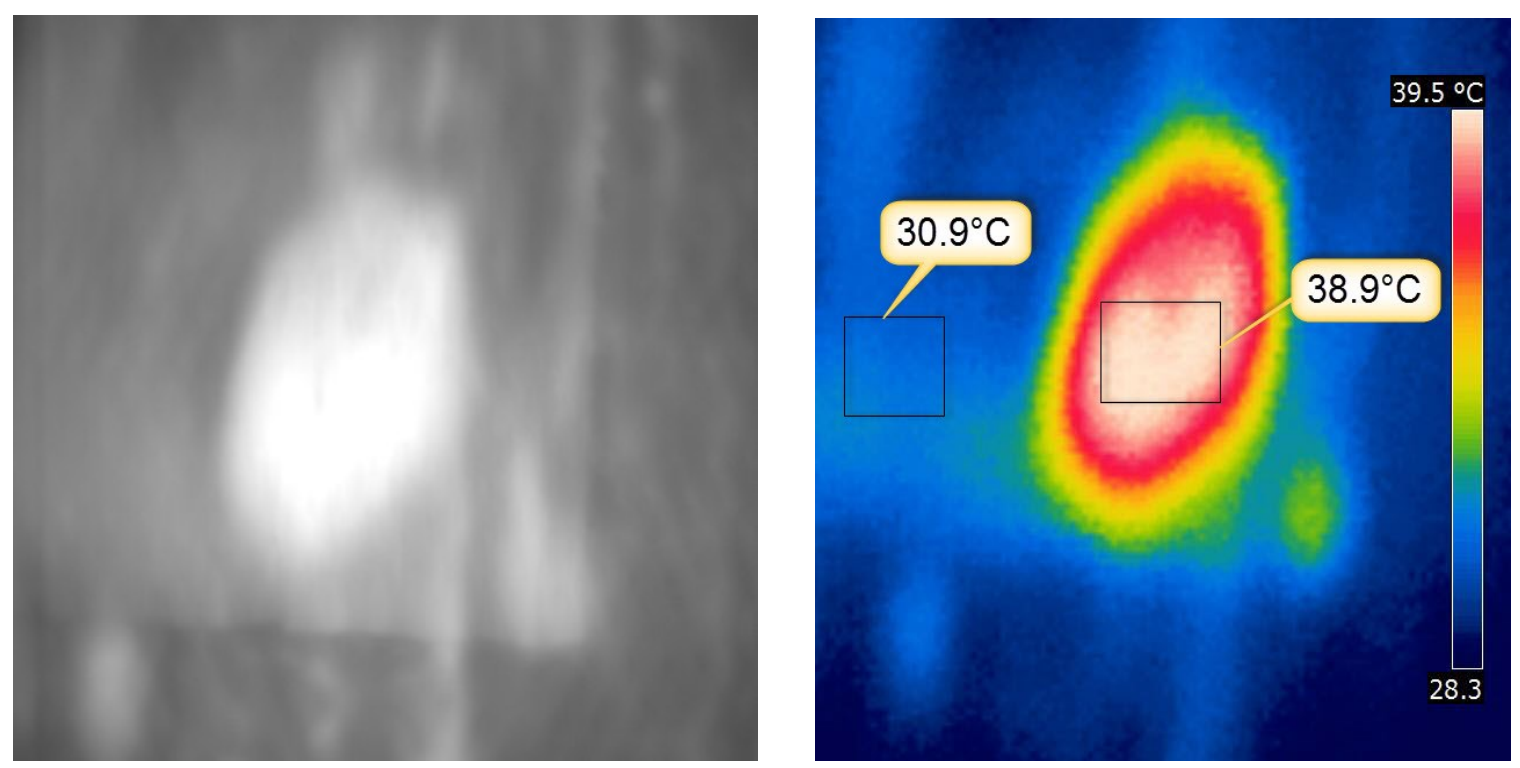

Figure 5-29: Raw Thermal Image from VoyageIR Pro (left) and Infrared Image from FLIR InfraCAM SD (right) of the Defective Spot 8-2 on Beam 8 of the Whiteday Bridge 
Figure 5-30 shows the thermal images of the defective spot 8-3 taken from VoyageIR Pro and FLIR InfraCAM SD. This defect had two small pockets of hot spots with temperatures in the range of $35.4^{\circ} \mathrm{C}-35.6^{\circ} \mathrm{C}$. The temperature of the surrounding CFRP fabric was $30.0^{\circ} \mathrm{C}$.
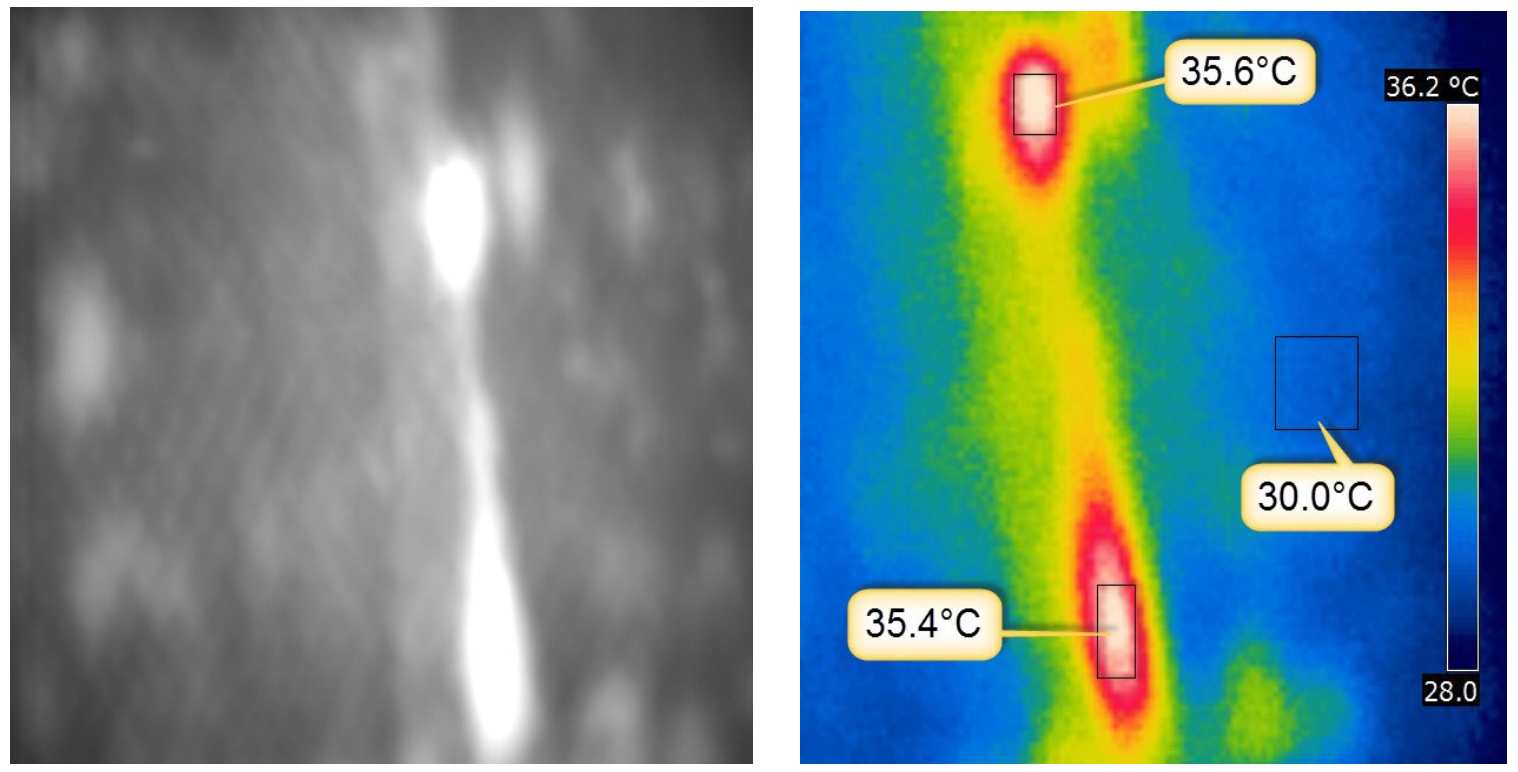

Figure 5-30: Raw Thermal Image from VoyageIR Pro (left) and Infrared Image from FLIR InfraCAM SD (right) of the Defective Spot 8-3 on Beam 8 of the Whiteday Bridge

\subsection{DIGITAL TAP TESTING RESULTS AFTER REPAIR WORKS}

The debonds identified from the nondestructive testing were marked so that the repair works could be done by the contractor. Small sized debonds were repaired by injecting resin into them while large debonds, especially bulges, were repaired by cutting off the CFRP fabric and replacing them with new fabric. After the repair works, a quick assessment of the CFRP bonded beams was needed to ensure that no more debonds were present. Thus, digital tap testing was done again on October 2, 2017 to evaluate all the previously detected and repaired debonds. Only digital tap testing was used this time since it is a quick and convenient method. Beams 1 through 6 were found to be free of debonds. However, Beams 7 and 8 had couple of debonded spots left.

Table 5-2 shows the list of debonds detected using digital tap testing during this second round of field testing. The previously identified debonds on Beam 7 - namely 7-1 
and 7-2 - were still detected but the sizes of these debonds had decreased. The size of spot $7-1$ had changed from 3 " x 1.5 " to 2 " x 1 " and that of spot 7-2 from 3" x 2" to 2" x 1 ". Debond 7-1, however, did not show a significant variance in tap testing reading but a hollow sound could be heard from the concrete upon tapping. This indicates that there is no debond between CFRP fabric and underlying concrete; instead, there is delamination within the concrete itself. For Beam 8, debond 8-2 of size 4" x 3" was still present, which was the bulge in the CFRP fabric. At the edge of the CFRP fabric on central area of Beam 8 , tap testing gave readings that indicated there was debond in that area. This was called Spot 8-5, which could have formed during the repair work. All the debonds were marked and the contractor was asked to repair these by either injecting resin or cutting and replacing the debonded CFRP fabric.

Table 5-2: Digital Tap Testing Results on the Whiteday Bridge after Repair Work

\begin{tabular}{|c|c|c|c|c|c|}
\hline Beam & Spot & Location & Debond Size & $\begin{array}{c}\text { Tap Testing } \\
\text { Reading for } \\
\text { Debonds }(\boldsymbol{\mu s})\end{array}$ & $\begin{array}{c}\text { Tap Testing } \\
\text { Reading for } \\
\text { Good Areas }(\boldsymbol{\mu})\end{array}$ \\
\hline $1-6$ & \multicolumn{5}{|c|}{ NO DEBONDS DETECTED } \\
\hline \multirow{2}{*}{7} & $7-1$ & Central Area & 2 2 x 1" & $1151-1222^{*}$ & \multirow{2}{*}{$1042-1172$} \\
\cline { 2 - 6 } & $7-2$ & Central Area & 2" x 1" & $1233-1250$ & \multirow{2}{*}{$1041-1160$} \\
\hline \multirow{2}{*}{8} & $8-2$ & Central Area & 4 4 x 3" & $1250-1269$ & \\
\cline { 2 - 5 } & $8-5$ & Central Area & Edge Patch & $1293-1480$ & \\
\hline
\end{tabular}

*Hollow sound coming from concrete, which indicates delamination in concrete rather than a debond between CFRP fabric and concrete 


\subsection{CONCLUSIONS}

The nondestructive testing was an essential part of the rehabilitation of the concrete boxed beams of the Whiteday Bridge. Through tap testing and infrared thermography testing, the repairing of the beams using CFRP fabric was successfully done by eliminating all the debonds under the fabric. This ensured that there was no loss in the strength as designed to be provided by the CFRP fabric laminate bonded to the beams. Since nondestructive testing is quicker and more convenient than conventional destructive testing (e.g., pull out testing), it allowed the contractor to take necessary remedial actions based on the results of the nondestructive testing. It should also be noted that destructive testing (e.g., pull out testing) cannot be used everywhere while nondestructive testing can be used over the entire CFRP bonded area to ensure good bond throughout the repair area.

The debonds detected by the digital tap testing and infrared testing were repaired by the contractor. Small debonds (size $\sim 1.5$ " x 0.75 ") and somewhat larger (up to 3" x 2") were repaired by injecting resin into them while very large debonds (size $\sim 4$ " x 3 ") were repaired by cutting out the old CFRP fabric and replacing them with new ones. These repair works are not always guaranteed to be successful in providing complete design strength of the repair system. It can be seen that the first round of testing detected around 13 debonds, which were repaired and tested again. The second testing also showed some debonds even after the repair work was done. This shows that even after repairing, there can always be some debonds present between the CFRP fabric laminate and the underlying concrete. However, it should be noted that the number of debonds decreased significantly after the repair work as shown in the second round of testing. Following the second testing, repair of the additional debonds was conducted by the contractor. Thus, the major advantage of using nondestructive testing techniques is that it allows quick assessment of the FRP bonded structures, especially when timing is crucial factor during construction. Use of nondestructive testing techniques is extremely important to ensure that the FRP repair is of high quality and will serve its intended purpose of strength enhancement.

This field testing, not only points out the importance of nondestructive testing in the rehabilitation of concrete bridges using composite fabric, but also helps in the decision- 
making of the type of nondestructive equipment or method as per the need of the project. Digital Tap Testing provides a quick and relatively convenient method of testing without damaging the structure or the repair area physically. It allows the contractor to work efficiently on projects requiring immediate results allowing them to repair the debonds while they are in the field. Infrared Thermography, on the other hand, provides thorough assessment of the debond areas where quantifying the extent of damage is a priority. Infrared Thermography is also useful in projects where the damage is relatively large and requires intensive evaluation before the repair work can be initiated.

Furthermore, the nondestructive testing can be implemented not only during the rehabilitation phase, but also during routine inspection. Based on the nondestructive testing on the Whiteday Bridge, it can be seen that these CFRP bonded beams can be tested during routine evaluation and maintenance phase in conjunction with visual inspection. The nondestructive testing provides a solid, unbiased evaluation of the FRP bonded beams as compared to the subjective evaluation provided by the visual inspection and regular tap hammer testing using a tapping rod. Periodic evaluation of the bridge using nondestructive testing can be very useful in taking timely remedial steps so as to prolong the life of the bridge. 


\section{CONCLUSIONS AND RECOMMENDATIONS}

\subsection{CONCLUSIONS}

The laboratory testing of FRP composite specimens using nondestructive testing methods was significant in defining the importance of infrared thermography and digital tap testing in the area of structural inspection and evaluation. The results from experiments helped evaluate the capabilities of NDT in practical field applications. The lab testing allowed evaluation of different settings and parameters related to the equipment and procedure of NDT evaluation of FRP structures. The infrared thermography and digital tap testing are the two methods of nondestructive testing used in this research study, from which the following conclusions can be made.

- The conventional FLIR InfraCAM SD produced still thermal images of the FRP test specimens, which in some cases, could not produce satisfactory results. The advanced VoyageIR Pro was able to process the raw thermal images into $1^{\text {st }}$ derivative and $2^{\text {nd }}$ derivative images which were helpful in detecting the subsurface defects in the specimens.

- In some exceptional cases, the processed images could not clearly identify the defects in the laboratory test specimens, whereas the plots of processed image intensity along the profile lines helped to locate the subsurface anomalies through the peaks in the graph. In some cases, defects could be detected in one processed image and not in the other (e.g., visible in $1^{\text {st }}$ derivative image and not in $2^{\text {nd }}$ derivative image).

- The use of VoyageIR Pro, as advanced infrared thermography device, was vital in accelerating the test procedure through its integrated heating system. The highperformance heating source, along with advanced processing capacity, of the VoyageIR Pro made it easier and quicker to inspect the structural components. After testing for various heating time intervals and analyzing the results in the laboratory, it was decided that 50 seconds was the optimum heating duration. 
- The VoyageIR Pro heating system worked exceptionally well, which can be useful in testing the structural members where conventional heaters are difficult to place and handle. The results for both VoyageIR Pro heating source and halogen lamp heater were comparatively similar. However, the ease in handling of the VoyageIR Pro heating system makes it superior to the conventional heater.

- Despite the convenience in use of the Digital Tap Hammer, the results from Digital Tap Testing in laboratory experiments demonstrated its inability to evaluate the thicker FRP bridge deck specimens. In addition, the method cannot be used on members with sharp, pointed surface (e.g., on wearing surface).

- Digital Tap Testing was very effective in detecting defects between the FRP composite fabric and the underlying surface in concrete cylinder specimens. In addition, the method was able to detect the delamination in FRP square tube specimen. The portable feature of Digital Tap hammer makes it very efficient in assessing structures wrapped or bonded with thin layers of FRP composite fabric.

- The application of nondestructive testing in field encompasses the evaluation of structural components of bridge rehabilitated using FRP composite fabric. The methods of infrared thermography and digital tap testing allowed necessary remedial actions to be taken for repair of debonded areas in the members.

- The field testing results showed that the repair works using FRP composite are not always perfect and debonds can be formed due to many errors in installation. So, NDT helps locate these debonds (between FRP fabric and underlying concrete surface) which can significantly weaken the structural strength of the rehabilitation system.

- The results from field testing also aided in deciding which NDT method suits best for any particular project. For instance, Digital Tap Testing provides quicker method of testing which can be used for projects demanding immediate results while Infrared Thermography offers thorough assessment of the defects in the members which can be useful for projects with relatively large and deeper damages requiring serious evaluation. 
- The results of laboratory experiments with field testing shows that the NDT techniques can be used for various purposes that ranges from repair of structural components to routine inspection of the structure. NDT provides objective approach to evaluation of the structure without affecting its physical properties.

\subsection{RECOMMENDATIONS}

The conclusion from this research study demonstrates the usefulness of nondestructive testing in field applications. It also helps in deciding and implementing further actions needed for improvement in assessing and repairing structurally deficient members. Following recommendations can be made for field applications.

- With powerful nondestructive evaluation technique like infrared thermography for integrity evaluation, using FRP composite decks in place of concrete decks can be very beneficial since the material is light, comparatively strong, highly durable and corrosion-resistant.

- The use of advanced infrared thermography can overcome the limitations of conventional infrared thermography and increase the speed of testing of structural components. Therefore, more research study can be done in the field of thermal data reconstruction to optimize the advanced thermography procedure.

- Development of more handy and portable equipment like VoyageIR Pro are essential in field application of nondestructive testing technique as it eliminates the use of inflexible conventional heaters and bulky infrared cameras.

- Nondestructive testing of structures rehabilitated with FRP composite fabric using Digital Tap Hammer can result in rapid and reliable assessment of the structure. Since the device is handheld and portable, it can be used frequently in case of repair of old bridges using FRP fabric.

- Periodic evaluation of rehabilitated bridge structures using NDT techniques can be very helpful in extending the life of the bridge. Routine inspection using NDT equipment is recommended every 2 years along with regularly scheduled visual inspection. 


\section{REFERENCES}

ACI 440.2R-17 (2017). “Guide for the Design and Construction of Externally Bonded FRP Systems for Strengthening Concrete Structures.” American Concrete Institute, Farmington Hills, MI, 20.

Caba. A.C. (2005). "Characterization of Carbon Mat Thermoplastic Composites: Flow and Mechanical Properties." Virginia Tech.

Dutta, S.S. (2010). "Nondestructive and Destructive Evaluation of FRP Composite Wrapped Concrete Cylinders with Embedded Debonds." PhD Dissertation, Department of Civil and Environmental Engineering, West Virginia University, Morgantown, WV.

Georgeson, G.E., Lea, S., and Hansen, J (1996). "Electronic tap hammer for composite damage assessment," Proceedings of SPIE 2945, Nondestructive Evaluation of Aging Aircraft, Airports, and Aerospace Hardware, November 14.

Halabe, U.B., GangaRao, H.V.S., and Perisetty, N. (2012). "Infrared Thermography and GPR Techniques for Condition Assessment of RC Bridges." Structural Materials Technology, New York, August 21-21, 120 -127.

Halabe, U.B., Vasudevan, A., Hing, C.L., and GangaRao, H.V.S. (2007). 'Nondestructive Evaluation of Fiber Reinforced Polymer Composite Bridge Components using Infrared Thermography." CD-ROM Proceedings of the Polymer Composites IV Conference, Morgantown, WV, March 20 - 22, 1-24.

Ibarra-Castanedo, C., González, D., Klein, M., Pilla, M., Vallerand, S., and Maldague, X. (2004). "Infrared Image Processing and Data Analysis." Infrared Physics 46: 75-83.

Kolias, A.A. (2015). “Opekiska - Whiteday Creek Public Access Bridge.” U.S. Army Corps of Engineers, Pittsburgh District, Monongalia County, WV, April. 
Lopez-Anido, R., Howdyshell, P.A., Stephenson, L.D., and Gangarao, H.V.S. "Fatigue and Failure Evaluation of Modular FRP Composite Bridge Deck", International Composites Expo Proceedings, SPI, New York, Session 4-B.

Lyu, X., Takahashi, J., and Ohsawa, I. (2015). “Applicability of a Tapping Method to Nondestructive Inspection of Carbon Fiber Reinforced Thermoplastics." The $20^{\text {th }}$ International Conference on Composite Materials, Copenhagen, July 19 - 24.

Maio, L., Memmelo, V., Boccardi, S., Meola, C., Ricci, F., Boffa, N.D., and Monaco, E. (2016). "Ultrasonic and IR Thermographic Detection of a Defect in a Multilayered Composite Plate.” Procedia Engineering, Naples, Italy, Vol. 167, 71-79.

Maldague, X.P.V. (2001). “Theory and Practice of Infrared Technology for Nondestructive Testing." Wiley-Interscience, $1^{\text {st }}$ edition, April.

Mara, V., Haghani, R., and Harryson, P. (2014). "Bridge Decks of Fiber Reinforced Polymer (FRP): A Sustainable Solution." Construction and Building Materials, January $15,50,190-199$.

Miceli, M., Duke, J.C., and Horne, M. (2003). “Thermal Infrared Inspection of FRP Bridge Decks for Health Monitoring." Proceedings of SPIE 5073, Thermosense XXV, Orlando, FL, April 1.

Oswald-Tranta, B., Maier, A., and Schledjewski, R. (2014). "Defect Depth Determination in a CFRP Structure using TSR Technique." Proceeding of Conference QIRT 2014, Bordeaux, France, July $7-11$.

Roy, M. (2004). "Nondestructive Testing of FRP Structural Components using Digital Infrared Thermography." MS Problem Report, Department of Civil and Environmental Engineering, West Virginia University, Morgantown, WV.

Shepard, S.M. (2013). "Thermographic Characterization of Composites.” SAMPE 2013.

Shepard, S.M., and Beemer M.F. (2015). "Characterization of Materials using Thermographic Signal Reconstruction.” InfraMation 2015 Proceedings. 
Shepard, S.M., Lhota, J.R., Rubadeux, B.A., Ahmed, T. and Wang, D. (2002). "Enhancement and Reconstruction of Thermographic NDT Data." Thermosense XXIV, Proceedings of SPIE, Vol. 4710, 531-535.

Spring, R., Huff, R., and Schwoegler, M. (2011). "Infrared Thermography: A Versatile Nondestructive Testing Technique.” Materials Evaluation, 69(8), 934-942.

Taillade, F., Quiertant, M., Benzarti, K., Dumoulin, J., and Aubagnac, C. (2012). "Nondestructive Evaluation of FRP Strengthening Systems Bonded on RC Structures Using Pulsed Stimulated Infrared Thermography." Université Paris-Est, IFSTTAR, F75015, Paris, France.

Titman, D. J. (2001). "Applications of thermography in non-destructive testing of structures." NDT \& e International, 34(2), 149-154.

Vasudevan, A. (2004). "Application of Digital Infrared Thermography for Nondestructive Evaluation of Composite Bridge Components." MS Thesis, Department of Civil and Environmental Engineering, West Virginia University, Morgantown, WV.

https://www.materialstoday.com/composite-applications/news/german-bridge-combinescomposite-and-steel

https://www.thomasnet.com/catalogs/item/10009847-13223-1005-1022/creativepultrusions-inc/superdeck-8482/ 


\section{APPENDIX A - ADDITIONAL FIGURES FOR LABORATORY EXPERIMENT}
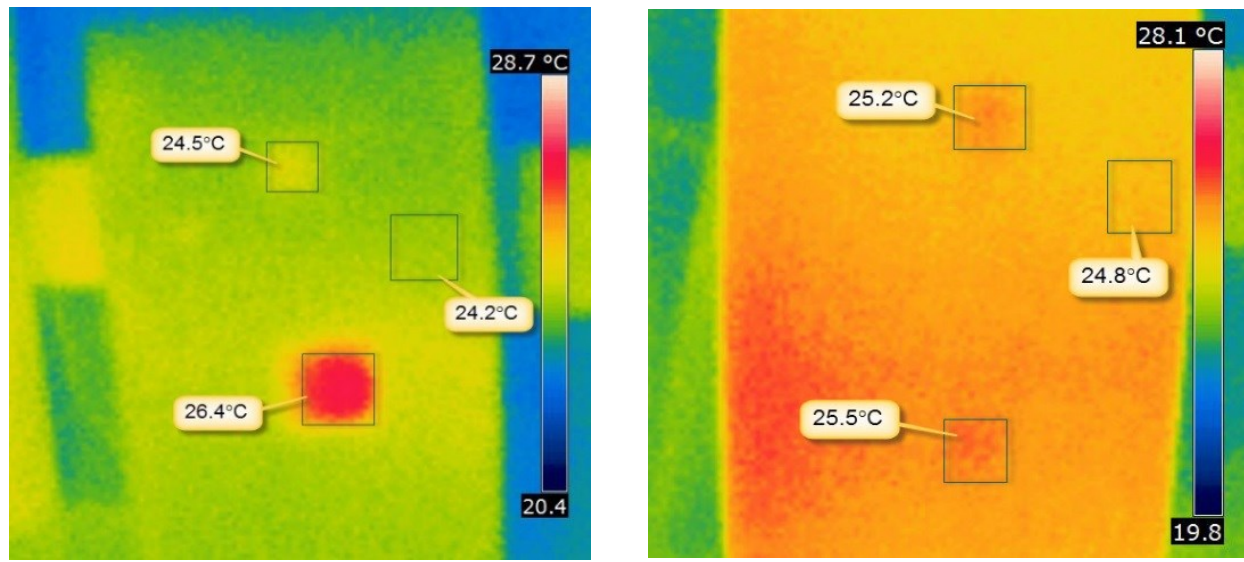

Figure A-1: Thermal images of Side 1 (left) and Side 2 (right) of BD1 taken from FLIR InfraCAM SD after 100 seconds of heating from VoyageIR Pro system
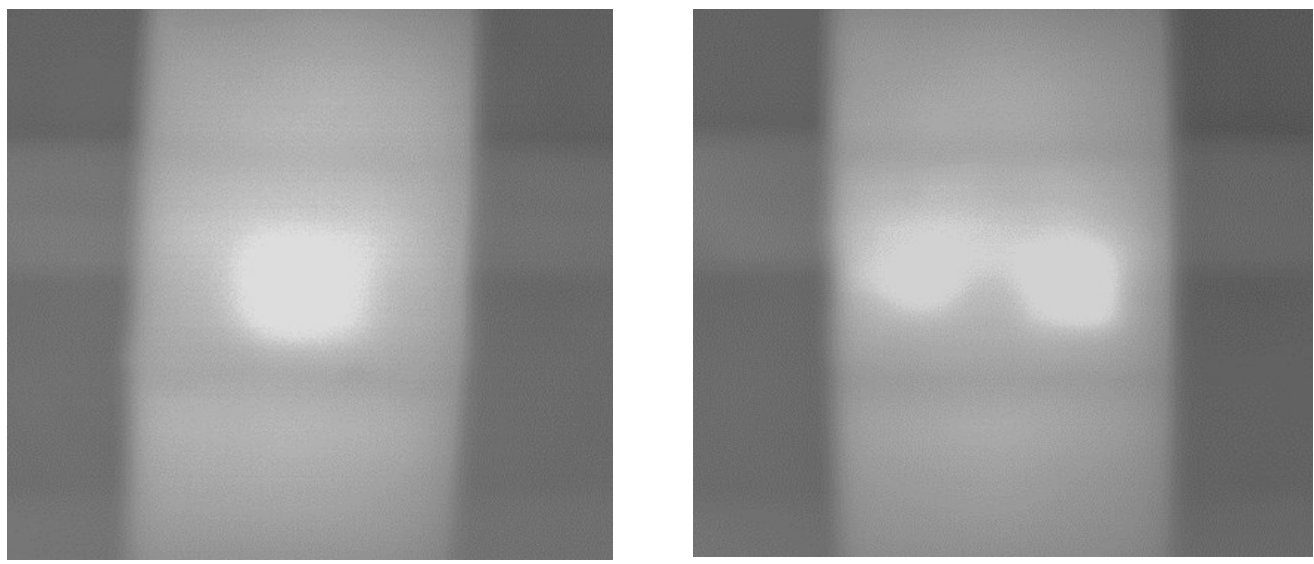

Figure A-2: Raw thermal images of Side 1 (left) and Side 2 (right) of the deck specimen JD1 after 100 seconds of heating
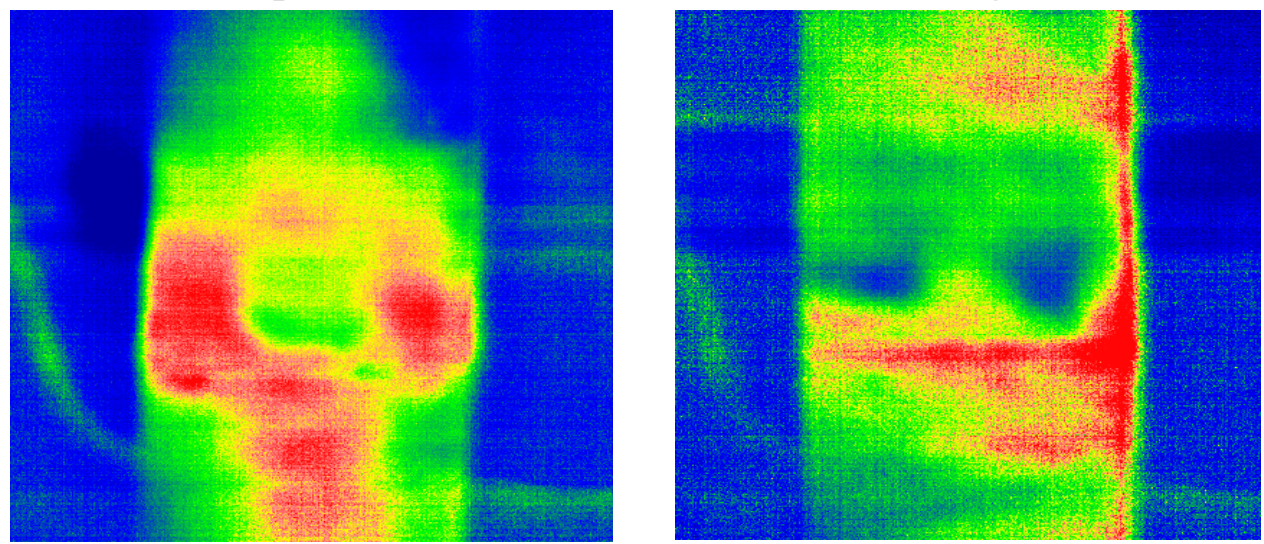

Figure A-3: $1^{\text {st }}$ derivative images of Side 1 (left) and Side 2 (right) of the deck specimen JD1 after 100 seconds of heating 

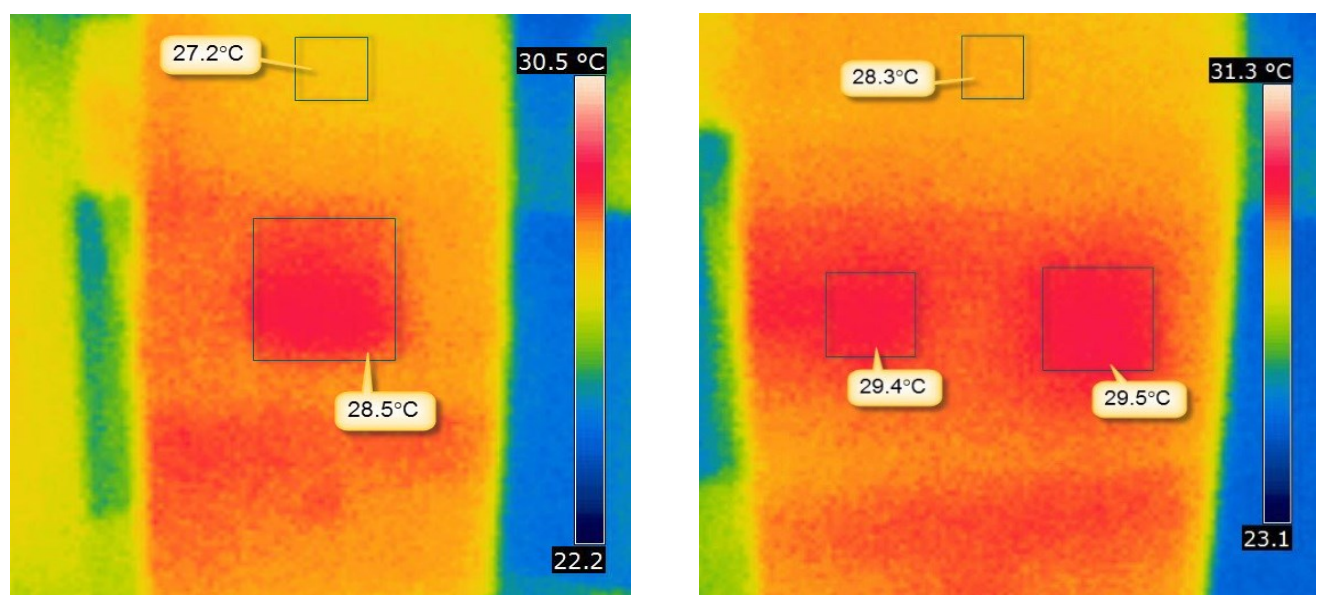

Figure A-4: Thermal images of Side 1 (left) and Side 2 (right) of JD1 taken from FLIR InfraCAM SD after 100 seconds of heating from VoyageIR Pro system
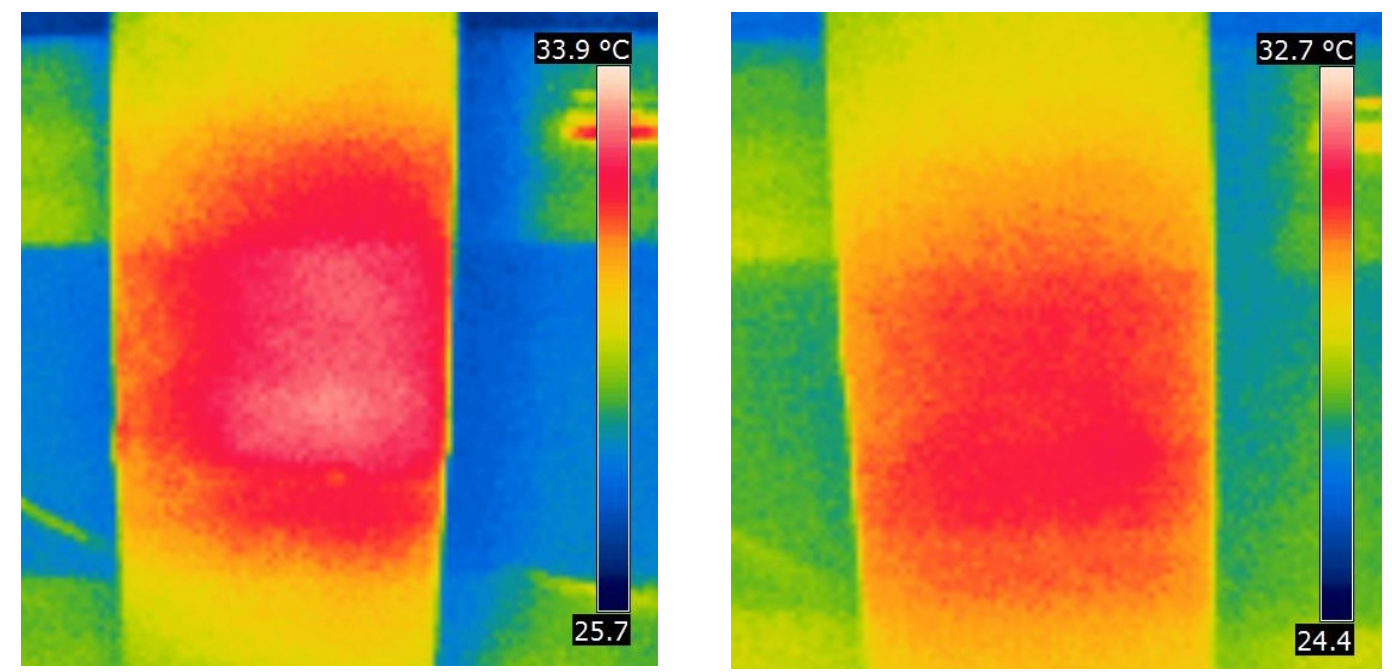

Figure A-5: Thermal images of Side 1 (left) and Side 2 (right) of JD1 taken from FLIR InfraCAM SD after 50 seconds of heating from halogen lamp heater

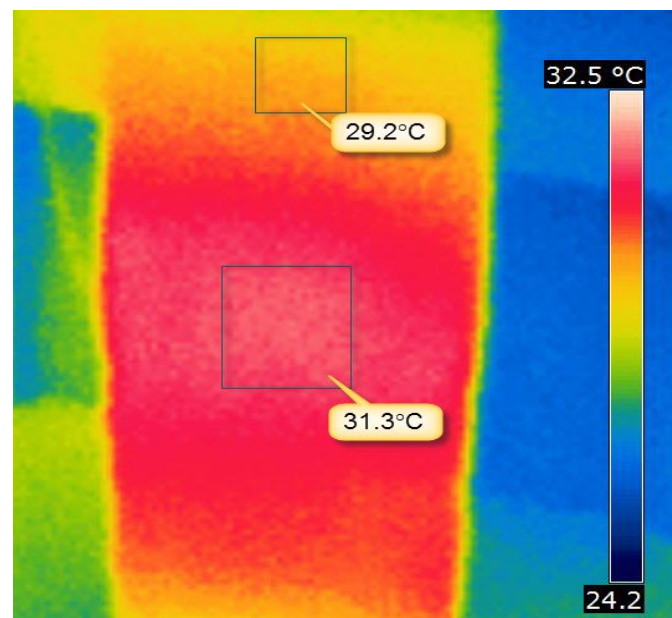

Figure A-6: Thermal images of Side 1 of JD2 taken from FLIR InfraCAM SD after 100 seconds of heating from VoyageIR Pro system 

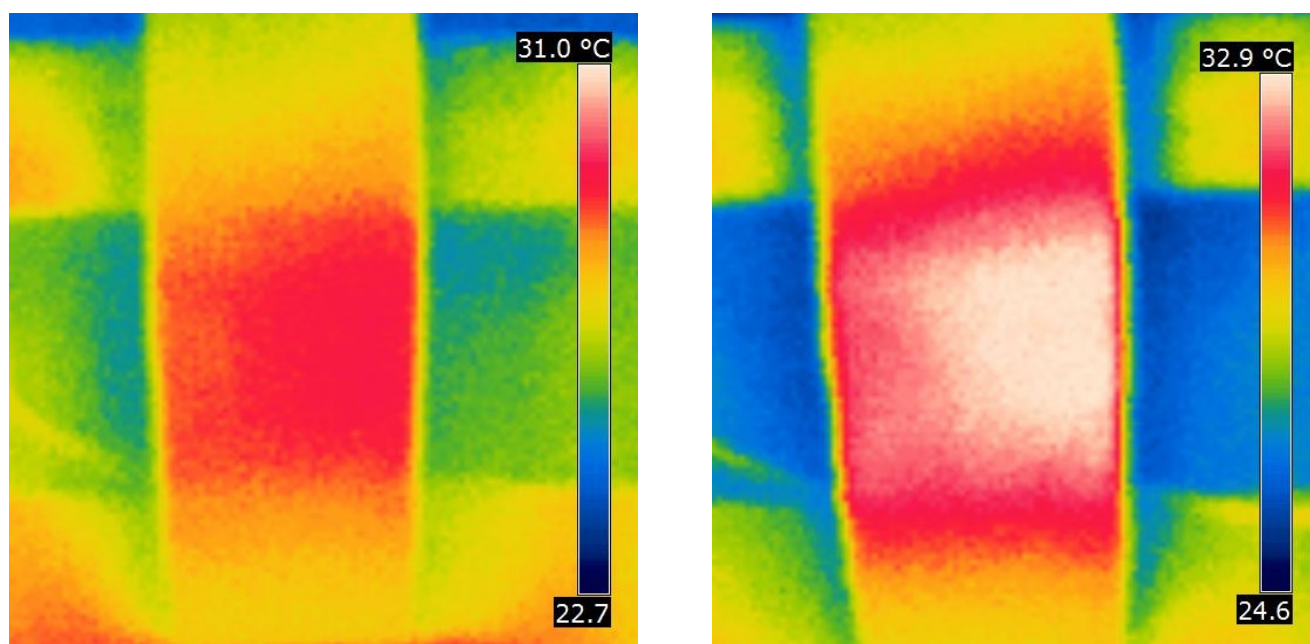

Figure A-7: Thermal images of Side 1 of JD2 taken from FLIR InfraCAM SD after 50 seconds (left) and 100 seconds (right) of heating from halogen lamp heater
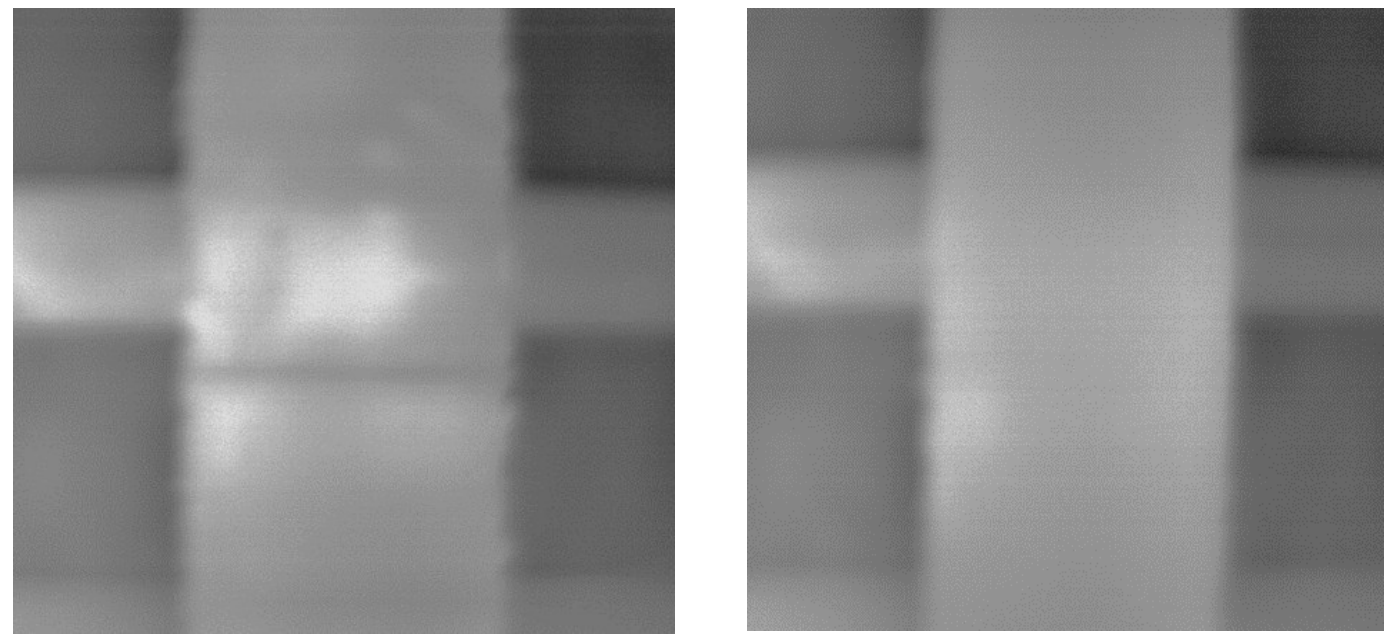

Figure A-8: Raw thermal images of uncovered Side 1 (left) and covered Side 2 (right) of the deck specimen WJD2 after 100 seconds of heating
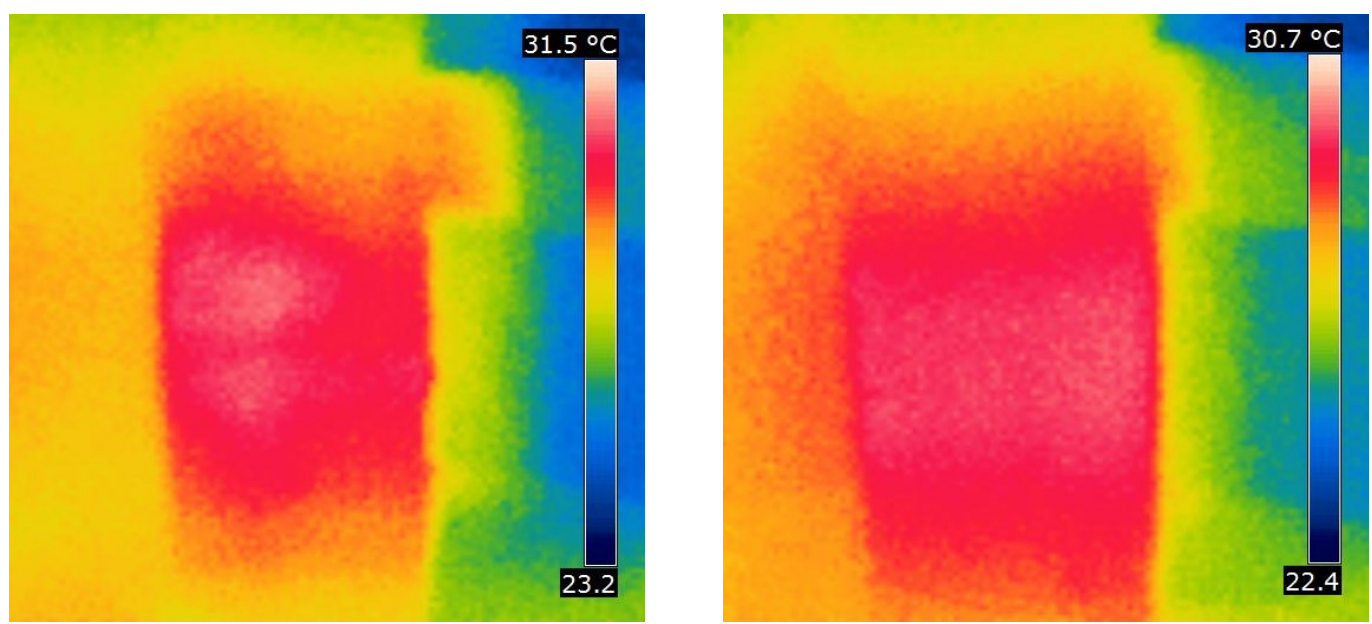

Figure A-9: Thermal images of Side 1 (left) and Side 2 (right) of WJD2 taken from FLIR InfraCAM SD after 50 seconds of heating from VoyageIR Pro system 

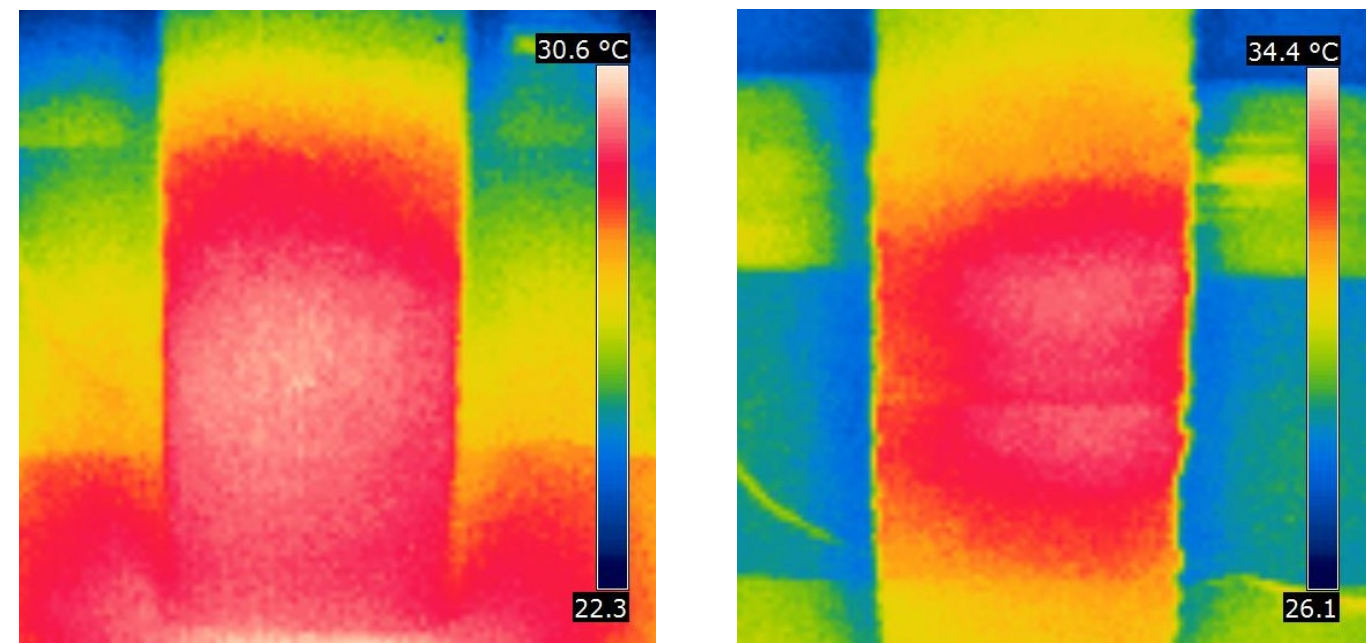

Figure A-10: Thermal images of Side 1 (left) and Side 2 (right) of WJD2 taken from FLIR InfraCAM SD after 50 seconds of heating from halogen lamp heater
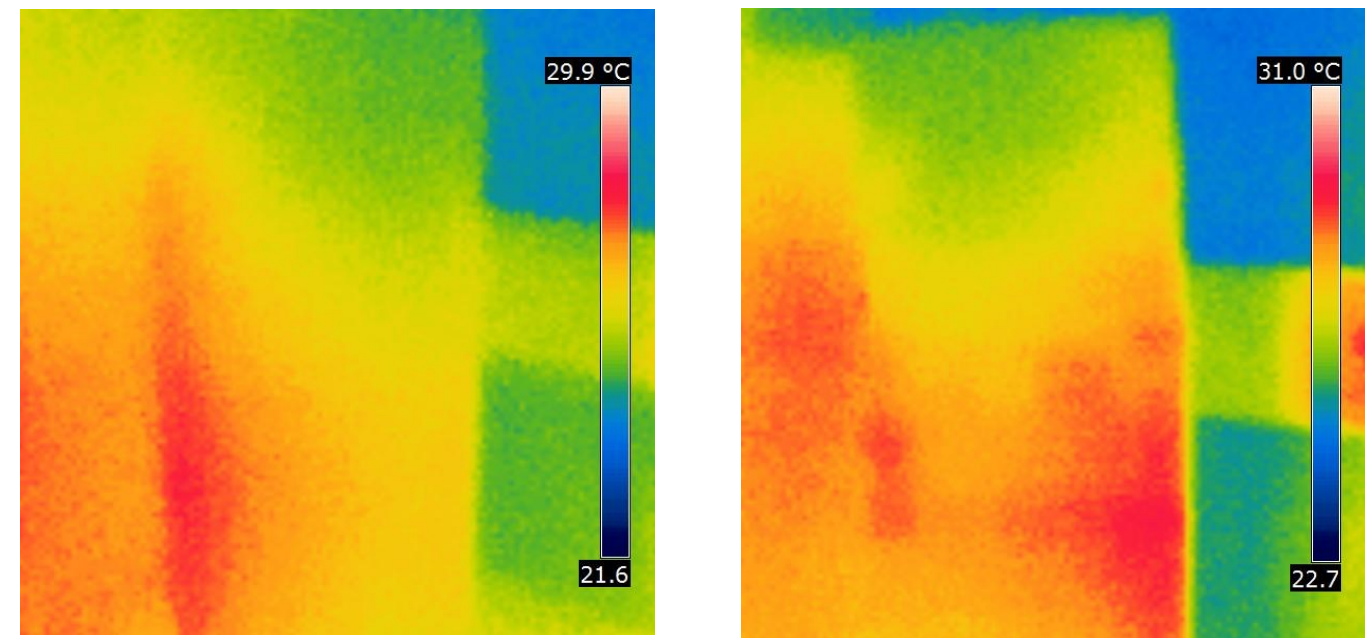

Figure A-11: Thermal images of Side 1 (left) and Side 2 (right) of WJD3 taken from FLIR InfraCAM SD after 50 seconds of heating from VoyageIR Pro system
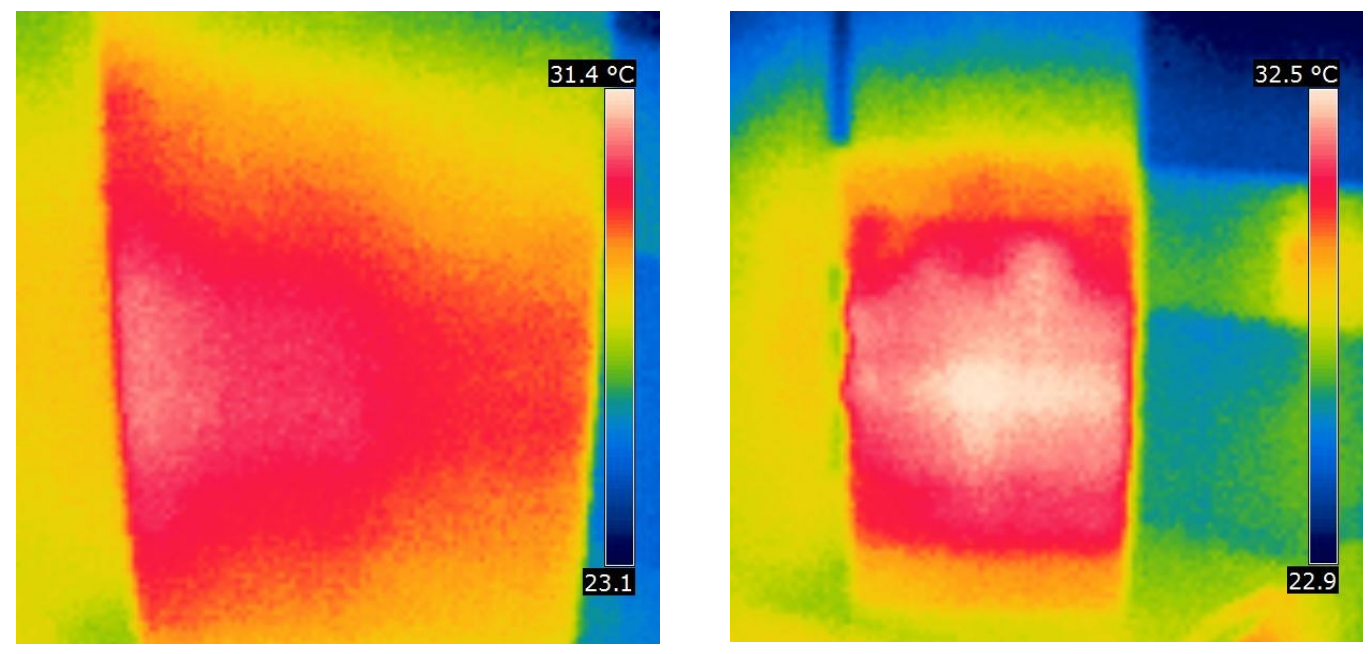

Figure A-12: Thermal images of Side 1 (left) and Side 2 (right) of WJD3 taken from FLIR InfraCAM SD after 100 seconds of heating from VoyageIR Pro system 

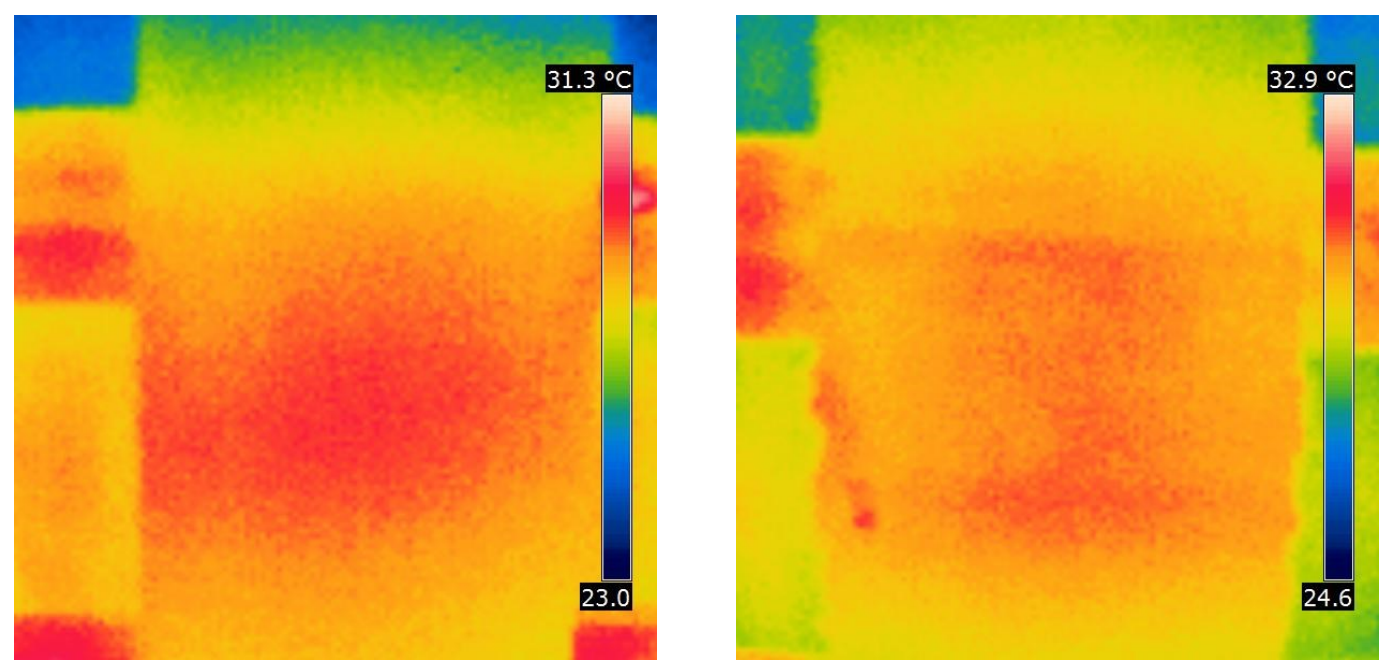

Figure A-13: Thermal images of Side 1 (left) and Side 2 (right) of WJD3 taken from FLIR InfraCAM SD after 50 seconds of heating from halogen lamp heater

Figure A-14: Raw thermal image of Side 1 of the deck specimen AS2 after 100 seconds of heating
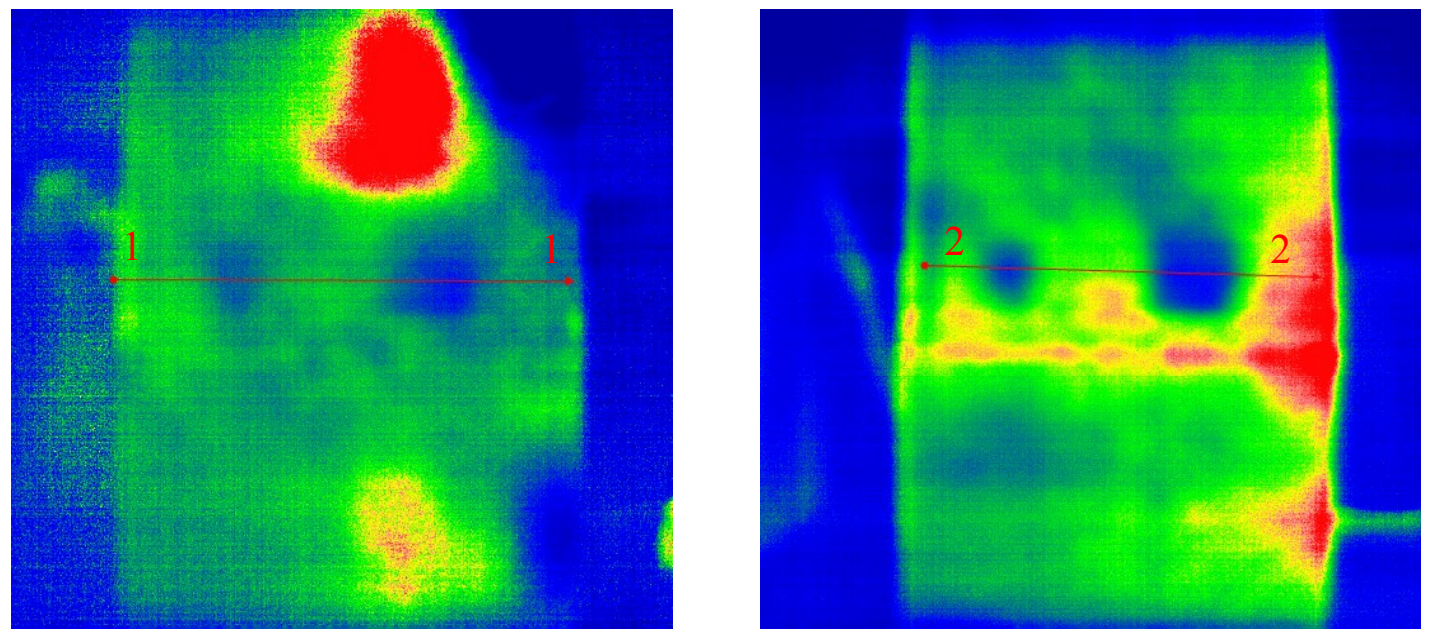

Figure A-15: $1^{\text {st }}$ derivative image of Side 1 of the deck specimen AS2 after 50 seconds (left) and 100 seconds (right) of heating 

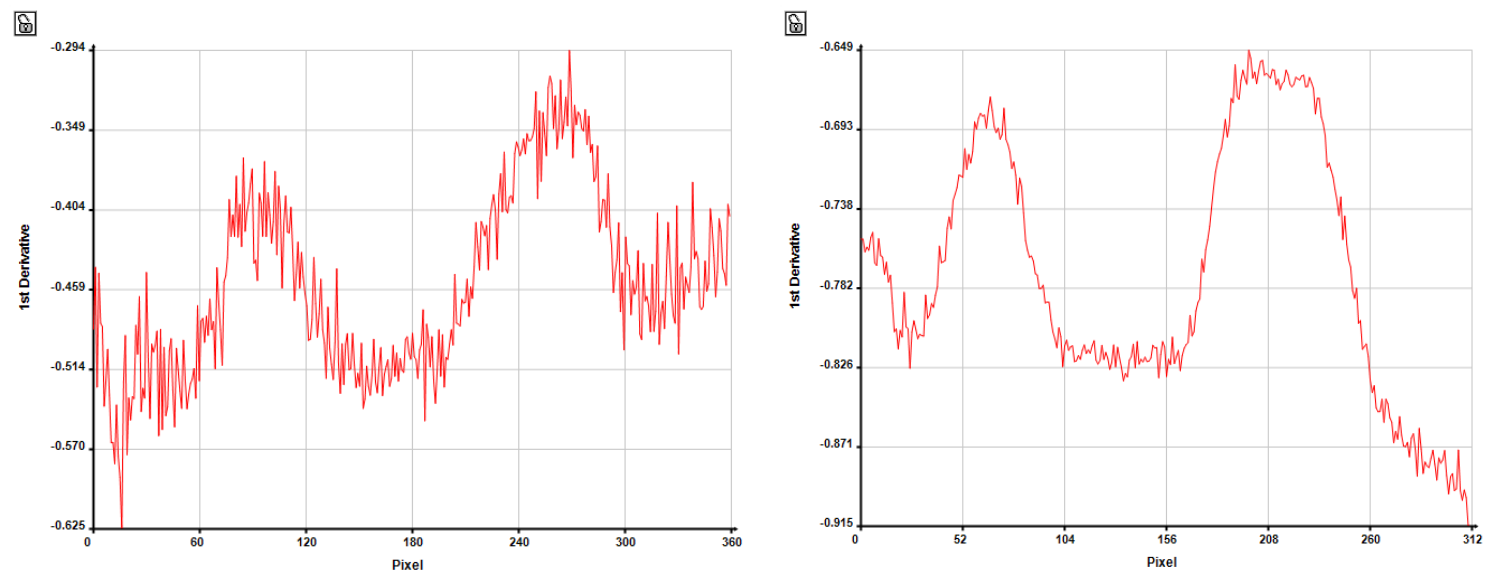

Figure A-16: Plot of $1^{\text {st }}$ derivative intensity along the line 1-1 (left) and line 2-2 (right)
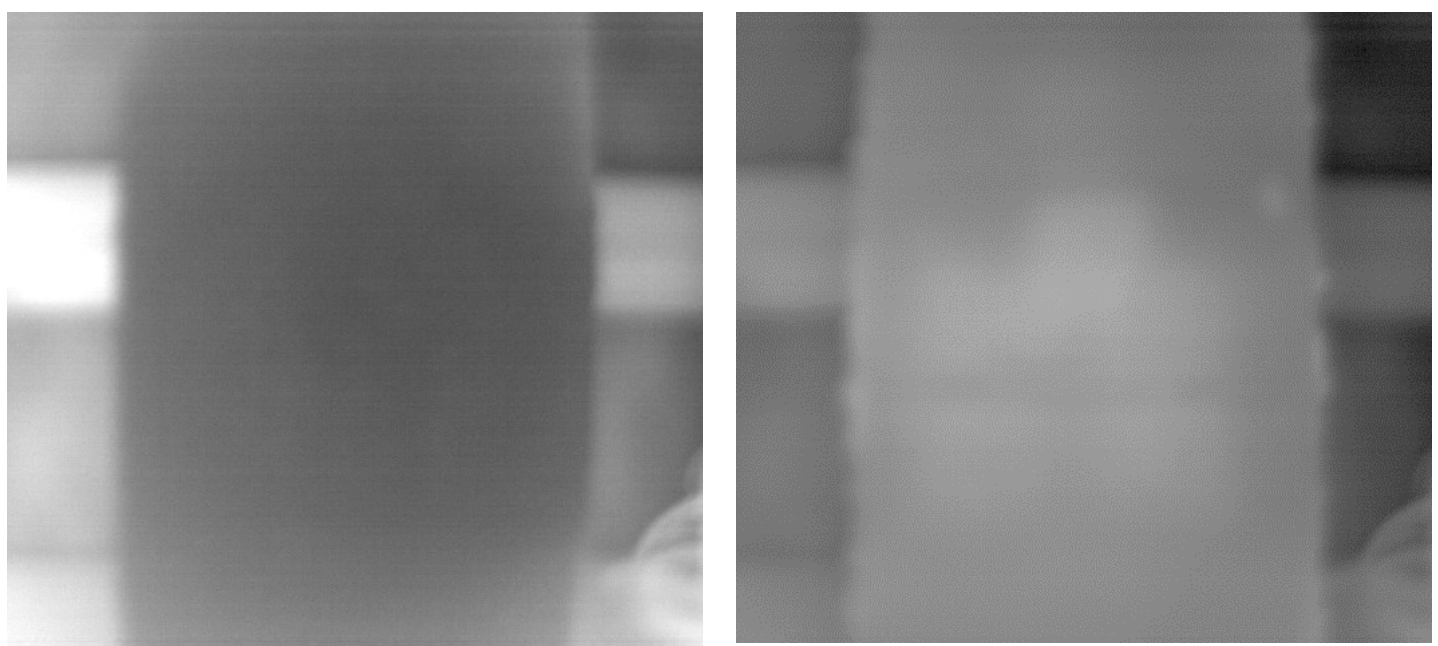

Figure A-17: Raw thermal images of Side 1 (left) and Side 2 (right) of the deck specimen AS3 after 50 seconds of heating
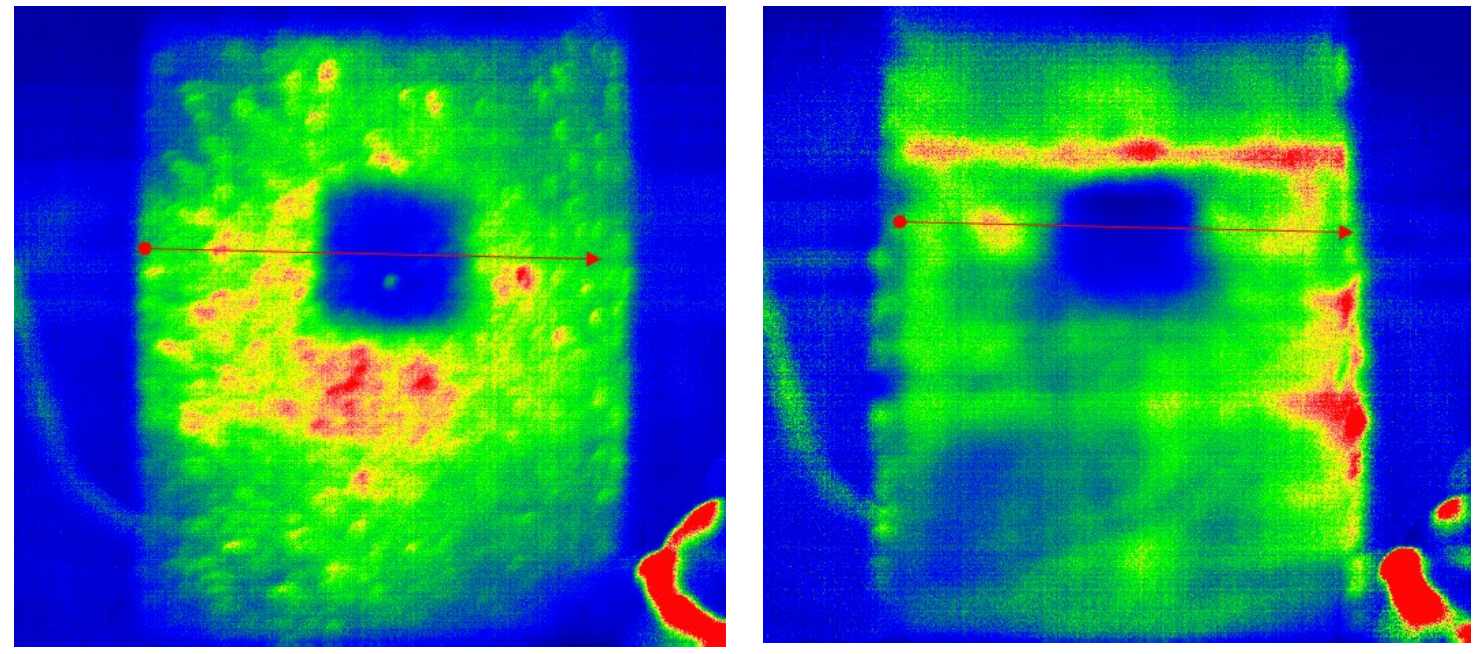

Figure A-18: $1^{\text {st }}$ derivative images of Side 1 (left) and Side 2 (right) of the deck specimen AS3 after 100 seconds of heating 

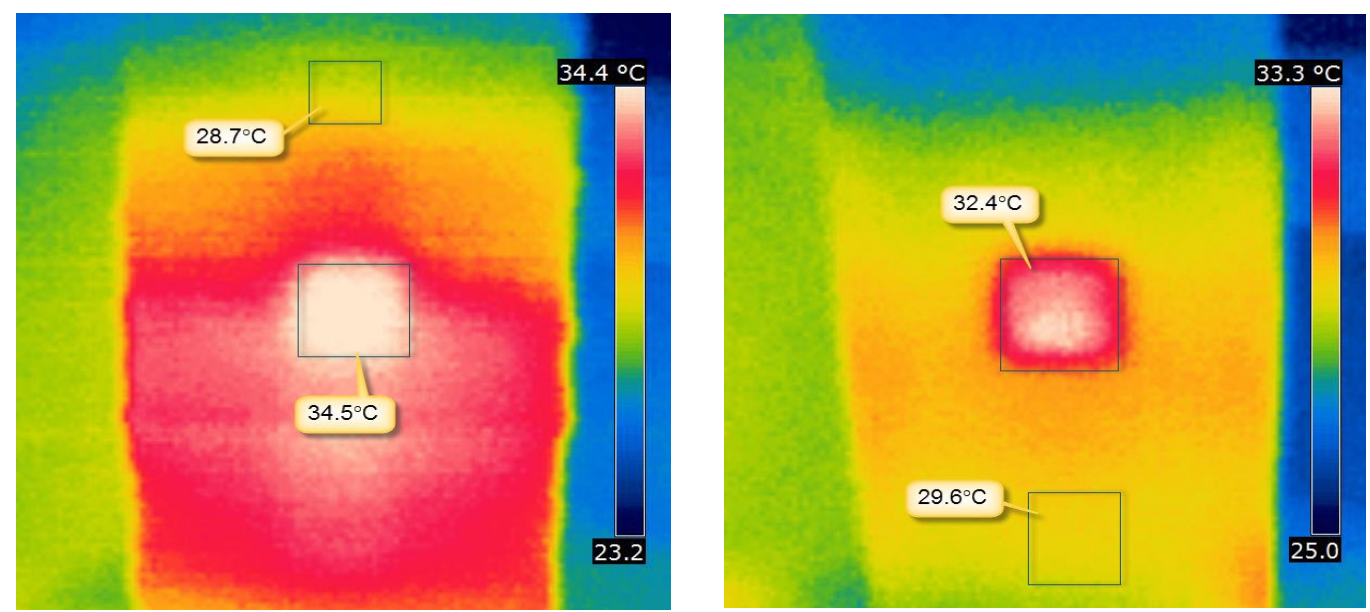

Figure A-19: : Thermal images of Side 1 (left) and Side 2 (right) of AS3 taken from FLIR InfraCAM SD after 100 seconds of heating from VoyageIR Pro system
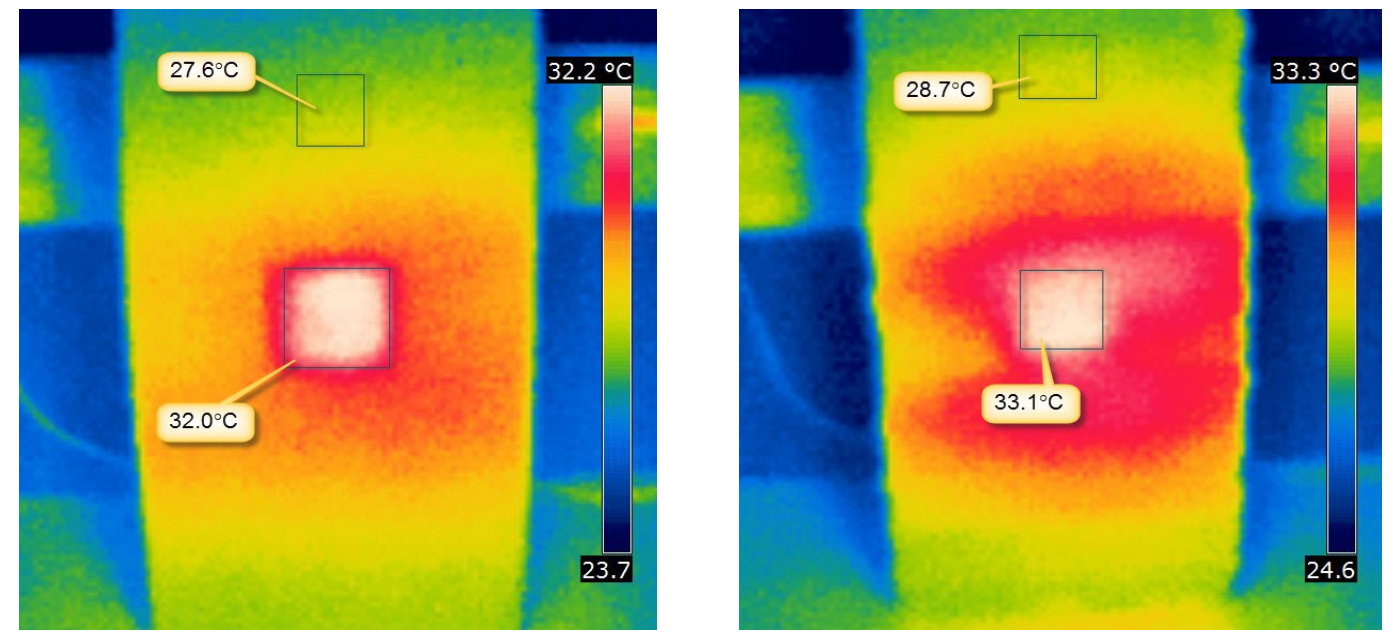

Figure A-20: Thermal images of Side 1 (left) and Side 2 (right) of AS3 taken from FLIR InfraCAM SD after 100 seconds of heating from halogen lamp heater
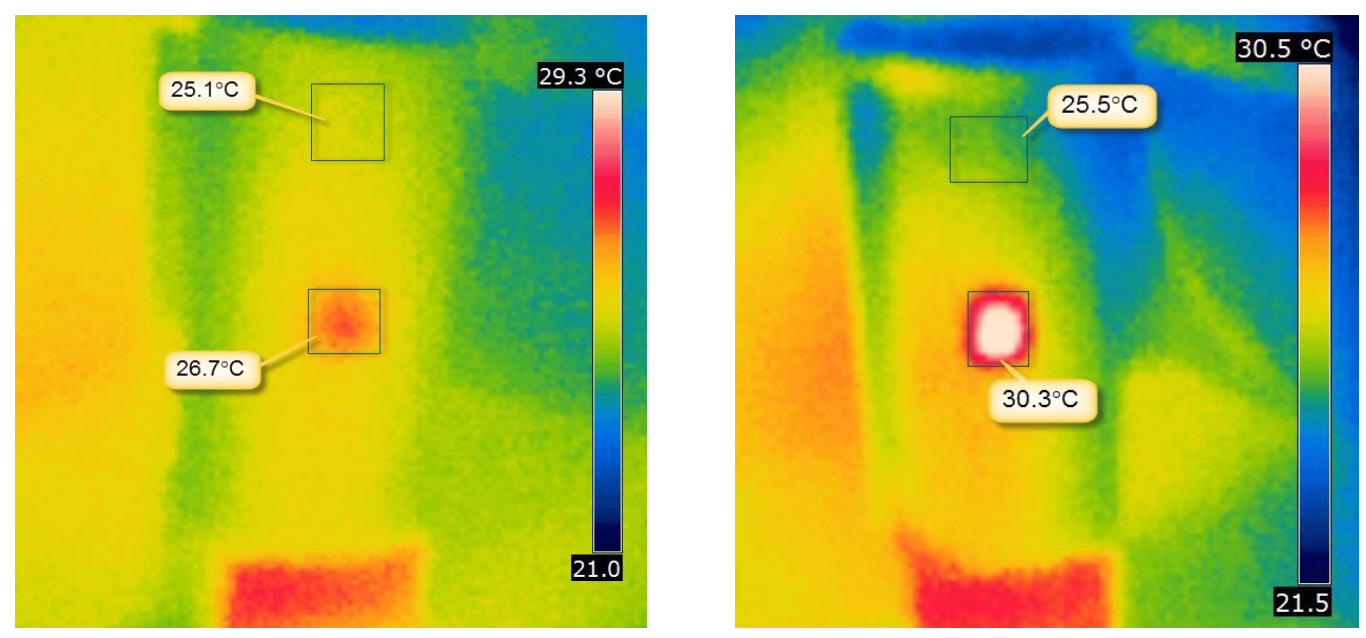

Figure A-21: Thermal images of Side 1 (left) and Side 2 (right) of the cylinder with water-filled debonds taken from FLIR InfraCAM SD after 100 seconds of heating from VoyageIR Pro system 

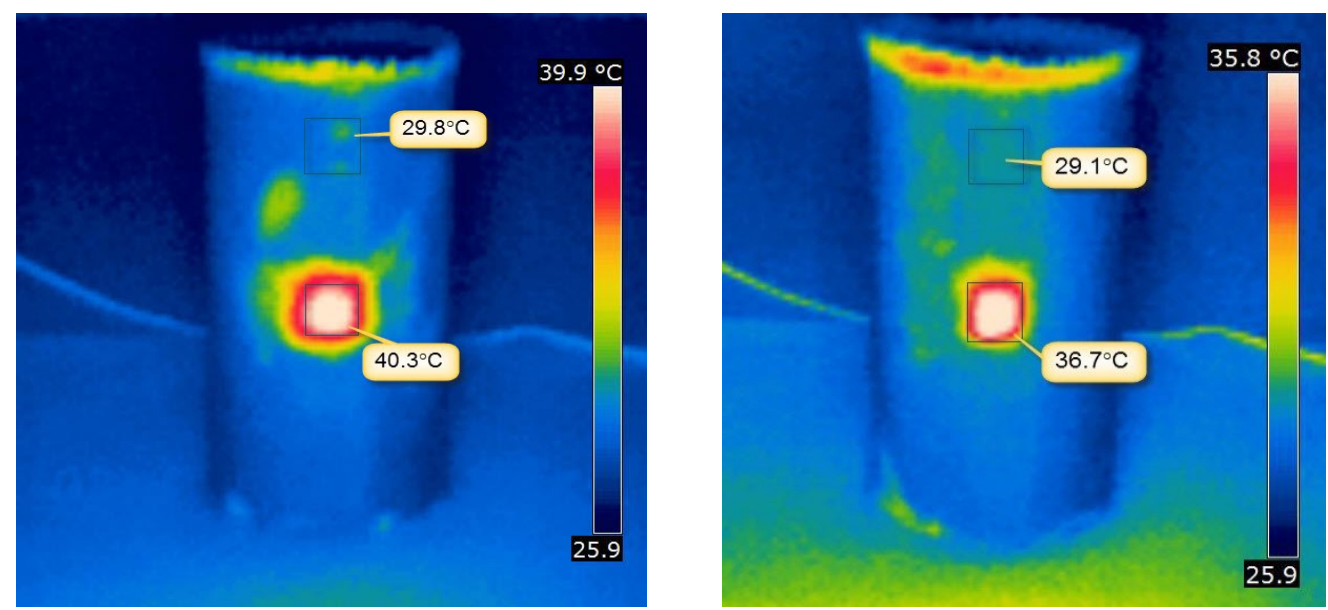

Figure A-22: Thermal images of Side 1 (left) and Side 2 (right) of the cylinder with water-filled debonds taken from FLIR InfraCAM SD after 100 seconds of heating from halogen lamp heater
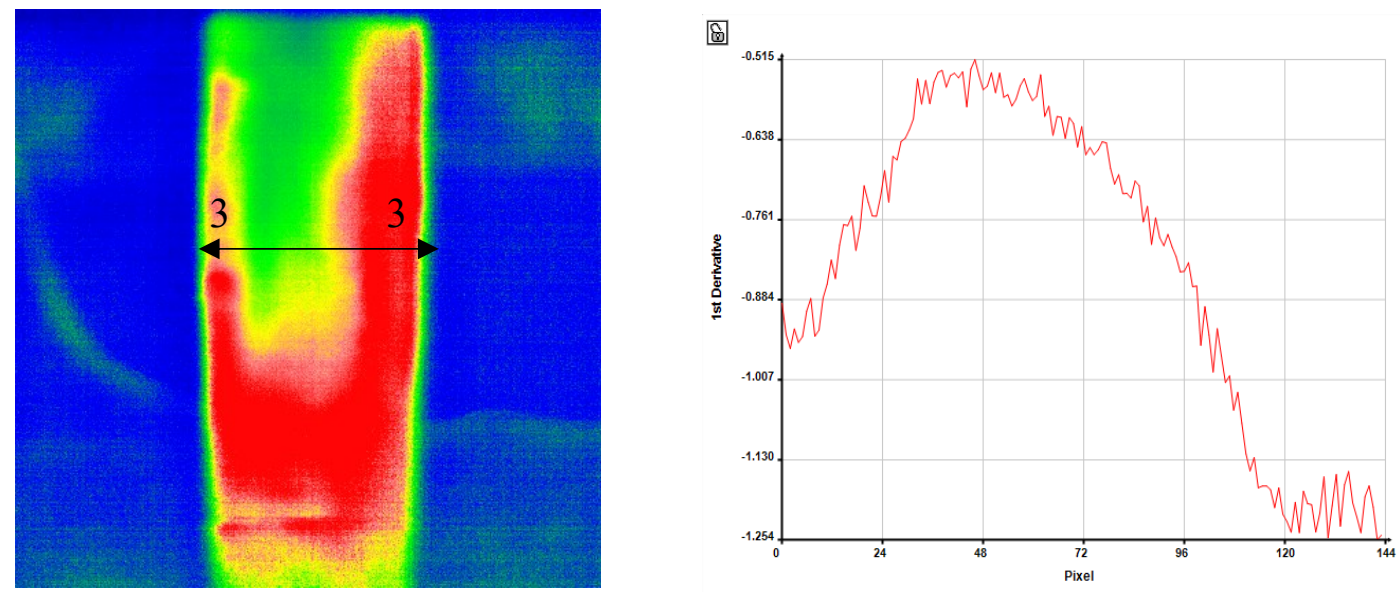

Figure A-23: $1^{\text {st }}$ derivative thermal image of Side 1 of the GFRP composite square tube specimen after 100 seconds of heating (left) and plot of $1^{\text {st }}$ derivative intensity along the line 3-3 (right)
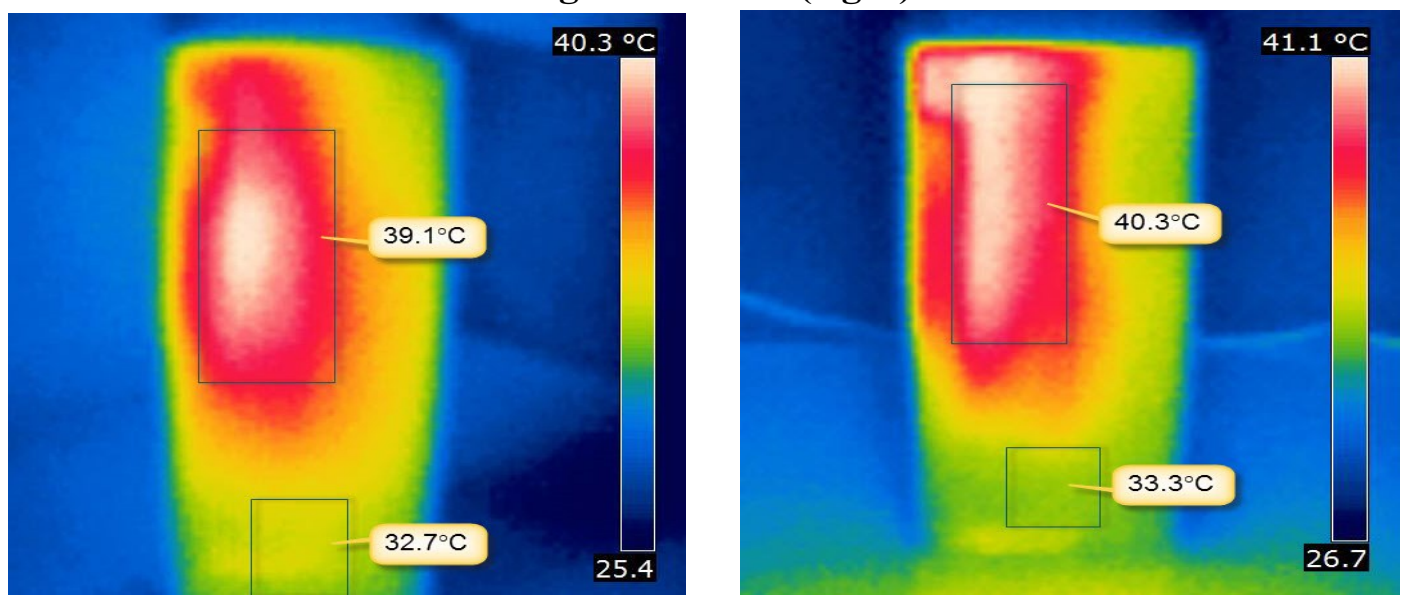

Figure A-24: Thermal image of Side 1 of the GFRP composite square tube taken from FLIR InfraCAM SD after 100 seconds of heating from VoyageIR Pro system (left) and halogen lamp heater (right) 